INSTITUTO DE PESQUISAS ENERGÉTICAS E NUCLEARES - IPEN/CNEN-SP Autarquia associada à Universidade de São Paulo

\title{
EFEITO DE TRATAMENTOS DE MODIFICAÇÃO DA SUPERFÍCIE NA RESISTÊNCIA À CORROSÃO DO ALUMÍNIO 1050
}

\section{DANIEL SIERRA YOSHIKAWA}

Dissertação apresentada como parte dos requisitos para obtenção do Grau de Mestre em Ciências na Área de tecnologia Nuclear - Materiais.

Orientadora: Dra. Isolda Costa

São Paulo 
DEDICATÓRIA

Dedico este trabalho às minhas raízes, meus Avós, Shozo Yoshikawa* e Shizuko Yoshikawa* Antônio Sierra* e Maria Augusta Amaro Sierra.

*(In memoriam) 


\section{AGRADECIMENTOS}

Primeiramente gostaria de agradecer a todos que fizeram e fazem da minha vida, uma vida mais feliz. Não é fácil, e ninguém disse que seria. Viver é um aprendizado constante da mesma maneira que é a realização do mestrado.

Agradeço especialmente à Magrela (Sabrina Paiva), namorada, mulher, "esposa" e parceira para todos os momentos, principalmente por ter "aturado" os piores deles, os estresses e as "nóias" e mesmo assim continuar me apoiando, ainda que por vezes sem a total compreensão que eu gostaria (rs). Ao Sr. Rei (meu Pai, Reinaldo Masatsugu Yoshikawa) e Dna. Nenê (Mãe Neide Sierra Yoshikawa) que sempre me apoiaram em conversas, incentivo, confiança e com a parte das finanças, tenho certeza que não foi fácil. Ao resto da família, meu irmão Cara Quadrada (Pablo S. Yoshikawa), minha avó Dna. Maria (Maria Augusta Amaro Sierra), meus irmãos-primos Tiaguento e Gordo (Tiago e Rogério Sierra Di Polito) e sobrinhos Luis Felipe e Santiago.

Aos bons amigos, Cara de Concha (Felipe Massicano), Leandrinho Taboeiro (Leandro Safra), Mi (Emerson Mi), Beleza lendário (Fábio Camargo), entre outros vários agradeço pelos desabafos, os jogos de futebol, cervejadas e a camaradagem.

À Dra. Isolda Costa por me orientar, me acolher em seu Laboratório e permitir a ótima experiência de pesquisa. Além de participar das pausas para os cafés que "saiam e logo voltavam", juntamente com suas boas risadas. Ao seu marido e Pesquisador Dr. Jesualdo Rossi por me apresentá-la.

Aos amigos Sérgio e Maysa (Dr. Sérgio Luiz de Assis e Dra. Maysa Terada) que sempre foram meus guias nesse trabalho, com sugestões, explicações e ajuda para minha formação como pesquisador. À Paty (Patricícia H. Suegama) por suas valiosas dicas e esclarecimentos ao trabalho.

Agradeço ao pessoal do Laboratório de Corrosão e Tratamento de Superfície - LABCORTS, CCTM - IPENICNEN- SP, Olandir V. Corrêa sempre prestativo "quebrando galhos" e rindo do seu jeito peculiar, grupo do alumínio, Wagner e Solange. À Rosele, Zé Mário, Wilma, Rogério, Antônio, Luis Rossi, Elki e Risomá. Ao Vinícius do MEV. Aos vizinhos do "Predinho" (Prédio dos Bolsistas CCTM), Chicão, Baby e Marilene. Ao amigo Pastor "boleiro" Cardoso. Às moças 
da faxina, principalmente Dna. Nilvana sempre faladeira e aos seguranças Edilson e Irineu (CCTM) e Daniel da portaria 2.

Ao IPEN que me acolheu e se tornou extensão da minha casa e ao CNPq pelo auxílio financeiro. Obrigado! 
O caminho se faz ao andar

António Machado

Poeta sevilhano. 


\section{EFEITO DE TRATAMENTOS DE MODIFICAÇÃO DA SUPERFÍCIE NA RESISTÊNCIA À CORROSÃO DO ALUMÍNIO 1050}

\section{RESUMO}

Neste trabalho foi investigado o efeito de vários tratamentos para modificação da superfície na resistência à corrosão do alumínio AA1050 com o objetivo de identificar um potencial substituto ao tratamento de cromatização. Os tratamentos adotados consistiram inicialmente de polimento da superfície até acabamento $1 \mu \mathrm{m}$, seguido por uma etapa comercial. Este tratamento foi utilizado como preparação preliminar da superfície, anterior aos demais tratamentos testados. Amostras com o tratamento preliminar foram submetidas a diferentes tratamentos de modificação da superfície, especificamente, imersão em solução com moléculas auto-organizáveis (SAM) à base de difosfonato, imersão em água fervente para acelerar o crescimento de óxido-hidróxido de alumínio; uma combinação destes dois últimos tratamentos e cromatização em solução à base de cromo hexavalente. O comportamento de corrosão do alumínio AA1050 submetido aos diferentes tipos de tratamentos foi investigado por ensaios eletroquímicos como: medidas de potencial a circuito aberto em função do tempo de imersão, espectroscopia de impedância eletroquímica e ensaios de polarização potenciodinâmica. Utilizou-se solução de $0,5 \mathrm{M}$ de $\mathrm{Na}_{2} \mathrm{SO}_{4}$ como meio corrosivo, tamponada a $\mathrm{pH}=4,0$. Microscopia eletrônica de varredura e análises semi-quantitativas de espectroscopia de energia dispersiva também foram utilizadas como medidas complementares nessa investigação. Observou-se que o tratamento com moléculas auto-organizáveis não se mostrou eficiente para proteção à corrosão para longos períodos de tempo em comparação aos demais tratamentos. A proteção fornecida pelos tratamentos, SAM e em solução a base de cromo hexavalente foi inferior à esperada. A etapa de "boemitização" ou crescimento acelerado de óxido-hidróxido de alumínio em água fervente se mostrou uma etapa essencial para aumento do desempenho frente à corrosão do alumínio AA1050. Os resultados obtidos para amostras submetidas ao tratamento de aceleração do crescimento de óxi-hidróxido seguido por imersão em solução com moléculas auto-organizáveis proporcionou uma melhora significativa na resistência à corrosão da superfície comparada aos demais tratamentos. 


\title{
EFFECT OF SURFACE TREATMENTS ON THE CORROSION RESISTANCE OF THE ALUMINUM AA1050
}

\begin{abstract}
The aim of this work is to investigate the effect of various treatments for surface modification on the corrosion resistance of the aluminum AA1050. All the samples were firstly exposed to a preliminary surface treatment that consisted of surface polishing, up to a finishing of $1 \mu \mathrm{m}$, succeeded by degreasing in two alkaline solutions and finally deoxidizing in an acid solution. This treatment was used as a preliminary surface preparation and adopted as a reference for comparison with the others. After this treatment, samples were exposed to various treatments for surface modification, specifically, immersion for 3 hours in a solution with self assembling molecules based on diphosphonates (SAM), immersion in boiling water for 20 minutes to promote bohemite growth (bohemitization); a combination of these two last treatments (bohemitization+SAM) and passivation in an hexavalent chromium solution. The objective was to investigate the potential of the tested treatments to replace the ones based on hexavalent chromium that generates toxic residues. The corrosion behavior of AA1050 aluminum samples with the various surface treatments was investigated by electrochemical methods such as: open circuit potential measurements, electrochemical impedance spectroscopy and potentiodynamic polarization curves. The electrolyte used was a $0.5 \mathrm{~mol} \mathrm{~L}^{-1} \mathrm{Na}_{2} \mathrm{SO}_{4}$ solution, buffered to $\mathrm{pH}=4.0$. Surface characterization techniques, such as scanning electron microscopy and energy dispersive spectroscopy were also used in this investigation. The results showed that the treatment with self assembling molecules was not effective to protect the AA1050 aluminum for long periods of exposure to the electrolyte comparatively to the other surface treatments tested. The effect of SAM treatment or passivation with hexavalent chromium solution on the AA1050 aluminum corrosion resistance was unexpected. The bohemitization treatment that consisted of favoring oxidehydroxide growth by immersion in boiling water increased the corrosion resistance of the AA1050 aluminum, but the highest corrosion resistance was associated to the treatment that combined bohemitization with SAM treatment.
\end{abstract}




\section{SUMÁRIO}

RESUMO

ABSTRACT .ii

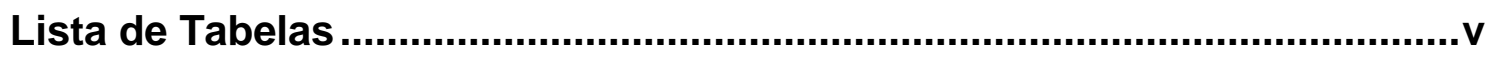

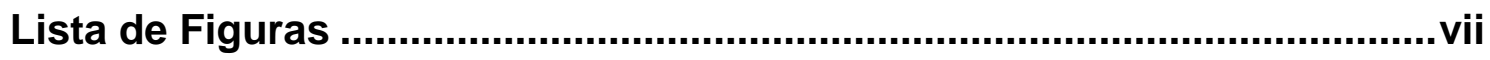

1. INTRODUÇÃO

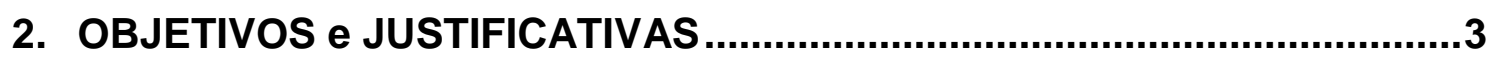

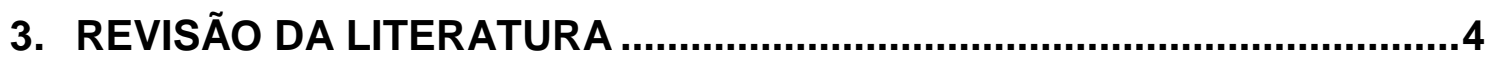

3.1. Resistência à corrosão de materiais metálicos .....................................4

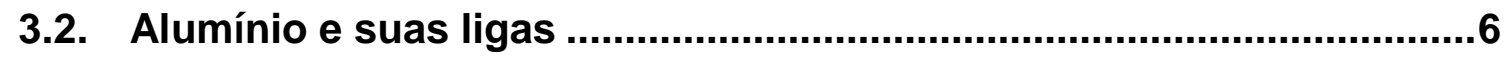

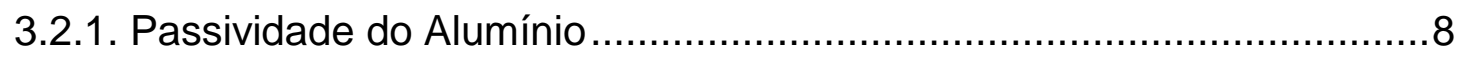

3.2.2. Importância das ligas de alumínio e o processo Alclad (AA1XXX) ......10

3.3. Tratamentos de Superfície para alumínio......................................12

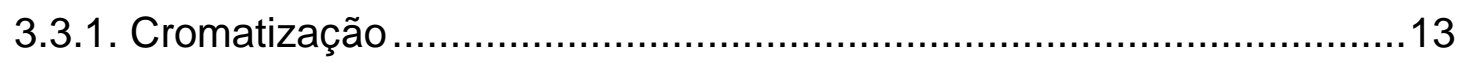

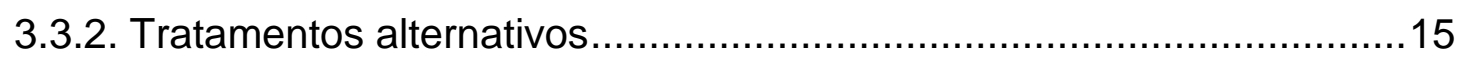

3.3.3. Moléculas Auto-organizáveis (SAM) ……...................................17

3.4. Técnicas eletroquímicas no estudo da resistência à corrosão.............22

3.4.1. Espectroscopia de Impedância Eletroquímica ...................................23

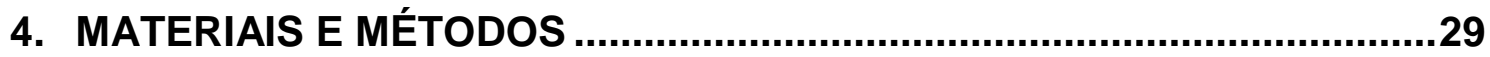

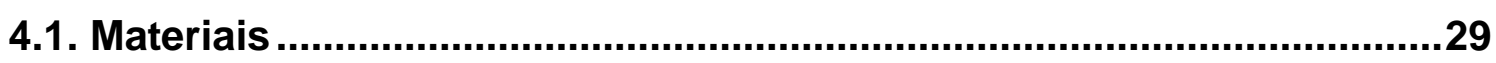

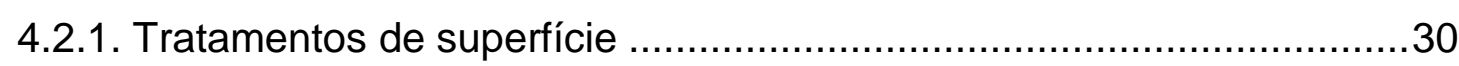

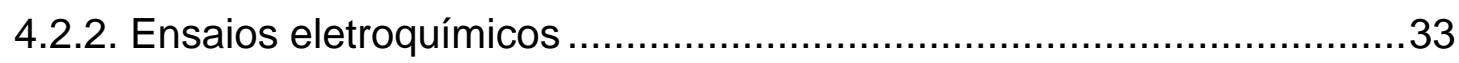

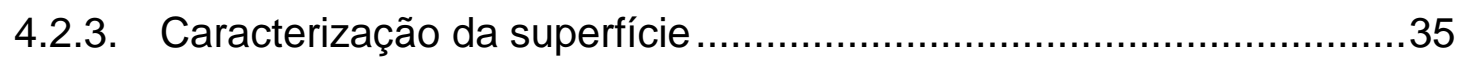

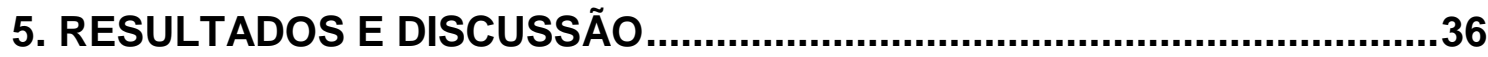

5.1. Caracterização da microestrutura do alumínio AA1050 ........................36

5.1.1. Efeito do pré-tratamento de desengraxe e desoxidação comercial $(P B)$ na superfície do alumínio 1050 .

5.1.2. Efeito dos tratamentos $\mathrm{PB}, \mathrm{SAM}, \mathrm{Cr}(\mathrm{VI})$, OX e OS na superfície do

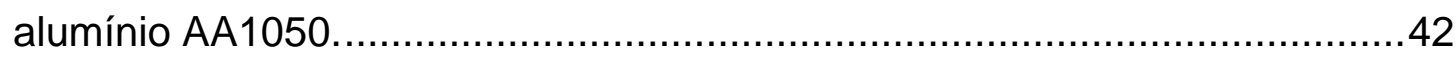

5.3. Caracterização eletroquímica do alumínio AA1050..............................43

5.3.1. AA1050 submetido ao tratamento PB ............................................ 43

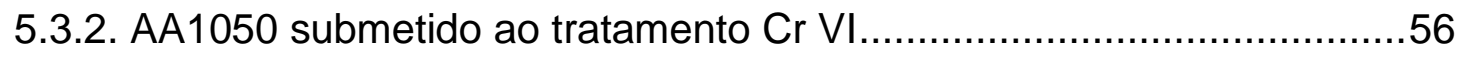




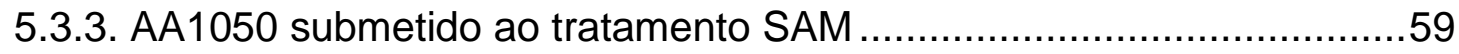

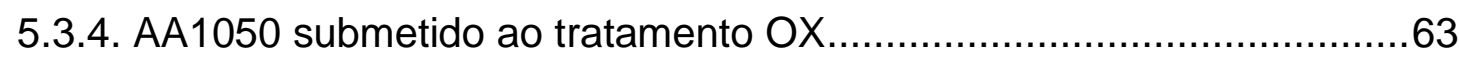

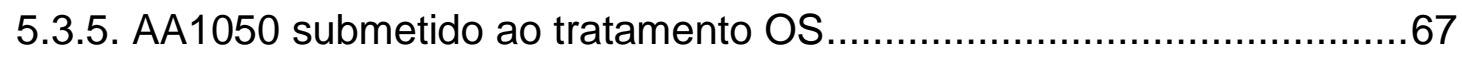

5.4. Estudo comparativo do desempenho dos tratamentos adotados ........71

5.4.1. Comparação dos ensaios eletroquímicos .........................................71

5.4.2. Uso de microscopia eletrônica de varredura para avaliar os tratamentos

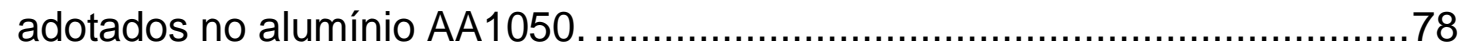

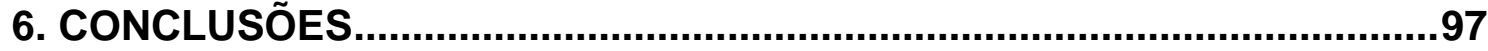

7. SUGESTÕES PARA TRABALHOS FUTUROS..........................................99

8. REFERÊNCIAS BIBLIOGRÁFICAS ....................................................100

Apêndice A 


\section{Lista de Tabelas}

Tabela 1. Lançamentos de Efluentes [Resolução Conama, 2005].........................2

Tabela 2. Classificação e usos de ligas de alumínio [The Aluminum Association, 1998].

Tabela 3: Composição química (obtida por Fluorescência de Raios-X e ICP-OES) e composição nominal do alumínio AA1050 segundo as especificações NBR7523 e ABAL [2010]

Tabela 4: Acabamento superficial e tratamentos utilizados para modificação da superfície do alumínio AA 1050.

Tabela 5: Composição química semi-quantitativa obtida por EDS dos diferentes tipos de precipitados encontrados na superfície do AA 1050.

Tabela 6. Concentração química (em mg. $\left.\mathrm{L}^{-1}\right)$ da solução de ensaio $(0,5 \mathrm{M}$ $\mathrm{Na}_{2} \mathrm{SO}_{4}$, tamponada a $\mathrm{pH}=4,0$ ) submetida a 3 dias de ensaios eletroquímicos com ECS e ESM em alumínio comercialmente puro AA1050.

Tabela 7: Valores dos parâmetros elétricos resultantes dos ajustes do CEE da Figura 38(A) aos diagramas experimentais do alumínio AA1050 com tratamento PB.

Tabela 8: Valores dos parâmetros elétricos resultantes dos ajustes do CEE da Figura 38(A) aos diagramas experimentais do alumínio AA1050 com tratamento SAM.

Tabela 9: Valores dos parâmetros elétricos resultantes dos ajustes do CEE da Figura 38(A) aos diagramas experimentais do alumínio AA1050 com tratamento $\mathrm{Cr}(\mathrm{VI})$.

Tabela 10. Valores dos parâmetros elétricos obtidos com ajuste do circuito elétrico equivalente (CEE) da Figura 38(B) aos resultados experimentais para alumínio AA1050 com tratamento OX após vários períodos de imersão em solução de ensaio, utilizando o software Zview. 
Tabela 11. Valores dos parâmetros elétricos obtidos com ajuste do circuito elétrico equivalente (CEE) da Figura 38(B) aos resultados experimentais para alumínio AA1050 com tratamento OS após vários períodos de imersão em solução de ensaio, utilizando o software Zview. .92 


\section{Lista de Figuras}

Figura 1: Diagrama de Pourbaix simplificado do alumínio em meio aquoso...........9

Figura 2. Representação esquemática da liga de alumínio Alclad 2024...............11

Figura 3: Representação de uma camada de SAM, mostrando os seus constituintes e a interação com o substrato.

Figura 4. Circuitos elétricos equivalentes propostos para caracterizar a camada passiva e fenômenos interfaciais em alumínio e suas ligas [Szurkalo, 2009;

Palomino et al., 2009, Queiroz, 2008, Bessone et al., 1983].

Figura 5. Micrografia por MEV do alumínio AA1050 polido com pasta de diamante $1 \mu \mathrm{m}$ .36

Figura 6: Micrografias por MEV com detector para elétrons retro-espalhados da superfície polida do alumínio AA1050 com pasta de diamante até $1 \mu \mathrm{m}$, com indicação dos vários tipos de morfologias dos precipitados encontrados.

Figura 7: Espectros de EDS para os quatro grupos de intermetálicos classificados: IM1 (A), IM2 (B), IM3(C), IM4(D) e (E) Matriz AA1050. 38

Figura 8: Micrografias por MEV do alumínio AA1050 (A) polido com pasta de diamante até $1 \mu \mathrm{m}$ e (B) polido e exposto a dois banhos desengraxantes e um banho desoxidante (PB).

Figura 9: Micrografias por MEV da superfície do alumínio AA1050, polido e submetido ao tratamento PB. A) Intermetálico tipo IM1, B) Intermetálico tipo IM2 e IM4, C) Intermetálicos tipos IM3 e IM4. 40

Figura 10: Micrografias por MEV da superfície do alumínio AA1050 polido e submetido aos tratamentos PB (a), SAM (b), Cr VI (c), OX (d) e OS (e). 43

Figura 11: Diagramas de impedância obtidos para alumínio AA1050 com tratamento PB em função do tempo de imersão na solução de ensaio (a) Nyquist e (b) Módulo de $Z$ e ângulo de fase de Bode.

Figura 12: Polarizações anódicas obtidas para o alumínio 1050 com tratamento PB após vários tempos de imersão em solução de ensaio. 
Figura 13: Monitoramento do Potencial a Circuito Aberto em função do tempo de imersão em solução de $0,5 \mathrm{~mol} \mathrm{~L}^{-1} \mathrm{Na}_{2} \mathrm{SO}_{4}, \mathrm{pH}=4,0$ para eletrodo de Calomelano Saturado (A) e eletrodo de Sulfato Mercuroso (B). .50

Figura 14: Valores de potencial a circuito aberto nos instantes anteriores à aquisição das medidas de EIE para amostras Polidas com ECS e ESM. .51

Figura 15: Diagramas de Nyquist (A) e Bode (B) para amostras Polidas de AA1050 após $10 \mathrm{~h}$ de imersão em solução de $0,5 \mathrm{~mol} \mathrm{~L}^{-1} \mathrm{Na}_{2} \mathrm{SO}_{4}, \mathrm{pH}=4,0$, utilizando ECS ou ESM.

Figura 16: Diagramas de Nyquist (A) e Bode (B) para amostras de AA1050 Polidas após $12 \mathrm{~h}$ e $14 \mathrm{~h}$ de imersão em solução de $0,5 \mathrm{~mol} \mathrm{~L}^{-1} \mathrm{Na}_{2} \mathrm{SO}_{4}, \mathrm{pH}=4,0$, utilizando ECS ou ESM

Figura 17: Diagramas de Nyquist (A) e (B) e Bode (C) e (D) para amostras "Polida" de AA1050 após 14, 16, 18, 20, 22 e 24 h de imersão em solução de 0,5 $\mathrm{mol} \mathrm{L}^{-1} \mathrm{Na}_{2} \mathrm{SO}_{4}, \mathrm{pH}=4,0$, utilizando ECS ou ESM na realização das medidas. ...54

Figura 18: Diagramas de EIE das amostras Polidas de AA1050 Nyquist (A) e (B) Bode para $24 \mathrm{~h}$ de imersão em solução de $0,5 \mathrm{~mol} \mathrm{~L}^{-1} \mathrm{Na}_{2} \mathrm{SO}_{4}, \mathrm{pH}=4,0$ utilizando ECS ou ESM. .55

Figura 19: Curvas de polarização anódica obtidas para amostras Polidas de AA1050 usando ECS ou ESM após 3 dias de imersão em solução de $0,5 \mathrm{~mol} \mathrm{~L}^{-1}$ $\mathrm{Na}_{2} \mathrm{SO}_{4}, \mathrm{pH}=4,0$. 55

Figura 20: Diagramas de impedância obtidos para alumínio AA 1050 com tratamento $\mathrm{Cr}(\mathrm{VI})$ em função do tempo de imersão na solução de $0,5 \mathrm{~mol} \mathrm{~L}^{-1}$ $\mathrm{Na}_{2} \mathrm{SO}_{4}, \mathrm{pH}=4,0$ (a) Nyquist e (b) Modulo de $\mathrm{Z}$ e ângulo de fase.

Figura 21: Polarização anódica obtida para alumínio AA 1050 com tratamento $\mathrm{Cr}(\mathrm{VI})$ em função do tempo de imersão na solução de $0,5 \mathrm{~mol} \mathrm{~L}^{-1} \mathrm{Na}_{2} \mathrm{SO}_{4}, \mathrm{pH}=$ 4,0 .

Figura 22: Diagramas de impedância obtidos para alumínio AA 1050 com tratamento SAM em função do tempo de imersão na solução de ensaio $(A)$ Nyquist e (B) Modulo de Z e ângulo de fase. 
Figura 23: Curvas de polarização anódica obtidas para alumínio AA $1050 \mathrm{com}$ tratamento SAM em função do tempo de imersão na solução de $0,5 \mathrm{~mol} \mathrm{~L}^{-1}$ $\mathrm{Na}_{2} \mathrm{SO}_{4}, \mathrm{pH}=4,0$.

Figura 24: Micrografia por MEV do alumínio AA1050 após tratamento SAM, seguido por imersão durante 3 dias em solução de $0,5 \mathrm{~mol} \mathrm{~L}^{-1} \mathrm{Na}_{2} \mathrm{SO}_{4}, \mathrm{pH}=4,0$ (A) e após polarização anódica (B) 63

Figura 25: Variação potencial a circuito aberto (PCA) durante 1 hora para o alumínio AA1050 com tratamento OX, após 1 e 3 dias de imersão em solução de $0,5 \mathrm{~mol} \mathrm{~L}^{-1} \mathrm{Na}_{2} \mathrm{SO}_{4}$ tamponada, $\mathrm{pH}=4,0$. .64

Figura 26: Diagramas de impedância obtidos para alumínio AA 1050 com tratamento para crescimento de óxido (OX) em função do tempo de imersão na solução $0,5 \mathrm{~mol} \mathrm{~L}^{-1}$ de $\mathrm{Na}_{2} \mathrm{SO}_{4}$ tamponada $(\mathrm{pH}=4,0)$. (A) Nyquist e (B) Módulo de $Z$ e ângulo de fase.

Figura 27. Curvas de polarização anódica para o alumínio AA1050 com tratamento $\mathrm{OX}$ em vários tempos de imersão em solução $0,5 \mathrm{~mol} \mathrm{~L}^{-1}$ de $\mathrm{Na}_{2} \mathrm{SO}_{4}$ $(\mathrm{pH}=4)$.

Figura 28: Evolução do comportamento eletroquímico do alumínio AA1050, após tratamento OS, em função do tempo de imersão em solução $0,5 \mathrm{~mol} \mathrm{~L}^{-1}$ de $\mathrm{Na}_{2} \mathrm{SO}_{4}(\mathrm{pH}=4,0)$ indicado por diagramas de A) Nyquist e B) Bode.

Figura 29: Curvas de polarização anódica para vários tempos de imersão do alumínio AA1050 com tratamento óxido+SAM (OS) em solução 0,5 mol L-1 de $\mathrm{Na}_{2} \mathrm{SO}_{4}(\mathrm{pH}=4,0)$

Figura 30: Diagramas de Nyquist para alumínio AA1050 com os tratamentos (A) PB, OX e OS e (B) PB, Cr(VI) e SAM após 3 dias de imersão em solução 0,5 mol. $\mathrm{L}^{-1}$ de $\mathrm{Na}_{2} \mathrm{SO}_{4}, \mathrm{pH}=4,0$.

Figura 31: Diagramas de (A) ângulo de fase de Bode e (B) módulo de Z para o alumínio AA1050 com tratamentos PB, $\mathrm{Cr}(\mathrm{VI})$, SAM, OX e OS para 3 dias de imersão em solução $0,5 \mathrm{~mol} \mathrm{~L}^{-1}$ de $\mathrm{Na}_{2} \mathrm{SO}_{4}$ tamponada, $\mathrm{pH}=4$.

Figura 32: Curvas de polarização anódica para alumínio AA1050 com tratamentos $\mathrm{PB}, \mathrm{SAM}, \mathrm{Cr} \mathrm{VI}, \mathrm{OX}$ e OS após 3 dias de imersão em solução de ensaio $(0,5 \mathrm{~mol}$ $\mathrm{L}^{-1}$ de sulfato de sódio, $\left.\mathrm{pH}=4,0\right)$. 
Figura 33: Curvas de polarização catódica para alumínio AA1050 com tratamentos PB, SAM, Cr(VI), OX e OS após 3 dias de imersão em solução de ensaio $\left(0,5 \mathrm{~mol} \mathrm{~L}^{-1}\right.$ de sulfato de sódio, $\left.\mathrm{pH}=4,0\right)$.

Figura 34: Micrografias de superfície do alumínio AA 1050 com os tratamentos $\mathrm{PB}, \mathrm{Cr}(\mathrm{VI})$ e SAM mostrando o efeito destes tratamentos da imersão e das polarizações anódicas ou catódicas nestas superfícies.

Figura 35: Micrografias da superfície do alumínio AA 1050 com os tratamentos OX e OS mostrando o efeito destes tratamentos, da imersão e das polarizações anódicas ou catódicas nestas superfícies. .83

Figura 36: Micrografias obtidas por MEV para amostras submetidas ao tratamento de SAM após polarização, (A) Catódica e (B) Anódica.

Figura 37: Espectros obtidos por EDS e quantificação para amostra tratada com $\mathrm{Cr}(\mathrm{VI})$ na região do intermetálico IM3, antes da imersão na solução de $0,5 \mathrm{~mol} \mathrm{~L}^{-1}$ de sulfato de sódio, $\mathrm{pH}=4,0$.

Figura 38: Circuitos elétricos equivalentes, $(A)$ para os tratamentos $P B, S A M$, $\mathrm{Cr}(\mathrm{VI})$ e (B) para os tratamentos OX e OS.

Figura 39: Micrografias obtidas por MEV para alumínio AA1050 após (A) tratamento PB e (B) tratamento SAM (PB seguido por imersão em solução com moléculas auto-organizáveis).

Figura 40: Micrografias obtidas por MEV com detector para elétrons secundários (A) e detector para elétrons retroespalhados $(B)$ para o tratamento OX. .89

Figura 41: Modelo físico proposto para representação da superfície do AA1050 após tratamento OX e imersão em solução $0,5 \mathrm{~mol} \mathrm{~L}^{-1}$ de $\mathrm{Na}_{2} \mathrm{SO}_{4}(\mathrm{pH}=4,0) \ldots . .90$ Figura 42: Modelo físico proposto para representar a superfície do AA1050 após tratamento OS e imersão em solução em solução e ensaio $\left(0,5 \mathrm{~mol} \mathrm{~L}^{-1}\right.$ de $\mathrm{Na}_{2} \mathrm{SO}_{4}$ $(\mathrm{pH}=4,0)$.

Figura 43: Evolução dos diagramas de EIE para alumínio AA1050 com tratamento OS até 20 dias de imiersão em solução $0,5 \mathrm{~mol} \mathrm{~L}^{-1}$ de sulfato de sódio, $\mathrm{pH}=4,0$, (A) e (B) Nyquist e (C) e (D) Bode. .96 


\section{INTRODUÇÃO}

O Brasil possui a terceira maior reserva mundial de bauxita, principal matéria-prima para a produção do alumínio consumido no planeta [ABAL, 2006, 2010]. Na área de Ciência e Tecnologia de Materiais, dados estatísticos revelam que aproximadamente $4 \%$ do produto interno bruto (PIB) de um país industrializado é gasto com a degradação de materiais causada pela corrosão. Devido ao alto custo envolvido nesse processo, a corrosão torna-se um fenômeno economicamente importante, a ser considerado por países em desenvolvimento [Ramanathan, 1988, Callister, 2008].

O alumínio, juntamente com ferro e o aço é um dos metais mais utilizados em diferentes aplicações e segmentos da indústria moderna. Em ambientes de baixa agressividade, o filme de óxido formado espontaneamente sobre a superfície do alumínio puro e suas ligas é considerado protetor e proporciona boa resistência à corrosão. Entretanto, em atmosferas mais agressivas, essa proteção não é suficiente para evitar processos corrosivos e, com isso, faz-se necessária a aplicação de tratamentos de superfície e revestimentos protetores visando o aumento da resistência à corrosão [Campestrini et al., 2001a, b, Palomino, 2008]

Entre os tratamentos de superfície utilizados em alumínio e suas ligas, destaca-se a cromatização, que promove efetiva proteção com baixo custo de aplicação e elevada aderência, tanto ao substrato metálico, quanto à camada orgânica protetora; porém, a cromatização torna-se inviável devido às restrições ambientais (utilização de cromo hexavalente) e ao elevado custo envolvido nos tratamentos de resíduos tóxicos gerados nesse tratamento.

No decorrer dos últimos 20 anos, a preocupação com sustentabilidade se intensificou de modo expressivo. Em junho de 1992, o Brasil sediou a Conferência das Nações Unidas para o Meio Ambiente e o Desenvolvimento, conhecida popularmente como ECO-92, que tinha como um dos objetivos a divulgação do conceito de sustentabilidade para o mundo. Esse conceito, na prática, se aplica na exploração de áreas ou no uso de recursos naturais e/ou artificiais, de forma a prejudicar o menos possível o equilíbrio entre o meio ambiente as comunidades 
humanas e toda a biosfera que deles dependem para existir [Atitudes Sustentáveis, 2010].

Em países desenvolvidos, especificamente na União Européia, restrições ambientais estabelecidas em 2006 (Diretivas RoHS - Restriction of Certain Hazardous Substances e WEEE - Waste Eletrical and Eletronics Equipment) impedem a utilização de determinadas substâncias nocivas nos processos de fabricação e produção de equipamentos eletrônicos, bem como a importação de produtos que contenham metais pesados em sua composição, como por exemplo, chumbo, cádmio e o cromo hexavalente, sem que os fabricantes paguem pela coleta de seus produtos após a utilização [Anvisa, 2010].

No Brasil, a Constituição Federal e a Lei no 6.938, de 31 de agosto de 1981, visam controlar a deposição de poluentes no meio ambiente impedindo o lançamento dos mesmos em níveis nocivos ou perigosos para os seres humanos e outras formas de vida. O artigo 24 da Resolução Conama nº 397 de 2005 Capítulo IV diz, "Desta forma, os efluentes de qualquer fonte poluidora somente poderão ser lançados nos corpos de água, direta ou indiretamente, após o devido tratamento e desde que obedeçam às condições, padrões e exigências dispostos nesta Resolução e em outras normas aplicáveis" [Resolução Conama, 2005]. A Tabela 1 apresenta os níveis de cromo máximo permitidos nos efluentes, segundo a resolução Conama de 2005.

Tabela 1. Lançamentos de Efluentes [Resolução Conama, 2005].

\begin{tabular}{|c|c|}
\hline \multicolumn{2}{|c|}{ Padrões } \\
\hline $\begin{array}{l}\text { Cromo total hexavalente } \\
\text { (nova redação e valor dados pela } \\
\text { Resolução } n^{\circ} 397 / 08 \text { ) }\end{array}$ & $\begin{array}{c}\left.{ }^{*} 0,5 \mathrm{mg} / \mathrm{L} \mathrm{Cr}^{+6}\right) \\
0,1 \mathrm{mg} / \mathrm{L} \mathrm{Cr}^{+6}\end{array}$ \\
\hline $\begin{array}{l}\text { Cromo total Trivalente } \\
\text { (nova redação e valor dados pela } \\
\text { Resolução } n^{\circ} 397 / 08 \text { ) }\end{array}$ & $1,0 \mathrm{mg} / \mathrm{L} \mathrm{Cr}^{+3}$ \\
\hline
\end{tabular}

Nesse contexto, a comunidade científica possui um papel importante no desenvolvimento e na execução da prática da sustentabilidade. Já existem vários grupos e centros de pesquisas que vêm estudando o desenvolvimento de métodos alternativos à cromatização, os quais podem ser classificados como ambientalmente "amigáveis", dentre elas as moléculas auto-organizáveis. 


\section{OBJETIVOS E JUSTIFICATIVAS}

Pré-tratamentos de superfície são frequentemente utilizados para maximizar o tempo de vida útil do alumínio e de suas ligas, visando diminuir os processos de degradação causados pela corrosão. O bom desempenho obtido por pré-tratamentos contendo soluções de ácido crômico (principalmente cromo hexavalente), aliado ao baixo custo e à facilidade de aplicação, justifica o fato desse tipo de tratamento ter sido amplamente consagrado e adotado durante muitos anos para a proteção do alumínio. Porém, sua utilização foi se tornando inviável devido à alta toxicidade e caráter cancerígeno do cromo hexavalente, o que levou às restrições de interesse ambiental. $O$ gasto elevado envolvido no tratamento do descarte final de substâncias nocivas é um dos aspectos que têm inviabilizado progressivamente os tratamentos que envolvem $\mathrm{Cr}(\mathrm{VI})$.

Tratamentos da superfície do alumínio e suas ligas, alternativos à cromatização com $\mathrm{Cr}(\mathrm{VI})$, vêm sendo estudados, dentre os quais pode-se citar o tratamento com moléculas auto-organizáveis (SAM). Nesse contexto, o objetivo principal deste trabalho é avaliar a viabilidade com relação à resistência à corrosão de se utilizar a modificação da superfície do alumínio 1050 (AA1050) com moléculas auto-organizáveis (SAM) à base de difosfonatos, para substituir a cromatização do alumínio AA1050 com soluções contendo $\mathrm{Cr}(\mathrm{VI})$.

Os objetivos específicos deste estudo foram:

1. Caracterizar a resistência à corrosão do alumínio comercialmente puro AA1050 após vários tratamentos de modificação da superfície, por métodos eletroquímicos em solução tamponada de sulfato $(\mathrm{pH}=4,0)$.

2. Investigar o efeito de tratamento prévio da superfície do AA1050, antes do tratamento com moléculas auto-organizáveis, na resistência à corrosão da superfície após este último tratamento.

3. Comparar os resultados dos tratamentos testados com os da cromatização em solução à base de $\mathrm{Cr}(\mathrm{VI})$. 


\section{REVISÃO DA LITERATURA}

\subsection{Resistência à corrosão de materiais metálicos}

A corrosão de materiais metálicos manifesta-se em diferentes meios. No entanto, o meio em que ela ocorre com maior frequência é o aquoso. Nesse meio, o mecanismo de corrosão é essencialmente eletroquímico.

Uma reação é considerada eletroquímica se ela estiver associada à passagem de corrente elétrica através de uma distância finita, maior que a distância interatômica. Esta passagem de corrente envolve o movimento de partículas carregadas, íons, elétrons, ou ambos. Dessa forma, a maioria das reações que se manifestam em uma superfície metálica são reações eletroquímicas em sua natureza [Wolynec, 2003]. Assim, técnicas eletroquímicas podem ser utilizadas na investigação e no controle do processo de corrosão.

Do ponto de vista termodinâmico, para ocorrência espontânea de uma reação química, é suficiente que a variação de energia livre seja negativa; porém, do ponto de vista cinético, esta condição não é suficiente. De fato, para que uma reação ocorra, é necessário que as espécies reagentes tenham energia suficiente para superar uma ou mais barreiras energéticas, sendo que a etapa controladora da velocidade da reação será aquela com maior barreira energética [Darken e Gurry, 1953, West, 1971, Wolynec, 2003]. Fundamentalmente, a corrosão ocorre porque os metais apresentam uma condição termodinâmica instável e, em razão disso, tendem a mudar para uma condição mais estável pela formação de óxidos, hidróxidos ou sais [Wolynec, 2003].

No caso da corrosão atmosférica, a reação de corrosão ocorre apenas durante os períodos em que o metal é recoberto por uma película de umidade ou em presença de água. Segundo a literatura, as seguintes reações de corrosão ocorrem para o metal alumínio em meio ácido [Reboul e Baroux, 2011].

$$
\mathrm{Al}+3 \mathrm{H}_{2} \mathrm{O} \rightarrow \mathrm{Al}(\mathrm{OH})_{3}+\frac{3}{2} \mathrm{H}_{2} \uparrow
$$

Essa reação global de corrosão é resultado de duas semi-reações eletroquímicas, indicadas em (2) e (3): 
Oxidação do alumínio nas áreas anódicas:

$$
A l \rightarrow A l^{3+}+3 e^{-}
$$

E redução da água (3) nas áreas catódicas:

$$
3 \mathrm{H}_{2} \mathrm{O}+3 e^{-} \rightarrow 3 \mathrm{OH}^{-}+\frac{3}{2} \mathrm{H}_{2} \uparrow
$$

A corrosão metálica é, muitas vezes, classificada em diferentes tipos, como por exemplo, corrosão generalizada, galvânica, por fresta, intergranular, corrosãoerosão, corrosão sob tensão, seletiva e por pites, sendo que esta última ocorre apenas em materiais passivos, como por exemplo, aços inoxidáveis e ligas de alumínio [Ramanathan, 1988, Wolynec, 2003, Callister, 2008].

\subsubsection{Corrosão por pite}

A boa resistência à corrosão dos metais passivos é resultado da proteção promovida pelo filme de óxido formado sob sua superfície [Davis,1993]. Este filme pode, todavia, ser rompido em presença de espécies corrosivas, causando ataque localizado. O alumínio é susceptível à corrosão por pite quando exposto a ambientes agressivos, particularmente aqueles que contêm íons cloreto.

A corrosão por pite consiste na formação de cavidades de pequena extensão e com razoável profundidade [Meng et al., 2009], sendo resultado de uma perda da passividade local do filme protetor. Geralmente, este tipo de corrosão ocorre em atmosferas e meios contaminados com cloreto (íons $\mathrm{Cl}^{-}$). Entretanto, embora o cloreto seja necessário, ele não é suficiente para desenvolver o processo de corrosão por pite, pois os pites não ocorrem em água do mar desaerada, já que a presença de um oxidante também é necessária [Reboul e Baroux, 2011].

No caso da água de torneira, que é naturalmente aerada, por exemplo,

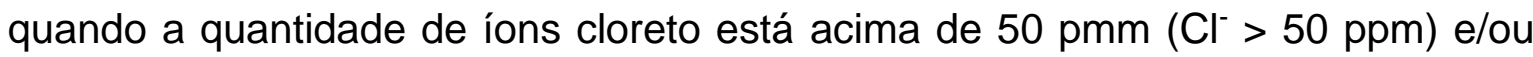
quando metais pesados estão presentes $\left(\mathrm{Cu}^{2+}, \mathrm{Pb}^{2+}\right.$, entre outros), é possível 
calcular o número de semanas para que o pite atinja uma profundidade de $1 \mathrm{~mm}$ no alumínio através de uma fórmula empírica [Pathack e Godard, 1968].

Segundo Pathack e Godard [1968], a equação (4) pode ser utilizada para predizer a agressividade da corrosão por pite em água, a partir da composição química em função da penetração do pite em Alumínio:

$$
\begin{aligned}
& \log P=2,5-0,28 x \log \left(S_{4}^{2-}\right)+0,18 x \log \left(C l^{-}\right)-0,20 x \log \left[(p H-7)^{2}-100\right] \\
& -0,42 x \log \left(\frac{3000}{R}\right)-0,06 x \log \left(\left(C u^{2+}\right) x 1000\right)
\end{aligned}
$$

Onde $P$ é o número de semanas necessárias para a corrosão por pite penetrar $1 \mathrm{~mm}$ no alumínio, $\left(\mathrm{SO}_{4}^{2-}\right),(\mathrm{Cl}),\left(\mathrm{Cu}^{2+}\right)$ são as concentração químicas dos íons em mg/L; e R é a resistividade da água (Ohm.cm).

Segundo alguns autores [Smialowska, 1992, Frankel e McCreery, 2001, Frankel e Sridhar, 2008, Meng et al., 2009] a corrosão por pite em substratos de alumínio pode ser dividida em uma seqüência de etapas, a saber (a) quebra do filme passivo, (b) nucleação e crescimento de pites metaestáveis (nesse contexto, metaestável indica que muitos dos pites param de crescer, não atingindo a etapa seguinte), (c) formação de pites estáveis, ou seja, corrosão localizada aumentando em grande escala o tamanho do pite e, finalmente, em determinadas condições, (d) repassivação ou término do ataque localizado.

A corrosão por pite é conhecida por se iniciar acima de um potencial crítico. Eventualmente, pode ocorrer a repassivação, geralmente em um potencial bem inferior ao valor do potencial crítico. Uma vez iniciado o ataque em condições agressivas, a estabilização e o desenvolvimento da corrosão localizada resultam na hidrólise dos cátions metálicos e na migração de íons cloreto $\left(\mathrm{Cl}^{-}\right)$para dentro do pite [Frankel e Sridhar, 2008].

\subsection{Alumínio e suas ligas}

As propriedades que fazem com que o alumínio seja um metal econômico e atraente para uma grande variedade de aplicações são: (a) aparência, (b) baixa densidade, (c) propriedades físicas apropriadas, (d) boas propriedades mecânicas 
de suas ligas, e (e) resistência à corrosão. Outras características que ampliam consideravelmente o campo de aplicação do alumínio são: comportamento nãoferromagnético, antifaiscante e não-tóxico, além da aparência brilhante, da elevada condutibilidade elétrica e térmica e da capacidade de reflexão de energia radiante [Shimizu et al., 1991, ABAL, 1996, Roelandts, 2001, Meng et al., 2009].

A grande variedade de propriedades mecânicas e físicas, que podem ser obtidas com o alumínio e suas ligas, justifica o fato de haver mais de 300 ligas reconhecidas e outras centenas de ligas especiais desenvolvidas de acordo com necessidades específicas.

O sistema de classificação das ligas de alumínio adotado pela Aluminium Association em 1971 [The Aluminum Association, 1998] é o mais aceito atualmente. Esse sistema subdivide-se em duas partes: o adotado para as ligas utilizadas em trabalhos mecânicos (laminação, extrusão, forjamento e outros), e o que foi adotado para ligas destinadas exclusivamente à produção de peças fundidas. Entretanto, a composição das ligas e as suas aplicações gerais são as mesmas, e estão apresentadas de forma simplificada na Tabela 2.

Tabela 2. Classificação e usos de ligas de alumínio [The Aluminum Association, 1998].

\begin{tabular}{lll}
\hline Série & Composição Química & Principais Aplicações \\
\hline \hline 1XXX & Al comercialmente puro & Contatos elétricos, Alclad \\
$2 X X X$ & Al-Cu e Al-Cu-Mg & Indústria aeronáutica \\
$3 X X X$ & Al-Mn e Al-Mn-Mg & Latas de bebidas, panelas. \\
4XXX & Al-Si & $\begin{array}{l}\text { Metal de adição para soldas, pistões } \\
\text { forjados de motores. }\end{array}$ \\
$5 X X X$ & Al-Mg & Aplicações náuticas (navios e barcos) \\
& & Perfis arquitetônicos, componentes \\
$6 X X X$ & Al-Mg-Si & automotivos. \\
$7 X X X$ & Al-Zn-Mg e Al-Zn-Mg-Cu & Indústria aeronáutica. \\
$8 X X X$ & Outras ligas (Al-Li, Al-Fe) & Diversas e Variadas \\
\hline
\end{tabular}




\subsubsection{Passividade do Alumínio}

O alumínio possui elevada resistência à corrosão em virtude da fina camada amorfa de óxido de alumínio $\left(\mathrm{Al}_{2} \mathrm{O}_{3}\right)$ que se forma naturalmente em sua superfície [ABAL, 1996, Reboul e Baroux, 2011]. Óxidos formados ao ar e à temperatura ambiente possuem espessura de 2 a $4 \mathrm{~nm}$, enquanto que óxidos formados a temperaturas de $425{ }^{\circ} \mathrm{C}$ podem dobrar de espessura após $24 \mathrm{~h}$ de recozimento e atingir até $20 \mathrm{~nm}$ de espessura [Alwitt, 1976, Bressiani E F, 1992]. A película de óxido é muito compacta e intimamente aderida à superfície metálica, ou seja, o volume de óxido é alto comparado ao volume do metal envolvido na oxidação $\left(\rho \mathrm{Al}_{2} \mathrm{O}_{3} / \rho \mathrm{Al}=1.4\right)$ [Reboul e Baroux, 2011].

Entretanto, para o uso industrial, este tipo de filme não proporciona longa proteção. A película de óxido em alumínio é muito fina e inclui um grande número de defeitos $\left(10^{4} \mathrm{~cm}^{2}\right)$, principalmente sob a forma de micro-falhas com tamanho aproximado de $10 \mathrm{~nm}$ [Thompson et al., 1982].

O alumínio é protegido por uma dupla camada de óxido, composta por uma película de óxido amorfo anidro na interface metal/filme e um filme de óxido hidratado na interface ambiente úmido/filme. Esta camada mais externa resulta da hidrólise do filme óxido em meio aquoso. Esta camada hidratada é menos protetora do que a camada mais interna e seca. A perda de proteção é automaticamente compensada por oxidação do metal formando uma camada de óxido-hidratado correspondente ao novo equilíbrio entre o metal e o ambiente úmido [Reboul e Baroux, 2011].

O alumínio pode sofrer corrosão tanto em meio ácido quanto em meio alcalino, sendo que, como já foi mencionado, o tipo de corrosão mais comum é a corrosão por pite [Van der Walde et al., 2005]. Todavia, em uma faixa de pH entre 4,0 a 9,0, ocorre a formação de uma camada passiva de óxido-hidróxido altamente protetora [Mattsson, 1989, Davis, 1993], fazendo com que o alumínio não sofra corrosão em uma extensa faixa de potenciais. Porém, uma alteração na natureza do ambiente, por exemplo, o aumento na concentração da espécie corrosiva ativa, pode fazer com que o material passivo passe para o estado ativo e qualquer dano subseqüente à película passivadora pode aumentar expressivamente a taxa de corrosão do metal [Callister, 2008]. 
O diagrama de Pourbaix simplificado, apresentado na Figura 1, ilustra as regiões onde ocorrem a passividade, a imunidade e a corrosão do alumínio. $A$ região de estabilidade do óxido-hidróxido de alumínio em meios aquosos pode ser indicada pela região de passividade, e corresponde a um intervalo de $\mathrm{pH}$ que varia entre 4,0 e 9,0. Porém, em regiões onde o pH está abaixo de 4,0 ou acima de 9,0, essa camada perde seu caráter protetor devido à alta solubilidade da camada passiva em meios agressivos ácidos ou básicos. Em meios ácidos $(\mathrm{pH}<$ $4,0)$ ocorre a formação de íons $\mathrm{Al}^{3+}$ e em meios alcalinos $(\mathrm{pH}>9,0)$ ocorre a formação de íons $\mathrm{AlO}_{2}^{-}$[Pourbaix, 1974, Reboul e Baroux, 2011].

É importante ressaltar a possível ocorrência da oxidação do alumínio através de um tipo específico de corrosão localizada (por pite), tanto dentro quanto fora de região de passividade. Além disso, pode-se notar a não ocorrência da oxidação do alumínio na região de corrosão do diagrama de Pourbaix devido à formação de filmes óxidos insolúveis no meio em questão [Reis, 2005].

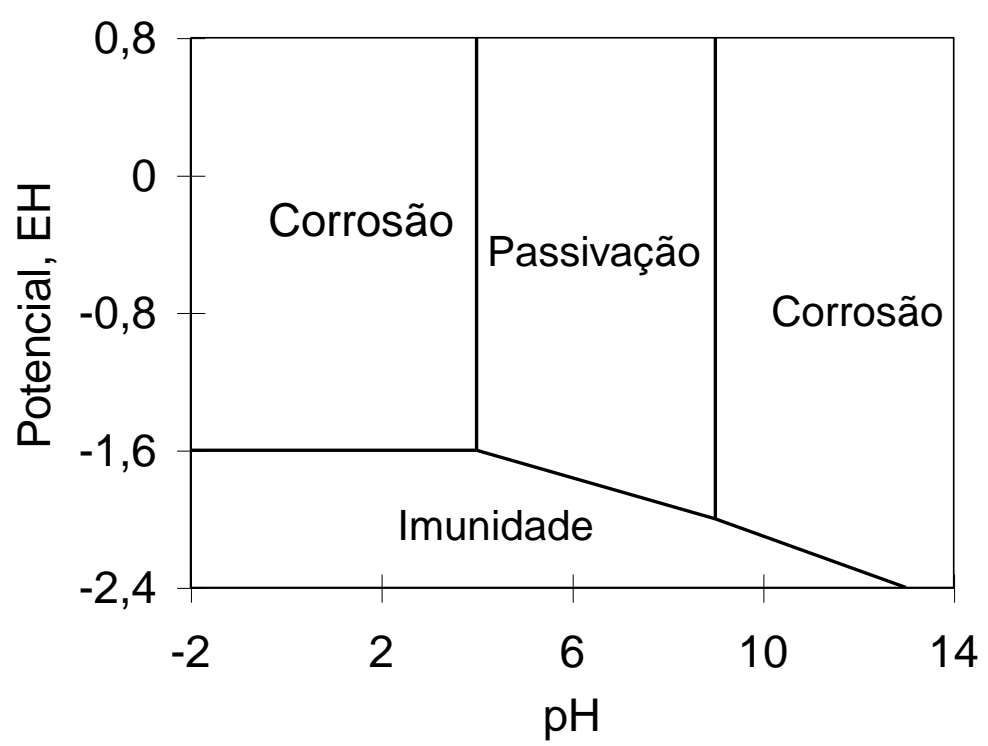

Figura 1: Diagrama de Pourbaix simplificado do alumínio em meio aquoso.

Os diagramas de Potencial-pH descrevem aspectos fundamentais das reações que controlam o comportamento de corrosão do alumínio, porém não levam em consideração um fator importando associado à velocidade das reações que limita a taxa de dissolução do filme óxido-hidróxido no processo de corrosão [Moshier et al., 1987]. 
A fase termodinâmica mais estável entre todos os hidróxidos ou oxihidróxidos de alumínio que podem ser formados durante a imersão em água é a Hidrargilita $\left(\mathrm{Al}(\mathrm{OH})_{3}\right)$ [Alwiit, 1976]. Outros autores [Hart, 1957, Vedder e Vermilyea, 1969] afirmam que a fase Pseudo-Boehmita $(\mathrm{AIOOH}=$ Boehmita, porém com diferenças na composição estrutural) é a primeira a se formar, sendo considerada precursora da fase $\mathrm{Al}(\mathrm{OH})_{3}$ e pode perdurar na superfície durante longos períodos de tempo.

Considerando que durante a polarização do alumínio uma grande variação de óxidos-hidróxidos pode ser formada, Moshier et al. [1987], utilizaram espectroscopia fotoelétrica de Raios-X (XPS - X-ray photoelectron spectroscopy) para determinar a composição e espessura do filme em diferentes condições de $\mathrm{pH}$, confirmando que a fase termodinamicamente mais estável é $\mathrm{Al}(\mathrm{OH})_{3}$, e que a fase $\mathrm{AlOOH}$ (Boehmita ou Pseudo-Boehmita) se forma na maioria do meios quando submetido a polarização.

\subsubsection{Importância das ligas de alumínio e o processo Alclad (AA1XXX)}

O alumínio comercialmente puro (Série $A A 1 X X X)$ pode ser identificado através do sistema de classificação da Aluminum Association (AA) em diferentes graus de pureza, desde 99,00\% (denominado 1000) até a 99,99\% (denominado 1099). Nesse sistema, os dois últimos algarismos referem-se ao grau de pureza da liga, ou seja, até a casa centesimal acima de 99,00\%. Assim sendo, o alumínio comercialmente puro com 99,50 \% de alumínio é conhecido como 1050, já o alumínio com 99,70 \% de pureza é denominado 1070 e assim por diante [Infomet, 2010, Reboul e Baroux, 2011].

Algumas características importantes do alumínio comercialmente puro são: sua baixa resistência mecânica, fato que restringe sua aplicação na indústria aeronáutica e automotiva, e sua elevada resistência à corrosão, devido à camada de óxido de alumínio $\left(\mathrm{Al}_{2} \mathrm{O}_{3}\right)$ protetora, fenômeno também conhecido como passivação [Callister, 2008, Infomet, 2010].

O alumínio possui a capacidade de combinar-se com a maioria dos metais, principalmente com ferro $(\mathrm{Fe})$, cobre $(\mathrm{Cu})$, magnésio $(\mathrm{Mg})$, manganês $(\mathrm{Mn})$ e 
zinco (Zn), além do silício (Si) semimetal, que nesse caso pode atuar como metal. Isto permite a introdução desses elementos no alumínio fundido como elementos de liga, originando uma série de ligas de alumínio (2XXX a 8XXX, Tabela 2), que possuem melhores propriedades mecânicas, ampliando o campo de aplicação deste material na indústria.

Porém, se por um lado a adição de determinados elementos de liga ao alumínio possibilita a formação de ligas de alta resistência mecânica (séries 2XXX e 7XXX) utilizadas principalmente na indústria aeronáutica, por outro, estes também interferem, muitas vezes negativamente, nas propriedades de resistência à corrosão, principalmente quando os elementos adicionados estão mais afastados do alumínio na tabela de potencial eletroquímico, por exemplo, o cobre, devido à formação de um par galvânico que pode dar início ao processo de corrosão localizada [Smialowska, 1999, ASM Handbook, 2003, Infomet, 2010].

Uma alternativa encontrada para reunir a elevada resistência à corrosão do alumínio puro com a alta resistência mecânica das ligas de alumínio utilizadas pela indústria aeronáutica (Séries $2 X X X$ e $7 X X X$ ) é o processo clad (do inglês "cladding" = revestimento), que consiste no revestimento de ligas com alumínio comercialmente puro. Um exemplo é a liga (Al-Cu) AA 2024 revestida com alumínio puro, denominada Alclad 2024 [Infomet, 2010] representada esquematicamente na Figura 2.

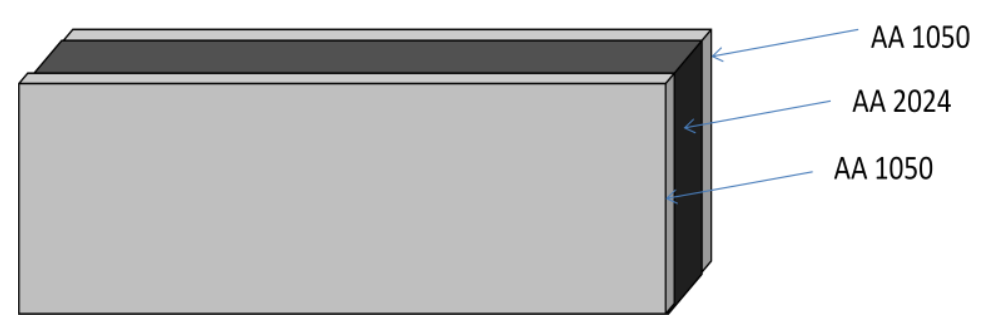

Figura 2. Representação esquemática da liga de alumínio Alclad 2024.

\subsubsection{Influência dos elementos de liga no Alumínio e suas ligas.}

Através de estudos em que a propriedade de resistência à corrosão das películas passivas de óxido-hidróxido de alumínio foram investigadas, Shimizu et 
al. [1998], afirmam que um elemento-chave nesse processo é a natureza heterogênea microscópica da superfície do alumínio. Brown et al. [1993], confirmaram que até mesmo em amostras de alumínio com grau de pureza 99,99\%, é possível perceber a presença de heterogeneidades na superfície. Pequenas quantidades de impurezas, como $\mathrm{Fe}$ e Si, formam soluções sólidas, ou seja, estão presentes de maneira uniforme dentro da matriz, mas também estão segregadas nos contornos de grão [Brown et al., 1992, Shimizu et al.,1998]. Precipitados intermetálicos formados por impurezas também podem ser observados no interior dos grãos.

Kruger et al. [1992] apud Scully et al. [1993] e Natishan et al. [1988] afirmam que elementos de liga normalmente são adicionados em porcentagem atômica acima do limite de solubilidade e, em certos casos, devem ser mantidos em solução sólida em condições de supersaturação, para garantir o aumento da resistência à corrosão. Porém, quando não ocorre a formação de solução sólida total, os elementos adicionados precipitam na forma de intermetálicos, que possuem atividade eletroquímica diferente da matriz, causando sérios problemas de corrosão localizada [Buchheit et al., 1995, 1997, 1999, 2000].

Os elementos mais comumente encontrados como impurezas no alumínio comercialmente puro utilizado como Alclad são: ferro (Fe) e silício (Si) [Campestrini, 2001a, Reboul e Baroux, 2011], em maior ou menor grau, dependendo do nível de pureza do material. Estes elementos podem formar fases intermetálicas, como $\mathrm{Al}_{3} \mathrm{Fe}, \mathrm{Al}_{6} \mathrm{Fe}$ [Metals Handbook, 2003], $\mathrm{Fe}_{3} \mathrm{SiAl}_{12}, \mathrm{FeSiAl}_{8}$, $\mathrm{FeSiAl}_{5}$, e $\mathrm{Fe}_{2} \mathrm{Si}_{2} \mathrm{Al}_{9}$, devido à limitada solubilidade do ferro no alumínio [Infomet, 2010]. Estas fases apresentam-se com diferentes tamanhos, formatos e distribuição, prejudicando as propriedades da matriz quando são grosseiras, alongadas e concentradas nos contornos de grão [Brown et al., 1993, Shimizu et al.,1998, Infomet, 2010].

\subsection{Tratamentos de Superfície para alumínio}

Tanto nas amostras de alumínio AA1050 com alto grau de pureza (99,50\%) quanto nas que possuem elementos de liga, são observadas heterogeneidades que interceptam a superfície e que desempenham um papel crucial no 
desenvolvimento de revestimentos de conversão química e na nucleação de pites [Shimizu et al., 1998, Campestrini et al., 2001b].

Em situações onde a camada passiva formada sobre a superfície do alumínio não confere a proteção desejada, geralmente é aplicado um revestimento orgânico (tinta) visando o aumento da resistência à corrosão. Nesses casos, a tinta atua como barreira física que impede parcialmente o acesso de espécies agressivas ao metal, reduzindo, portanto, o ataque corrosivo.

Quanto mais denso e compacto for o revestimento, maior será a proteção do material. No entanto, nenhum tipo de tinta é capaz de formar uma camada isenta de defeitos e sem poros o bastante para bloquear a penetração da umidade, do oxigênio, bem como de íons que possuem raio iônico de menor tamanho $\left(\mathrm{Cl}^{-}\right)$. Assim, a interface revestimento orgânico/substrato se torna susceptível ao início dos processos corrosivos que favorecem a perda de aderência da tinta e a delaminação do revestimento pelo acúmulo dos produtos de corrosão [Mendoza e Corvo, 2000, Bierwagen e Tallman, 2001, Palomino, 2008].

Deste modo, tratamentos de superfície são realizados em alumínio e suas ligas na etapa anterior à pintura com a finalidade de suprir a deficiência dos revestimentos orgânicos, aumentando a adesão entre a tinta e o substrato metálico e promovendo a inibição do mecanismo de ataque corrosivo do metal [Bressiani, 1992, ABAL, 1996].

\subsubsection{Cromatização}

Dentre os tratamentos de superfície mais efetivos para o alumínio e suas ligas, encontra-se a cromatização. Neste processo, uma solução contendo íons cromato é colocada em contato com a superfície da liga de alumínio, sendo formada uma camada de óxido-hidróxido de cromo (III), com propriedades anticorrosivas altamente favoráveis [Brown et al., 1992, Zhao et al., 1998, Frankel e McCreery, 2001]. Esta camada também contém em sua composição cromo (VI), que favorece um mecanismo de auto-proteção (self-healing), conforme observado por Zhao et al. [1998]. Estes autores verificaram que o cromo (VI) possui a 
habilidade para migrar e reparar defeitos em regiões da liga de alumínio AA2024 promovendo assim maior proteção ao substrato metálico.

O tratamento de cromatização, que leva à formação de cromato na superfície, também é chamado de camada de conversão de cromo (CCC) porque uma camada é formada a partir de reação química/eletroquímica entre o metal e uma solução de composição específica, contendo uma mistura de cromo hexavalente, ou $\mathrm{Cr}^{6+}$, com outros compostos [Palomino, 2009]. Na formação da CCC, o $\mathrm{Cr}^{6+}$ é parcialmente reduzido a cromo trivalente, $\mathrm{Cr}^{3+}$, e também retido no interior da camada. Nesse processo, a CCC formada é composta por óxidos de $\mathrm{Cr}^{3+}$ insolúveis, na qual se encontram incorporados os compostos solúveis de $\mathrm{Cr}^{6+}$. O filme resultante adere ao substrato metálico formando uma barreira de proteção anti-corrosiva que, além de atuar como barreira, possui a desejável propriedade de auto-regeneração (self-healing), conferida pelos cromatos aprisionados, que quando liberados reparam as regiões atacadas melhorando ainda mais o desempenho contra o ataque do meio.

A função chave dos cromatos é inibir reações catódicas, como a redução do oxigênio $\left(\mathrm{O}_{2}\right)$, as quais, por sua vez, possibilitam processos anódicos (como corrosão por pite) sob condições de potencial de circuito aberto [Bressiani Filho, 1992, Kendig, M.W. e R.G. Buchheit 2003].

Revestimentos de cromato têm sido produzidos não apenas em alumínio, mas também sobre vários metais por tratamento químico ou eletroquímico. O uso destes compostos foi bastante difundido devido ao seu baixo custo, facilidade de aplicação e de controle, além da grande eficiência na proteção contra a corrosão [Darken e Gurry, 1953, Bonnel et al., 1999, Kolics et al., 2001, Clark et al., 2002, Kendig e Jeanjaquet, 2002].

Um grande problema encontrado no uso do tratamento de cromatização convencional com $\mathrm{Cr}(\mathrm{VI})$ é o seu caráter altamente tóxico e poluente. Os cromatos podem ocasionar lesões graves nas áreas expostas do corpo humano, afetando principalmente a pele e as vias respiratórias. Compostos de cromo (VI), em contato constante com a pele ocasionam dermatites, podendo ocorrer também casos de alergia. Nas vias respiratórias, com a exposição contínua ao cromo (VI), podem ocorrer problemas no septo nasal [Gentil, 1996]. 
Além disso, há também o problema ambiental dos efluentes da cromatização, que geram água residual (efluente) contendo cromatos os quais são extremamente prejudiciais ao meio ambiente (mananciais). Esses efluentes necessitam ser tratados antes de serem lançados nos mananciais receptores. $O$ tratamento adotado consiste na redução do cromo VI para III, para que haja precipitação do mesmo. Este tratamento gera custos adicionais além dos problemas ambientais [Abal, 1996, Palomino, 2008, Palomino et al., 2009].

\subsubsection{Tratamentos alternativos}

Apesar da agressividade dos íons $\mathrm{Cr}^{6+}$ ao meio ambiente, de suas propriedades cancerígenas e da sua elevada toxicidade, os tratamentos de superfície à base de $\mathrm{Cr}(\mathrm{VI})$ ainda vêm sendo utilizados, principalmente pela dificuldade de encontrar um tratamento que produza uma superfície com características de proteção superior ou similar às das camadas de cromato, do ponto de vista da resistência à corrosão.

Estudos realizados com tratamentos alternativos à cromatização, ou seja, livres de cromo hexavalente, têm sido publicados em grande quantidade com 0 objetivo de investigar novos tratamentos que possam ser possíveis substitutos ao processo de cromatização.

\subsubsection{Camada de conversão de cério}

Dentre as alternativas investigadas visando a substituição de tratamentos com cromo hexavalente podem ser citados os tratamentos de conversão com camadas de cério, como um efetivo inibidor de corrosão para o alumínio e suas ligas [Xingwen et al., 2001] A literatura afirma que o cério atua mais precisamente como inibidor catódico, dificultando a reação de redução do oxigênio [Cohen, 1995, Bethencourt et al., 1998, Campestrini et al., 2004].

Uma importante característica da camada composta por óxido de cério hidratado $\left(\mathrm{CeO}_{2} \cdot 2 \mathrm{H}_{2} \mathrm{O}\right)$ depositada sobre metal é a auto-reparação (self-healing). Este processo pode ser atribuído, segundo a literatura [Buchheit et al., 2002], à 
inter-conversão de $\mathrm{Ce}^{3+}$ em íons $\mathrm{Ce}(\mathrm{OH})_{2}{ }^{2+}$, que sofrem redução em contato com a camada de óxido de alumínio, precipitando na forma de $\mathrm{Ce}(\mathrm{OH})_{3}$, provavelmente em conjunto com $\mathrm{Al}(\mathrm{OH})_{3}$, selando ou fechando as falhas e defeitos da camada, inibindo assim a continuidade da oxidação do metal de modo similar às camadas de conversão de cromatos.

Decroly e Petitjean [2005], utilizando uma solução de cloreto de cério $\left(\mathrm{CeCl}_{3}\right)$ em concentração $2,0 \times 10^{-2} \mathrm{M}$ de íons $\mathrm{Ce}^{3+}$ com adição de peróxido de hidrogênio e tamponada para $\mathrm{pH}=2,0$, obtiveram facilmente a deposição da camada de óxido de cério hidratado. Nesse estudo, os autores concluíram que um pré-tratamento superficial em meio alcalino promove a formação de oxi-hidróxido de alumínio (gel), sendo esta uma etapa importante para acelerar a deposição. A presença de $\mathrm{CuCl}_{2}$ como catalisador da etapa de deposição do óxido de cério também acelera o processo, além de aumentar a capacidade de adesão da camada. Porém, a presença do cobre prejudica as propriedades de corrosão do filme, o que pode ser comprovado através dos resultados de impedância eletroquímica, que revelam um desempenho inferior da camada de cério em comparação aos resultados das camadas de conversão de cromatos.

Mansfeld et al. [1992, 1995] obtiveram resultados satisfatórios com camadas de conversão de cério e que foram considerados similares aos obtidos com camadas de cromatos. Porém, existe ainda a dificuldade de aplicação em escala industrial da camada de cério, pois este é um processo lento que necessita de diversas etapas.

\subsubsection{Revestimento com organo-silanos}

Uma das principais características dos revestimentos de organo-silanos é que a camada protetora formada se estabelece como uma densa rede organizada, "rica" em silício e oxigênio, que atua como barreira física à absorção de eletrólitos e ao ataque químico [Palomino et al., 2008]. O filme de silano apresenta boa adesão ao substrato e à camada de tinta posteriormente aplicada, além de elevada estabilidade térmica [van Ooij et al., 2005]. 
A utilização de revestimentos à base de organo-silanos ou silanos para proteção à corrosão tem se mostrado uma alternativa promissora na substituição dos tratamentos de cromatização com cromo hexavalente, para diferentes tipos de substratos metálicos [van Ooij, et al., 2005]. No entanto, esse tratamento também possui algumas limitações, já que muitas vezes as soluções de silanos não são estáveis e tendem a se condensar, o que leva à formação de um filme pobre, além de serem soluções de fácil contaminação, podendo ser utilizadas apenas por um curto período de tempo antes de serem descartadas.

Além disso, o grau de limpeza da superfície metálica desempenha um papel importante na formação da camada, pois a presença de oleosidades residuais e outros contaminantes podem influenciar negativamente a deposição da mesma, ao contrário do que ocorre com os banhos de cromatização, que possuem $\mathrm{pH}$ ácido, tornando a superfície do metal pouco sensível à deposição [van Ooij et al., 2005].

\subsubsection{Revestimentos Mistos}

A utilização de revestimentos mistos formados por filmes de silanos conjuntamente com nanopartículas de sílica e/ou íons de terras raras, como o $\mathrm{Ce}^{3+}$, surgiu recentemente como uma nova e promissora alternativa na substituição dos revestimentos de cromatos [Palomino, 2009, Suegama, 2009]. Todavia, as desvantagens já mencionadas previamente para ambos os tratamentos isolados ainda se mostram presentes nessa nova alternativa de proteção.

\subsubsection{Moléculas Auto-organizáveis (SAM)}

Moléculas auto-organizáveis ou auto-montadas (SAM = self-assembled molecules) são formadas por moléculas que se adsorvem de forma ordenada na superfície de um substrato metálico pela imersão deste em uma solução contendo este tipo de composto. Essas moléculas possuem propriedades únicas, como a 
formação de camadas bem definidas, ordenadas e estáveis, proporcionando um filme protetor com estabilidade apropriada [Ulman, 1995, Aramaki e Shimura, 2004].

As moléculas auto-organizáveis, quando utilizadas como pré-tratamento da superfície para pintura, tendem a aumentar a aderência do substrato à camada de tinta, devendo ainda formar uma camada compacta. A adsorção deste tipo de moléculas (SAM) no substrato metálico modifica as propriedades da superfície e, consequentemente, a resistência frente à corrosão do metal em meios agressivos [Kálman, 2001].

A eliminação de toxicidade envolvida na preparação da superfície, aliada à redução de custos do processo de tratamento devido tanto ao menor consumo de água estimado, quanto ao menor custo no tratamento dos resíduos gerados por se tratar de processo isento de metais (cromo, zinco, titânio), torna o processo SAM potencialmente mais econômico que os atuais. Outra grande vantagem é o desenvolvimento de procedimentos para minimizar o uso de materiais, ou seja, reduzir a espessura da camada protetora sem diminuir a eficiência da proteção, tornando ainda mais viável a aplicação desse método [Free, 2002].

Segundo Stratmann e Rohwerder [1999] apud Reis et al. [2006], moléculas auto-organizáveis são constituídas por três partes: (i) a cabeça, que é responsável em promover adsorção química ao substrato, (ii) o corpo da molécula, constituído por uma cadeia carbônica (alcano), e (iii) a parte funcional da molécula, que pode ser desde um grupo metil $\left(\mathrm{CH}_{3}\right)$ até outro composto específico, desenvolvido para cada aplicação.

Existem vários tipos de moléculas que se enquadram na classificação de SAM, sendo cada uma específica para um ou mais tipos de substrato, como por exemplo, difosfonildecano para camadas de óxido-hidróxido de alumínio [Ulman, 1995], alcanotióis para ouro [Maege et al., 1998], prata [Bain et al., 1989] e cobre [Ulman, 1989], e álcoois e aminas para platina [Troughton et al., 1988].

Estudos realizados com ácidos fosfônicos têm despertado grande interesse prático devido à habilidade de essas moléculas formarem camadas autoorganizadas com boa ancoragem em uma extensa variedade de superfícies metálicas [Pellerite et al., 2003, Hoque et al., 2006]. Maege et al. [1998] 
observaram que compostos fosfonatos são efetivos no tratamento de amostras de alumínio, apresentando alta hidrofobicidade, independentemente do valor de $\mathrm{pH}$ da solução. Estes autores concluíram que o uso destas moléculas teria um futuro promissor, devido à sua adsorção espontânea em superfícies de alumínio, formando uma camada ordenada e aderente que promove resistência frente à corrosão similar à dos corpos-de-prova cromatizados.

A formação de camadas auto-organizáveis à base de fosfonatos pode ser dividida nas etapas de adsorção e organização, sendo a última determinada por interação intermolecular de Van der Waals entre os alcanos [Stewart et al., 1986]. $O$ espaçamento entre os grupos funcionais assegura o ordenamento e a estrutura compacta da camada automontada.

As moléculas à base de difosfonatos possuem a vantagem de gerar uma forte interação entre o metal (ou seu óxido-hidróxido) e a camada de tinta, sendo que quanto mais compacta é a camada, maior o poder de inibição da reação de redução do oxigênio, e maior a estabilidade frente aos produtos gerados por esta reação [Stewart et al., 1986].

Segundo Stewart et al. [1986] e Szurkalo [2009], o tratamento com moléculas auto-organizáveis (SAM) pode ser realizado em meios aquosos ou não aquosos e, após interação com o substrato, estas moléculas permanecem na superfície mesmo após a remoção do substrato do meio. No estágio inicial de tratamento, as SAM se aderem de forma desordenada ao substrato, e, no estágio seguinte, se ordenam de forma paralela umas as outras, como ilustra a Figura 3.

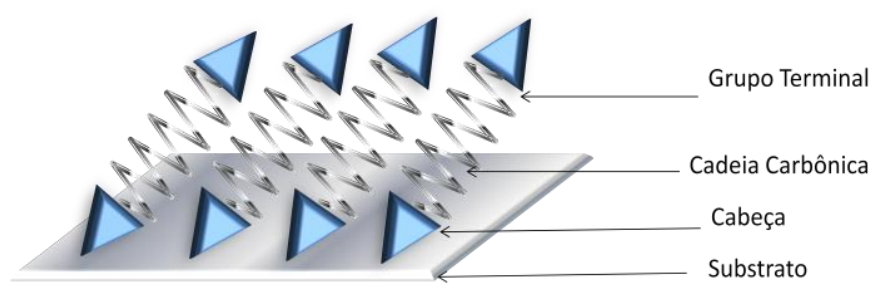

Figura 3: Representação de uma camada de SAM, mostrando os seus constituintes e a interação com o substrato. 
Segundo alguns autores [Maniasso, 2001, Free, 2002, Moraes e Resende, 2004], a adsorção das moléculas de SAM produz monocamadas quando a concentração da solução está abaixo da concentração micelar crítica (CMC), enquanto que para valores acima da CMC, existe a formação de multicamadas e agregados moleculares (micelas) [Free, 2002]. As micelas são formadas espontaneamente por adsorção química entre as moléculas, as quais possuem uma componente hidrofílica e outra hidrofóbica. Estes agregados se associam espontaneamente em solução aquosa formando aglomerados moleculares de dimensão coloidal [Maniasso, 2001, Szurkalo et al., 2008].

A literatura [Free, 2002] relata que, em termos de inibição da corrosão, a formação de multicamadas que ocorre em concentrações acima da CMC não é satisfatória, pois o aumento da proteção é muito pequeno. Isso porque a formação de multicamadas seria similar à aplicação de duas camadas de tinta para proteger uma superfície contra a corrosão, sendo que a presença de apenas uma única camada promoveria a proteção necessária.

Em termos de propriedades físicas e químicas, pode-se afirmar que acima da CMC não existe um aumento significativo no número de monômeros isolados e, consequentemente, a força de coesão das moléculas da superfície é pouco afetada, não se observando efeitos significativos sobre a tensão superficial da solução, [Pébère et al., 1988, Free, 2002]. Em relação à condutividade elétrica da solução, a partir da CMC, o aumento desta é menor, pois os aglomerados micelares conduzem menos que os respectivos monômeros individuais. A avaliação dessas alterações, as quais são perceptíveis quando se inicia a formação de micelas, possibilita a determinação da CMC. Assim, a CMC pode ser determinada pelo estudo de propriedades, como condutividade elétrica e tensão superficial [Free, 2002, Szurkalo, 2009].

Zhao e Mu [1999] utilizaram técnicas de perda massa e medidas de ângulo de contato, no estudo da adsorção de surfactantes em superfície de alumino AA 1050. Os resultados obtidos por aqueles pesquisadores confirmaram que, quando a concentração de surfactantes está mais próxima da CMC, os maiores valores de adsorção e também as menores taxas de perda de massa são atingidos, proporcionando assim as melhores propriedades de proteção à corrosão do substrato. 
Embora as moléculas auto-organizáveis sejam classificadas como inibidores de corrosão, os inibidores de corrosão geralmente diminuem a velocidade de uma ou de mais reações do processo de corrosão por adsorção física, na qual a troca de ânions ou cátions pode ser constante. Esta adsorção puramente eletrostática é rápida e reversível devido à baixa energia de ativação. No caso específico da interação das moléculas auto-organizáveis, a transferência de elétrons entre o substrato e as moléculas adsorvidas ocorre por interação entre o par de elétrons da molécula adsorvida e o subnível vazio do metal [Fischer, 1972].

Assim, se observa uma maior intensidade na interação, tornando a adsorção altamente irreversível, e isto é conhecido como adsorção química. As camadas auto-organizáveis atuam por este tipo de adsorção, funcionando como doadoras de elétrons, e o metal como receptor. Esta atuação é específica apenas para alguns metais, particularmente para metais de transição, os quais possuem orbitais do tipo d com baixa energia de valência [Maege et al., 1998; Wang et al., 2005]

Além do tipo de adsorção envolvida, existem outras diferenças entre inibidores de corrosão e as camadas auto-organizáveis, por exemplo: (a) para inibidores de corrosão, a propriedade de resistência à corrosão é definida pelo meio corrosivo, enquanto que uma superfície com camadas auto-organizáveis tem suas propriedades alteradas e, consequentemente, sua resistência à corrosão independe do meio agressivo; (b) inibidores de corrosão são solúveis no eletrólito e podem ser aplicados apenas para reações específicas, enquanto camadas auto-organizáveis (materiais anfifílicos) podem ser aplicadas através de soluções aquosas e não aquosas. Devido à baixa solubilidade dos materiais anfifílicos, o processo de adsorção torna-se menos sensível à concentração do composto no meio estudado [Chen et al., 1998, Schreiber, 2000, Wang et al., 2005].

O uso de camadas auto-organizáveis para a proteção contra a corrosão tem sido foco de muito estudos [Stewart et al., 1986, Maege et al., 1998, Chen et al., 1998, Zhao et al., 1998, Dai et al., 2000, Schreiber, 2000, Wang et al., 2005, Reis et al., 2006, Wapner et al., 2007, Alagta et al., 2008]. Em publicações recentes, Yoshikawa et al., [2009] e de Souza et al. [2010, 2011] avaliaram 
diferentes tipos de tratamentos superficiais para o aumento da resistência à corrosão em liga de alumínio AA5052 e alumínio AA1050, respectivamente. Estes autores obtiveram resultados compatíveis com tratamentos de cromatização com

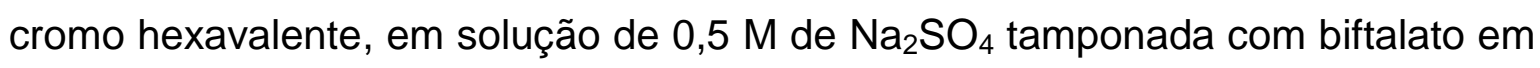
$\mathrm{pH}=4,0$, utilizando pré-tratamento superficial de jateamento com microesferas de sílica, antes da aplicação de monocamadas auto-organizáveis (alcano difosfonato $\mathrm{PO}(\mathrm{OH})_{2}-\left(\mathrm{CH}_{2}\right)_{n}-\mathrm{PO}(\mathrm{OH})_{2}$, onde $\left.10<\mathrm{n}<12\right)$.

O mesmo grupo de pesquisadores, em outro estudo [Izaltino et al., 2010], avaliou o comportamento de corrosão da liga de alumínio, AA7475 Alclad, através de ensaios eletroquímicos e ensaios acelerados de névoa salina. No trabalho daqueles pesquisadores foi investigada a influência do tratamento de imersão em água fervente para crescimento da camada de óxido-hidróxido por diferentes tempos, etapa anterior ao tratamento por imersão em solução de SAM (alcano difosfonato). Os resultados dos ensaios eletroquímicos em solução $10,0 \mathrm{mmol} \mathrm{L}{ }^{-1}$ de $\mathrm{NaCl}$, indicaram que um tempo de tratamento de 20 minutos em água fervente, proporciona melhor resistência à corrosão entre os tempos testados. Entretanto, o tratamento em solução de SAM sem a preparação da superfície da liga de alumínio com uma etapa intermediária para crescimento de óxido-hidróxido, resultou em uma leve diminuição na resistência a corrosão da liga, revelando que nesse caso (para liga AA7475 Alclad) o tratamento com SAM foi danoso.

\subsection{Técnicas eletroquímicas no estudo da resistência à corrosão}

Geralmente empregam-se técnicas eletroquímicas com o objetivo de investigar os mecanismos e cinética de corrosão de um sistema. Pelo uso destas técnicas podem ser obtidas taxas de corrosão instantâneas. Os métodos eletroquímicos podem ser divididos em técnicas de corrente contínua (d.c.) e de corrente alternada (a.c.) [Wolynec, 2003]. Em meios de baixa condutividade, as técnicas d.c. apresentam o inconveniente da queda ôhmica elevada devido à resistência da solução, o que pode introduzir erros significativos aos resultados.

A utilização de técnicas a.c. permite a identificação da resistência da solução e, portanto, possibilita a detecção de sua contribuição na resposta. Outra limitação das técnicas d.c. é que as altas polarizações requeridas para obter 
informação cinética completa podem alterar irreversivelmente a superfície do eletrodo, impossibilitando o monitoramento contínuo do mesmo. As técnicas d.c. também não permitem a identificação de propriedades que não envolvam a transferência de carga, como por exemplo, a capacitância da dupla camada elétrica.

\subsubsection{Espectroscopia de Impedância Eletroquímica}

A técnica de espectroscopia de impedância eletroquímica (EIE) é cada vez mais aplicada em diversos estudos de corrosão por possibilitar a separação de vários processos que ocorrem com cinéticas diferentes [Mansfeld e Shih, 1988]. Essa técnica tem sido amplamente utilizada, juntamente com análises de superfície na investigação de propriedades protetoras de revestimentos para metais, especificamente para alumínio e suas ligas [Bonora et al., 1996, Campestrini et al., 2001b, Domigues et al., 2003, Reis et al., 2006, Yoshikawa et al., 2009, de Souza et al., 2010, Suegama et al., 2010, de Souza et al., 2011].

A impedância é uma excelente ferramenta de análise de superfícies, interfaces, substratos metálicos e revestimentos orgânicos [Bonora et al., 1996]. Possibilita obter informações sobre o processo de corrosão, adsorção de espécies, processos de difusão, e propriedades de revestimentos, como defeitos e propriedade barreira.

É possível analisar através dos resultados experimentais de EIE as características do sistema estudado, como propriedades da interface, utilizando modelos de circuito elétrico equivalente (CEE) compostos por elementos passivos, (resistências, capacitores e indutores) para ajuste dos dados de impedância, os quais devem estar associados fisicamente às propriedades características do sistema eletroquímico em estudo [Bonora et al., 1996].

Em estudos que envolvem sistemas de alumínio e suas ligas, a técnica de espectroscopia de impedância eletroquímica é uma importante ferramenta de análise e identificação das propriedades anti-corrosivas de revestimentos de proteção, bem como do filme de óxido-hidróxido passivo formado na superfície [Bessone et al., 1992]. 
Como já foi descrito anteriormente, através dos ajustes dos resultados experimentais de EIE a circuitos elétricos equivalentes, é possível obter diferentes tipos de informação sobre fenômenos de interface do sistema de estudo. Contudo, o circuito proposto para o ajuste dos dados deve conter o menor número de componentes possíveis dentro de um erro aceitável.

Muitas vezes é utilizado o elemento de fase constante (CPE = Constant Phase Element) em um CEE, levando em consideração o comportamento de capacitor em um sistema eletroquímico que não corresponde a um capacitor ideal (puro). Esse artifício é frequentemente utilizado com o objetivo de compensar a não homogeneidade do sistema. A impedância do CPE é representada pela equação (5), onde o expoente está associado com a distribuição de corrente que não é uniforme, devido à heterogeneidades na superfície [Lasia, 1999, Assis, 2006].

$$
Z_{C P E}=\left(\frac{1}{Y_{0}}\right)(j \omega)^{-\alpha}
$$

$\mathrm{Na}$ equação (5), $\mathrm{Y}_{0}\left(\mathrm{Y}_{0}=1 / \mathrm{C}\right)$ e a são as constantes do CPE e representam, respectivamente, as características superficiais das espécies eletroativas independentes e a distribuição não uniforme de corrente, devido às heterogeneidades superficiais [Matini e Muller, 2000]; j é um número complexo que equivale $\sqrt{-1}$ e $\omega$ é a frequência angular $(\omega=2 \pi f$, sendo $f$ a frequência em $\mathrm{Hz})$.

O expoente a pode variar de -1 a 1 . Quando $\alpha=1, Y_{0}=C$, o CPE é representado por um capacitor puro. Se $\alpha=0$, CPE se torna um resistor puro, pois as impedâncias de um capacitor, de um resistor e de um indutor são dadas pelas equações (6), (7) e (8), respectivamente por $Z_{C}, Z_{R}$ e $Z_{L}$ :

$$
\begin{aligned}
& Z_{C}=\left(\frac{1}{j w C}\right) \\
& Z_{R}=(j w R) \\
& Z_{L}=(j w L)
\end{aligned}
$$


Na literatura, vários CEE são propostos para explicar as características físicas da superfície de alumínio e suas ligas, e alguns destes estão representados na Figura 4.

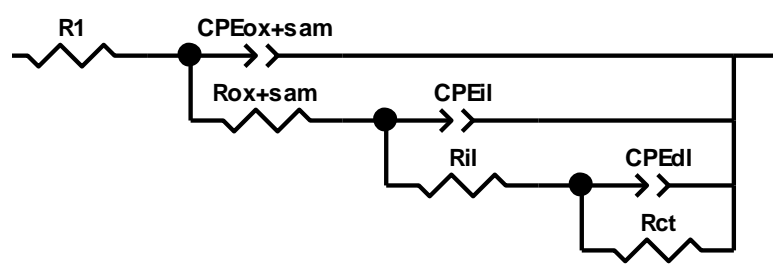

(a)

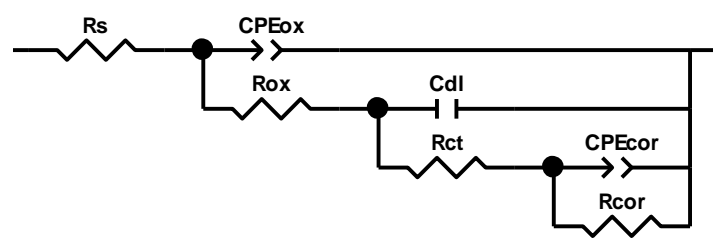

(c)

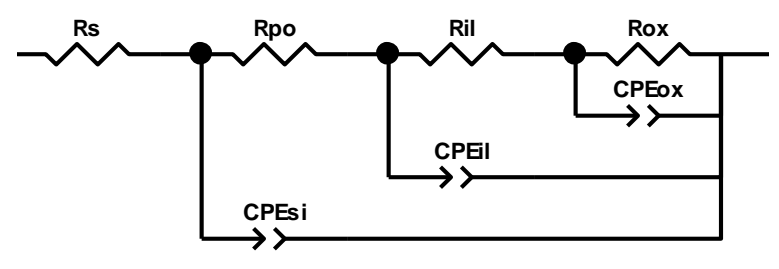

(b)

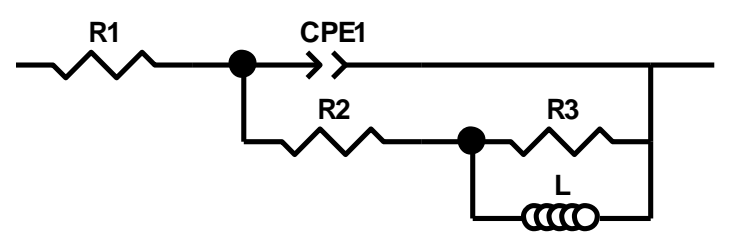

(d)

Figura 4. Circuitos elétricos equivalentes propostos para caracterizar a camada passiva e fenômenos interfaciais em alumínio e suas ligas [Szurkalo, 2009; Palomino et al., 2009, Queiroz, 2008, Bessone et al., 1983].

O circuito elétrico equivalente da Figura 4(a) foi utilizado por Szurkalo [2009] para Alumínio AA1050 pré-tratado com SAM e inclui a presença de três constantes de tempo, onde a primeira descreve o comportamento em altas frequências (AF) associado ao filme de óxido-hidróxido de alumínio com moléculas auto-organizáveis adsorvidas, outra em médias (MF) associada aos fenômenos interfaciais e a última na região de baixas frequências (BF), representando o início do processo de corrosão. Nesse trabalho, a constante de tempo intermediária foi considerada como uma região de transição entre a camada de óxido-hidróxido com SAM e o substrato de AA1050. Outros autores [Cabral et al., 2005, Palomino, 2009], em estudos com camadas de silanos, adotaram circuitos elétricos equivalentes contendo três constantes de tempo, com a constante de tempo em MF sendo atribuída à presença de uma camada intermediária, como ilustra a Figura 4(b). 
No circuito equivalente proposto por Queiroz [2008], Figura 4(c), também aparece três constantes, sendo que a primeira em AF (par Rox//CPEox), representa a resposta dos defeitos na camada de óxido-hidróxido, devido à grande quantidade de intermetálicos presentes na liga de alumínio AA2024-T3. A segunda constante de tempo, em MF (par Rct//Cdl), é atribuída às reações de transferência de carga que ocorrem na interface da matriz e, finalmente, a terceira constante em BF (Rcor//Ccor), associada ao fenômeno de corrosão na matriz da liga, principalmente ao redor dos intermetálicos.

A Figura 4(d) apresenta o circuito proposto por Bessone et al. [1983], para a camada de óxido-hidróxido de alumínio com 99,99\% de pureza, em solução eletrolítica 0,16 $\mathrm{M}$ de $\mathrm{NH}_{4}$-tartarato. Em outro trabalho do mesmo grupo [Bessone et al., 1992], foram utilizados diferentes tipos de eletrólitos $(0,5 \mathrm{M}$ de $\mathrm{NaCl}, 0,5 \mathrm{M}$

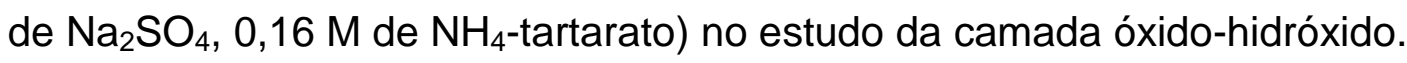

Cabot et al. [1995], baseados no circuito proposto por Bessone et al. [1983], também ajustaram os dados de EIE obtidos para uma liga de alumínio, zinco e magnésio ( $\mathrm{Al}-\mathrm{Zn}-\mathrm{Mg}$ da série $\mathrm{AA7XXX)}$ em solução $0,1 \mathrm{M}$ de $\mathrm{NaCl}$, utilizando o mesmo CEE da Figura $4 d$, onde $R_{1}$ é associada à resistência do eletrólito, $\mathrm{R}_{2}$ à resistência da solução dentro de um "caminho facilitado", por defeitos do filme óxido-hidróxido que é acessado conforme o crescimento dos pites, $\mathrm{L}$ ao processo de adsorção de íons cloreto $\left(\mathrm{Cl}^{-}\right)$e $\mathrm{R}_{3}$ à resistência a transferência de carga.

A origem das alterações no comportamento do filme passivo em relação ao eletrólito de ensaio ainda não é totalmente esclarecida. Nesse sentido é compreensiva a falta de consenso encontrada na literatura, em relação às interpretações associadas às diferentes constantes de tempo obtidas nos resultados de ensaios de impedância.

Visto que existem várias propostas na literatura para explicar o arco capacitivo que se observa na região de alta freqüência, em diagramas de EIE para alumínio e suas ligas. Brett et al. [1992] relacionam este arco às reações que envolvem a formação da camada de óxido. Eles sugerem que o alumínio presente na interface metal/óxido é oxidado a $\mathrm{Al}^{+}$, que posteriormente passa a $\mathrm{Al}^{3+}$ (na interface solução/óxido), acompanhado pela formação de $\mathrm{O}^{2-}$ ou $\mathrm{OH}^{-}$. Bessone et al., [1992] também associaram o arco capacitivo observado às propriedades 
dielétricas do filme óxido passivo na superfície do alumínio puro. Outros autores relacionam esse arco a processos de transporte através da camada de óxido de alumínio [Frers et al., 1990, Lendenrink et al.,1993], ou devido ao carregamento da dupla camada em paralelo com a transferência de carga, ou a ambos os processos, gerando a sobreposição dos arcos capacitivos [de Wit e Lenderink, 1996].

Arcos indutivos têm sido relacionados em trabalhos publicados na literatura a sistemas variados e em diferentes condições experimentais, como a inibição da dissolução metálica numa região de transição ativo-passivo [Epelboin et al., 1975], a existência de espécies adsorvidas à superfície do metal [Franceschetti e MacDonald, 1977, Bechet et al.,1977 e Dawson e Ferreira, 1986] ou ainda a formação de um depósito não passivante de produtos de corrosão [Fernandes, 2000]. Entretanto, a origem desse fenômeno ainda não é totalmente esclarecida. Este tipo de comportamento (indutivo) tem sido frequentemente observado para alumínio e suas ligas e reportado em diversos trabalhos publicados [Bessone et al., 1983, Bessone et al., 1992, De Wit e Lenderink, 1996, Aoki et al., 2001, Sayed et al., 2002].

Em geral, o fenômeno que origina o arco indutivo nos diagramas de impedância, é atribuído à relaxação de intermediários adsorvidos [Aoki et al., 2001], como ânions sulfato, cloreto, tartarato ou citrato, dependendo da solução eletrolítica utilizada e também aos íons oxigênio adsorvidos na superfície do eletrodo [Bessone et al., 1992, Aoki et al., 2001]. A literatura [Reis et al., 2006] também sugere que a formação do arco indutivo em médias e baixas frequências pode ser associada à competição de íons sulfato pela superfície do alumínio, bem como ao ataque localizado, particularmente nas regiões de vizinhança entre os precipitados e a matriz, pelo efeito de micropilhas galvânicas. Outros autores [de Wit et al., 1979] sugerem também que a constante de tempo indutiva seja um resultado do rearranjo das cargas na interface metal-óxido.

Medidas de impedância realizadas por Burstein e Cinderey [1991] e Burstein e Liu [1994] visando estudar a repassivação da camada passiva em alumínio propositalmente danificada por uma guilhotina, não mostraram a presença de arco indutivo, sugerindo que esse tipo de constante de tempo está fortemente relacionado com a existência de um filme passivo na superfície de 
alumínio [De Wit e Lenderink, 1996]. Outra característica relevante são os diferentes tipos de comportamento do filme passivo, indicados nas respostas de impedância em diferentes soluções de ensaio. Arcos indutivos não foram observados em alguns eletrólitos como sulfato de potássio, nitrato de sódio, ou ácido nítrico. Segundo os autores, isso pode ser devido à influência especifica da adsorção de íons da solução de ensaio, em particular ânions incorporados nas lacunas da camada porosa do alumínio [De Wit e Lenderink, 1996]. 


\section{MATERIAIS E MÉTODOS}

\subsection{Materiais}

Nesse estudo foi utilizado o alumínio comercialmente puro AA1050 na forma de chapa (tamanho de uma folha A4) com espessura de $(2,95 \pm 0,05) \mathrm{mm}$. Todo o desenvolvimento do trabalho foi realizado com amostras do mesmo lote para evitar possíveis diferenças e propagação de erros entre lotes distintos. $\mathrm{Na}$ Tabela 3 são apresentadas a composição química e a composição nominal do alumínio AA1050 referentes às especificações NBR7523 e ABAL [2010].

Tabela 3: Composição química (obtida por Fluorescência de Raios-X e ICP-OES) e composição nominal do alumínio AA1050 segundo as especificações NBR7523 e ABAL [2010]

\begin{tabular}{ccc}
\hline Elementos & $\begin{array}{l}\text { Composição Química } \\
\text { (\% em massa, Erro) }\end{array}$ & $\begin{array}{l}\text { NBR7523 = ABAL } \\
\text { (\% em massa, limite } \\
\text { máx.) }\end{array}$ \\
\hline \hline $\mathrm{Al}$ & Balanço & Balanço \\
\hline $\mathrm{Fe}$ & $0,40 \pm 0,01$ & 0,40 \\
\hline $\mathrm{Cu}$ & $0,16 \pm 0,01$ & 0,05 \\
\hline $\mathrm{Mg}$ & $0,011 \pm 0,003$ & 0,05 \\
\hline $\mathrm{Mn}$ & $0,004 \pm 0,001$ & 0,05 \\
\hline $\mathrm{Si}$ & $0,11 \pm 0,01$ & 0,25 \\
\hline $\mathrm{Cr}$ & $<8 \mathrm{ppm}$ & --- \\
\hline $\mathrm{Ti}$ & $0,009 \pm 0,001$ & 0,03 \\
\hline $\mathrm{Zn}$ & $0,002 \pm 0,001$ & 0,01 \\
\hline $\mathrm{V}$ & $0,002 \pm 0,001$ & 0,05 \\
\hline $\mathrm{Outros}$ & & 0,03 \\
\hline
\end{tabular}

* não detectado

A composição química do AA1050 foi obtida por Fluorescência de Raios-X e Espectrometria de Emissão Óptica com Fonte de Plasma Acoplado (ICP-OES) no Laboratório de Materiais Nucleares (LABMAT) do Centro Tecnológico da Marinha em São Paulo, Centro Experimental ARAMAR. 
A composição química dos elementos presentes no AA1050 utilizado nesse trabalho, dado na Tabela 3, está em concordância com os valores de composição nominal, especificados na norma NBR e ABAL com exceção à composição do $\mathrm{Cu}$. Vale, portanto ressaltar que o alumínio 1050 utilizado nos ensaios possui alto teor de Cobre.

As substâncias utilizadas, reagentes e solventes, foram de pureza analítica e obtidos por fontes comerciais. A solução de sulfato de sódio $\left(\mathrm{Na}_{2} \mathrm{SO}_{4}\right)$ 0,5 $\mathrm{M}$, naturalmente aerada, à temperatura ambiente, com pH ajustado em 4,0 utilizando uma solução tampão de biftalato de potássio $\left(\mathrm{C}_{8} \mathrm{H}_{5} \mathrm{O}_{4} \mathrm{~K}\right)$ e hidróxido de sódio $(\mathrm{NaOH})$ foi utilizada como eletrólito de teste nos ensaios eletroquímicos, e a partir daqui será denominada por: solução de ensaio.

\subsection{Métodos}

\subsubsection{Tratamentos de superfície}

Amostras de alumínio AA1050 nas dimensões de $20 \mathrm{~mm} \times 20 \mathrm{~mm}$ foram submetidas aos tratamentos de superfície especificados na Tabela 4.

Todas as amostras foram submetidas ao procedimento de acabamento superficial por lixamento e polimento, descrito na Tabela 4 como tipo A. Nessa parte de preparação, as amostras foram inicialmente desbastadas com lixa de granulometria 600\# e depois de enxaguadas com água deionizada, passaram por lixa 1200\#. Apenas após a limpeza das amostras com água deionizada em ultrasom por 5 minutos, estas foram submetidas ao polimento com suspensão de diamante de 3 e $1 \mu \mathrm{m}$. O mesmo procedimento de limpeza em ultra-som foi seguido na mudança de suspensão de diamante de 3 para $1 \mu \mathrm{m}$. Parte dessas amostras submetidas ao acabamento superficial até $1 \mu \mathrm{m}$, foram utilizadas nos ensaios de caracterização da superfície e influência dos íons $\mathrm{Cl}^{-}$nos ensaios eletroquímicos que foram realizados posteriormente e, portanto, foram denominadas amostras Polidas.

Em seguida, o restante das amostras foi submetido ao procedimento de tratamento da superfície descrito na Tabela 4 como tipo B. Nessa parte, as 
amostras foram imersas em três banhos comerciais, dois desengraxantes alcalinos e um desoxidante ácido à temperatura de $40 \stackrel{\circ}{\mathrm{C}}$ por três minutos em cada um deles. Entre cada etapa (1 $\mathbf{1}^{\mathbf{a}}, \mathbf{2}^{\mathbf{a}}$ e $\left.\mathbf{3}^{\mathbf{a}}\right)$ de imersão nos banhos comerciais, as amostras foram enxaguadas com água deionizada em abundância, visando à limpeza e descontaminação das amostras dos banhos anteriores para as etapas posteriores. As amostras que sofreram polimento e posterior aplicação dos banhos comerciais foram denominadas PB (polimento + banhos).

Em seguida foram realizados os tratamentos para modificação da superfície, segundo os procedimentos, C, D, E, descritos na Tabela 4. Portanto, depois do enxágue final das amostras, ou seja, após a 3a etapa dos banhos comerciais, parte das amostras foi imersa em solução de $90 \mathrm{mg} \cdot \mathrm{L}^{-1}$ de $S A M$ por três horas a $40^{\circ} \mathrm{C}$. Assim, amostras tratadas pelo procedimento tipo $\mathbf{C}$ foram denominadas SAM. Os procedimentos tipo D e E da Tabela 4 também foram realizados em amostras submetidas ao polimento e tratamento de imersão em banhos comerciais, sendo seguidos por três minutos de imersão em solução de cromatização de cromo hexavalente (tipo D) à $40 \stackrel{\circ}{\mathrm{C}}$, ou por 20 minutos de imersão em água fervente $~ 98 \stackrel{\circ}{ } \mathrm{C}$ (tipo E) para crescimento de óxido de alumínio hidratado (ou óxido-hidróxido de alumínio), respectivamente.

Amostras tratadas segundo o procedimento tipo $\mathbf{D}$, foram denominadas $\mathbf{C r}(\mathbf{V I})$, e aquelas tratadas pelo procedimento tipo $\mathbf{E}$, foram chamadas $\mathbf{O X}$. Finalmente, uma parte das amostras que foi submetida ao procedimento de imersão em água fervente por 20 minutos (tipo E), foi em seguida submetida à imersão por 3 horas em solução de SAM (tipo C), foram denominadas OS, por terem sido realizados ambos os procedimentos, crescimento de óxido de alumínio hidratado e posterior imersão em solução de $90 \mathrm{mg} \cdot \mathrm{L}^{-1}$ de SAM (Ox + SAM = OS).

A concentração da solução de $90 \mathrm{mg} \cdot \mathrm{L}^{-1}$ de SAM e o tempo de imersão de 3 horas para o tratamento de SAM, foram adotados neste trabalho de acordo com estudos realizados previamente por colaboradores do Laboratório de Corrosão e Tratamentos de Superfície - Labcorts - IPEN - CCTM.

O tempo de tratamento de imersão do AA1050 para a adsorção das moléculas auto-organizáveis e formação da monocamada protetora em solução de $90 \mathrm{mg} \cdot \mathrm{L}^{-1}$ de SAM (na CMC) foi adotado a partir dos resultados de uma série de ensaios realizados por Szurkalo et al. [2008], tais como, monitoração do 
potencial de circuito aberto (PCA), medidas de ângulo de contato, espectroscopia de impedância eletroquímica (EIE) e polarização potenciodinâmica. Utilizando essa metodologia, foi selecionado um período de 3 horas em solução SAM, por apresentar características mais protetoras dentre as testadas [Szurkalo, 2009].

Tabela 4: Acabamento superficial e tratamentos utilizados para modificação da superfície do alumínio AA 1050.

\begin{tabular}{|c|c|c|c|}
\hline \multicolumn{4}{|c|}{ Acabamento superficial do alumínio AA1050 } \\
\hline \multirow{2}{*}{$\begin{array}{l}\text { A - } \\
\text { Lixamento + Polimento }\end{array}$} & \multicolumn{3}{|c|}{ Lixas de carboneto de silício com grana 600\# e 1200\# } \\
\hline & \multicolumn{3}{|c|}{ Suspensão de diamante DiaPro(Struers) - 3 e $1 \mu \mathrm{m}$} \\
\hline \multicolumn{4}{|c|}{ Tratamentos de superfície } \\
\hline \multirow[t]{3}{*}{$\begin{array}{l}\text { B - } \\
\text { Banhos Comerciais } \\
\text { (PB) }\end{array}$} & $\begin{array}{l}\text { 1- etapa - desengraxe alcalino } \\
\text { Desengraxante -133(SurTec } \AA) \\
\text { pH } 8,5-9,5\end{array}$ & $3 \mathrm{~min}$ & $40 \pm 2{ }^{\circ} \mathrm{C}$ \\
\hline & $\begin{array}{l}2^{\mathbf{a}} \text { etapa - desengraxe alcalino } \\
\text { Desengraxante } 181-\mathrm{B}(\operatorname{SurTec} \AA) \\
\mathrm{pH} 12,0-13,0\end{array}$ & $3 \min$ & $40 \pm 2{ }^{\circ} \mathrm{C}$ \\
\hline & $\begin{array}{l}\text { 3a etapa - desoxidação } \\
\text { Desoxidante 495-B(SurTec } \AA) \\
\text { pH } 1,5-2,0\end{array}$ & $3 \mathrm{~min}$ & $40 \pm 2^{\circ} \mathrm{C}$ \\
\hline $\begin{array}{l}\text { C - Tratamento em } \\
\text { solução de SAM } \\
\text { (SAM) }\end{array}$ & $\begin{array}{l}\text { Solução } 90 \mathrm{mg} \cdot \mathrm{L}^{-1} \text { de } S A M, \mathrm{pH} \mathrm{3,0} \\
\text { Moléculas de alcano difosfonato } \\
{\left[\mathrm{PO}(\mathrm{OH})_{2}-\left(\mathrm{CH}_{2}\right)_{\mathrm{n}}-\mathrm{PO}(\mathrm{OH})_{2}\right],} \\
(10 \leq \mathrm{n} \leq 12), \\
\text { Gardobond }{ }^{\circledR} \mathrm{X} 4661 \text { (Chemetall } \\
\text { GmbH) }\end{array}$ & $3 \mathrm{~h}$ & $40 \pm 2^{\circ} \mathrm{C}$ \\
\hline $\begin{array}{l}\text { D - Cromatização } \\
\text { Hexavalente (CrVI) }\end{array}$ & $\begin{array}{l}\left.\text { (SurTec }{ }^{\circledR}\right) 653 \\
\text { Sem posterior aplicação de tinta } \\
\text { pH } 3,7\end{array}$ & $3 \min$ & $40 \pm 2^{\circ} \mathrm{C}$ \\
\hline E - Oxidação (OX) & $\begin{array}{l}\text { Crescimento de óxido-hidróxido em } \\
\text { água fervente }\end{array}$ & $20 \mathrm{~min}$ & $100 \pm 2^{\circ} \mathrm{C}$ \\
\hline $\begin{array}{l}\text { F - Oxidação e adsorção } \\
\text { de SAM (OS) }\end{array}$ & $\begin{array}{l}\text { Crescimento de óxido-hidróxido em } \\
\text { água fervente + aplicação de } \\
\text { Solução } 90 \mathrm{mg} \cdot \mathrm{L}^{-1} \text { de } S A M\end{array}$ & $\begin{array}{l}20 \mathrm{~min} \\
+3 \mathrm{~h}\end{array}$ & $\begin{array}{l}100 \pm 2^{\circ} \mathrm{C} \\
+40 \pm 2{ }^{\circ} \mathrm{C}\end{array}$ \\
\hline
\end{tabular}




\subsubsection{Ensaios eletroquímicos}

Os ensaios eletroquímicos foram realizados em solução de sulfato de sódio $\left(\mathrm{Na}_{2} \mathrm{SO}_{4}\right)$ 0,5 M, naturalmente aerada, à temperatura ambiente, com pH ajustado em 4,0 utilizando uma solução tampão de biftalato de potássio $\left(\mathrm{C}_{8} \mathrm{H}_{5} \mathrm{O}_{4} \mathrm{~K}\right)$ e hidróxido de sódio $(\mathrm{NaOH})$. Essa solução, apesar de ser um eletrólito de baixa agressividade para alumínio devido à ausência de íons cloreto, foi escolhida a fim de avaliar a contribuição do revestimento com moléculas auto-organizáveis na resistência à corrosão do material. $\mathrm{O}$ pH da solução de ensaio foi ajustado para 4,0 pois esse valor de $\mathrm{pH}$ se localiza no limiar de estabilidade do filme passivo, conforme ilustra o diagrama simplificado de Pourbaix mostrado na Figura 1, tornando a solução mais apropriada para a identificação dos fenômenos de corrosão.

$\mathrm{Na}$ realização dos ensaios eletroquímicos, foi utilizado um arranjo experimental de três eletrodos, com uma célula eletroquímica com capacidade de $200 \mathrm{~mL}$ de solução, sendo usado um fio de platina como contra eletrodo, um eletrodo de referência de calomelano saturado ( $E C S, H g / \mathrm{Hg}_{2} \mathrm{Cl}_{2}(\mathrm{KCl}$ saturado)) e o alumínio 1050 com os vários tratamentos superficiais, como eletrodo de trabalho, onde a área exposta foi igual a $0,64 \mathrm{~cm}^{2}$. Os ensaios de polarização e espectroscopia de impedância foram realizados em triplicata, para avaliar a reprodutibilidade dos resultados. Também foi estudada a influência nos resultados eletroquímicos quando utilizado um eletrodo de referência de sulfato mercuroso (ESM) em comparação ao ECS.

Para a realização dos ensaios eletroquímicos, os eletrodos de trabalho foram imersos em solução de ensaio (sulfato de sódio $\left(\mathrm{Na}_{2} \mathrm{SO}_{4}\right)$ 0,5 M, pH=4,0) e o comportamento eletroquímico foi monitorado durante 3 dias por medidas de espectroscopia de impedância eletroquímica.

Ensaios de polarização potenciodinâmica anódica foram realizados em diferentes amostras para períodos de imersão em solução de ensaio correspondentes a 1 h, 4 h, 8 h, 24 h e 72 horas.

Ensaios de polarização catódica potenciodinâmica foram feitos apenas após 3 dias de imersão em solução de ensaio. 


\subsubsection{Medidas de potencial a circuito aberto em função do tempo de imersão}

Medidas de potencial a circuito aberto em função do tempo (PCA) foram realizadas desde os períodos iniciais de imersão. Estas medidas foram utilizadas também para avaliar a estabilidade do potencial, necessária para a validação dos resultados de espectroscopia de impedância eletroquímica. Amostras do alumínio AA1050 com os vários tratamentos tiveram seus potenciais monitorados por $24 \mathrm{~h}$, para determinação do tempo necessário para estabilização do potencial.

\subsubsection{Espectroscopia de impedância eletroquímica (EIE)}

Os ensaios de EIE foram realizados no potencial de circuito aberto, após 24 h 48 h e 72 h de imersão na solução de ensaio, utilizando um analisador de respostas em freqüências Solartron SI-1260 acoplado ao potenciostato SI1287A, em uma faixa de freqüências de $10 \mathrm{kHz}$ a $10 \mathrm{mHz}$, com sinal de $10 \mathrm{mV}$ de amplitude e taxa de aquisição de 10 pontos por década. Os ajustes dos circuitos elétricos equivalentes foram realizados no Software Zwiew.

\subsubsection{Polarização potenciodinâmica}

Curvas de polarização potenciodinâmica, catódicas e anódicas, foram obtidas utilizando um potenciostato SI1287 A, com taxa de varredura de $1 \mathrm{mV} . \mathrm{s}^{-1}$. As curvas catódicas foram obtidas a partir do potencial a circuito aberto (PCA) até um potencial de $\mathrm{E}=-1,5 \mathrm{~V}_{\mathrm{PCA}}$. As curvas de polarização anódica foram obtidas a partir do $\mathrm{PCA}$ até um potencial de $\mathrm{E}=+2,5 \mathrm{~V}_{\mathrm{PCA}}$. 


\subsubsection{Caracterização da superfície}

\subsubsection{Microscopia eletrônica de varredura (MEV)}

A observação da superfície das amostras nas várias condições de acabamento superficial foi realizada por Microscopia Eletrônica de Varredura (MEV) e Espectroscopia de Energia Dispersiva (EDS), em um microscópio Phillips XL 30, no Departamento de Engenharia Metalúrgica e de Materiais da Escola Politécnica da Universidade de São Paulo. O equipamento dispõe de um detector para elétrons secundários e outro para elétrons retro-espalhados que permite a diferenciação de fases com diferentes número atômico.

A microscopia eletrônica de varredura permite a análise de superfícies irregulares devido à sua excelente profundidade de foco. Uma vantagem deste método de análise em relação à microscopia eletrônica de transmissão é a facilidade na preparação de amostras e a quantidade de análises estatísticas coletadas em uma única amostra, permitindo a realização de dados estatísticos [Gourgues, 2002]. O funcionamento deste microscópio é baseado em um feixe de elétrons de alta energia que incide na amostra. Os elétrons podem sofrer aceleração entre $2 \mathrm{kV}$ e $40 \mathrm{kV}$ e são direcionados para uma coluna formada por um conjunto de três lentes magnéticas. Estas lentes geram um feixe fino de elétrons que focaliza a superfície a ser analisada [Phillips, 1971].

O feixe de elétrons, ao incidir na amostra, causa os seguintes fenômenos principais: emissão de elétrons secundários, emissão de elétrons retroespalhados, absorção de elétrons, emissão de raios-X característicos, emissão de elétrons Auger e emissão de luz. Para cada tipo de emissão ou sinal pode-se usar um ou mais tipos de detector. Por exemplo, para detecção e análise dos raios-X característicos pode ser utilizada tanto a análise por dispersão de energia como a análise por comprimentos de onda [Padilha e Ambrozio Filho, 1985]. 


\section{RESULTADOS E DISCUSSÃO}

\subsection{Caracterização da microestrutura do alumínio AA1050}

As Figuras 5 e 6 apresentam micrografias da superfície do alumínio AA1050 polido com pasta de diamante até $1 \mu \mathrm{m}$. Além das ligas, o alumínio puro também pode conter impurezas e elementos de liga em solução sólida e precipitados intermetálicos. Nas micrografias, observa-se a existência de partículas de segunda fase em diferentes tamanhos e formatos. Estas partículas são chamadas de intermetálicos ou precipitados que se formam durante o processo de solidificação ou tratamentos térmicos (homogeneização, solubilização, recozimento e envelhecimento) no caso de ligas de alumínio tratáveis termicamente.

Os intermetálicos (IMs) foram identificados e separados em quatro grupos. Essa divisão foi realizada considerando as diferentes morfologias observadas a partir das micrografias.

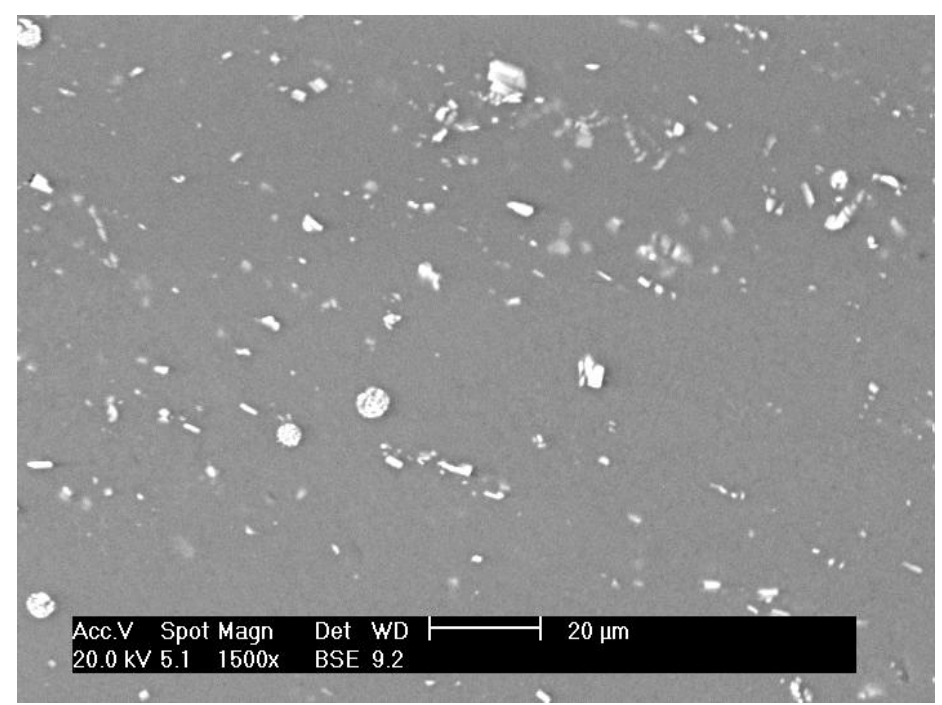

Figura 5. Micrografia por MEV do alumínio AA1050 polido com pasta de diamante $1 \mu \mathrm{m}$.

A Figura 6 apresenta a classificação dos precipitados em: IM1-Quebradiço, IM2-Redondo Quebradiço, IM3-Redondo Maciço e IM4-Alongado. 

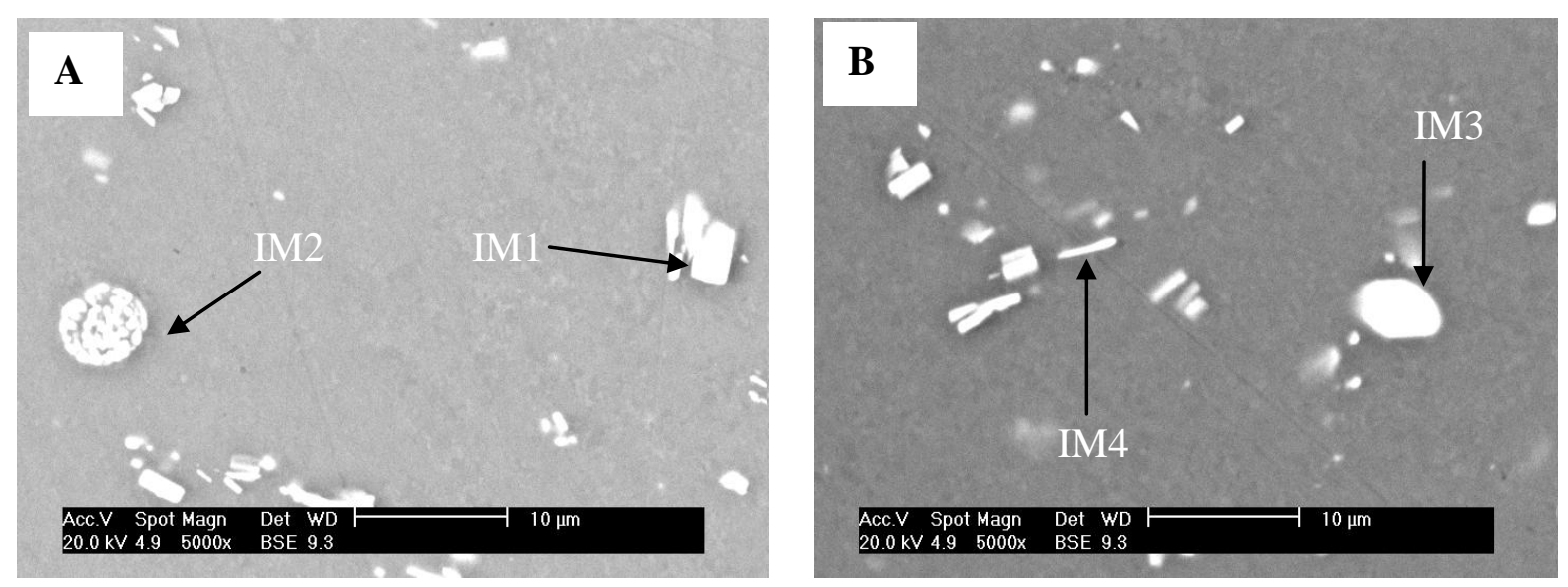

Figura 6: Micrografias por MEV com detector para elétrons retro-espalhados da superfície polida do alumínio AA1050 com pasta de diamante até $1 \mu \mathrm{m}$, com indicação dos vários tipos de morfologias dos precipitados encontrados.

Análises semi-quantitativas por EDS, Figura 7, foram realizadas nos quatro grupos de precipitados e repetidas no mínimo 5 vezes, tanto na matriz quanto nos grupos de mesma classificação. Desse modo, foi determinada a composição química aproximada de cada grupo de precipitados e os resultados estão apresentados na Tabela 5. Esses resultados mostraram que todos os tipos de precipitados possuem elevadas concentrações de ferro em relação à matriz. $\mathrm{O}$ ferro e o silício são impurezas comuns encontradas no alumínio [Reboul e Baroux, 2011] dificilmente eliminadas nos processos de produção.

A formação de IMs ocorre devido à baixa solubilidade de alguns elementos em relação à matriz de alumínio, por exemplo, a solubilidade para o ferro em alumínio é cerca de 0,05\% em massa [Oliveira, 2009]. Isso é um aspecto importante, principalmente em relação aos elementos $\mathrm{Fe}, \mathrm{Cu}, \mathrm{Mg}$ e $\mathrm{Si}$, pois a elevada concentração de determinados elementos faz com que o precipitado tenha comportamento anódico ou catódico em relação à matriz, tornando a superfície mais susceptível à corrosão localizada devido à formação de micropilhas galvânicas na superfície do alumínio [Guilaumin e Mankolski, 1999]. 

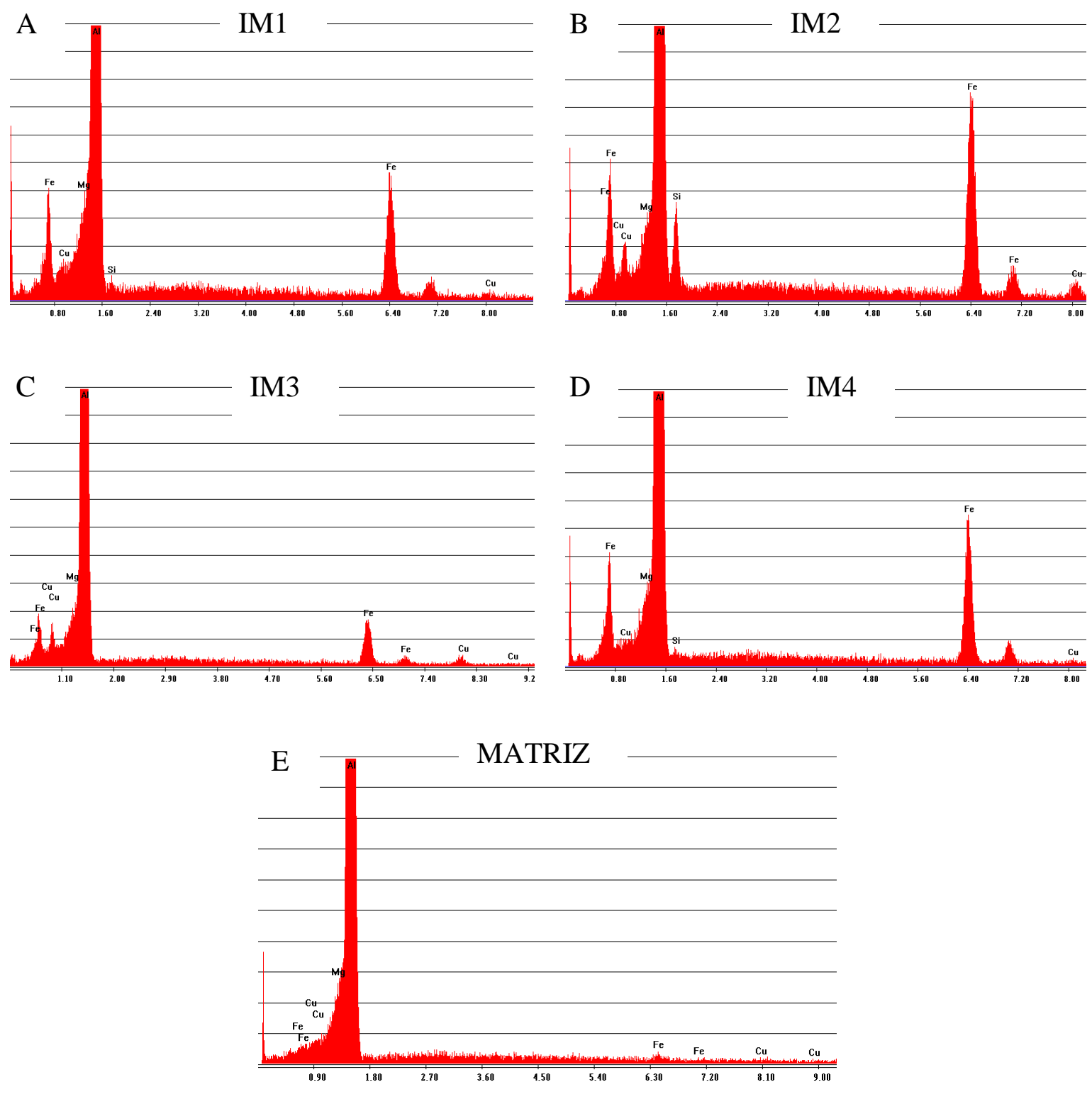

Figura 7: Espectros de EDS para os quatro grupos de intermetálicos classificados: IM1 (A), IM2 (B), IM3(C), IM4(D) e (E) Matriz AA1050.

Segundo Reboul e Baroux [2011] os elementos mais ativos que o alumínio, quando em solução sólida (Ex.: Fe e Cu), são oxidados e formam uma camada protetora pobre na superfície durante a formação do filme. Elementos mais nobres do que o alumínio em solução sólida, tais como o cobre, mas também outros elementos mais ativos e volumosos, tais como o magnésio, são acumulados na interface metal/óxido durante a formação do filme. Estes elementos podem passar para a camada de óxido somente acima de um limiar específico para cada elemento [Thompson, 1982]. 
Tabela 5: Composição química semi-quantitativa obtida por EDS dos diferentes tipos de precipitados encontrados na superfície do AA 1050.

\begin{tabular}{|c|c|c|c|c|c|}
\hline \multirow{2}{*}{$\begin{array}{c}\text { Composição } \\
\text { AA1050 }\end{array}$} & \multicolumn{5}{|c|}{$(\%)$ massa } \\
\hline & $\mathrm{Fe}$ & $\mathrm{Cu}$ & $\mathrm{Mg}$ & $\mathrm{Si}$ & $\mathrm{Al}$ \\
\hline Matriz & $0,96 \pm 0,22$ & $0,63 \pm 0,17$ & $1,26 \pm 0,19$ & -- & Balanço \\
\hline IM1.Quebradiço & $10,29 \pm 5,33$ & $1,03 \pm 0,25$ & $1,39 \pm 0,04$ & $0,24 \pm 0,16$ & Balanço \\
\hline IM2.Redondo Q & $12,48 \pm 4,26$ & $2,39 \pm 0,51$ & $1,26 \pm 0,13$ & $2,58 \pm 0,55$ & Balanço \\
\hline IM3.Redondo M & $10,28 \pm 4,28$ & $1,48 \pm 1,18$ & $1,43 \pm 0,14$ & -- & Balanço \\
\hline IM4.Alongado & $10,26 \pm 3,54$ & $0,95 \pm 0,20$ & $1,51 \pm 0,09$ & $0,36 \pm 0,14$ & Balanço \\
\hline
\end{tabular}

5.1.1. Efeito do pré-tratamento de desengraxe e desoxidação comercial (PB) na superfície do alumínio 1050.

A Figura 8 apresenta micrografias da superfície do alumínio AA1050 (A) após polimento com pasta de diamante $1 \mu \mathrm{m}$ e (B) polimento com pasta de diamante $1 \mu \mathrm{m}$ seguido por tratamento de imersão em três banhos comerciais, sendo dois desengraxantes alcalinos e um desoxidante. Este tratamento foi denominado PB, conforme indicado na Tabela 4. É possível observar que o tratamento PB promoveu ataque corrosivo na superfície, removendo parte dos precipitados e deixando cavidades nas regiões onde o precipitado foi totalmente ou parcialmente removido. 

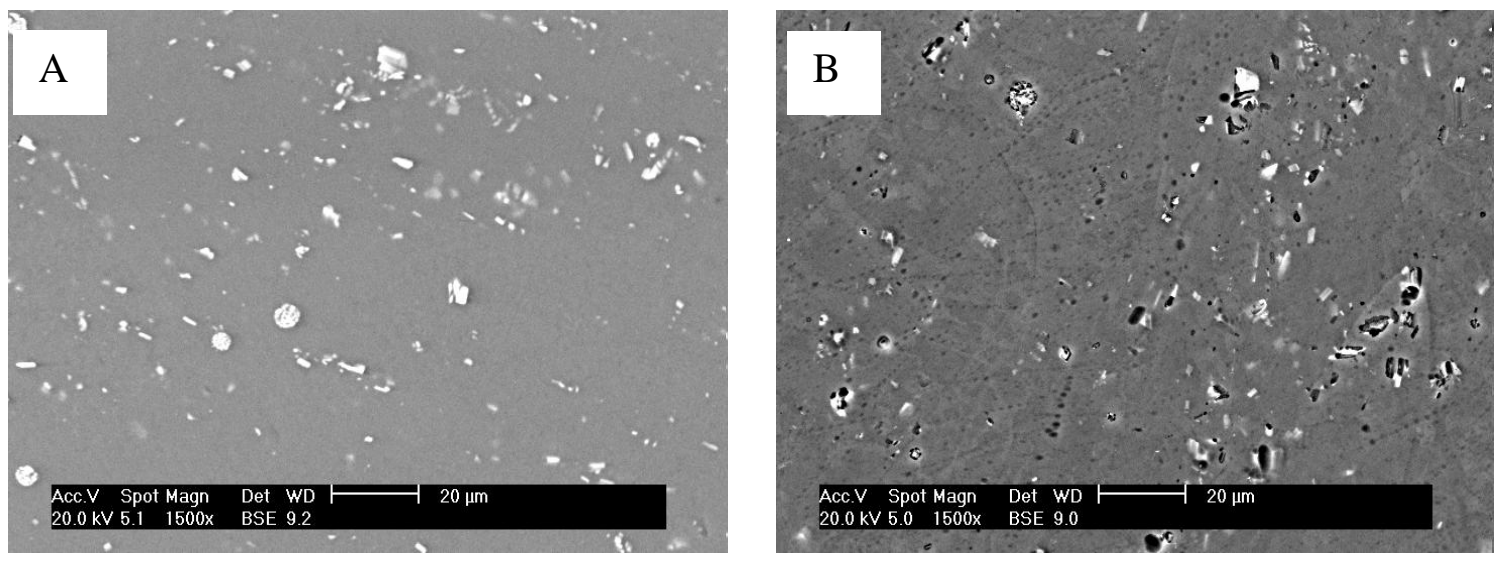

Figura 8: Micrografias por MEV do alumínio AA1050 (A) polido com pasta de diamante até $1 \mu \mathrm{m}$ e $(B)$ polido e exposto a dois banhos desengraxantes e um banho desoxidante (PB).
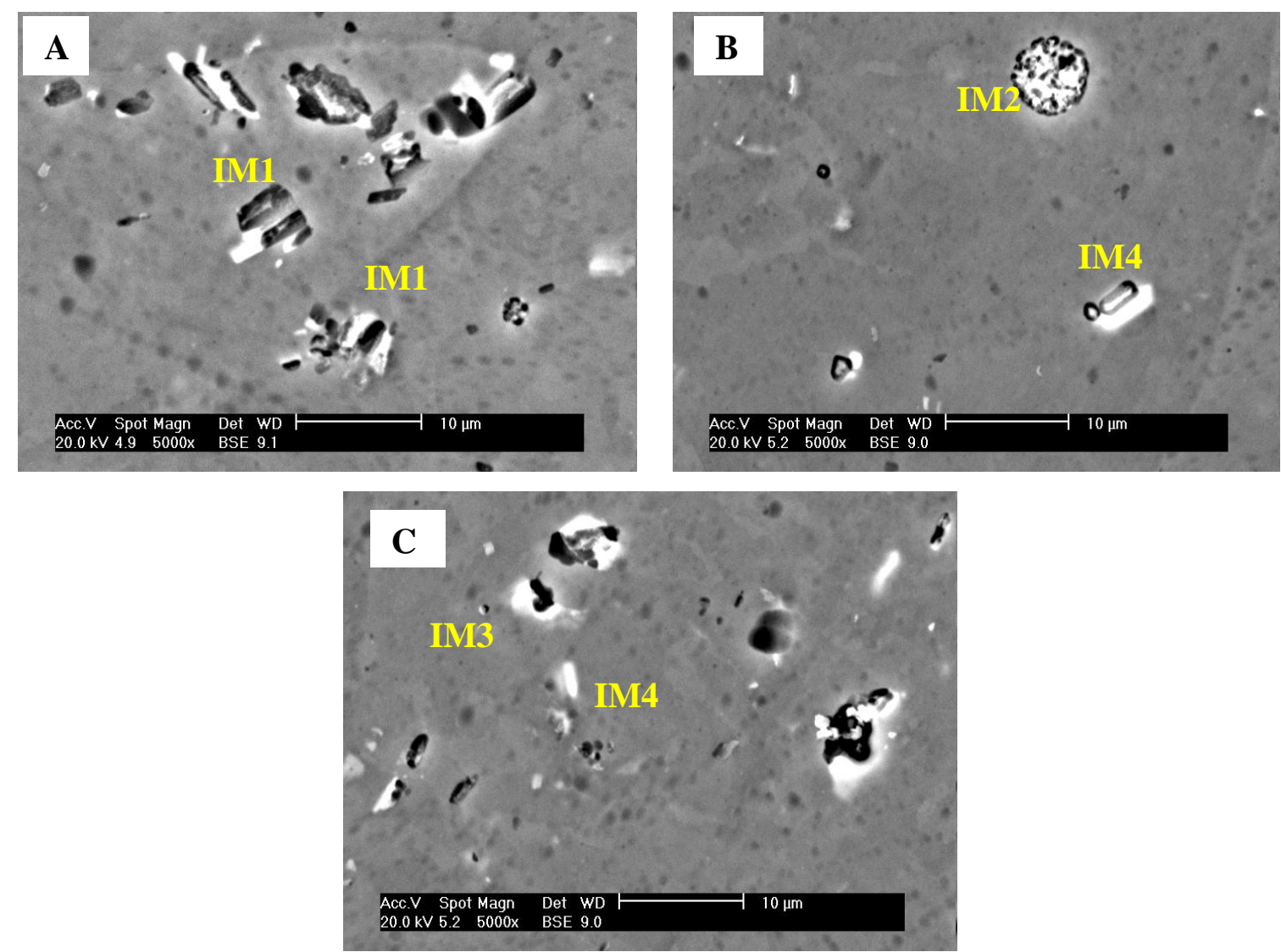

Figura 9: Micrografias por MEV da superfície do alumínio AA1050, polido e submetido ao tratamento PB. A) Intermetálico tipo IM1, B) Intermetálico tipo IM2 e IM4, C) Intermetálicos tipos IM3 e IM4.

Na Figura 9 são apresentadas as micrografias obtidas por MEV da superfície do alumínio AA1050, polido e submetido ao tratamento PB com 
maiores aumentos destacando os intermetálicos dos diferentes grupos. A Figura 9 sugere a ocorrência de dissolução seletiva dos precipitados devido ao ataque preferencial dos seus constituintes menos nobres, com 0 ataque corrosivo provavelmente tendo início na interface matriz-precipitado pela formação de pilhas galvânicas.

Nota-se que, nas regiões em volta dos precipitados ocorreu um intenso ataque, independente de sua composição. Os precipitados classificados como IM1-Quebradiços (10,29\%Fe, 1,03\%Cu e 0,24\%Si) e IM2-Redondo Quebradiço $(12,48 \% \mathrm{Fe}, 2,39 \% \mathrm{Cu}$ e 2,58\%Si) aparentemente sofreram corrosão de maneira distinta. Os IM2 possuem praticamente o dobro da concentração de $\mathrm{Cu}$ e dez vezes a concentração de Si em comparação ao IM1 e, nesse caso, o ataque mais intenso parece se localizar na matriz em volta do precipitado, particularmente na região da matriz que está próxima ao precipitado de formato redondo.

Os precipitados do tipo IM1, todavia, aparentemente são atacados quando submetidos ao tratamento PB, preservando-se a matriz, Figura 9(A). Estes últimos precipitados apresentam comparativamente baixos teores de cobre em relação à matriz. Por outro lado, precipitados com maior concentração de Cu (IM2 e IM3) e, no caso do IM2, também maior concentração de Si (2,58\%), aparentemente são catódicos em relação à matriz, Figura 9(B), e a matriz de alumínio ao redor dos precipitados IM2 e IM3 parece sofrer corrosão.

Ainda na Figura 9 é possível observar que as etapas de tratamento da superfície em banhos comerciais desengraxantes e desoxidante não foram suficientes para a remoção completa dos precipitados.

Segundo a literatura [Queiroz, 2008], como agravante ao processo galvânico, a película passiva sobre a matriz é mais frágil nas proximidades dos precipitados, podendo haver também a formação de zonas empobrecidas em $\mathrm{Cu}$ na matriz, diminuindo ainda mais a resistência à corrosão destas regiões (regiões circunvizinhas aos precipitados). Esses fatores as tornam sítios ideais para o início da corrosão por pite, principalmente em meios contendo íons cloreto. 
5.1.2. Efeito dos tratamentos $\mathrm{PB}, \mathrm{SAM}, \mathrm{Cr}(\mathrm{VI}), \mathrm{OX}$ e OS na superfície do alumínio AA1050.

A Figura 10 apresenta as micrografias do alumínio AA1050 submetido aos tratamentos denominados $\mathrm{PB}, \mathrm{SAM}, \mathrm{Cr}(\mathrm{VI})$, OX e OS. É possível observar que, quando a amostra é exposta ao tratamento de imersão em solução com SAM, Figura 10(b), sua superfície torna-se visivelmente mais atacada que a superfície do alumínio com tratamento PB e os demais tratamentos (Figura 10).

A Figura 10(c) apresenta a micrografia do AA1050 exposto ao tratamento de cromatização em solução à base de cromo hexavalente $(\mathrm{Cr}(\mathrm{VI}))$. É possível observar que a superfície das amostras submetidas a este tratamento apresentase menos corroída quando comparada à superfície após o tratamento SAM, embora parte dos precipitados tenham sido removidos devido ao tratamento. $\mathrm{O}$ ataque menos intenso da superfície pelo tratamento $\operatorname{com~} \mathrm{Cr}(\mathrm{VI})$ pode ser explicado pelo menor tempo de imersão no tratamento (3 min) em comparação à solução com SAM $(3 \mathrm{~h})$, bem como à menor acidez do banho cromatizante $(\mathrm{pH}=$ $3,7)$ em comparação ao da solução de SAM $(\mathrm{pH}=3,0)$.

A superfície do alumínio AA1050 submetido ao tratamento de imersão em água fervente para favorecimento do crescimento de uma camada de óxidohidróxido, OX Figura 10(d), mostra uma nítida diferença em relação à superfície com o tratamento PB (Figura 10a). O tratamento OX favorece o crescimento de uma camada mais espessa, particularmente nas regiões vizinhas aos precipitados, pela maior atividade nestas áreas, resultando em proteção por efeito de resistência ôhmica.

O efeito do tratamento OS por imersão em solução com moléculas autoorganizáveis (SAM) da superfície do alumínio após tratamento OX é mostrado na Figura 10(e). Nota-se um menor ataque da superfície em comparação àquela que foi imersa em solução com SAM após tratamento PB, mostrando que a camada de oxi-hidróxido formada atua como barreira ao ataque da superfície pela solução com moléculas auto-organizáveis de caráter ácido. 


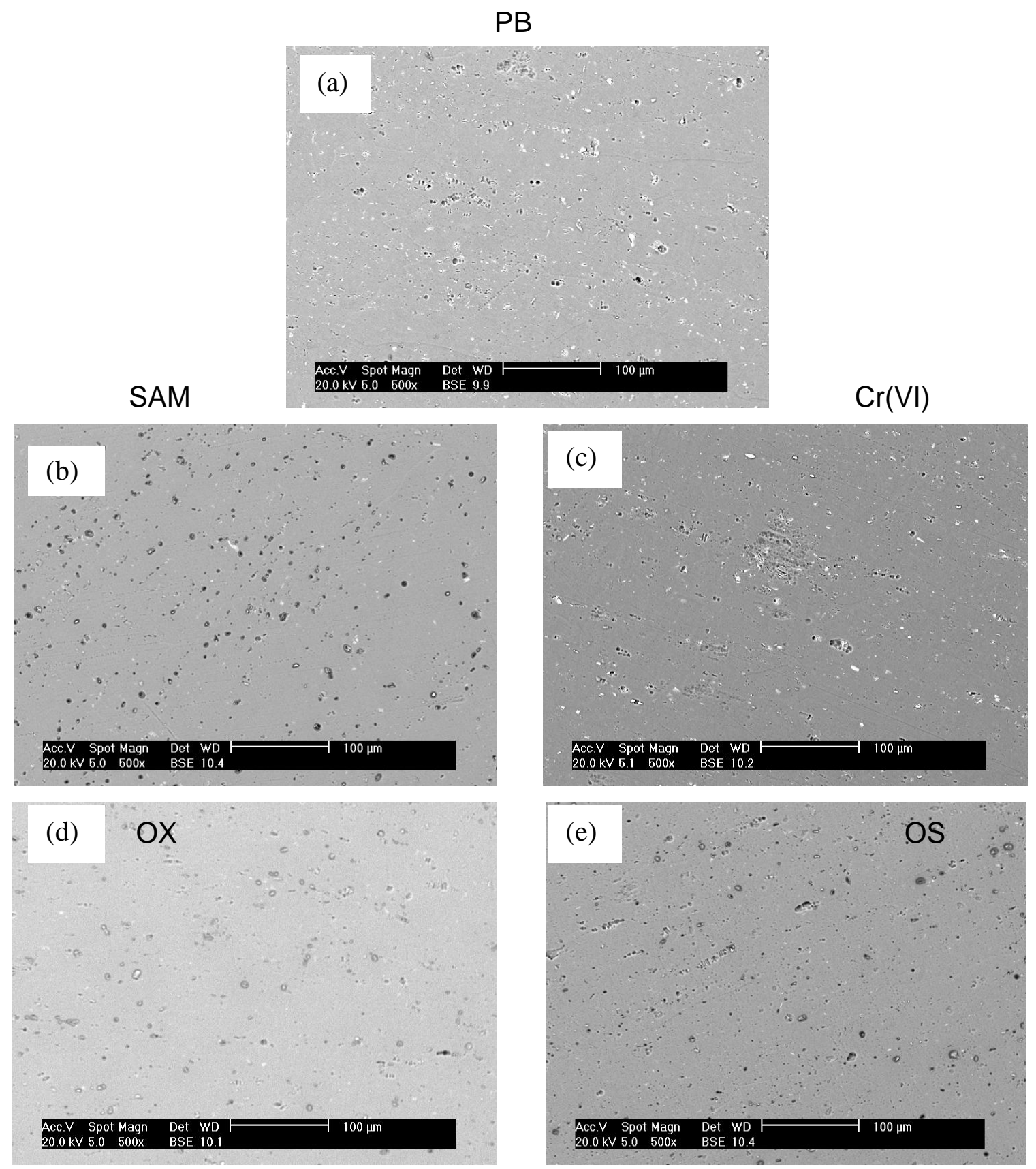

Figura 10: Micrografias por MEV da superfície do alumínio AA1050 polido e submetido aos tratamentos PB (a), SAM (b), Cr VI (c), OX (d) e OS (e).

5.3. Caracterização eletroquímica do alumínio AA1050.

5.3.1. AA1050 submetido ao tratamento PB

Os resultados das medidas de PCA antes dos ensaios de EIE mostraram estabilidade do potencial para os três tempos de imersão avaliados (1, 2 e 3 dias). 
A Figura 11 apresenta diagramas de Nyquist (11a) e de Bode (11b) para o alumínio AA1050 com tratamento PB em função do tempo de imersão em solução de ensaio. Esses diagramas foram obtidos sequencialmente para uma mesma amostra, portanto, representam a evolução da resposta do eletrodo em função do tempo de imersão na solução de ensaio. Na Figura 11(a), observa-se pequena diminuição do arco capacitivo com o tempo de imersão, provavelmente devido à hidratação da camada ou agressividade do eletrólito teste à superfície do alumínio cuja acidez encontra-se no limiar de estabilidade do óxido de alumínio $(\mathrm{pH}=4,0)$.

Apesar da indicação de ataque corrosivo da superfície pelo meio de ensaio, os valores de impedância relativamente altos (ordem de $10^{4} \Omega . \mathrm{cm}^{2}$ ), sugerindo a presença de filme passivo na superfície do alumínio, mesmo após 3 dias de imersão. Estes resultados indicam que o ataque corrosivo se dá de forma localizada com preservação do filme passivo na maior parte da superfície. Os diagramas de Bode sugerem alta estabilidade da superfície, o que se deve à presença da película passiva.

Nos diagramas de Nyquist é possível observar claramente a formação de um arco capacitivo achatado associado às heterogeneidades da superfície e, em baixas freqüências, à presença de um arco indutivo. Existem várias propostas na literatura para explicar o arco capacitivo que se observa na região de alta frequência em diagramas de impedância para alumínio e suas ligas, sempre relacionadas à camada de óxido de alumínio. Brett et al. [1992] relacionam este arco às reações que envolvem os processos dinâmicos da camada de óxido, por exemplo, crescimento e degradação.

Arcos indutivos têm sido associados com a presença da camada passiva [de Wit e Lenderink 1996] e, frequentemente, para Al e suas ligas, atribuídos à relaxação de espécies adsorvidas na superfície do eletrodo [Bessone et al., 1992, De Wit e Lenderink, 1996, Aoki et al., 2001, Sayed et al., 2002, Reis et al., 2006,].

No presente trabalho, a formação do arco indutivo em baixas freqüências pode ser associada à adsorção de íons sulfato $\left(\mathrm{SO}^{2-}{ }_{4}\right)$ da solução de ensaio, à adsorção de oxigênio, ou a adsorção de íons $\mathrm{Cl}^{-}$do eletrodo de calomelano saturado utilizado como eletrodo de referência na superfície do alumínio. Outra possibilidade para o arco indutivo é a ocorrência de ataque localizado na forma de pites, favorecido pela presença de íons cloreto no meio como contaminante de 
origem no eletrodo de referência, particularmente nas regiões de vizinhança entre os precipitados e a matriz, pelo efeito de micropilhas galvânicas.

Os diagramas de ângulo de fase de Bode para amostras submetidas ao tratamento PB, Figura 11(b), apresentam um patamar na região de médias freqüências, o que pode indicar a sobreposição de mais de uma constante de tempo. Acredita-se que, para as condições adotadas no presente estudo, há interação entre pelo menos duas constantes de tempo, uma devido à capacitância do filme de óxido-hidróxido fino superficial acoplada à resistência do eletrólito nos poros/defeitos deste óxido e, a outra, associada a processos interfaciais de carregamento da dupla camada elétrica e processo de transferência de carga na interface metal-eletrólito.

Segundo Baltat-Bazia et al. [1992], duas constantes de tempo seriam atribuídas ao caráter dúplex do filme de óxido de alumínio, que é composto por uma camada externa e porosa, e outra mais interna e compacta, sendo esta última a principal responsável pela proteção do substrato metálico. Todavia, acredita-se que este modelo aplica-se a camadas mais espessas de óxido geralmente obtidas por processos de anodização. Nesse caso, os filmes muito finos obtidos por exposição ao meio ambiente, após preparação da superfície, não permitiram uma analogia com o modelo proposto por Baltat-Bazia et al. [1992].

O formato dos diagramas de impedância se manteve constante durante 0 período de imersão, indicando que os mecanismos atuantes no alumínio exposto ao eletrólito teste da solução de ensaio permanecem os mesmos ao longo do período de realização das medidas. 


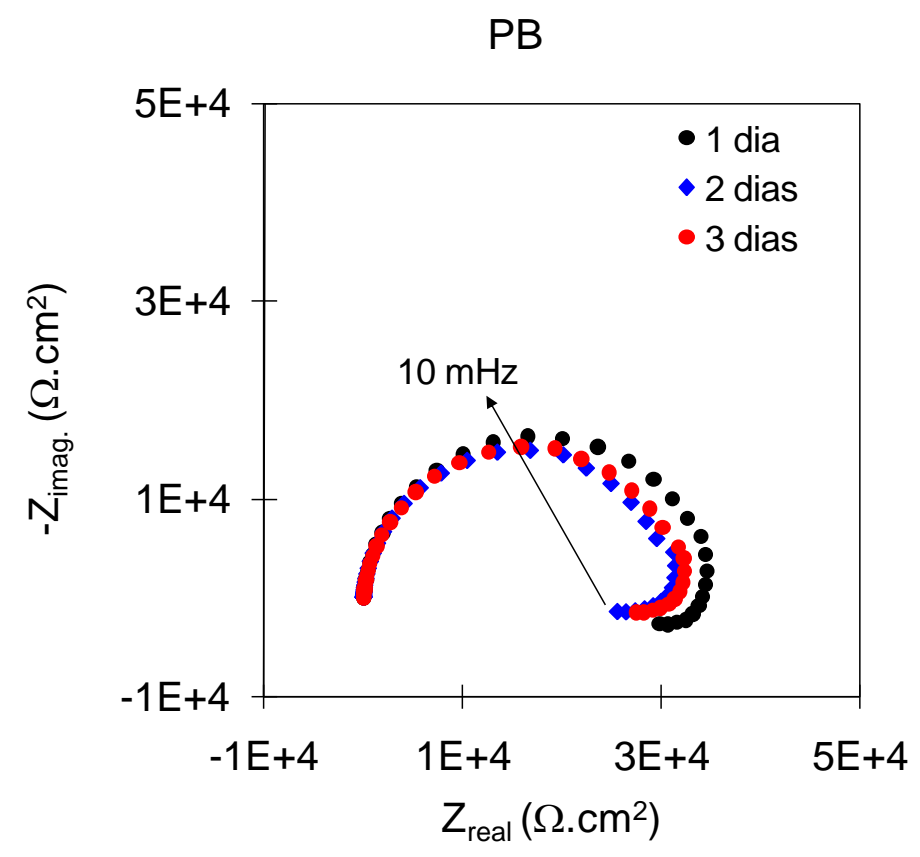

(a)

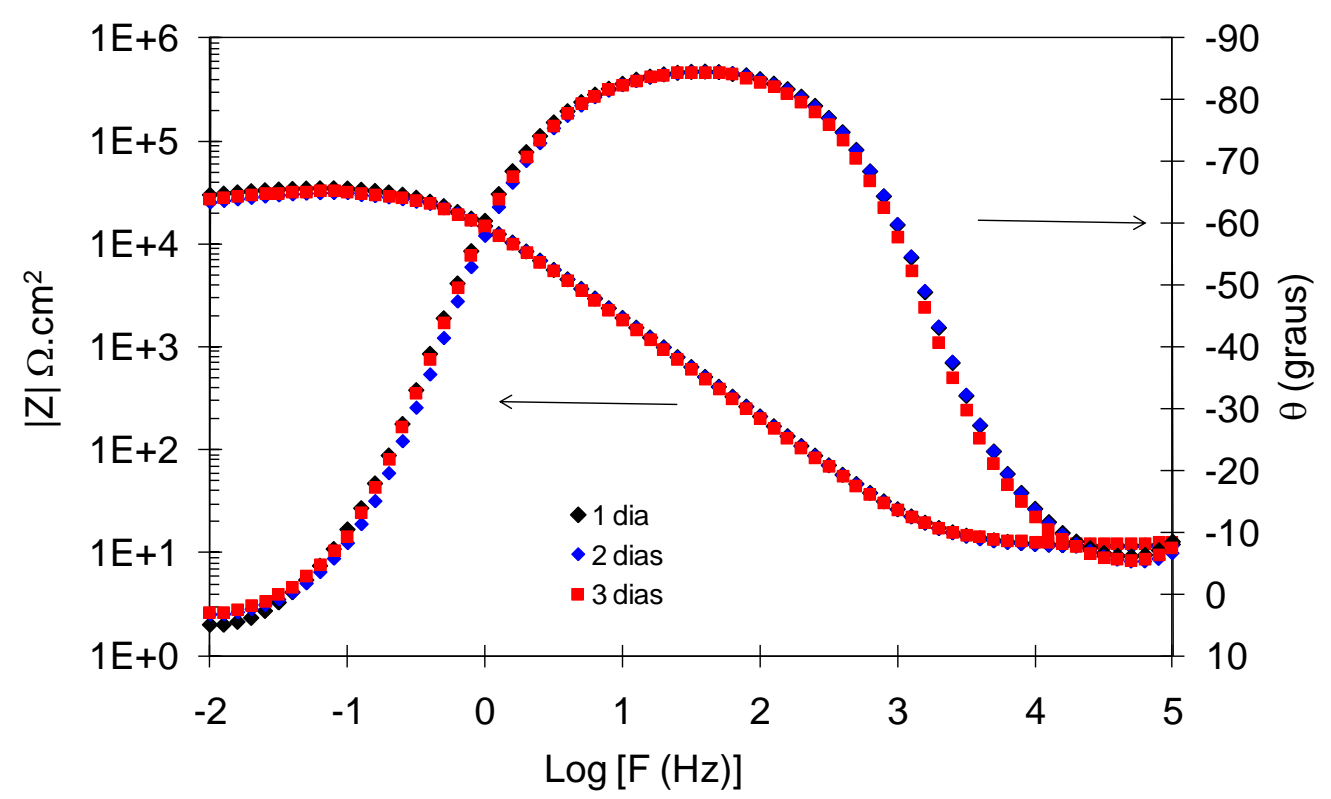

(b)

Figura 11: Diagramas de impedância obtidos para alumínio AA1050 com tratamento PB em função do tempo de imersão na solução de ensaio (a) Nyquist e (b) Módulo de Z e ângulo de fase de Bode.

Os modelos propostos e os ajustes dos circuitos equivalentes serão discutidos na seção 5.6., após a apresentação dos resultados dos ensaios eletroquímicos para os diferentes tipos de tratamentos de superfície avaliados. 
A Figura 12 apresenta as curvas de polarização potenciodinâmica anódicas que foram obtidas para o alumínio AA1050 com tratamento PB para vários tempos de imersão na solução de ensaio.

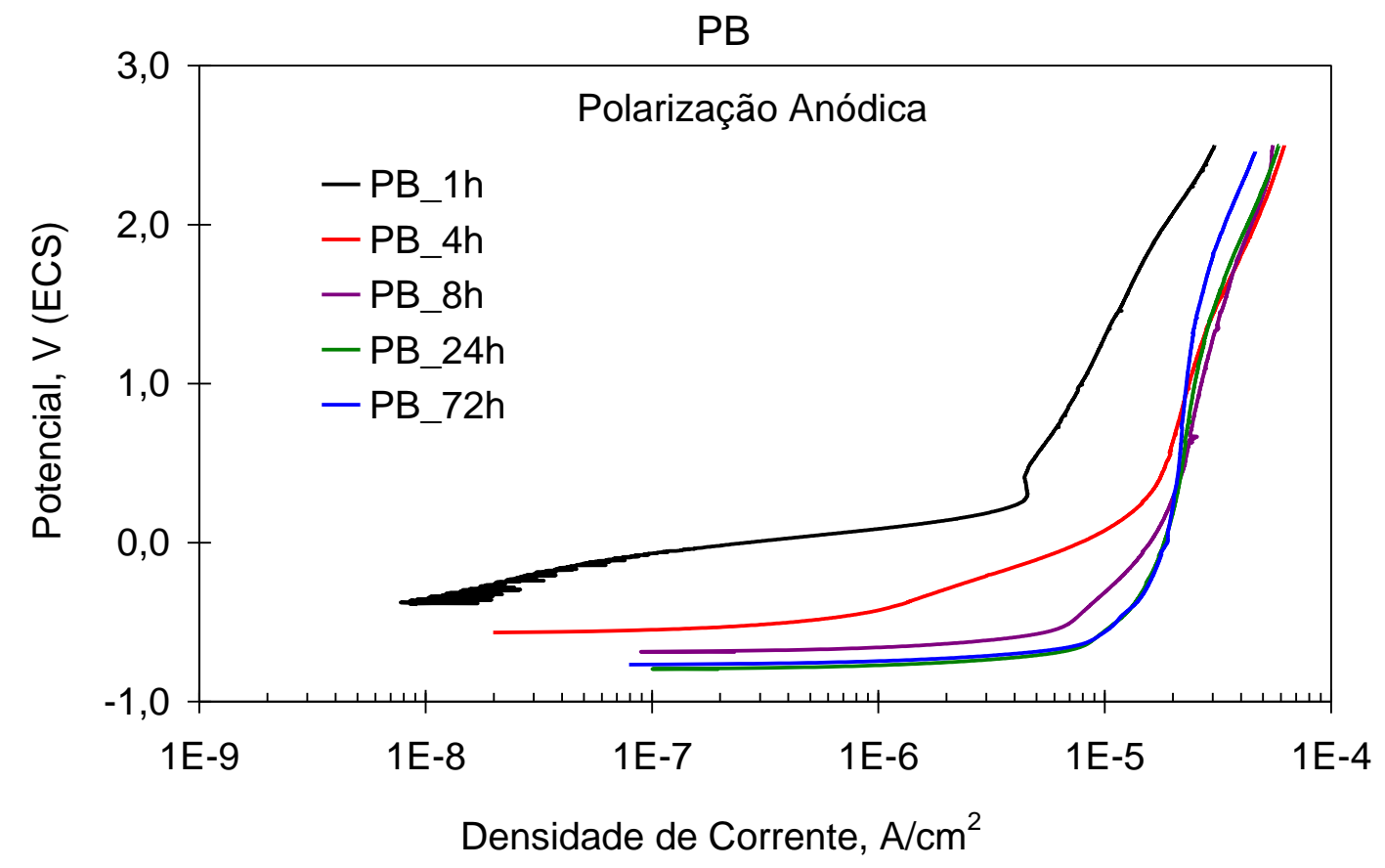

Figura 12: Polarizações anódicas obtidas para o alumínio 1050 com tratamento PB após vários tempos de imersão em solução de ensaio.

Observam-se maiores densidades de corrente anódica com o aumento do tempo de imersão entre $1 \mathrm{~h}$ e 24 h de exposição ao eletrólito. Nota-se também a diminuição da região correspondente à região passiva o que sugere um crescente ataque do filme passivo neste período. Estes resultados mostram que o eletrólito de ensaio possui características corrosivas com relação ao filme passivo. O grande aumento de corrente anódica em função do tempo de ensaio ocorreu principalmente entre $1 \mathrm{~h}$ e $8 \mathrm{~h}$ de ensaio, sendo este da ordem de duas ordens grandeza, mostrando o ataque ao filme passivo.

Entre 24 h e 72 h, praticamente não ocorreu variação nas curvas de polarização mostrando que a superfície atinge estabilidade após $24 \mathrm{~h}$ de ensaio. Após $72 \mathrm{~h}$ de exposição ao meio, as amostras ainda apresentavam densidades de corrente, características de filmes passivos, i.e., ordem de $10^{-5} \mathrm{~A} / \mathrm{cm}^{2}$ até em elevados potenciais de polarização 
As curvas de polarização apóiam os resultados de espectroscopia de impedância que mostraram pouca alteração na superfície do alumínio para o período de ensaio entre $24 \mathrm{~h}$ e $72 \mathrm{~h}$.

\subsection{Influência do Eletrodo de Referência nos resultados eletroquímicos.}

Íons cloreto possuem enorme influência na corrosão por pite em substratos de alumínio [Smialowska,1992, Frankel, 1998, Frankel e Sridhar, 2008, Meng et al., 2009], já que a perda da passividade local ocorre devido à agressividade desses íons. Mesmo em baixas contrações, os íons $\mathrm{Cl}^{-}$podem ser extremamente agressivos. Quando essa concentração se encontra acima de 50 ppm é possível predizer o grau da corrosão por pite em alumínio, em função do número de semanas em que a profundidade do pite leva para avançar $1 \mathrm{~mm}$ [Pathack $e$ Godard, 1968].

Como já mencionado, trabalhos realizados com substratos de alumínio associam o comportamento indutivo observado nos diagramas de EIE à adsorção de espécies químicas na superfície da camada de óxido-hidróxido passiva [Franceschetti e MacDonald, 1977, Bechet et al.,1977 e Dawson e Ferreira, 1986]. Pesquisadores reportaram que este comportamento está associado à adsorção de espécies ou a intermediários presentes no eletrólito, sejam estes sulfato [Reis et al., 2006], cloreto [Bessone et al., 1992, Cabot et al., 1995, De Wit e Lenderink, 1996], citrato ou tartarato [Aoki et al., 2001, Sayed et al., 2002].

O eletrodo de calomelano saturado (ECS) contém íons cloreto (ou ânions $\left.\mathrm{Cl}^{-}\right)$que podem se difundir pela região porosa do eletrodo (raio iônico $0,181 \mathrm{~nm}$ ) [Callister, 2008], contaminar a solução de ensaio e atingir a camada de óxidohidróxido na superfície da amostra de AA1050, influenciando o comportamento de corrosão e, portanto, os resultados dos ensaios eletroquímicos.

A influência do eletrodo de referência usado nos ensaios eletroquímicos foi um dos pontos de discussão do presente trabalho, por isso a utilização de um eletrodo de referência, por exemplo, de Prata-Cloreto de Prata ou de Calomelano Saturado composto com ânions diferentes dos ânions da solução de ensaio $\left(\mathrm{SO}_{4}{ }^{2-}\right)$ em substratos de alumínio é um ponto importante a ser considerado. 
Para quantificar a contaminação por íons $\mathrm{Cl}^{-}$causada na solução de ensaio quando utilizado um ECS, foi realizada uma análise dos ânions presentes nessa solução, em comparação com a solução de ensaio quando utilizado o eletrodo de referência de Sulfato Mercuroso (ESM).

A quantificação dos íons $\mathrm{Cl}^{-}$foi realizada pelo Centro de Química e Meio Ambiente - CQMA do Instituto de Pesquisas Energéticas e Nucleares, IPEN/CNEN-SP, utilizando a técnica de Cromatografia de ĺons e os resultados estão apresentados na Tabela 6. Os resultados obtidos através da quantificação não apresentaram valores elevados de contaminação de $\mathrm{Cl}^{-}$. No entanto, a presença dos íons $\mathrm{Cl}^{-}$foi aproximadamente 6 vezes maior quando usado o ECS em comparação ao ESM.

Tabela 6. Concentração química (em $\mathrm{mg} \cdot \mathrm{L}^{-1}$ ) da solução de ensaio $(0,5 \mathrm{M}$ $\mathrm{Na}_{2} \mathrm{SO}_{4}$, tamponada a $\left.\mathrm{pH}=4,0\right)$ submetida a 3 dias de ensaios eletroquímicos com ECS e ESM em alumínio comercialmente puro AA1050.

\begin{tabular}{cc}
\hline $\begin{array}{c}\text { Solução de ensaio } \\
\left(0,5 \mathrm{M} \mathrm{Na}_{2} \mathrm{SO}_{4}, \mathrm{pH}=4,0\right)\end{array}$ & $\begin{array}{c}\text { Concentração química de cloreto } \\
\left(\mathrm{mg} . \mathrm{L}^{-1} \text { ou ppm }\right)\end{array}$ \\
\hline \hline Não-contaminada (ESM) & $\mathbf{1 , 4 7 \pm 0 , 2 0}$ \\
Contaminada $\quad(E C S)$ & $9,08 \pm 0,20$ \\
\hline
\end{tabular}

Apesar dos resultados obtidos através da quantificação dos íons de cloreto na solução de ensaio não apresentarem valores elevados de contaminação quando usado o ECS, pode ser observada uma diferença a partir do monitoramento do PCA para amostras Polidas em comparação ao ESM.

As Figuras $13(\mathrm{~A})$ e $13(\mathrm{~B})$ apresentam as curvas dos potenciais a circuito aberto em função do tempo de imersão na solução de ensaio para as duas condições, com ECS (A) e ESM (B).

Uma maior variação do PCA nas primeiras horas de imersão em solução de ensaio foi evidente quando se comparada aos resultados obtidos com ECS, Figura 13(a), em relação aos obtidos com ESM, Figura 13(B). Supõe-se que a maior agressividade dos íons $\mathrm{Cl}^{-}$ao óxido-hidróxido de alumínio promove um 
ataque localizado nas regiões ativas da superfície. Em decorrência da menor atividade, o tempo de estabilização do PCA é menor para a medida com o ECS, que ocorreu após 8 horas de imersão, em comparação àquela com o ESM, que se estabilizou apenas após 10 horas de imersão na solução de $0,5 \mathrm{~mol} \mathrm{~L}^{-1}$ $\mathrm{Na}_{2} \mathrm{SO}_{4}, \mathrm{pH}=4,0$.

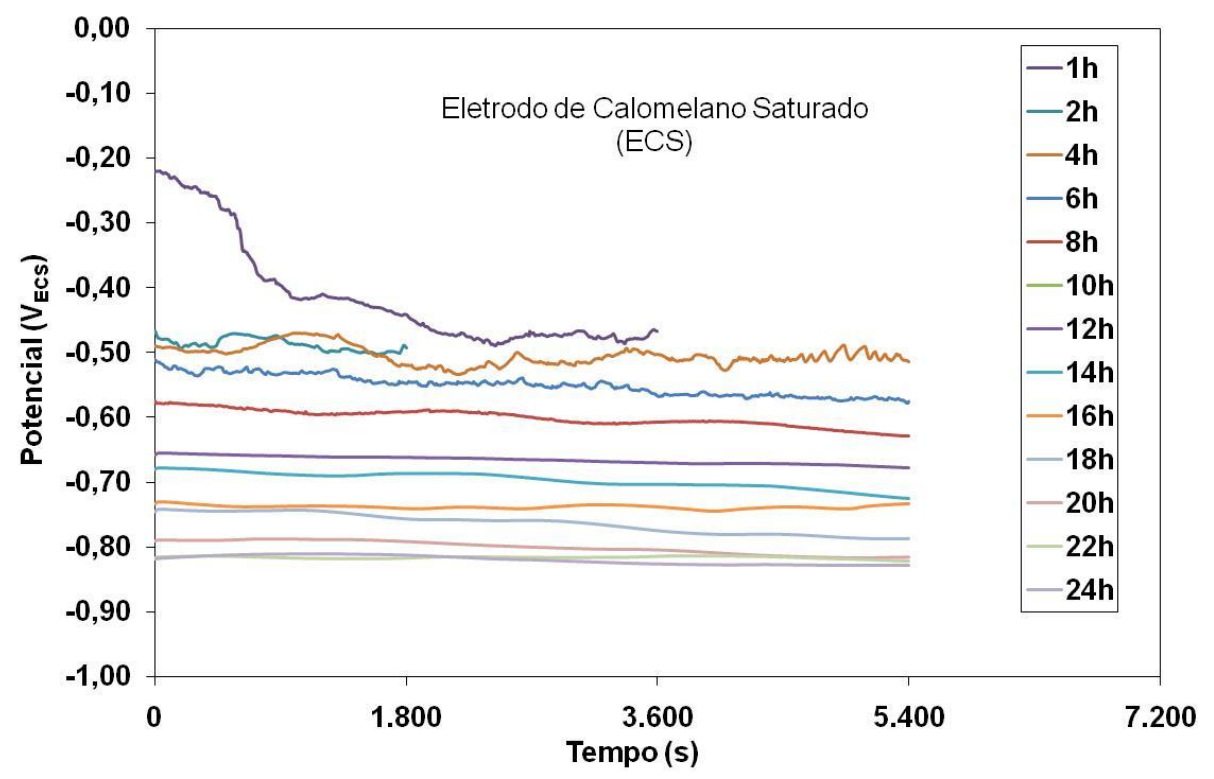

(A)

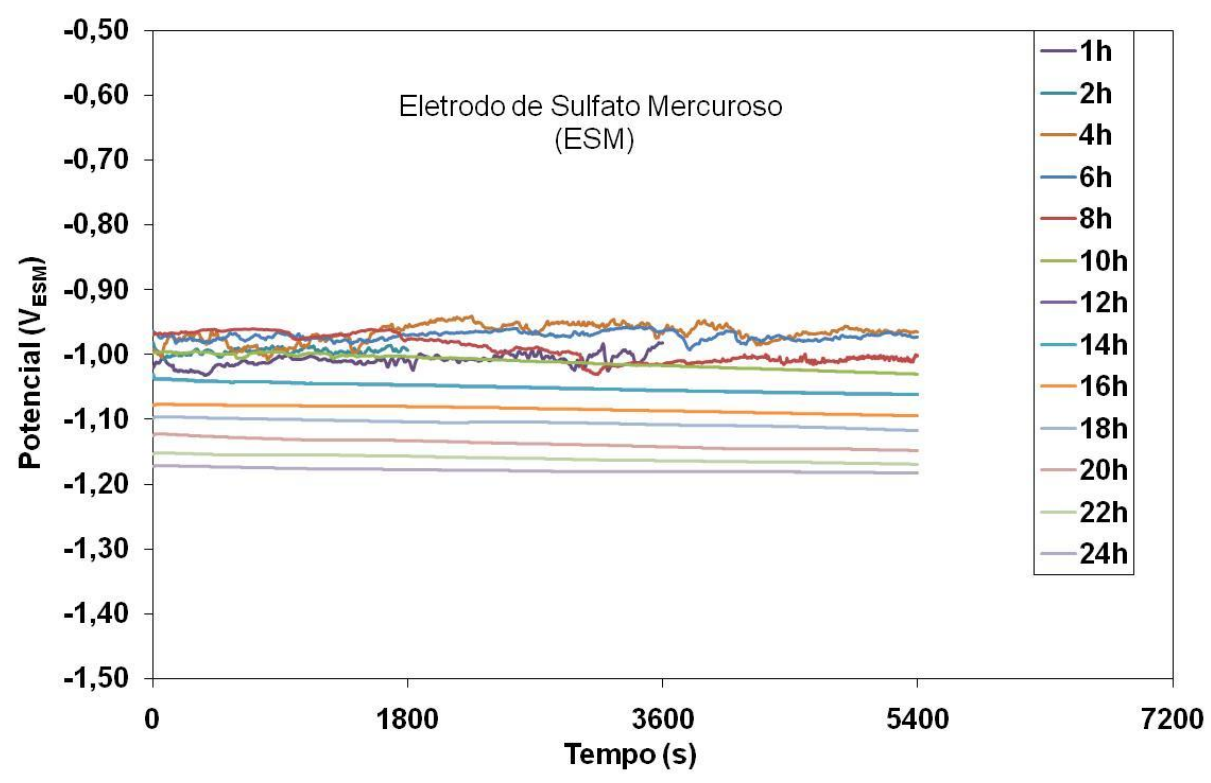

(B)

Figura 13: Monitoramento do Potencial a Circuito Aberto em função do tempo de imersão em solução de $0,5 \mathrm{~mol} \mathrm{~L}^{-1} \mathrm{Na}_{2} \mathrm{SO}_{4}, \mathrm{pH}=4,0$ para eletrodo de Calomelano Saturado (A) e eletrodo de Sulfato Mercuroso (B). 
A Figura 14 apresenta os valores do PCA medidos no instante anterior às medidas de EIE com ECS e ESM para amostras Polidas. Os pontos indicados correspondem à última medida de potencial antes da realização do ensaio de EIE. Deve-se ressaltar que a diferença de potencial entre os dois eletrodos de referência é da ordem de $0,4 \mathrm{~V}$, o que explica a diferença de valores de potenciais de circuito aberto indicados nas Figuras 13 e 14.

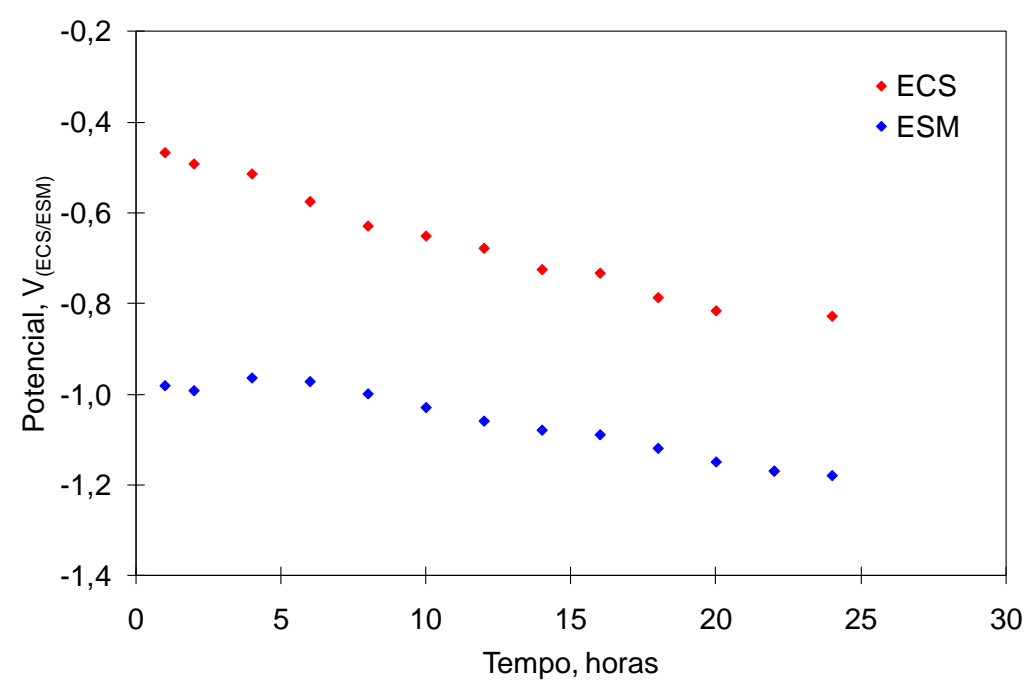

Figura 14: Valores de potencial a circuito aberto nos instantes anteriores à aquisição das medidas de EIE para amostras Polidas com ECS e ESM.

A partir dos resultados de EIE obtidos para amostras de AA1050 Polidas e posteriormente imersas em solução de ensaio utilizando ECS em comparação ao ESM, foi possível confirmar que mesmo em baixas concentrações, os íons $\mathrm{Cl}^{-}$têm influência no comportamento de corrosão do alumínio AA1050 e o comportamento indutivo está associado não somente à adsorção de íons $\mathrm{Cl}^{-}$presentes como contaminantes na solução de ensaio, mas também à adsorção de $\mathrm{SO}_{4}{ }^{2-}$ na camada passiva de óxido-hidróxido de alumínio e regiões de vizinhança entre precipitados e matriz.

A Figura 15 apresenta os diagramas de EIE para amostras de AA1050 Polidas, após a estabilização do PCA (10 h) e posteriormente submetidas à imersão em solução de ensaio utilizando ECS ou ESM. 


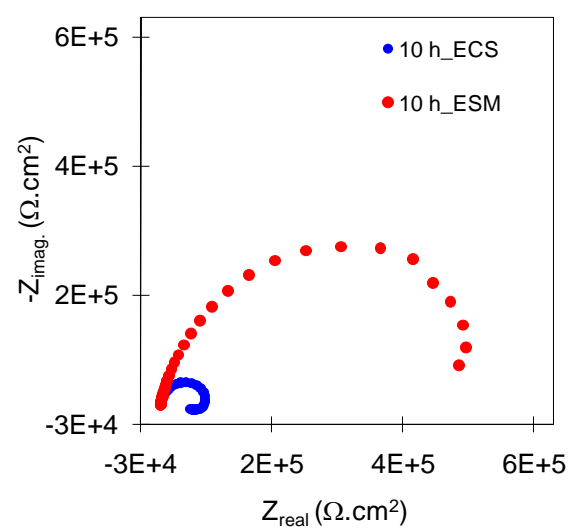

(A)

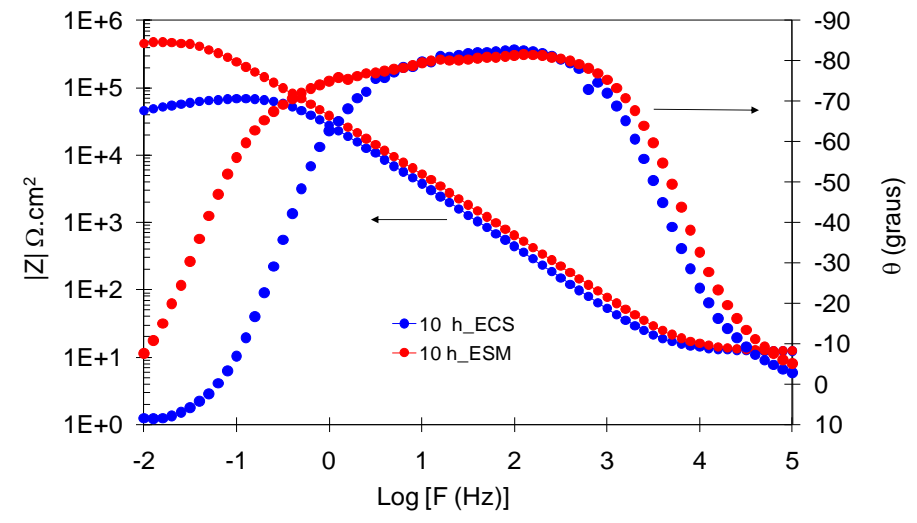

(B)

Figura 15: Diagramas de Nyquist (A) e Bode (B) para amostras Polidas de AA1050 após $10 \mathrm{~h}$ de imersão em solução de $0,5 \mathrm{~mol} \mathrm{~L}^{-1} \mathrm{Na}_{2} \mathrm{SO}_{4}, \mathrm{pH}=4,0$, utilizando ECS ou ESM.

A Figura 16 apresenta os diagramas de EIE para amostras de AA1050 Polidas após $12 \mathrm{~h}$ e $14 \mathrm{~h}$ de imersão em solução de ensaio utilizando ECS ou ESM.

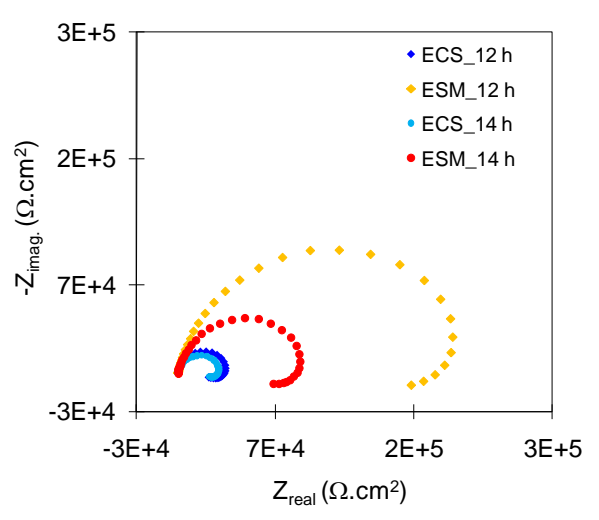

(A)

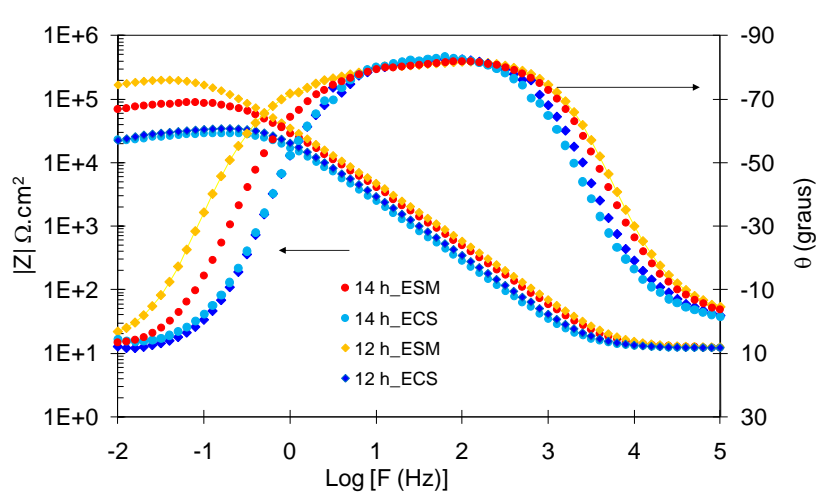

(B)

Figura 16: Diagramas de Nyquist (A) e Bode (B) para amostras de AA1050 Polidas após $12 \mathrm{~h}$ e $14 \mathrm{~h}$ de imersão em solução de $0,5 \mathrm{~mol} \mathrm{~L}^{-1} \mathrm{Na}_{2} \mathrm{SO}_{4}, \mathrm{pH}=4,0$, utilizando ECS ou ESM.

Nos diagramas de EIE das Figuras 15 e 16 é possível observar que, quando utilizado o ESM, os valores de impedância se mostraram muito superiores aos obtidos em relação ao ECS. 
As medidas para $10 \mathrm{~h}$ de imersão em solução de ensaio utilizando o ESM não apresentaram o comportamento indutivo como pode ser observado nos diagramas da Figura 15. Apenas a partir de $12 \mathrm{~h}$ de imersão foi possível a observação desse comportamento (Figura 16). Em comparação com o ECS, após $10 \mathrm{~h}$ de imersão o comportamento indutivo já estava presente, além dos valores de impedância (IZI) se mostrarem bem inferiores (1 ordem de grandeza) em comparação aos obtidos com ESM.

As Figuras $17(\mathrm{~A})$ e $17(\mathrm{~B})$ apresentam os diagramas de Nyquist e as Figuras $17(\mathrm{C})$ e $17(\mathrm{D})$ os diagramas Bode para amostras "Polidas" nas duas condições, quando utilizado ECS ou ESM, após os tempos de aquisição das medidas EIE de 14, 16, 18, 20, 22, e $24 \mathrm{~h}$.

Uma comparação com os resultados obtidos com ESM no mesmo período de imersão, mostra que para este eletrodo de referência ocorre redução dos valores de impedância entre 14 e 18 h, observando-se que pra 14 h, os valores obtidos com ESM erram aproximadamente três vezes maiores que para o ECS, mas a partir de $20 \mathrm{~h}$ estes se tornam mais similares. 


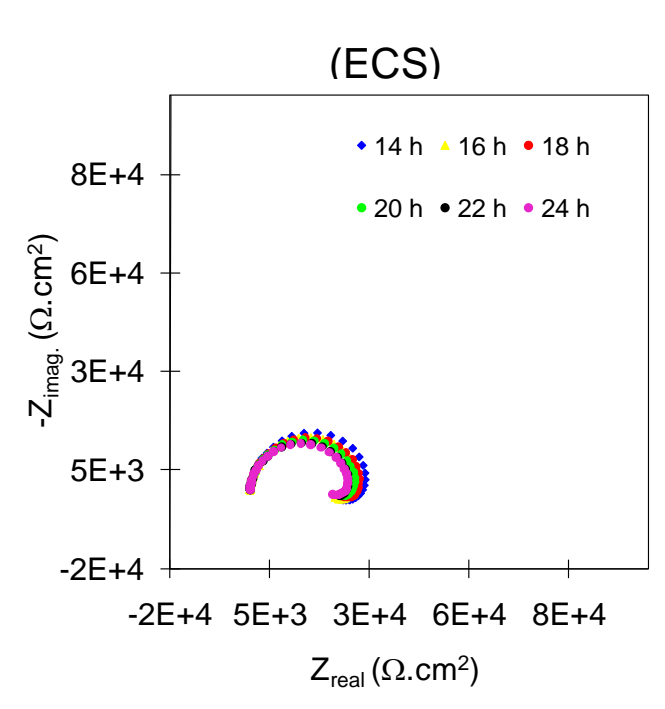

(A)

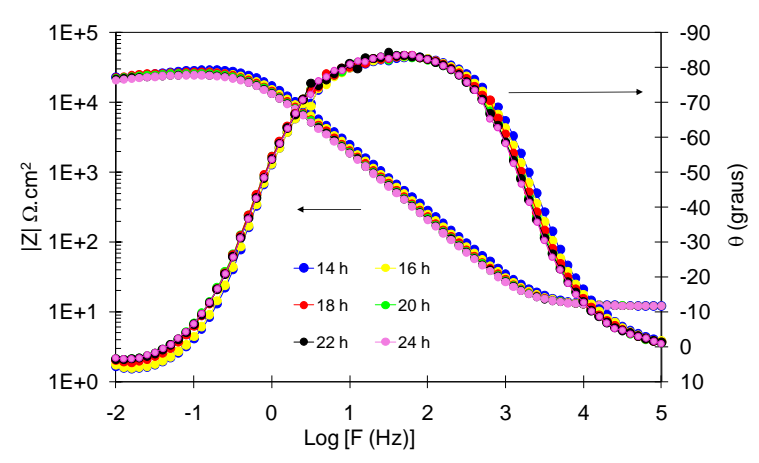

(C)

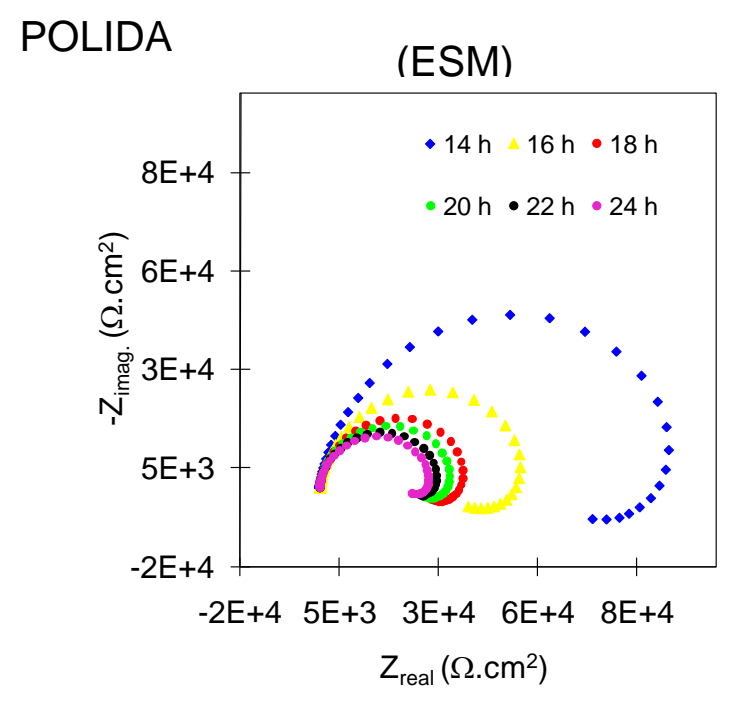

(B)

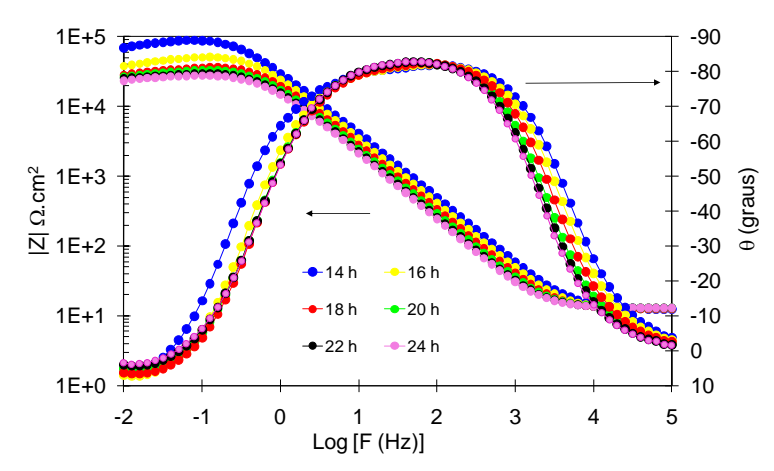

(D)

Figura 17: Diagramas de Nyquist (A) e (B) e Bode (C) e (D) para amostras "Polida" de AA1050 após 14, 16, 18, 20, 22 e 24 h de imersão em solução de 0,5 mol L-1 $\mathrm{Na}_{2} \mathrm{SO}_{4}, \mathrm{pH}=4,0$, utilizando ECS ou ESM na realização das medidas.

As Figuras 18(A) e (B) apresentam os diagramas de EIE para amostras de AA1050 Polidas após 24 h de imersão em solução de ensaio utilizando ECS ou ESM. Neste período de imersão, os diagramas de Bode se mostraram muito próximos e praticamente sobrepostos, Figura 18(B). Isto sugere que para períodos superiores a $24 \mathrm{~h}$ de imersão, qualquer um dos dois eletrodos de referência poderia ser utilizado nos estudos de corrosão do alumínio em meios de sulfato. 


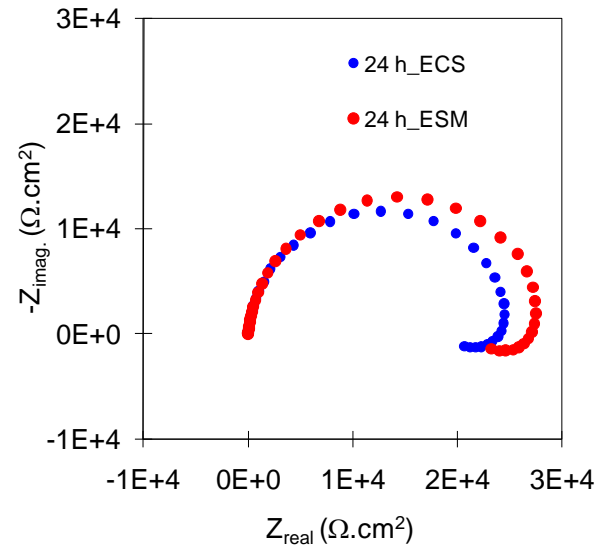

(A)

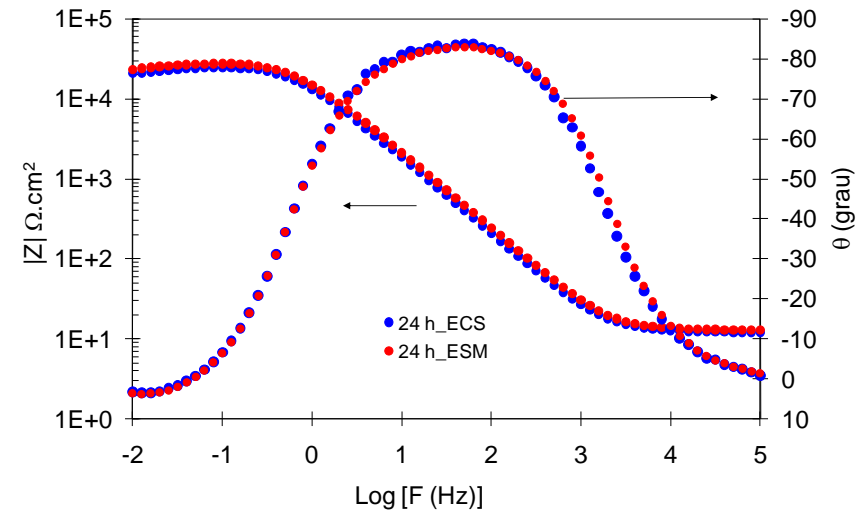

(B)

Figura 18: Diagramas de EIE das amostras Polidas de AA1050 Nyquist $(A)$ e (B) Bode para $24 \mathrm{~h}$ de imersão em solução de $0,5 \mathrm{~mol} \mathrm{~L}^{-1} \mathrm{Na}_{2} \mathrm{SO}_{4}, \mathrm{pH}=4,0$ utilizando ECS ou ESM.

As curvas de polarização anódicas obtidas após 3 dias de imersão em solução de ensaio para os dois tipos de eletrodo (ECS ou ESM) são apresentadas na Figura 19.

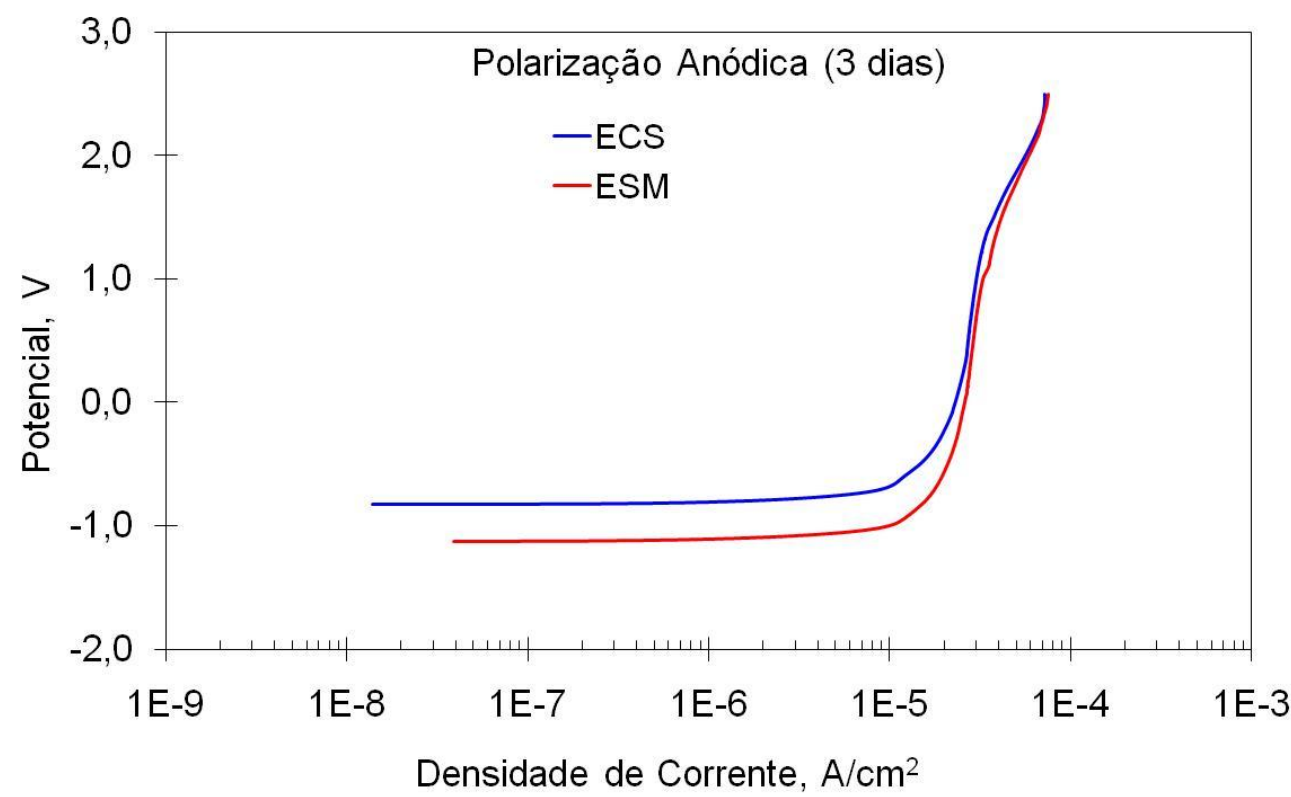

Figura 19: Curvas de polarização anódica obtidas para amostras Polidas de AA1050 usando ECS ou ESM após 3 dias de imersão em solução de $0,5 \mathrm{~mol} \mathrm{~L}^{-1}$ $\mathrm{Na}_{2} \mathrm{SO}_{4}, \mathrm{pH}=4,0$. 
As curvas de polarização da Figura 19 mostram potenciais de corrosão mais nobre para o ensaio realizado com eletrodo ECS em comparação ao ESM, sendo esta diferença atribuída à diferença de potencial entre eles $(0,4 \mathrm{~V})$.

Os resultados de polarização apóiam os resultados de EIE, pois após 3 dias de imersão em solução de ensaio, as amostras polarizadas anodicamente também apresentaram comportamento similar, confirmando que a influência da contaminação do meio por íons $\mathrm{Cl}^{-}$do ECS não afeta significativamente o comportamento eletroquímico do alumínio para tempos de imersão de $24 \mathrm{~h}$ ou superiores.

\subsubsection{AA1050 submetido ao tratamento $\mathrm{Cr}$ VI}

As Figuras 20(A) e 20(B) apresentam a evolução dos diagramas de Nyquist e de Bode, respectivamente, para o AA1050, com tratamento de cromatização em solução com $\mathrm{Cr}(\mathrm{VI})$, em função do tempo de imersão na solução de ensaio, como descrito na seção 5.3.1.

De forma análoga ao alumínio com tratamento $\mathrm{PB}$, observa-se a presença de um arco capacitivo em altas a médias frequências e um arco indutivo na região de baixas freqüências. É possível observar que os valores de impedância sofreram uma pequena diminuição com o tempo de exposição ao eletrólito, particularmente entre 2 e 3 dias de imersão, indicando também a degradação da camada passiva superficial para o tratamento de cromo hexavalente. Isto ocorre devido à penetração de íons agressivos do meio, através das falhas e poros do filme passivo [Campestrini et al., 2001].

Os diagramas de Nyquist e de Bode mostraram que o mecanismo permanece o mesmo ao longo do tempo de ensaio. 


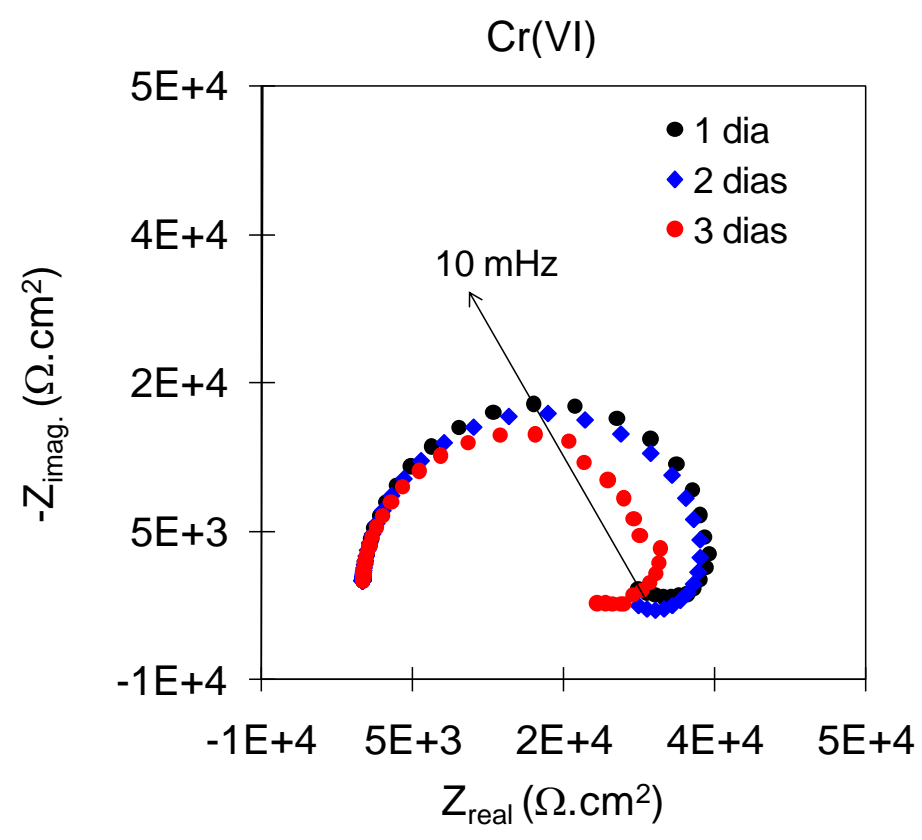

(A)

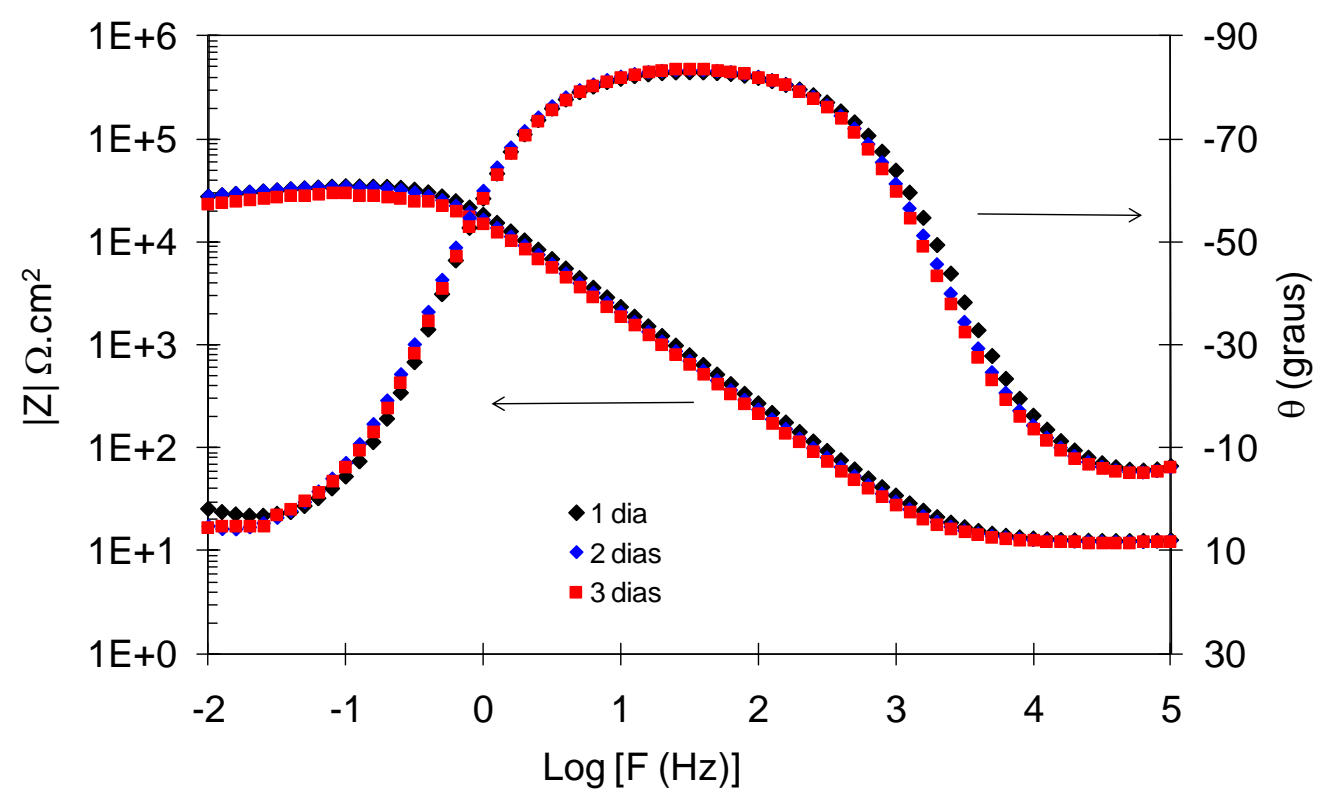

(B)

Figura 20: Diagramas de impedância obtidos para alumínio AA $1050 \mathrm{com}$ tratamento $\mathrm{Cr}(\mathrm{VI})$ em função do tempo de imersão na solução de $0,5 \mathrm{~mol} \mathrm{~L}^{-1}$ $\mathrm{Na}_{2} \mathrm{SO}_{4}, \mathrm{pH}=4,0$ (a) Nyquist e (b) Modulo de $\mathrm{Z}$ e ângulo de fase.

A Figura 21 apresenta as curvas de polarização anódica, obtidas para o alumínio AA1050 com tratamento de cromatização $\mathrm{Cr}(\mathrm{VI})$ para vários tempos de imersão na solução de ensaio. 


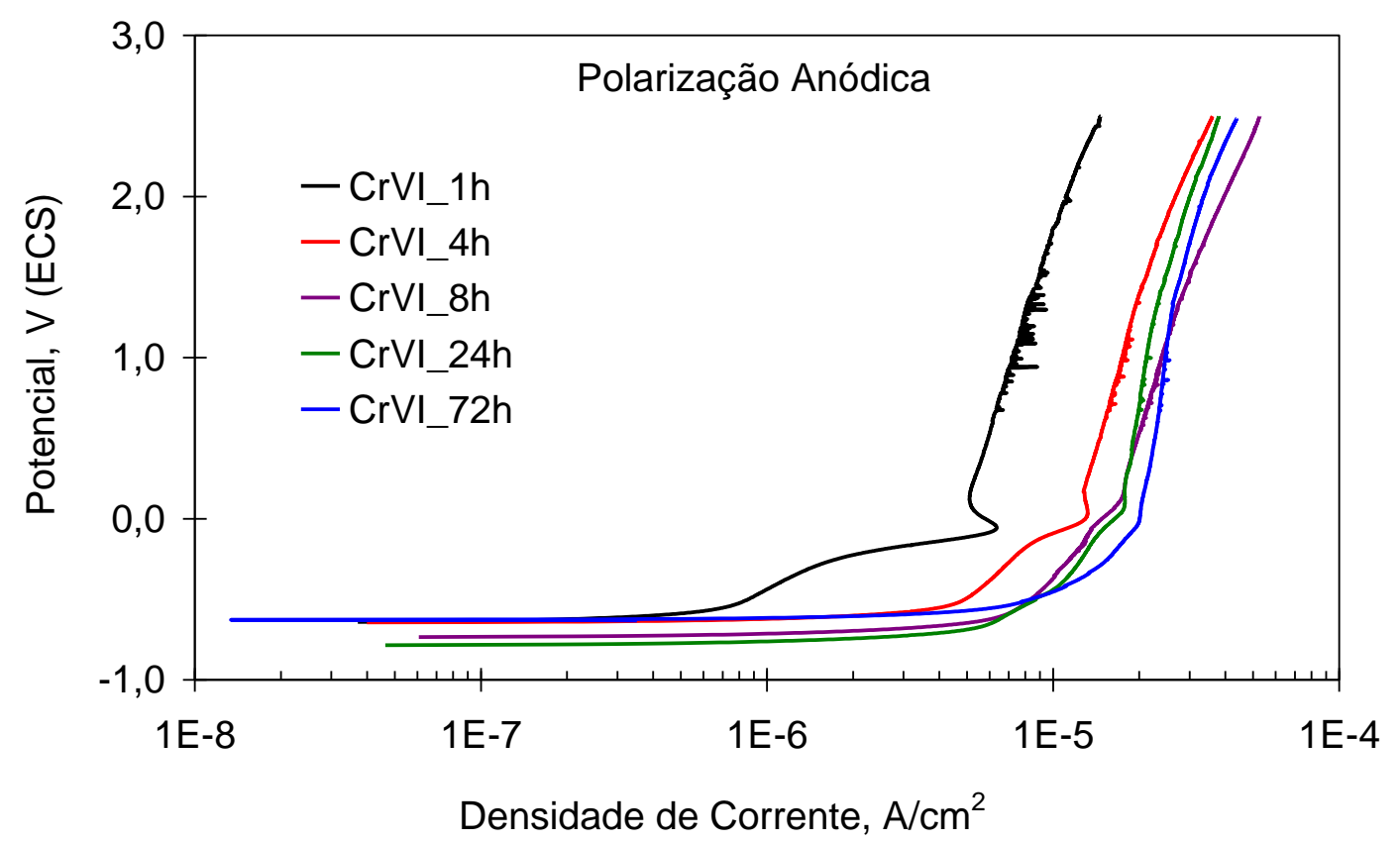

Figura 21: Polarização anódica obtida para alumínio AA 1050 com tratamento $\mathrm{Cr}(\mathrm{VI})$ em função do tempo de imersão na solução de $0,5 \mathrm{~mol} \mathrm{~L}^{-1} \mathrm{Na}_{2} \mathrm{SO}_{4}, \mathrm{pH}=$ 4,0 .

Os resultados de polarização anódica das amostras submetidas ao tratamento com cromo hexavalente obtidos em vários tempos de imersão mostraram correntes menores para os menores tempos de imersão e indicam que a superfície se deteriora entre $1 \mathrm{~h}$ e $8 \mathrm{~h}$ de imersão. Uma comparação com os resultados referentes ao tratamento PB (Figura 12) sugere a formação de um filme menos permeável no tratamento com $\mathrm{Cr}(\mathrm{VI})$, com maior resistência à passagem de corrente para os períodos de exposição ao eletrólito correspondentes a $1 \mathrm{~h} \mathrm{e} 4 \mathrm{~h}$.

A deterioração da superfície tratada com cromo hexavalente é aparentemente mais lenta do que a resultante do tratamento PB, observando-se que, entre 24 h e 72 h de imersão, há aumento das densidades de corrente. Para o tratamento com cromo hexavalente, de forma similar ao tratamento PB, observou-se que as densidades de corrente foram da ordem de $10^{-5} \mathrm{~A} / \mathrm{cm}^{2}$ mesmo em potenciais elevados de polarização. Estes valores são característicos de filmes passivos e durante a polarização, até potenciais de aproximadamente 2,5 $\mathrm{V}_{\mathrm{ECS}}$ não se observou aumento de corrente típico de quebra localizada, apesar da 
tendência à ocorrência de pites metaestáveis em potenciais de aproximadamente $0,7 \mathrm{~V}_{\mathrm{ECS}}$, indicada pelas pequenas instabilidades de corrente.

\subsubsection{AA1050 submetido ao tratamento SAM}

$\mathrm{Na}$ Figura 22 são apresentados os diagramas de impedância para o alumínio 1050 após tratamento por imersão em solução com SAM. Para um dia de imersão os resultados mostraram maiores impedâncias em relação aos dois tratamentos anteriores ( $\mathrm{PB}$ e $\mathrm{Cr}(\mathrm{VI})$ ) e diminuição da impedância entre o primeiro e o segundo dia de imersão, sugerindo que nesse período houve uma significativa degradação da superfície com tratamento em SAM, e um pequeno aumento da impedância entre o segundo e o terceiro dia de ensaio.

Uma possível explicação para tal resultado é que para o menor período de ensaio entre os testados ( $1 \mathrm{dia}$ ), a amostra tratada com SAM contém menos precipitados, pois parte foi removida durante as 3 horas de imersão em solução de SAM $(\mathrm{pH}=3,0)$, apresentando menor atividade na solução de ensaio $(\mathrm{pH}=$ 4,0), indicada pela maior impedância, frente aos tratamentos PB e CrVI. Ao se remover as amostras de alumínio AA1050 da solução de SAM, enxaguá-las e secá-las, o processo de corrosão é atenuado e ocorre crescimento de um óxido fino superficial, o qual será formado sobre uma superfície mais "limpa", porém com maior quantidade de cavidades. Ao se imergir estas superfícies em solução de ensaio $(\mathrm{pH}=4,0)$, ter-se-ia inicialmente a predominância dos efeitos benéficos da remoção de precipitados mais ativos, devido à menor agressividade do eletrólito. Outro fator a ser considerado é o de que essa maior impedância poderia ser causada pela adsorção de moléculas auto-organizáveis na superfície do óxido, contribuindo ainda mais para sua maior resistência.

A grande diminuição da impedância entre um e dois dias de ensaio, por sua vez, pode ser conseqüência da baixa estabilidade das moléculas adsorvidas e da remoção das mesmas nas regiões próximas aos precipitados, gerando locais de maior susceptibilidade à corrosão localizada [Suegama et al., 2010]. Além disso, a remoção de precipitados seria responsável pela formação de cavidades 
na superfície da amostra, que atuariam como sítios de nucleação de pites. Vale ressaltar que a solução de SAM usada é ácida $(\mathrm{pH}=3,0)$ e o tratamento foi realizado por 3 horas, promovendo o ataque corrosivo nas regiões de maior atividade, correspondentes à interface matriz/precipitados. O ataque corrosivo favorece a remoção destes últimos da superfície, conforme ilustra a Figura 10(b).

Entre 2 e 3 dias foi observado um pequeno aumento de impedância, o que poderia ser explicado tanto pelo processo de repassivação, quanto pelo "preenchimento" dos sítios ativos por produtos de corrosão.

Uma separação nítida de duas constantes de tempo pode ser observada no diagrama de Bode (Figura 22B) correspondente a um dia de imersão, com a primeira constante de tempo ocorrendo em freqüências da ordem de $1 \mathrm{kHz}$, e a segunda a $1 \mathrm{~Hz}$. A constante de tempo a mais altas freqüências (1 kHz) deve-se provavelmente à combinação do filme óxido com moléculas auto-organizáveis, enquanto aquela a médias freqüências $(1 \mathrm{~Hz})$ a processos de transferência de carga associados a carregamento da dupla camada elétrica. A interação destas duas constantes de tempo é causada, provavelmente, pela deterioração da camada de óxido+SAM no meio corrosivo, permitindo a exposição de maiores áreas ativas do substrato ao eletrólito e o aumento da atividade eletroquímica deste. 


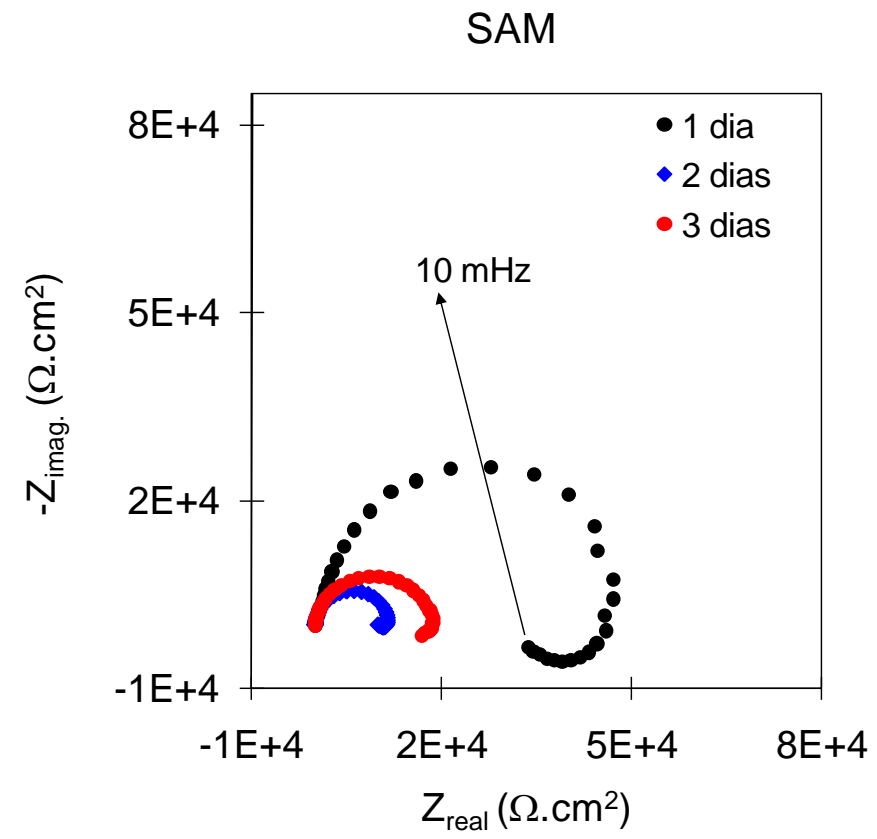

(A)

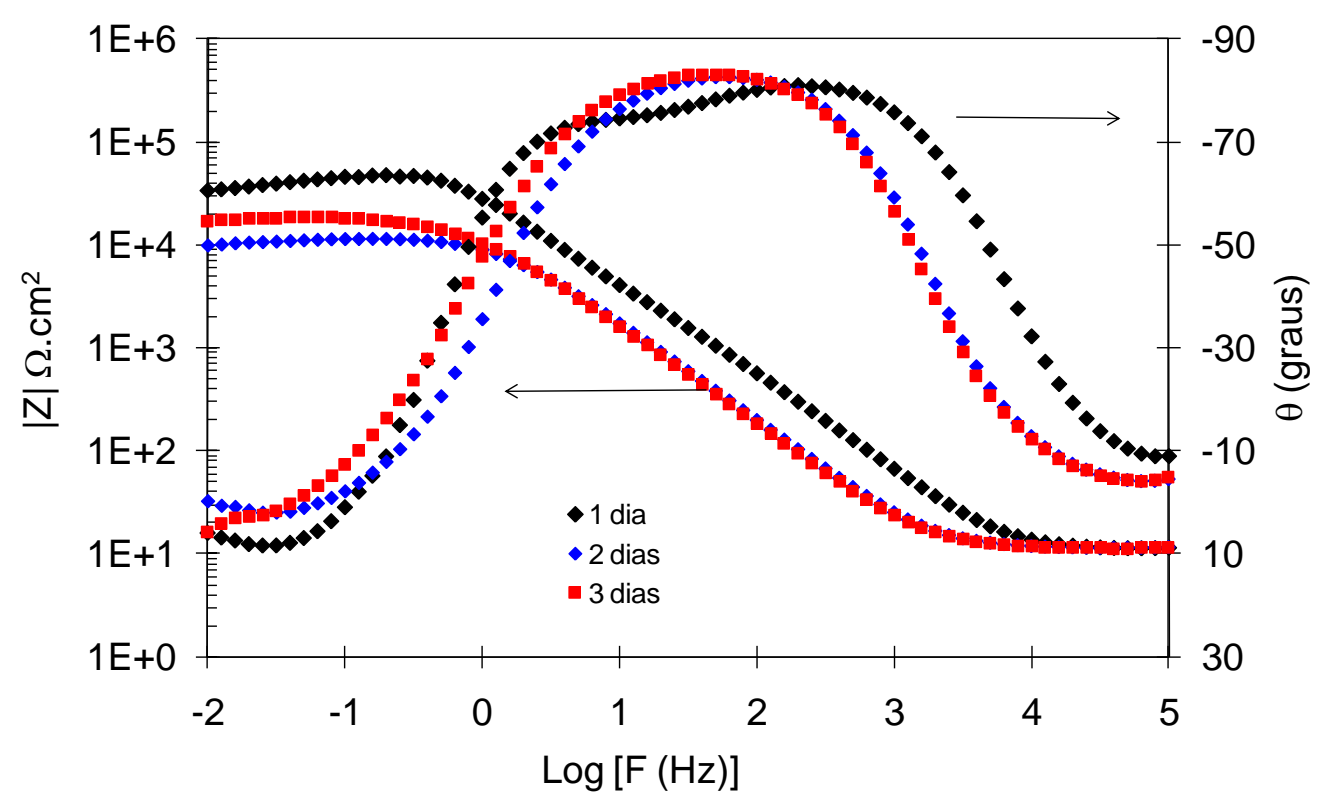

(B)

Figura 22: Diagramas de impedância obtidos para alumínio AA $1050 \mathrm{com}$ tratamento SAM em função do tempo de imersão na solução de ensaio $(A)$ Nyquist e (B) Modulo de $Z$ e ângulo de fase.

A Figura 23 apresenta as curvas de polarização anódica do alumínio AA1050 com tratamento SAM para vários tempos de imersão na solução de ensaio. Os resultados sugerem degradação do filme passivo entre $1 \mathrm{~h}$ e $8 \mathrm{~h}$ de exposição ao eletrólito teste. Todavia, a comparação entre as correntes passivas 
obtidas para 8 h e 24 h, sugere aumento da resistência da superfície neste último período. Porém as oscilações de corrente observadas na região passiva para o período de imersão correspondente a $24 \mathrm{~h}$ indica nucleação de pites metaestáveis. Esta observação parece ser confirmada pela definição de um potencial de pite, claramente obtido para $72 \mathrm{~h}$ de exposição. Estes resultados apóiam os resultados obtidos por EIE que mostraram elevada impedância para 24 h de imersão e grande diminuição desta entre 24 h e 72 h de ensaio. Apenas para o último período de imersão (72 h), observou-se a tendência à quebra do filme passivo em potenciais de cerca de $-0,26 \mathrm{~V}_{\mathrm{ECS}}$, enquanto que para os menores tempos de ensaio, os valores de corrente foram da ordem de $10^{-6} \mathrm{~A} / \mathrm{cm}^{2}$ mesmo para potenciais elevados.

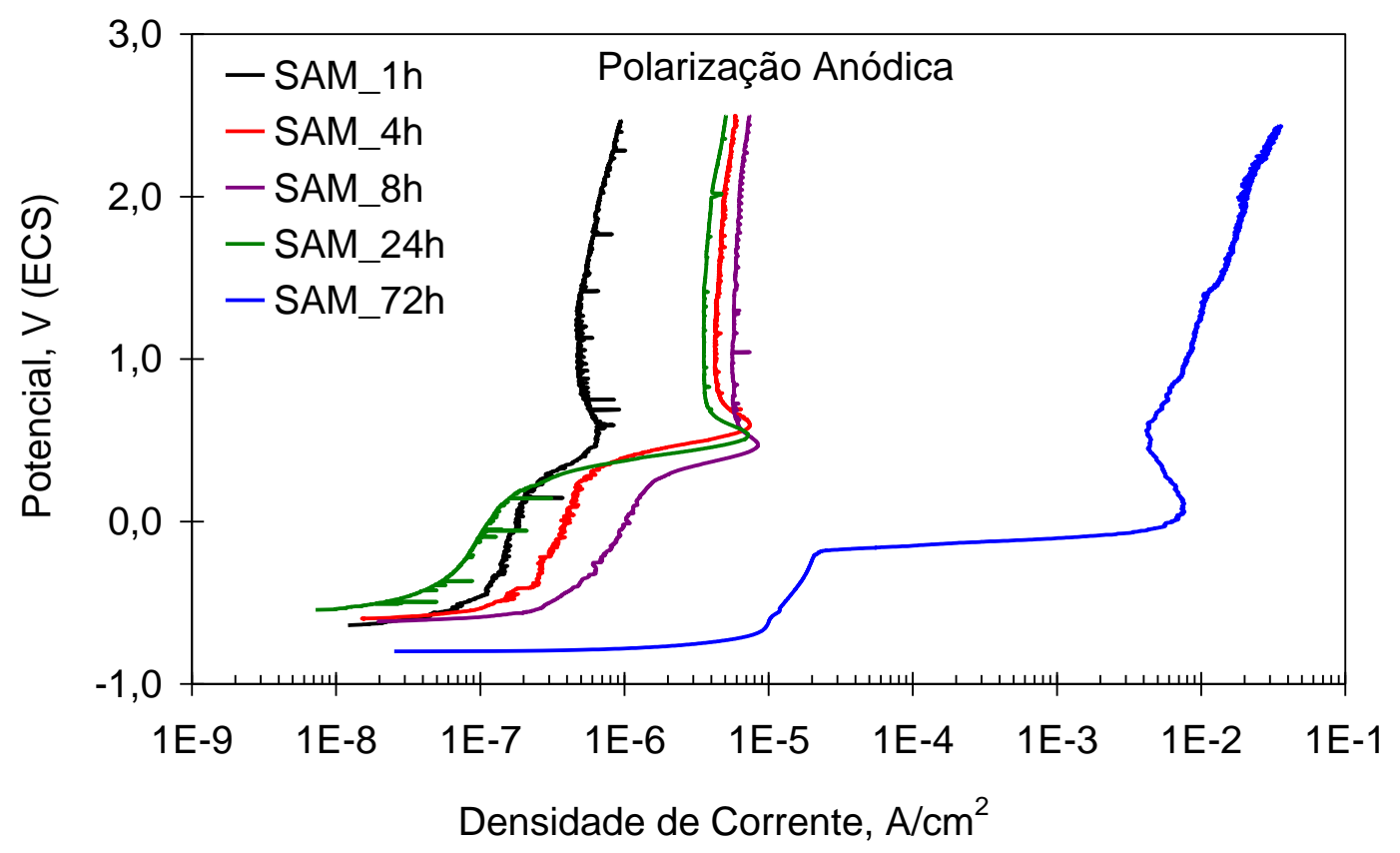

Figura 23: Curvas de polarização anódica obtidas para alumínio AA 1050 com tratamento SAM em função do tempo de imersão na solução de $0,5 \mathrm{~mol} \mathrm{~L}^{-1}$ $\mathrm{Na}_{2} \mathrm{SO}_{4}, \mathrm{pH}=4,0$.

A superfície da amostra exposta por 72 h ao eletrólito teste e então polarizada foi observada por microscopia eletrônica de varredura (MEV) sendo identificados pites de várias dimensões. Em algumas amostras observou-se pites após 3 dias imersão em solução de $0,5 \mathrm{~mol} \mathrm{~L}^{-1} \mathrm{Na}_{2} \mathrm{SO}_{4}, \mathrm{pH}=4,0$, que podem ser observados na Figura 24(A). Após a polarização anódica, estes pites se tornaram muito mais profundos e aparecem em maior quantidade, fato este que explica o 
aumento dos valores de densidade corrente para valores da ordem de $10^{-2} \mathrm{~A} / \mathrm{cm}^{2}$, Figura 24(B).

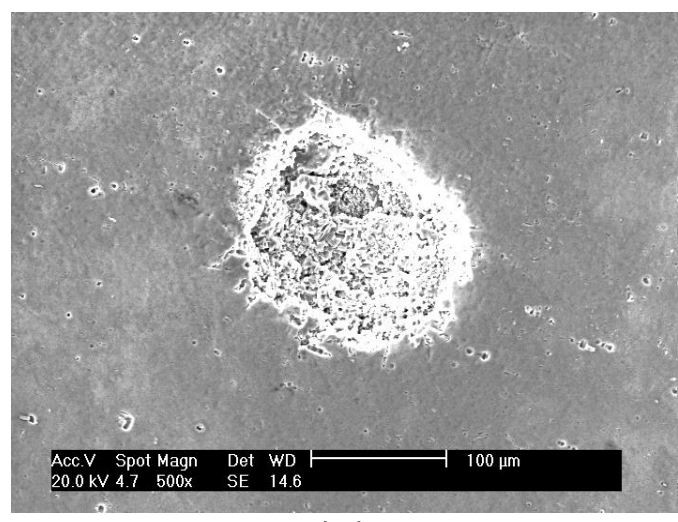

(A)

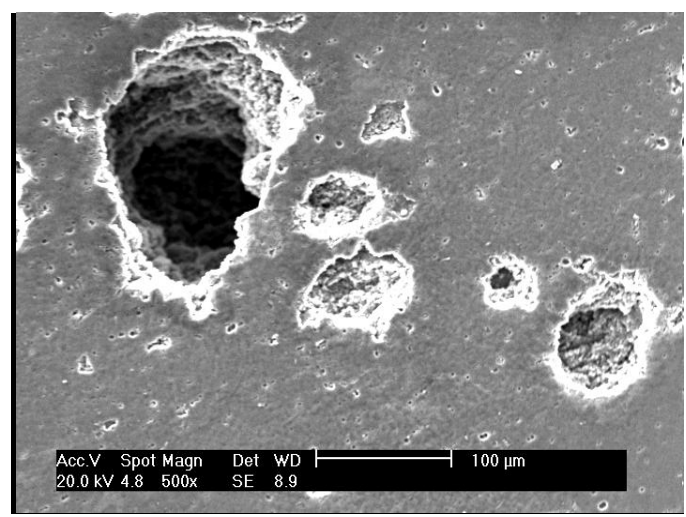

(B)

Figura 24: Micrografia por MEV do alumínio AA1050 após tratamento SAM, seguido por imersão durante 3 dias em solução de $0,5 \mathrm{~mol} \mathrm{~L}^{-1} \mathrm{Na}_{2} \mathrm{SO}_{4}, \mathrm{pH}=4,0$ (A) e após polarização anódica (B).

\subsubsection{AA1050 submetido ao tratamento OX}

A Figura 25 apresenta a variação das curvas de potencial a circuito aberto (PCA) para o alumínio AA1050 com tratamento OX, durante um intervalo de $1 \mathrm{~h}$ anterior à realização dos ensaios de EIE para o tempo de 1 e 3 dias de imersão na solução de $0,5 \mathrm{~mol} \mathrm{~L}^{-1} \mathrm{Na}_{2} \mathrm{SO}_{4}, \mathrm{pH}=4,0$. Observa-se nesta figura, elevada estabilidade do potencial após 1 dia de imersão e indicação de ataque por pites após 3 dias. Supõe-se que as espécies agressivas do meio levam até 3 dias para se difundirem através das porosidades/defeitos no óxido crescido artificialmente e atingirem o substrato metálico, retardando o início de um ataque localizado. A recuperação exponencial do potencial com o tempo observada na curva após 3 dias de imersão, sugere a repassivação do pite, mostrando que este não atinge o estágio de crescimento e propagação. 


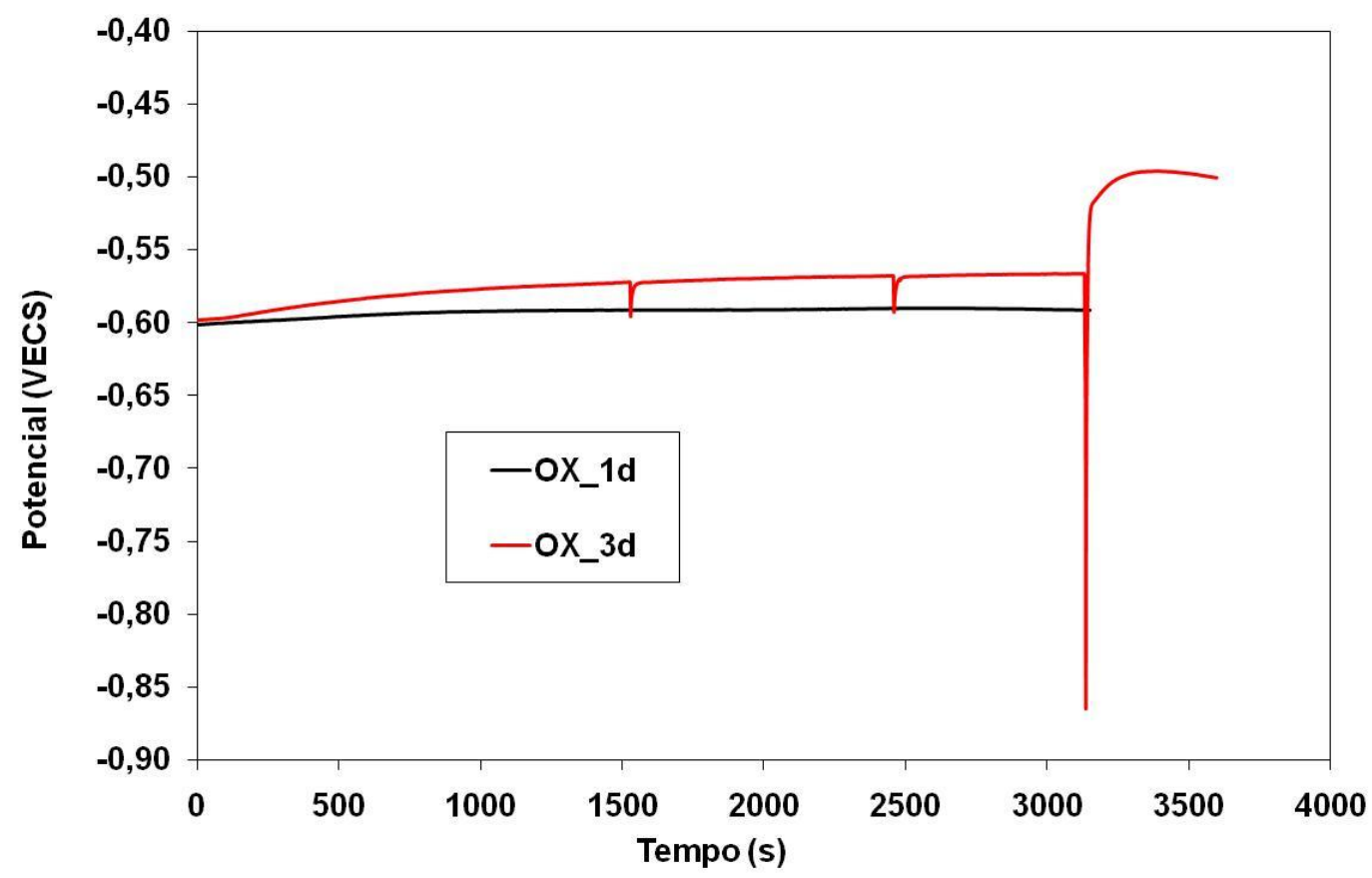

Figura 25: Variação potencial a circuito aberto (PCA) durante 1 hora para 0 alumínio AA1050 com tratamento OX, após 1 e 3 dias de imersão em solução de $0,5 \mathrm{~mol} \mathrm{~L}^{-1} \mathrm{Na}_{2} \mathrm{SO}_{4}$ tamponada, $\mathrm{pH}=4,0$.

As Figuras 26(A) e 26(B) apresentam os diagramas de Nyquist e Bode, respectivamente, para o alumínio AA1050, submetido ao tratamento OX em função do tempo de imersão na solução de ensaio. Maiores impedâncias foram associadas com o tratamento de imersão em água fervente para favorecer 0 crescimento de óxido (OX) em relação aos tratamentos $\mathrm{PB}, \mathrm{Cr}(\mathrm{VI})$ e $\mathrm{SAM}$. Isto se deve à resistência da camada de óxido-hidróxido formada, promovendo o aumento da impedância global.

Observa-se pelos diagramas de ângulo de fase de Bode, Figura 26(B), a indicação de 3 constantes de tempo para um dia de imersão, sendo a terceira observada em baixas freqüências. Supõe-se que a constante de tempo em baixas freqüências esteja relacionada com processos de transferência de carga e o deslocamento desta para maiores freqüências sugere o aumento da cinética destes processos entre 1 e 2 dias.

Para 2 e 3 dias, observa-se a presença de apenas duas constantes de tempo bem separadas e definidas, sendo facilmente identificadas. A constante de tempo a baixas freqüências que aparece para um dia de imersão e ocorre em 
freqüências entre $0,1 \mathrm{~Hz}$ e $0,01 \mathrm{~Hz}$ não é facilmente identificada para períodos mais longos, aparecendo apenas como um pequeno "ombro".

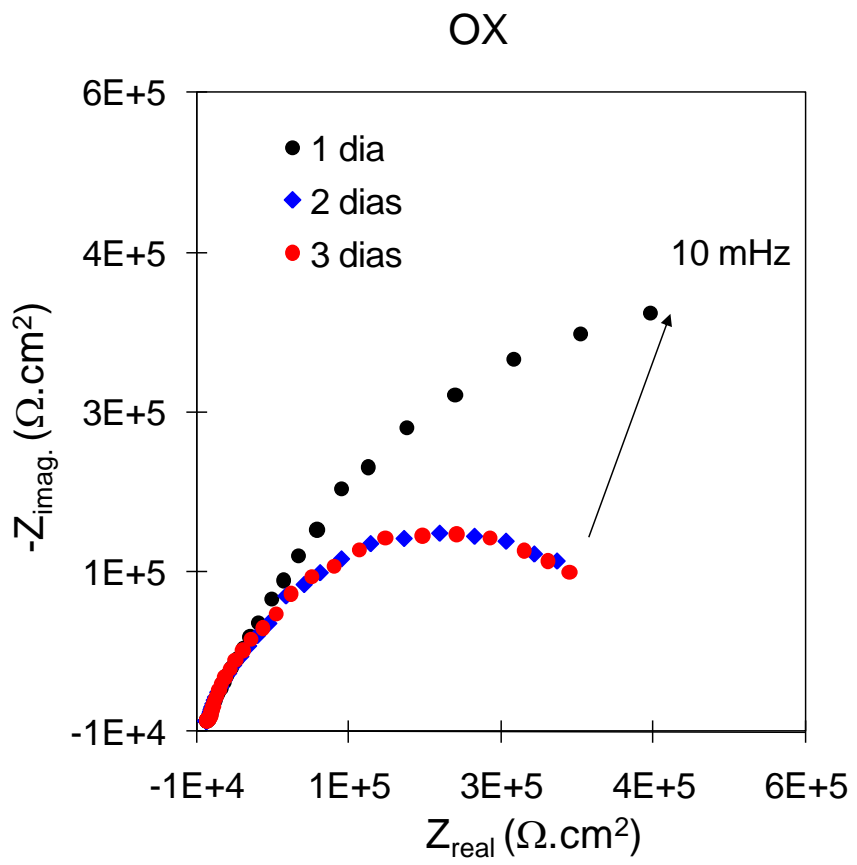

(A)

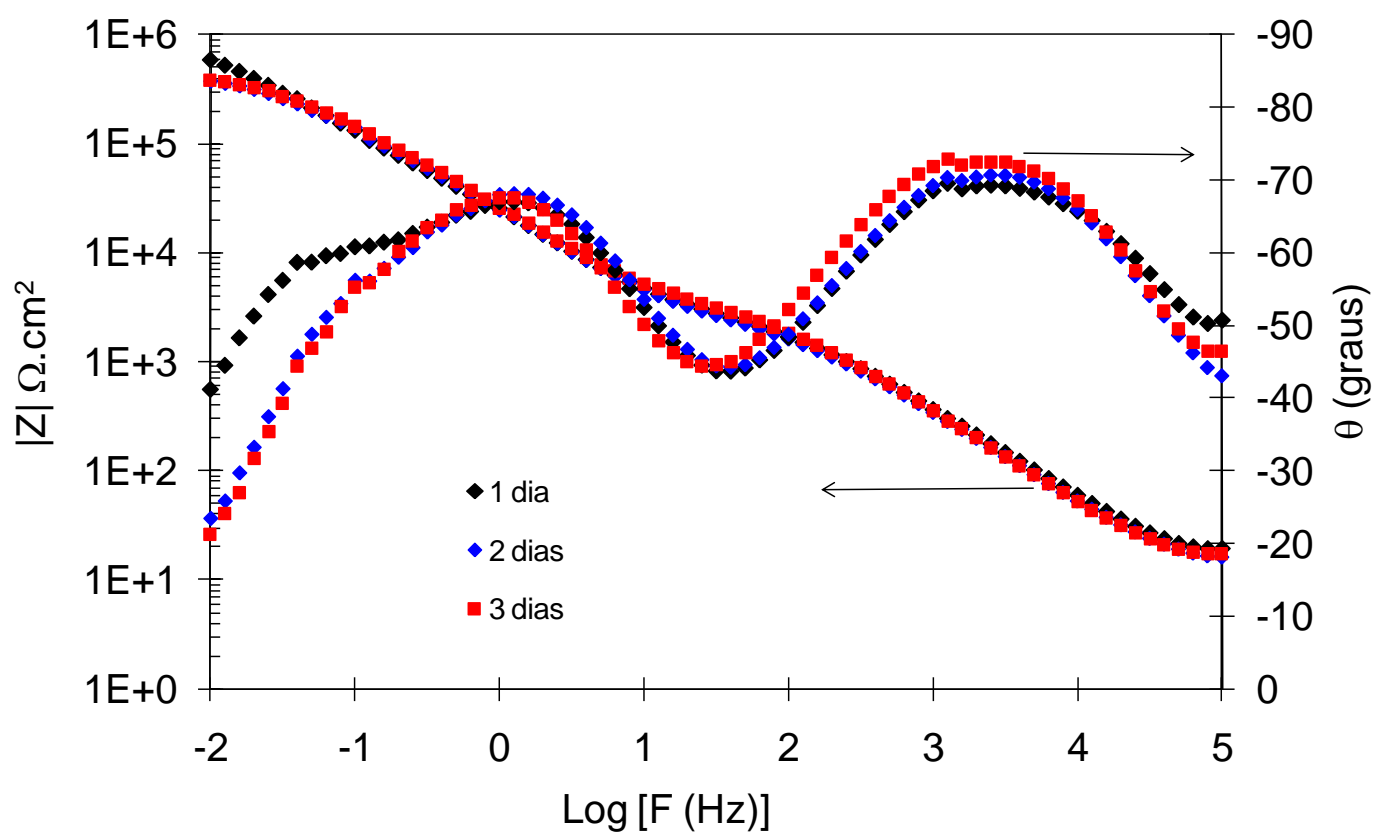

(B)

Figura 26: Diagramas de impedância obtidos para alumínio AA 1050 com tratamento para crescimento de óxido (OX) em função do tempo de imersão na solução 0,5 mol L-1 de $\mathrm{Na}_{2} \mathrm{SO}_{4}$ tamponada ( $\mathrm{pH}=4,0$ ). (A) Nyquist e (B) Módulo de $Z$ e ângulo de fase. 
A Figura 27 apresenta as curvas de polarização anódica para alumínio AA1050 com tratamento OX em vários tempos de imersão na solução de ensaio. Os resultados de polarização de amostras submetidas ao tratamento OX mostram que, entre $1 \mathrm{~h}$ e $4 \mathrm{~h}$ de imersão ocorreu um aumento do potencial de corrosão. Entre $4 \mathrm{~h}$ e $8 \mathrm{~h}$ o potencial diminui sugerindo que o filme torna-se menos permeável, provavelmente pela formação de produtos de corrosão nos defeitos do filme de oxi-hidróxido. Estes produtos não são suficientemente protetores e para $24 \mathrm{~h}$ de exposição, pois nota-se instabilidade de corrente que sugerem tendência à quebra do filme passivo.

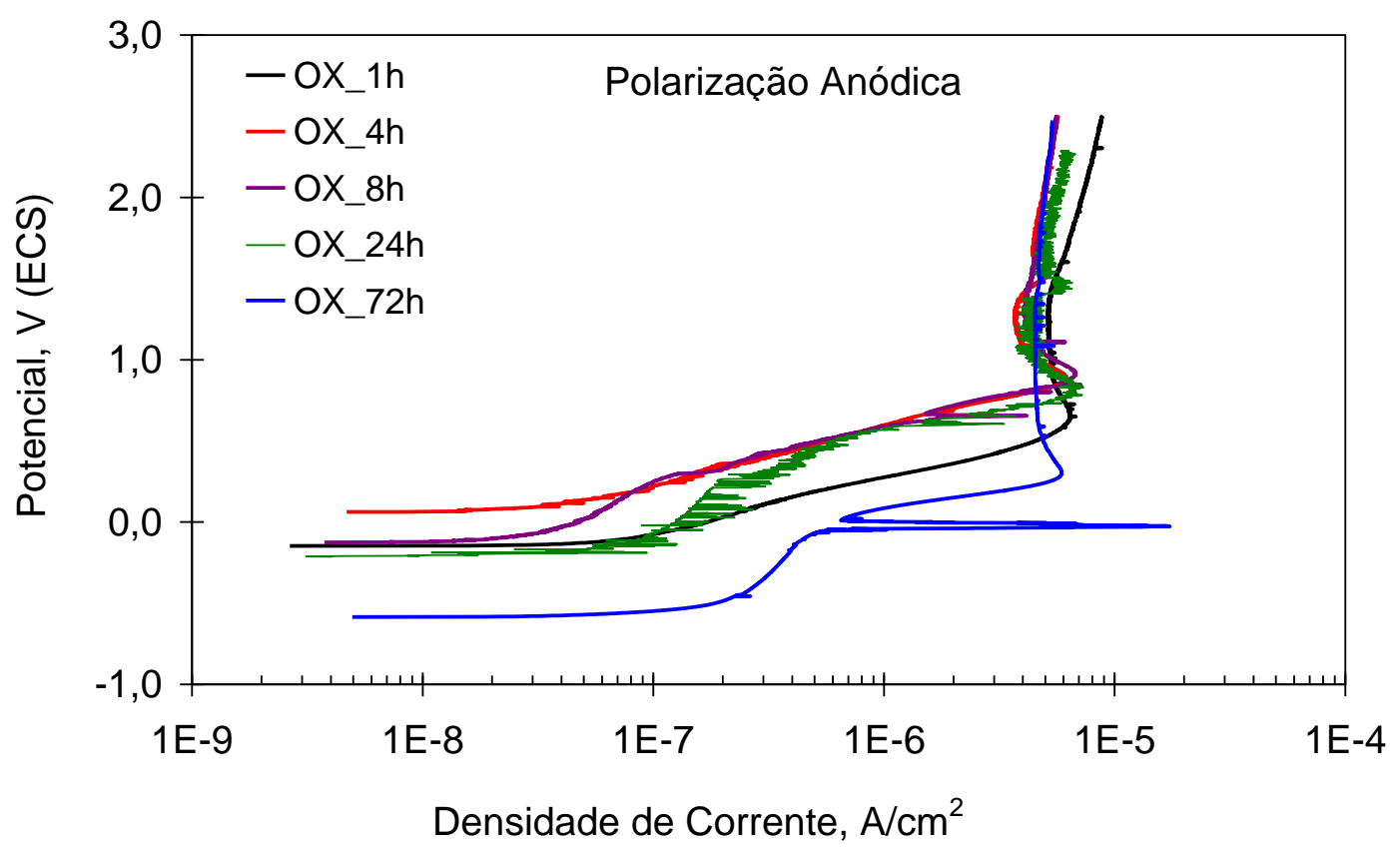

Figura 27. Curvas de polarização anódica para o alumínio AA1050 com tratamento $\mathrm{OX}$ em vários tempos de imersão em solução $0,5 \mathrm{~mol} \mathrm{~L}^{-1}$ de $\mathrm{Na}_{2} \mathrm{SO}_{4}$ $(\mathrm{pH}=4)$.

A tendência à quebra é um indício de que a camada passiva apresenta defeitos/porosidades, observando-se que, entre $24 \mathrm{~h}$ e $72 \mathrm{~h}$ de imersão o potencial diminui e as correntes através da camada passiva aumentam mostrando a diminuição da resistência desta camada. Essa hipótese também é suportada pela variação do potencial a circuito aberto em função do tempo após 3 dias de imersão, indicativo de corrosão por pite (Figura 25). 
5.3.5. AA1050 submetido ao tratamento OS

A Figura 28 apresenta a variação do potencial da superfície do alumínio AA1050 com tratamento OS em períodos que antecedem os ensaios de EIE, para tempos de imersão correspondentes a 1, 2 e 3 dias de exposição ao eletrólito. Nota-se que os potenciais referentes a este tratamento foram inferiores aos obtidos para o tratamento OX, porém não se identifica um comportamento típico de corrosão por pite, mas sim relativa estabilidade de potencial durante as medidas obtidas, embora se observem oscilações de potencial indicativas de nucleação de pites metaestáveis.

Entre um dia e dois dias de imersão ocorre aumento de cerca de $30 \mathrm{mV}$ no potencial. No entanto, este se mantém praticamente invariável entre 2 e 3 dias. Uma possível explicação para o aumento em potencial pode ser a formação de produtos de corrosão nestas regiões, o que dificultaria o acesso de novas espécies reagentes causada pela penetração do eletrólito através das porosidades/defeitos da camada de óxido-hidróxido. Por outro lado, a presença das moléculas de SAM nas regiões porosas do óxido pode ser responsável por um aumento na resistência do filme passivo.

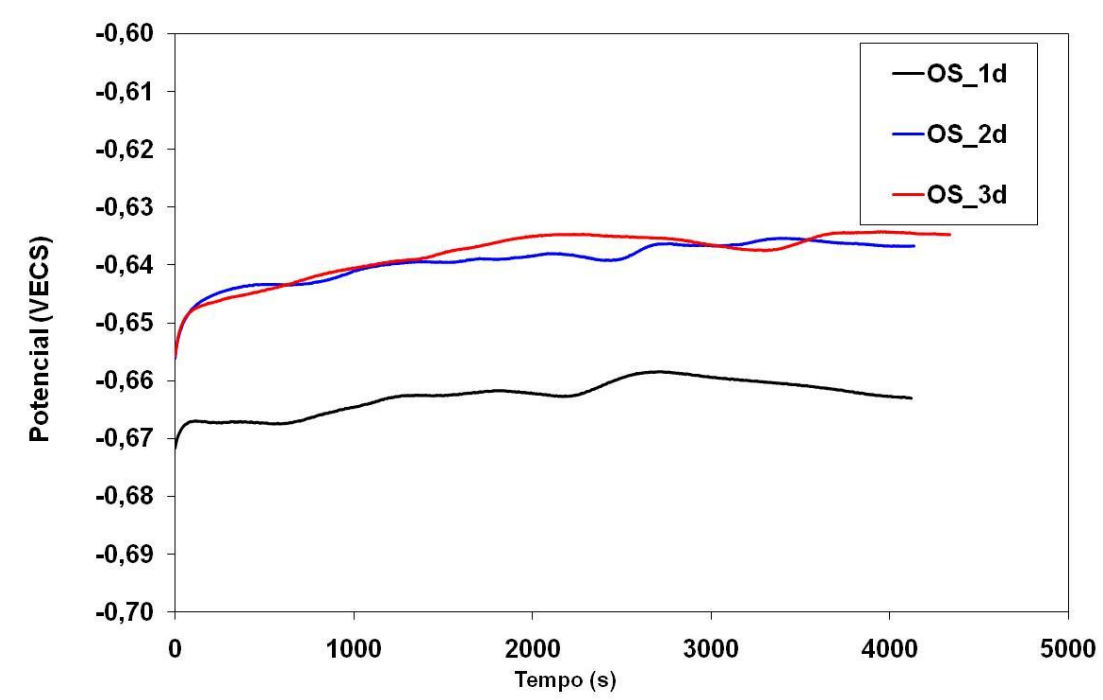

Figura 28: Variação do potencial a circuito aberto (PCA) para o alumínio AA1050 com tratamento OS em função do tempo de imersão na solução $0,5 \mathrm{~mol} \mathrm{~L}^{-1}$ de $\mathrm{Na}_{2} \mathrm{SO}_{4}(\mathrm{pH}=4,0)$. 
Os diagramas de Nyquist (Figura 29A) e de Bode (Figura 29B) indicam altas impedâncias e estabilidade da superfície, com pequeno aumento de impedância ao longo do tempo de ensaio. Estes resultados mostraram que a combinação do tratamento de crescimento do óxido com o tratamento com SAM resultou em superfícies com alta resistência à corrosão a qual foi preservada durante todo o período de ensaio (até 3 dias).

Os diagramas de Bode apresentaram duas constantes de tempo bem definidas sendo a constante em altas frequências associada ao óxido com moléculas adsorvidas, incluindo algumas regiões de porosidades, enquanto a constante a frequências mais baixas deve estar relacionada com os processos de transferência de carga nas regiões expostas do substrato.

Os elevados ângulos de fase nas baixas frequências sugerem comportamento altamente capacitivo, indicando a presença de filme protetor nestas regiões devido ao tratamento de exposição às moléculas autoorganizáveis por 3 horas. A continuação do crescimento do filme durante o período de tratamento, bem como a adsorção de moléculas de SAM podem ter causado o crescente fechamento das porosidades e, consequentemente, um aumento da resistência nestas regiões.

O pequeno aumento de impedância entre 1 e 3 dias de imersão mostrou que a precipitação de produtos de corrosão continua em solução de sulfato de sódio, sem indicação de deterioração das propriedades do filme. 


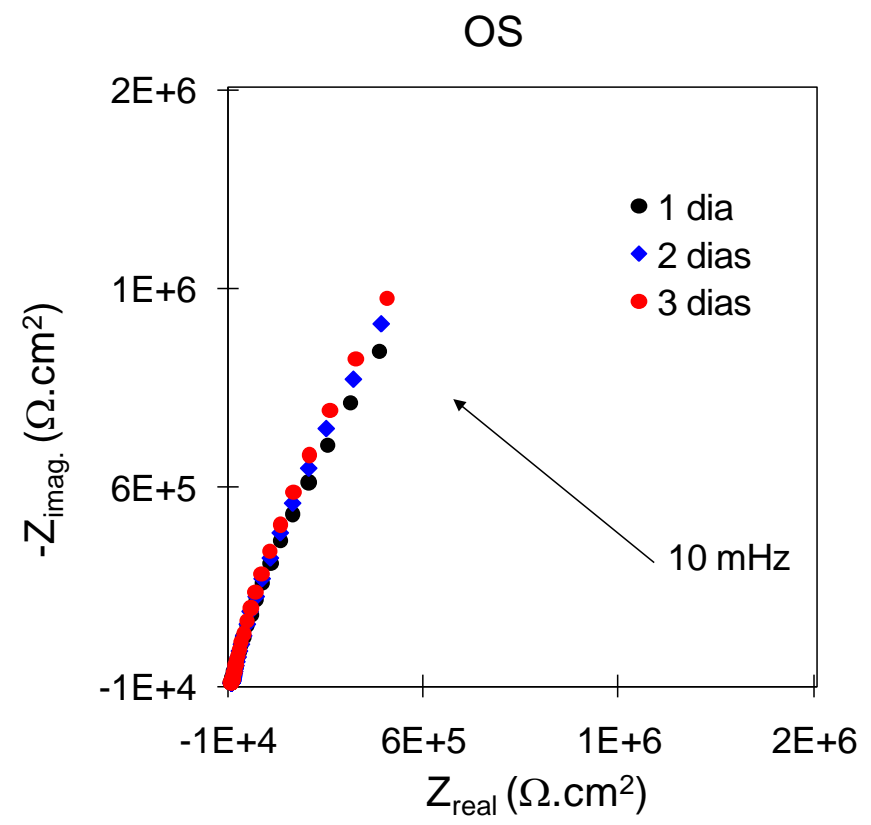

(A)

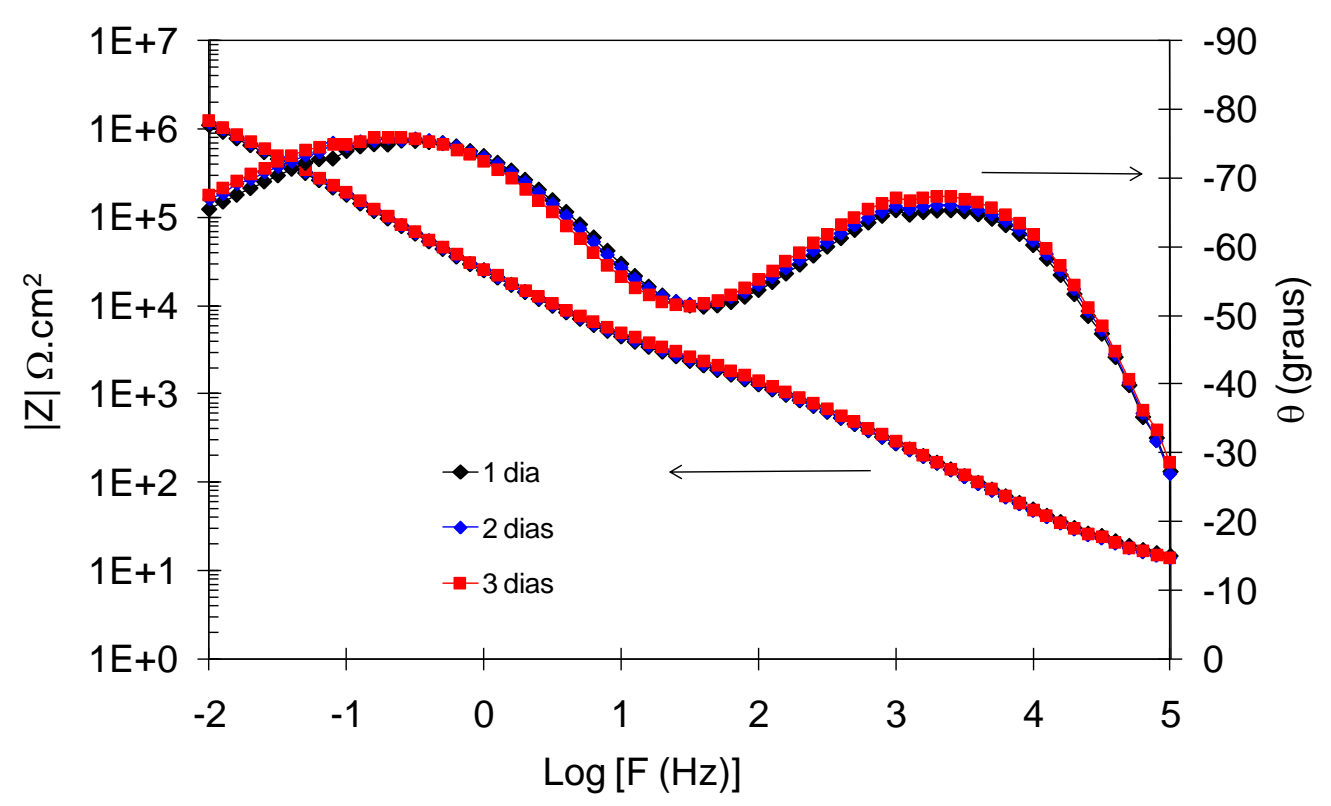

(B)

Figura 28: Evolução do comportamento eletroquímico do alumínio AA1050, após tratamento OS, em função do tempo de imersão em solução $0,5 \mathrm{~mol} \mathrm{~L}^{-1}$ de $\mathrm{Na}_{2} \mathrm{SO}_{4}(\mathrm{pH}=4,0)$ indicado por diagramas de A) Nyquist e B) Bode.

As curvas de polarização anódica em vários tempos de imersão do alumínio AA1050 com tratamento OS são mostradas na Figura 29. Valores extremamente baixos de corrente (ordem de $10^{-7} \mathrm{~A} / \mathrm{cm}^{2}$ ) foram observados para 
todos os tempos de imersão nas amostras OS. Todavia, uma grande oscilação de corrente é observada em uma ampla faixa de potenciais, indicando alta instabilidade, principalmente para tempos de imersão entre 1 h e 8 h, o que apóia a hipótese de atividade continuada durante a imersão na solução de ensaio.

A comparação das curvas obtidas para $8 \mathrm{~h}$ e $24 \mathrm{~h}$ de imersão indica diminuição das oscilações e dos valores de corrente, o que sugere melhoria nas características protetoras do filme neste período, confirmando os resultados de EIE. Entre $24 \mathrm{~h}$ e $72 \mathrm{~h}$ de imersão, o potencial diminuiu e as correntes ficaram ainda mais estáveis, provavelmente em conseqüência da polarização das reações catódicas gerada pelo crescente fechamento das porosidades e consequente diminuição da atividade superficial.

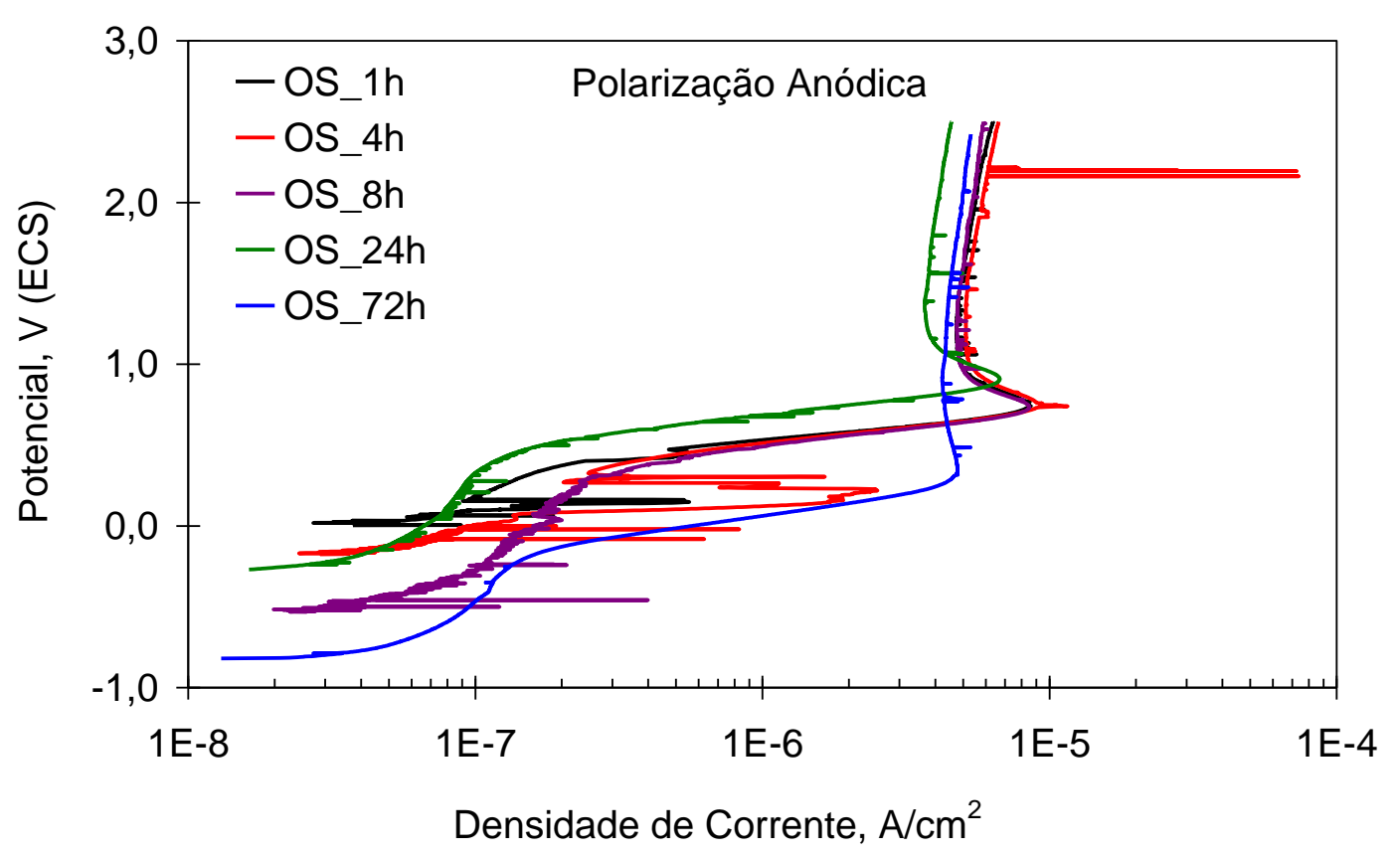

Figura 29: Curvas de polarização anódica para vários tempos de imersão do alumínio AA1050 com tratamento óxido+SAM (OS) em solução $0,5 \mathrm{~mol} \mathrm{~L}^{-1}$ de $\mathrm{Na}_{2} \mathrm{SO}_{4}(\mathrm{pH}=4,0)$.

Diferentemente dos outros tratamentos, o tratamento OS proporcionou a formação de um filme que possui alta resistência e que aumenta com o tempo de imersão em solução, provavelmente em consequência da crescente obstrução de porosidades/defeitos pela ação de produtos de corrosão de óxido-hidróxidos nestas regiões. Em todas as condições de superfície testadas, observou-se a 
indicação de uma região passiva com valores de densidade de corrente de corrosão entre $10^{-7} \mathrm{~A} / \mathrm{cm}^{2}$ e $10^{-8} \mathrm{~A} / \mathrm{cm}^{2}$.

\subsection{Estudo comparativo do desempenho dos tratamentos adotados}

O desempenho dos tratamentos adotados foi comparado utilizando os espectroscopia de impedância eletroquímica, curvas de polarização anódica e catódica, ajustes com circuitos elétricos equivalentes e microscopia eletrônica de varredura.

\subsubsection{Comparação dos ensaios eletroquímicos}

A Figura 30 apresenta a comparação dos diagramas de Nyquist para o alumínio AA1050 com os tratamentos PB, $\mathrm{Cr}(\mathrm{VI}), \mathrm{SAM}, \mathrm{OX}$ e OS para 3 dias de imersão na solução de sulfato de sódio. Estes resultados sugerem que o tratamento de imersão em água fervente (boehmitization) para crescimento de óxido-hidróxido (OX) resulta em significativo aumento na resistência à corrosão. Todavia, vale salientar, que este tratamento aparentemente também aumentou a susceptibilidade à corrosão por pite.

Também se deve observar que o tratamento com SAM resultou em alta impedância para períodos curtos de imersão (1 dia). Porém, a superfície apresentou forte degradação com o passar do tempo de exposição à solução de ensaio (Figura 22), com aumento de tendência à corrosão localizada. Após 3 dias de exposição ao eletrólito, foi notado um pequeno aumento de impedância, o que poderia ser explicado pelo tanto pelo processo de repassivação, quanto pelo "preenchimento" dos sítios ativos por produtos de corrosão.

Outra observação importante é a indicação de alta atividade eletroquímica da superfície com tratamento cromatizante em $\mathrm{Cr}(\mathrm{VI})$, que pode ser causada pelo mecanismo de proteção deste tipo de filme para promover proteção em regiões de defeitos em revestimentos.

Os maiores valores de impedância das amostras OS mostraram que não há deterioração das propriedades do filme mesmo após 3 dias de imersão. 


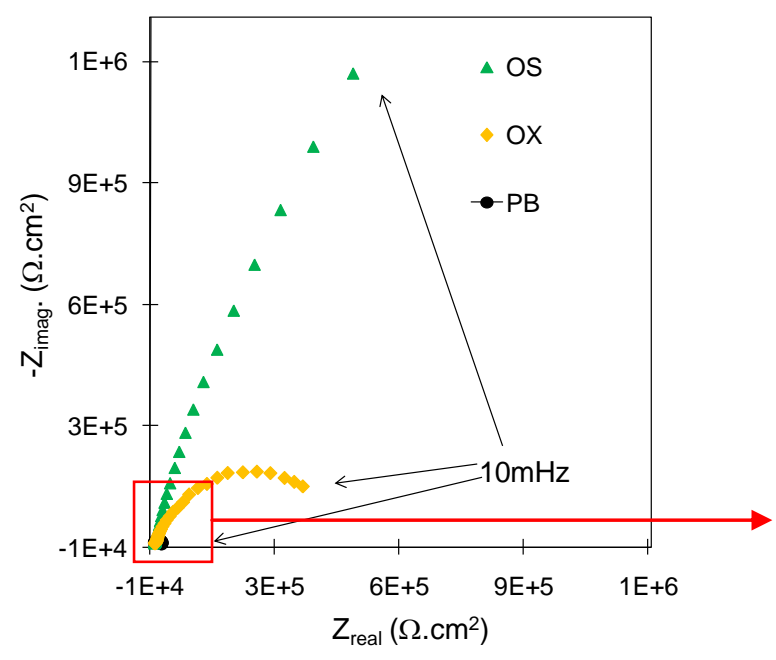

(A)

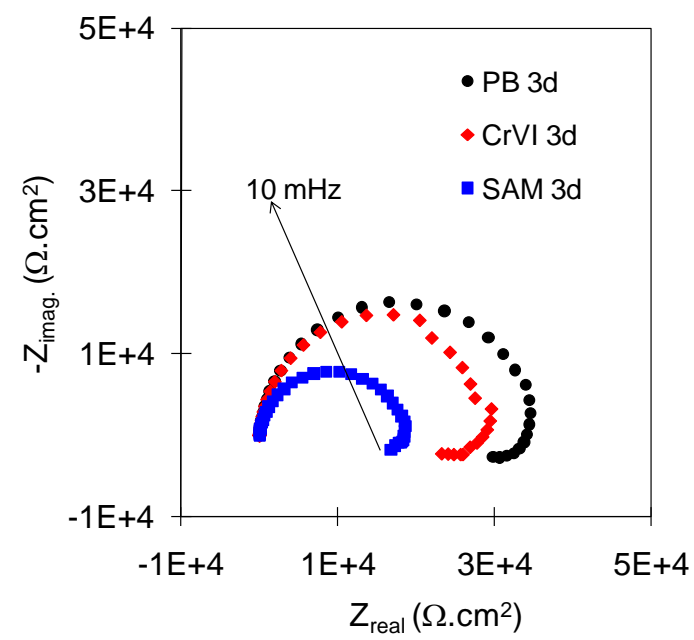

(B)

Figura 30: Diagramas de Nyquist para alumínio AA1050 com os tratamentos (A) $\mathrm{PB}, \mathrm{OX}$ e OS e (B) PB, Cr(VI) e SAM após 3 dias de imersão em solução 0,5 mol. $L^{-1}$ de $\mathrm{Na}_{2} \mathrm{SO}_{4}, \mathrm{pH}=4,0$.

A Figura 31 apresenta os diagramas de Bode correspondentes aos resultados mostrados na Figura 30. Os diagramas de ângulo de fase (Figura 31A) para os tratamentos $\mathrm{PB}, \mathrm{SAM}$ e $\mathrm{Cr}(\mathrm{VI})$ são muito similares, apresentando um pico alargado, sugerindo a interação de constantes de tempo. Este resultado mostra que o tratamento de cromatização com $\mathrm{Cr}(\mathrm{VI})$ adotado não foi muito efetivo nas condições adotadas neste estudo.

Para os tratamentos OX e OS, há uma separação nítida de duas constantes. Em estudo similar para a liga de alumínio AA 5052, a separação das constantes de tempo foi relacionada à presença de um óxido de natureza dupla, composto por uma camada externa e porosa e uma camada interna e contínua [Yoshikawa et al., 2009]. No presente estudo, foi observado que a presença da segunda constante não está relacionada com o caráter duplex do filme de óxidohidróxido proposto por Baltat-Bazia et al. [1992], mas possivelmente com a contribuição do crescimento continuado de produtos hidratados nas regiões de elevada atividade superficial. 
Os diagramas de módulo de Z (Figura 31b) mostram impedâncias da mesma ordem de grandeza nas freqüências mais baixas $\left(10^{4} \Omega . \mathrm{cm}^{2}\right)$ para os tratamentos $\mathrm{PB}, \mathrm{Cr}(\mathrm{VI})$ e SAM. Já os tratamentos OX e OS, apresentaram valores uma ordem $\left(10^{5} \Omega . \mathrm{cm}^{2}\right)$ ou duas $\left(10^{6} \Omega . \mathrm{cm}^{2}\right)$ ordens de grandeza superiores, respectivamente.

O tratamento com SAM nas condições adotadas neste estudo pode ter efeito prejudicial, a longo prazo, na resistência à corrosão do alumínio e suas ligas, caso a superfície não seja previamente preparada favorecendo-se a formação de filmes mais espessos de óxido-hidróxido de alumínio, aos quais as moléculas possuem alta afinidade, e, portanto, promovem efeito altamente benéfico. Em trabalho presente na literatura com a liga AA 5052 [Reis, 2005], foi observado que a imersão em banho ultrasônico para remoção de solução retida em pites resultantes da remoção de precipitados resultou em aumento da resistência à corrosão por pite. Além disso, de acordo com a literatura [Suegama et al., 2010], o tratamento com SAM pode não recobrir toda superfície do alumínio, principalmente nas regiões próximas a alguns tipos de precipitados na liga AA 7475 Alclad, gerando a formação de pilhas galvânicas localizadas.

O tratamento OS foi o responsável pelos maiores valores de impedância, mostrando-se uma alternativa em potencial para substituição de tratamentos à base de cromo hexavalente.

A Figura 32 apresenta a comparação das curvas de polarização anódica para o alumínio AA1050 após 3 dias de imersão em solução de ensaio. A comparação das curvas de polarização dos vários tratamentos indica o efeito benéfico da camada de óxido-hidróxido associada aos tratamentos OX e OS. Estas superfícies mostraram polarização da reação anódica, em comparação ao tratamento $\mathrm{PB}$, enquanto que para os demais tratamentos ( $\mathrm{Cr}(\mathrm{VI})$ e SAM), após 3 dias de imersão em solução de ensaio, nota-se evidente despolarização da reação anódica em comparação a amostra PB. 
(A)

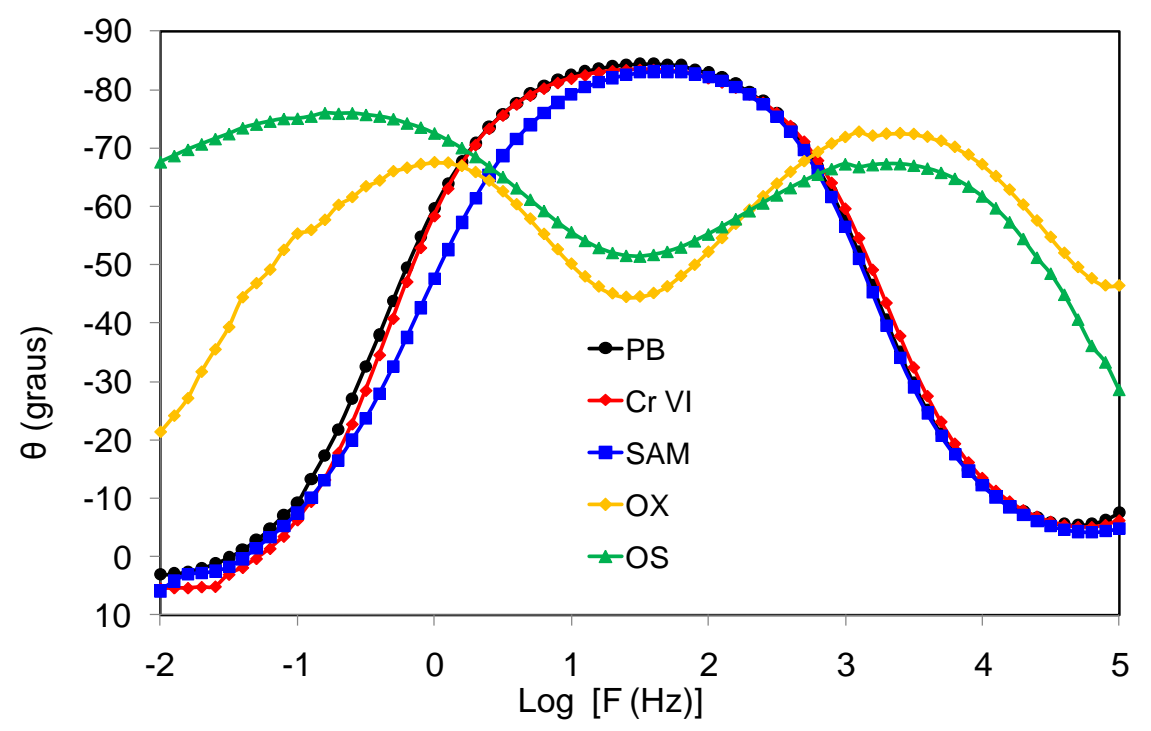

(B)

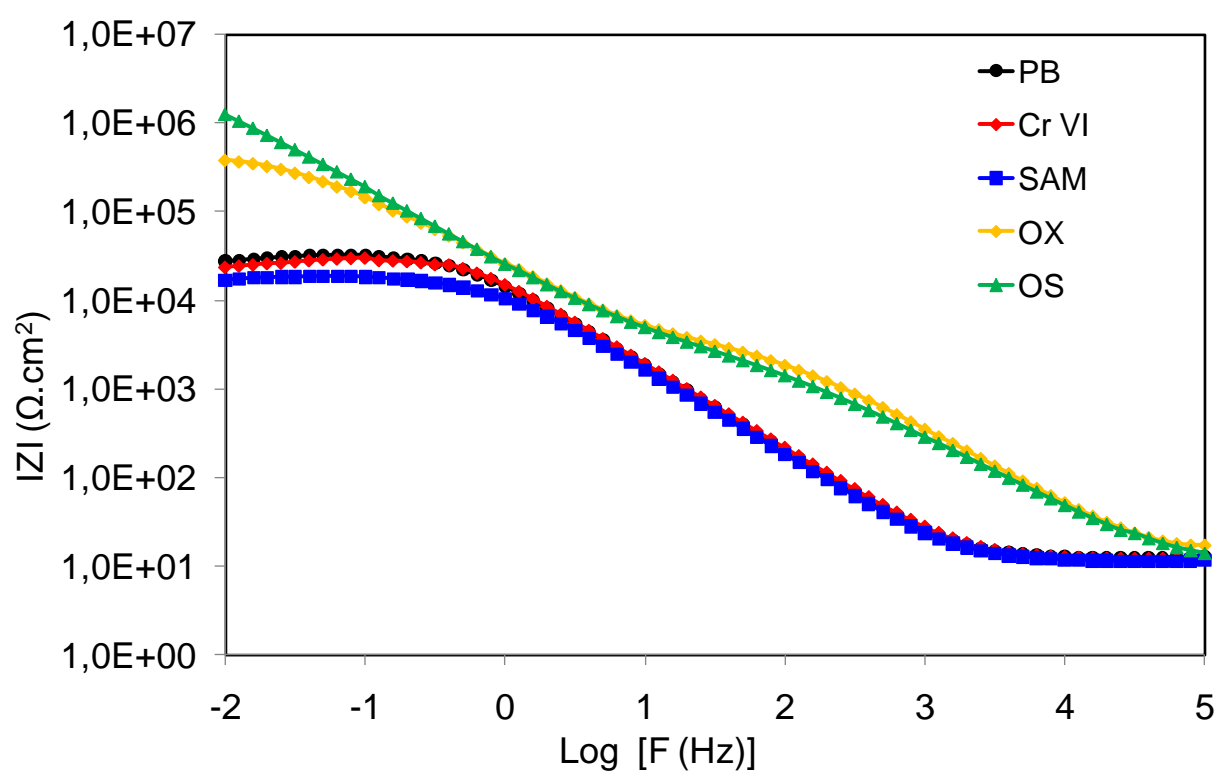

Figura 31: Diagramas de (A) ângulo de fase de Bode e (B) módulo de Z para o alumínio AA1050 com tratamentos PB, Cr(VI), SAM, OX e OS para 3 dias de imersão em solução $0,5 \mathrm{~mol} \mathrm{~L}^{-1}$ de $\mathrm{Na}_{2} \mathrm{SO}_{4}$ tamponada, $\mathrm{pH}=4$.

Todas as amostras ao final da polarização apresentaram densidades de correntes de corrosão típicas de materiais passivos, sendo as densidades de corrente para as amostras com tratamentos $\mathrm{PB}, \mathrm{Cr}(\mathrm{VI})$ e SAM da ordem de $10^{-6} \mathrm{~A}$ $\mathrm{cm}^{-2}$, OX da ordem de $10^{-7} \mathrm{~A} \mathrm{~cm}^{-2}$ e OS da ordem de $10^{-8} \mathrm{~A} \mathrm{~cm}^{-2}$. Outra observação comum a todas as curvas é a indicação de um filme passivo que, dependentemente do tipo de tratamento é rapidamente atacado, apresentando baixa resistência no eletrólito teste, principalmente no caso do tratamento de cromatização com $\mathrm{Cr}(\mathrm{VI})$ (entre 1 h e 4 h). 
As curvas referentes às amostras $\mathrm{PB}$ e $\mathrm{Cr}(\mathrm{VI})$ são muito similares, confirmando os resultados obtidos por espectroscopia de impedância eletroquímica. $\mathrm{O}$ aumento da densidade de corrente observado para o tratamento $\mathrm{OX}$ em $\mathrm{E}=-0,06 \mathrm{~V}_{\mathrm{ECS}}$ mostrou que a corrente máxima atingida é muito próxima às densidades de corrente passivas observadas nos tratamentos $\mathrm{PB}$ e $\mathrm{Cr}(\mathrm{VI})$, para os quais tem-se a presença de um filme fino de óxido-hidróxido. No entanto, logo após o aumento de corrente houve uma diminuição e recuperação dos valores de corrente anteriormente observados (em $-0,06 \quad V_{E C S}$ ), indicando a recuperação da camada protetora. A região de maior fragilidade da superfície provavelmente foi responsável por esse aumento de corrente, devido à quebra localizada do filme obtido com tratamento OX.

O tratamento com SAM foi o único a apresentar aumento de corrente típico de quebra da camada passiva em potenciais de cerca de $E=-0,26 V_{E C S}$. Possíveis causas para este comportamento são o tempo prolongado de tratamento em solução com SAM provocando um maior ataque da camada de passiva com SAM e a permanência de solução agressiva dentro dos defeitos e buracos na superfície das amostras após remoção dos precipitados, gerando condições ideais para nucleação e crescimento dos pites. Estes resultados confirmaram o efeito prejudicial do tratamento SAM para o alumínio AA1050 sem tratamento preliminar que favoreça a formação de uma camada espessa de óxido-hidróxido, mas resistente ao ataque pela solução de SAM.

A maior resistência proporcionada pelo tratamento OS pode ser confirmada pelas curvas de polarização para 1, 4, 8, e 24 h, Figura 29. Nota-se que apesar das oscilações de corrente observadas nas curvas de polarização, há tendência de diminuição das instabilidades do filme passivo com o tempo de imersão. Possivelmente a formação de produtos de corrosão na forma de oxi-hidróxidos associada à adsorção de moléculas auto-organizáveis tenha sido responsável pelo melhor desempenho desse tipo de tratamento. 


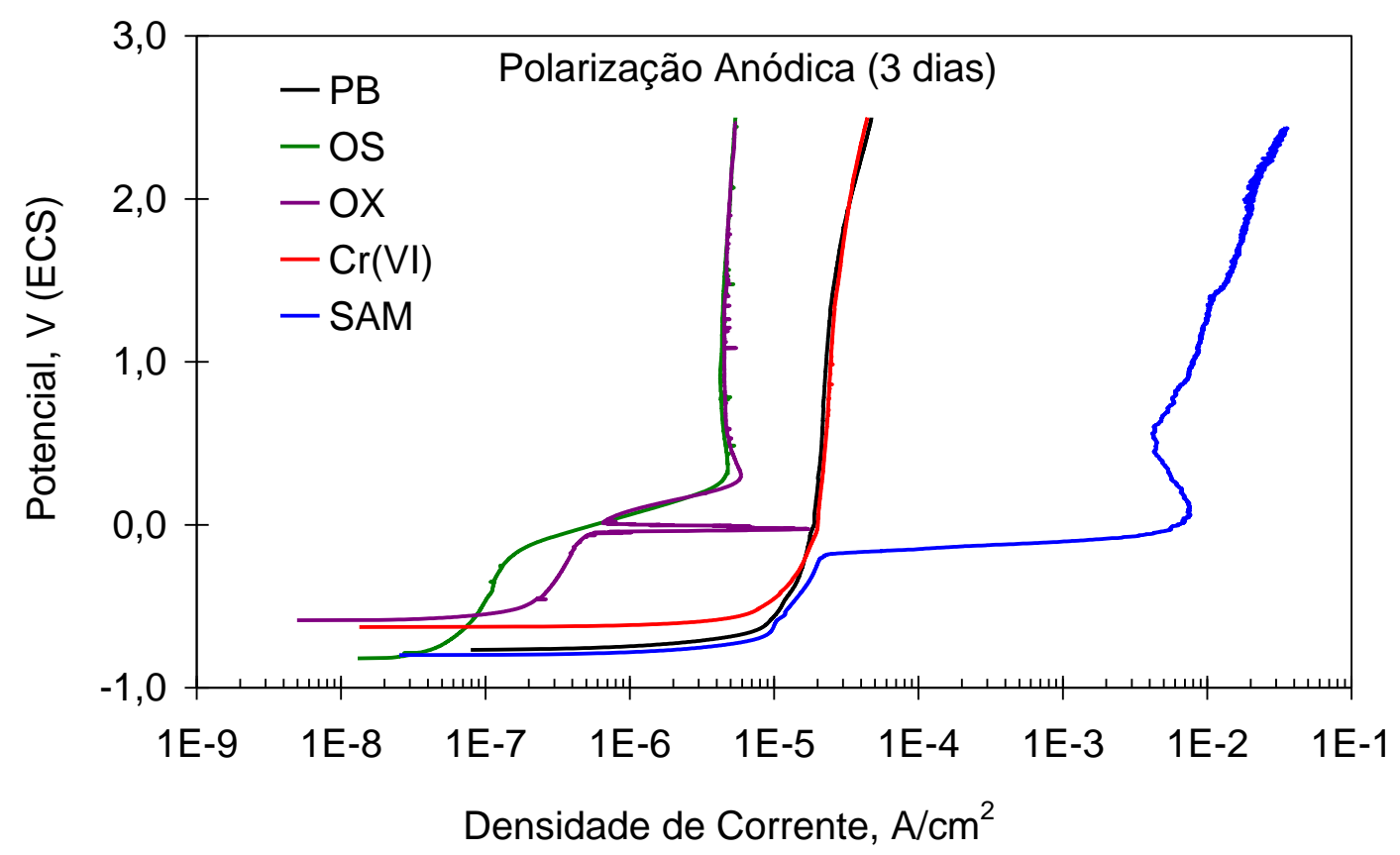

Figura 32: Curvas de polarização anódica para alumínio AA1050 com tratamentos $\mathrm{PB}, \mathrm{SAM}, \mathrm{Cr}$ VI, OX e OS após 3 dias de imersão em solução de ensaio $(0,5 \mathrm{~mol}$ $\mathrm{L}^{-1}$ de sulfato de sódio, $\mathrm{pH}=4,0$ ).

As curvas de polarização catódica para os diferentes tratamentos estudados são mostradas na Figura 33 para 3 dias de imersão. A polarização catódica mostra controle por difusão em larga faixa de potenciais. Esse controle é mais evidente nas amostras com tratamentos OX e OS provavelmente pela resistência do filme de óxido-hidróxido ao acesso de espécies reagentes à superfície metálica. Os demais tratamentos não tiveram efeito significativo na reação catódica, provavelmente por se tratarem de camadas muito finas, como as promovidas pelo tratamento $\mathrm{PB}$.

A combinação de polarização da reação catódica com polarização da reação anódica observada para os dois tratamentos, OX e OS, em relação ao tratamento PB explica o grande aumento de resistência à corrosão associada aos dois primeiros tratamentos. 


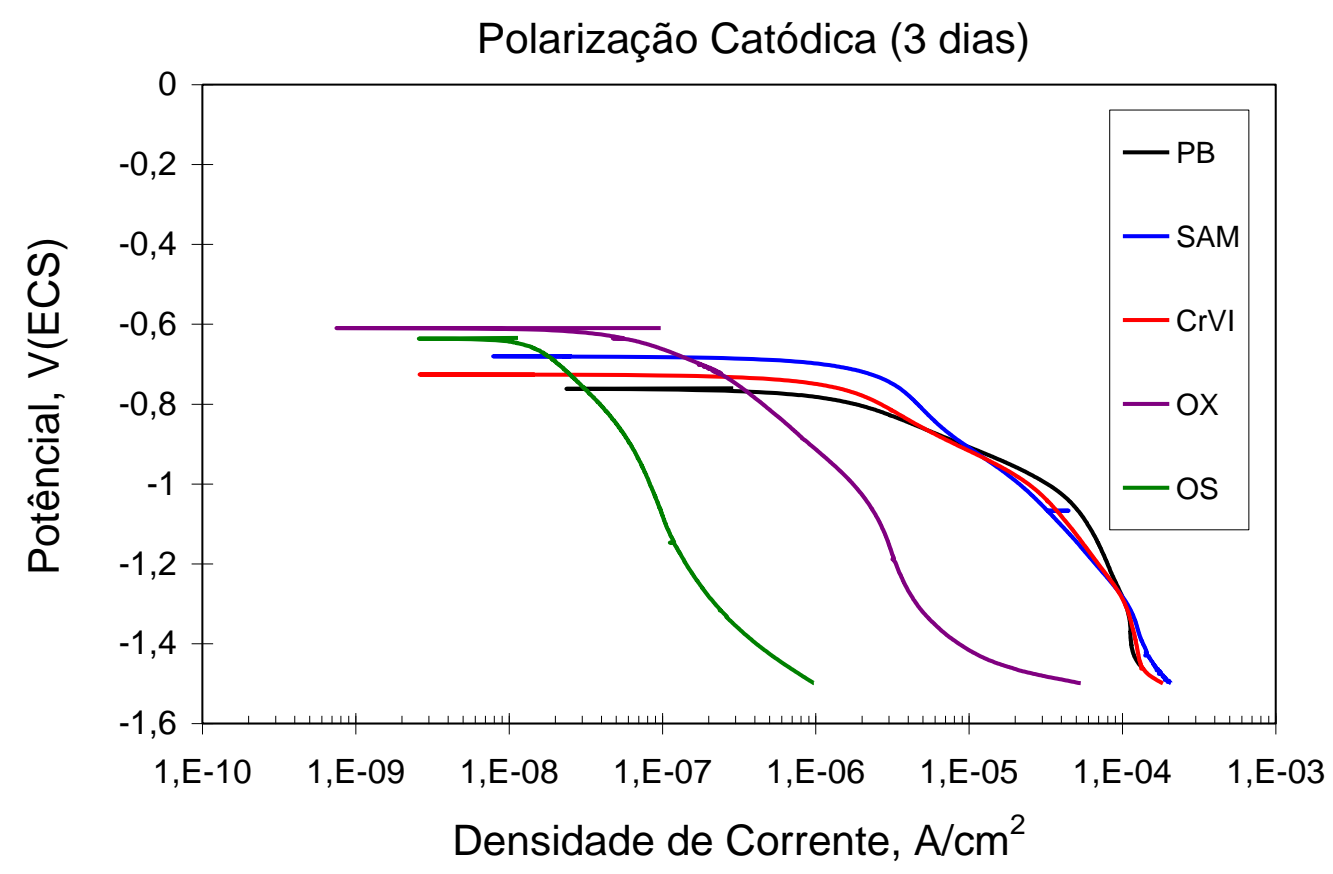

Figura 33: Curvas de polarização catódica para alumínio AA1050 com tratamentos PB, SAM, $\mathrm{Cr}(\mathrm{VI})$, OX e OS após 3 dias de imersão em solução de ensaio $\left(0,5 \mathrm{~mol} \mathrm{~L}^{-1}\right.$ de sulfato de sódio, $\left.\mathrm{pH}=4,0\right)$.

Comparando-se os dois tratamentos, OX e OS, pode-se propor que $\mathrm{O}$ tratamento SAM na superfície do alumínio combinado com o tratamento de crescimento de óxido-hidróxido $(\mathrm{OX}+\mathrm{SAM}=\mathrm{OS})$ promove a dissolução parcial da camada de óxido-hidróxido e ataque corrosivo nas regiões de interface entre precipitados e matriz (produtos hidratados formados no tratamento OX), além de adsorção de moléculas auto-organizáveis nestas regiões dificultando o acesso do meio corrosivo às partes interiores das porosidades/defeitos formados, causando a polarização da reação catódica e também da reação anódica por aumento de resistência ôhmica.

Neste trabalho os tratamentos superficiais adotados mostraram comportamentos que podem ser separados em dois grupos, segundo a resposta eletroquímica obtida por EIE e polarização potênciodinâmica. O primeiro grupo inclui os tratamentos PB, SAM e CrVI, e o segundo, os tratamentos OX e OS. 
5.4.2. Uso de microscopia eletrônica de varredura para avaliar os tratamentos adotados no alumínio AA1050.

As Figuras 34 e 35 apresentam micrografias da superfície do alumínio AA1050 após os tratamentos PB, Cr(VI), SAM, OX e OS, antes e após 3 dias de imersão em solução de ensaio, e após polarização catódica e anódica, para todos os tratamentos testados.

Como já foi explicado no item 5.2.2. as amostras antes da imersão na solução de ensaio (Figuras 34a, 34e, 34i, 35a e 35e) mostraram que o tratamento de desengraxe é responsável pela remoção parcial de precipitados, devido à corrosão localizada entre estes e a matriz.

No caso do tratamento PB, o período de imersão no eletrólito teste (Figura 34b) também foi responsável pela corrosão, gerando uma superfície mais atacada após 3 dias de imersão em comparação à superfície das amostras antes da imersão. Aparentemente, as micrografias obtidas após os ensaios de polarização, apresentadas nas Figuras 34(c) e 34(d) não resultaram em pites com dimensões muito maiores que os observados nas Figuras 34(a) e 34(b).

As micrografias obtidas para alumínio AA1050 com tratamento SAM, antes, Figura 34(e), e após 3 dias de imersão em solução de ensaio, Figura 34(f), permitem observar corrosão localizada nas áreas próximas aos precipitados resultando na remoção dos mesmos. Nota-se também um filme menos uniforme sobre a matriz do alumínio, o que sugere ataque causado pela solução de ensaio. Ao mesmo tempo, são observados precipitados totalmente preservados, conforme indicado na Figura 34(f). O pior desempenho obtido nos ensaios de EIE para 3 dias de imersão correspondeu à superfície submetida ao tratamento com SAM. No entanto, este resultado não fica muito evidente nas Figuras 34(g) e 34(h), já que a escala utilizada não permite a visualização de um panorama geral das regiões corroídas. Micrografias com uma visão mais ampla que comprovam a intensa corrosão localizada nas amostras polarizadas podem ser vistas nas Figuras $36(\mathrm{~A})$ e $36(\mathrm{~B})$. 
Nas micrografias do alumínio AA1050 com tratamento cromatizante, $\mathrm{Cr}(\mathrm{VI})$, após 3 dias de imersão em solução de ensaio, Figura 34(j), nota-se que ocorreu um ataque localizado em alguns precipitados, já que a região da matriz apresentava-se relativamente homogênea antes da imersão (Figura 34e). Além disso, são notadas apenas algumas áreas recobertas por um filme devido ao ataque da solução de ensaio, confirmando a degradação do filme indicada nos resultados de EIE. Outro ponto a ser destacado é que alguns precipitados parecem ter sido preservados mesmo após a polarização, mostrando a grande diferença de atividade entre os precipitados presentes neste material, conforme indicado nas Figuras 34(j), 34(k) e 34(l).

Acredita-se que o tratamento com cromo hexavalente utilizado nesse trabalho tenha dado origem a uma camada muito fina composta por um óxido misto de $\mathrm{Cr}(\mathrm{III}) / \mathrm{Cr}(\mathrm{VI})$. Sabe-se que o filme de cromato em alumínio atua como um sistema dinâmico que pode alterar tanto sua morfologia quanto sua composição, dependendo do meio ao qual está exposto [Lytle et al.,1995]. No caso de um revestimento de conversão de cromato, a camada é formada por um óxido amorfo e insolúvel de $\mathrm{Cr}(\mathrm{III})$ que possui grupos $\mathrm{OH}^{-}$disponíveis e responsáveis pela formação das ligações $\mathrm{Cr}(\mathrm{III})-\mathrm{O}-\mathrm{Cr}(\mathrm{VI})$. Além disso, os grupos hidroxila presentes na interface externa do filme $\mathrm{Cr}(\mathrm{OH})_{3}$ são os sítios de adsorção dos íons $\left(\mathrm{HCrO}_{4}\right)^{-}$e $\left(\mathrm{Cr}_{2} \mathrm{O}_{7}\right)^{2-}$ presentes no banho, ou seja, íons $\mathrm{Cr}^{6+} \mathrm{e}$ $\mathrm{Cr}^{3+}$, respectivamente. Essa adsorção ocorre em baixos valores de $\mathrm{pH}$, formando uma camada de óxido misto de $\mathrm{Cr}(\mathrm{III}) / \mathrm{Cr}(\mathrm{VI})$ [Campestrini et al., 2001b].

Ramsey e McCreery [1999] analisaram a composição dos produtos de corrosão dos cromatos dentro dos pites formados na liga AA2024-T3 e encontraram uma diferença na composição do óxido misto presente na camada $\mathrm{Cr}(\mathrm{III}) / \mathrm{Cr}(\mathrm{VI})$, em comparação ao óxido formado por precipitação no interior do pite composto por $\mathrm{Al}(\mathrm{III}) / \mathrm{Cr}(\mathrm{VI})$, essa diferença foi associada pelos autores à presença de alta concentração de íons $\mathrm{Cr}^{6+}$ e $\mathrm{F}^{-}$, além de aceleradores para formação da camada de conversão de cromato, possibilitando a formação do óxido misto $(\mathrm{Al}(\mathrm{III}) / \mathrm{Cr}(\mathrm{VI}))$.

A comparação das micrografias após as polarizações catódicas e anódicas apresentadas nas Figuras $34(\mathrm{k})$ e $34(\mathrm{I})$, respectivamente, sugere que o filme protetor formado possibilita a ocorrência da reação de redução do cromo (VI) para 
cromo (III), ou seja, ocorre o fenômeno denominado de mecanismo de autoregeneração ou "self-healing". Em contato com a solução de ensaio, os íons $\mathrm{Cr}(\mathrm{VI})$ presentes na camada se destacam na forma de $\left(\mathrm{HCrO}_{4}\right)^{-}$, migrando para as regiões mais susceptíveis à corrosão. Assim, os íons cromato podem se adsorver e formar produtos de corrosão e/ou sofrer redução nas paredes dos defeitos da camada, de acordo com as seguintes reações: [Sharman apud Campestrini et al., 2001b]:

$$
\begin{gathered}
\mathrm{HCrO}_{4}^{-}+7 \mathrm{H}^{+}+3 e^{-} \rightarrow \mathrm{Cr}^{+}+4 \mathrm{H}_{2} \mathrm{O} \\
\mathrm{HCrO}_{4}^{-}+6 \mathrm{H}^{+}+3 e^{-} \rightarrow \mathrm{CrOH}^{2+}+3 \mathrm{H}_{2} \mathrm{O} \\
\mathrm{CrOH}^{2+}+\mathrm{H}^{+}+e^{-} \rightarrow \mathrm{Cr}^{2+}+\mathrm{H}_{2} \mathrm{O}
\end{gathered}
$$

Devido às reações apresentadas nas equações 9, 10 e 11, o pH nos locais onde está ocorrendo a corrosão aumenta rapidamente, levando à precipitação dos íons $\mathrm{Al}^{3+}$ e $\mathrm{Cr}^{3+}$ na forma de hidróxidos ou óxidos hidratados, causando a repassivação dos pites [Campestrini et al., 2001b]. Acredita-se que este mecanismo esteja acontecendo próximo às regiões ativas (próximas aos precipitados intermetálicos), pois nessas regiões pode ser observada a presença de uma fina camada recobrindo as precipitados, como mostram as micrografias e as análises por EDS apresentadas na Figura 37. Não foi observada a presença de trincas típicas de revestimentos mais espessos associados com camadas de conversão de cromato.

A Figura 37 apresenta o espectro obtido por EDS para uma amostra de AA1050 submetido ao tratamento $\mathrm{Cr}(\mathrm{VI})$ e a sua respectiva quantificação realizada em uma região próxima a um intermetálico IM3. O resultado confirma a presença de cromo próximo ao precipitado, permitindo detectar a camada de cromato decorrente do tratamento com $\mathrm{Cr}(\mathrm{VI})$, apesar da baixa espessura do filme formado.

As micrografias do alumínio AA1050 com tratamento de imersão em água fervente para crescimento da camada de óxido-hidróxido (OX) antes e após 3 dias de imersão na solução de ensaio, são apresentadas nas Figuras 35(a) e 35(b). A comparação das superfícies mostra aumento das áreas atacadas em torno dos 
precipitados e maior quantidade de precipitados removidos após a imersão no eletrólito por 3 dias. Nota-se a presença de ataque localizado e a formação de produtos de corrosão aparentemente em alto relevo, ao redor das regiões em que houve ataque aos intermetálicos. Este ataque também pode ser observado após a polarização catódica, mas é notavelmente intensificado com a polarização anódica, Figuras 35(c) e 35(d).

As micrografias do alumínio AA1050 com tratamento OS, antes e após 3 dias de imersão em solução de ensaio (Figura $35 \mathrm{e}$ e $35 \mathrm{f}$ ), sugerem alta estabilidade da superfície das amostras ao longo dos 3 dias de imersão em solução de sulfato. Deste modo, apesar das Figuras 35(g) e 35(h) apresentarem regiões que sofreram corrosão localizada, este fenômeno pode estar associado a um processo que se originou durante o pré-tratamento comercial da amostra.

Os produtos precipitados aparentemente se encontram em maior quantidade nas amostras com tratamento OX em comparação ao tratamento OS, Figura 35(f), o que pode ser decorrência da dissolução parcial e ataque dos produtos de corrosão durante exposição ao eletrólito ácido $(\mathrm{pH}=4,0)$. Uma possível causa para a maior resistência da superfície com tratamento OS em comparação ao OX, é o leve ataque ao filme superficial durante imersão na solução de SAM, levando ao alargamento de poros e adsorção de moléculas nessas regiões, facilitando o acesso dos reagentes meio externo.

No caso do tratamento OX acredita-se que os defeitos/porosidades no filme de óxi-hidróxido são regiões de maior confinamento de eletrólito e, conseqüentemente, maior agressividade, indicada pela diminuição da impedância com o tempo de ensaio. Deve-se lembrar que as condições do tratamento OX são menos agressivas em comparação ao tratamento OS. 


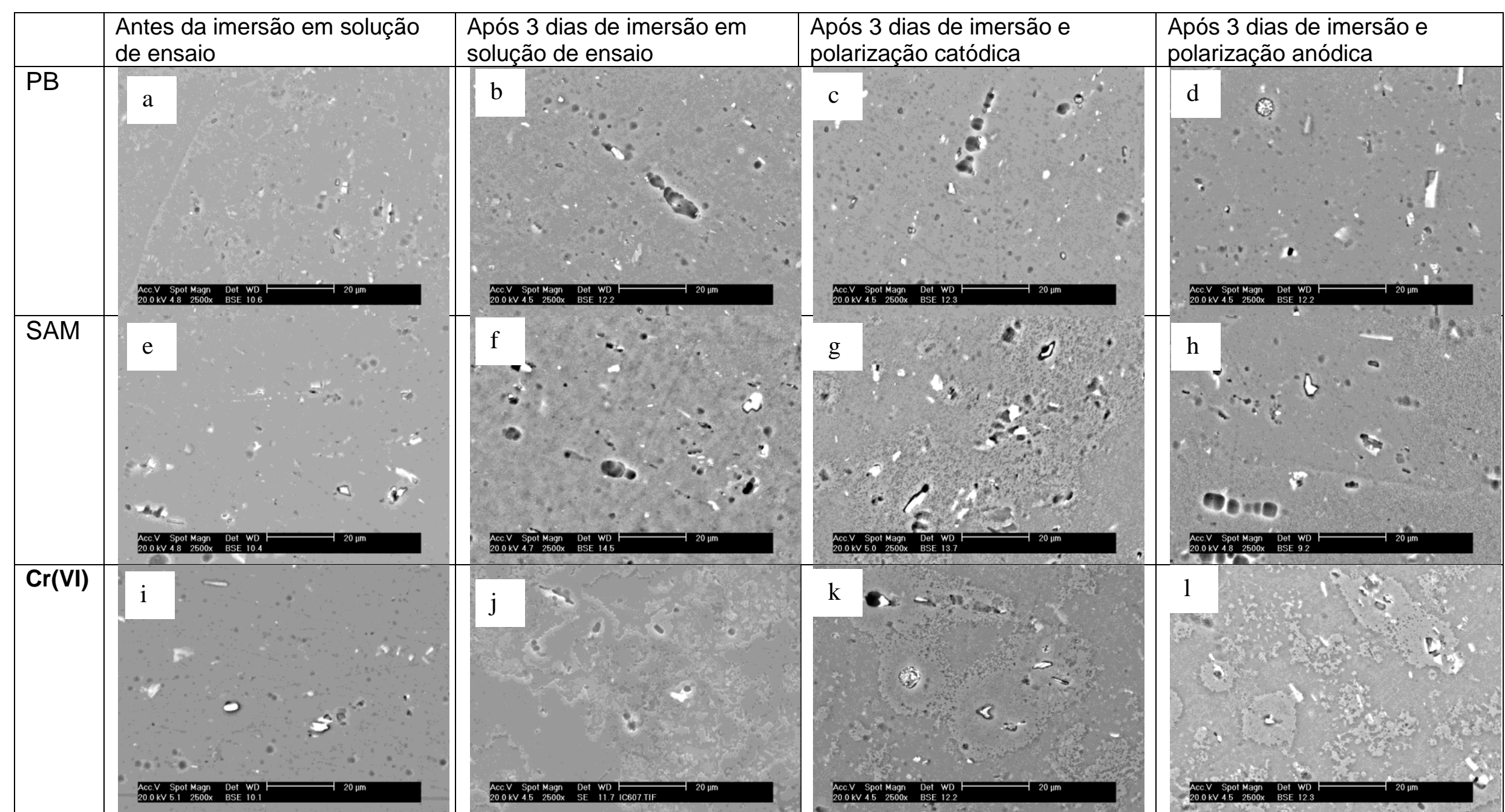

Figura 34: Micrografias de superfície do alumínio AA 1050 com os tratamentos PB, Cr(VI) e SAM mostrando o efeito destes tratamentos da imersão e das polarizações anódicas ou catódicas nestas superfícies. 


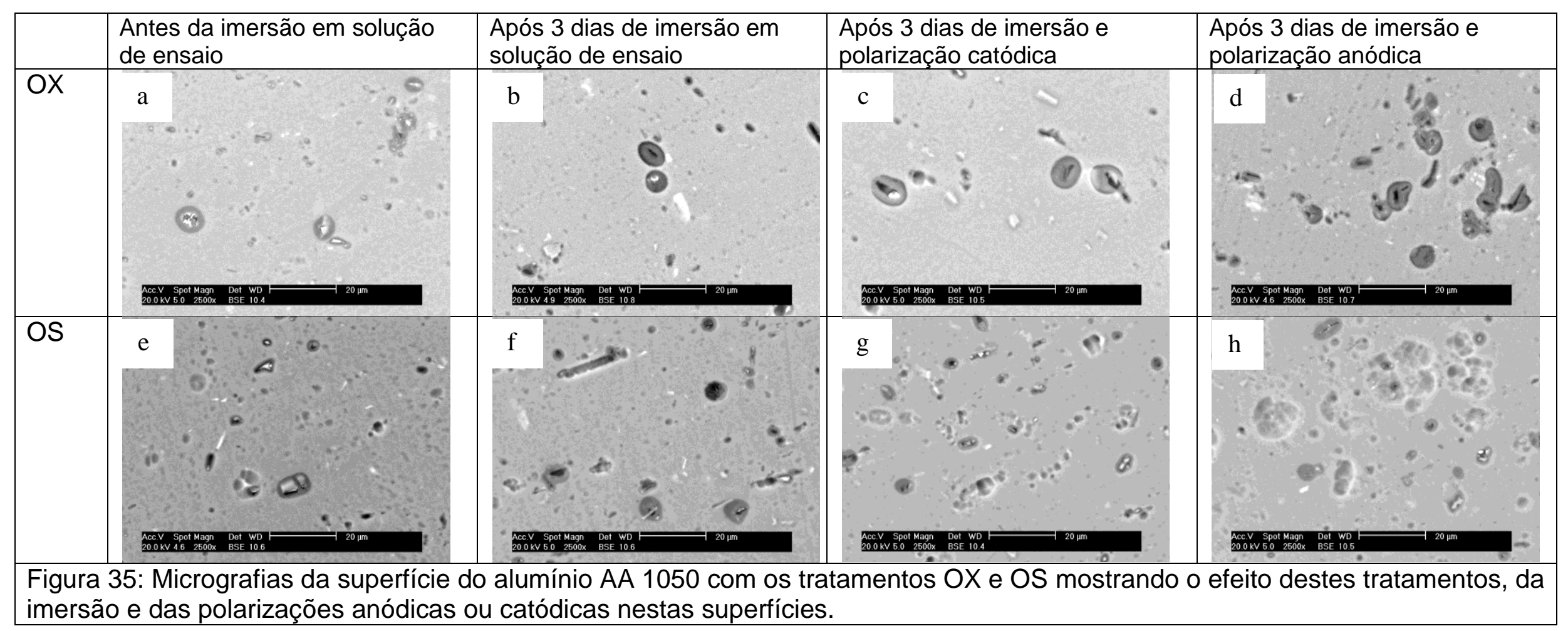



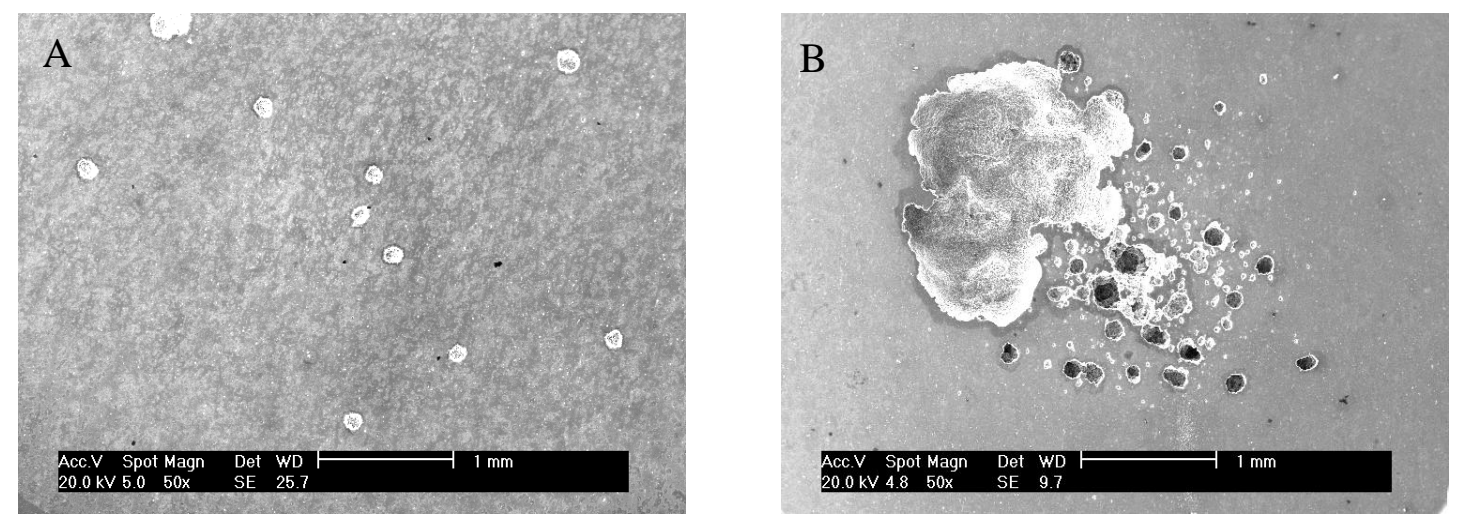

Figura 36: Micrografias obtidas por MEV para amostras submetidas ao tratamento de SAM após polarização, (A) Catódica e (B) Anódica.

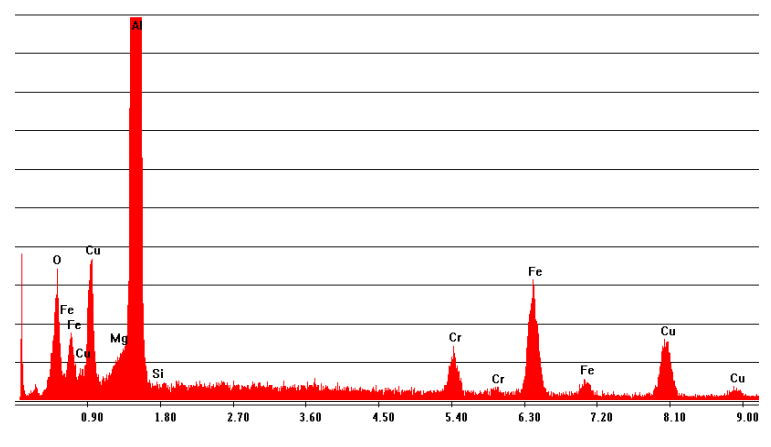

Região do IM3 - Maciço Arredondado
\begin{tabular}{|l|l|l|}
\hline \hline Elemento & $\%$ massa & $\%$ Atômica \\
\hline \hline O K & 6,33 & 11,92 \\
\hline MgK & 1,12 & 1,39 \\
\hline AlK & 64,72 & 72,22 \\
\hline SiK & 0,29 & 0,31 \\
\hline$\underline{\text { CrK }}$ & $\underline{3,11}$ & $\underline{1,80}$ \\
\hline FeK & 11,97 & 6,46 \\
\hline CuK & 12,45 & 5,90 \\
\hline Total 100.00 & &
\end{tabular}

Figura 37: Espectros obtidos por EDS e quantificação para amostra tratada com $\mathrm{Cr}(\mathrm{VI})$ na região do intermetálico $\mathrm{IM} 3$, antes da imersão na solução de $0,5 \mathrm{~mol}$ $\mathrm{L}^{-1}$ de sulfato de sódio, $\mathrm{pH}=4,0$.

Conforme mensionado os tratamentos superficiais adotados mostraram comportamentos que podem ser separados em dois grupos, segundo as resposta eletroquímicas obtida por EIE e polarização. O primeiro grupo inclui os tratamentos PB, SAM e CrVI, e o segundo, os tratamentos OX e OS.

Para o primeiro grupo, foram observadas duas constantes de tempo, uma correspondente a um par $\mathrm{RC}$ em paralelo $(\mathrm{R} / / \mathrm{C})$, e a outra a um par $\mathrm{R} / \mathrm{L}$. $\mathrm{A}$ literatura relaciona o comportamento indutivo com processos de adsorção de várias espécies [Aoki et al., 2001, Reis et al, 2006]. Porém, é difícil correlacionar o significado físico de um indutor com o comportamento eletroquímico de uma 
interface. Por este motivo, neste trabalho não se levou em consideração os valores referentes a este componente elétrico, obtidos pelo ajuste segundo o modelo da Figura 38(A). Todavia, os valores de resistência e capacitância associados à primeira constante de tempo foram úteis para uma comparação entre as características de resistência à corrosão dos três tipos de tratamento (PB, SAM e Cr(VI)), conforme indicado nas Tabelas 7 a 9.

As Figuras 38(A) e 38(B) apresentam os circuitos elétricos equivalentes usados nos ajustes dos dados experimentais de EIE. Para amostras tratadas com PB, Cr(VI) e SAM, foi utilizado o CCE da Figura 38(A), e para amostras com OX e OS, o CCE da Figura 38(B).

As Tabelas 7, 8 e 9 apresentam os valores dos parâmetros elétricos obtidos pelo software Zview, resultantes dos ajustes do circuito da Figura 38(a) aos diagramas experimentais para alumínio AA1050 tratado com PB, SAM e $\mathrm{Cr}(\mathrm{VI})$, respectivamente, após os períodos de 1, 2 e 3 dias em imersão em solução de ensaio.

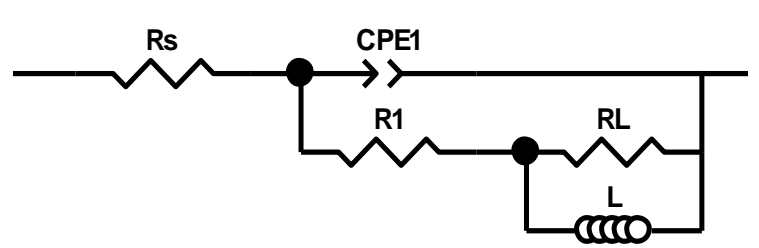

A)

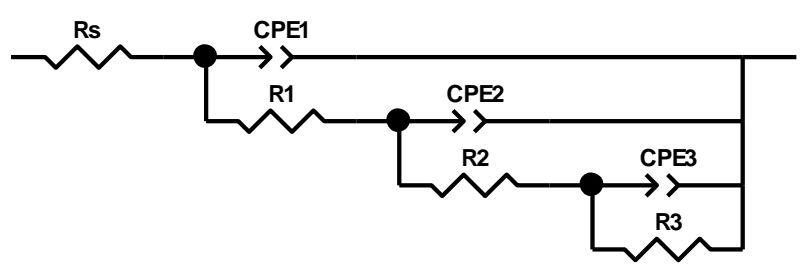

B)

Figura 38: Circuitos elétricos equivalentes, (A) para os tratamentos PB, SAM, $\mathrm{Cr}(\mathrm{VI})$ e (B) para os tratamentos OX e OS.

Tabela 7: Valores dos parâmetros elétricos resultantes dos ajustes do CEE da Figura 38(A) aos diagramas experimentais do alumínio AA1050 com tratamento PB.

\begin{tabular}{lcccccc}
\hline PB & $\begin{array}{c}\mathrm{Rs} \\
\left(\Omega . \mathrm{cm}^{2}\right)\end{array}$ & $\begin{array}{c}\mathrm{CPE}_{1} \\
\left(\mu \mathrm{F} . \mathrm{cm}^{-2}\right)\end{array}$ & $\mathrm{a}_{1}$ & $\begin{array}{c}\mathrm{R}_{1} \\
\left(\mathrm{~K} \Omega . \mathrm{cm}^{2}\right)\end{array}$ & $\begin{array}{c}\mathrm{RL} \\
\left(\mathrm{K} \Omega . \mathrm{cm}^{2}\right)\end{array}$ & $\begin{array}{c}\mathrm{L} \\
\left(\mathrm{H} . \mathrm{cm}^{2}\right)\end{array}$ \\
\hline $1 \mathrm{~d}$ & 11,56 & 10,07 & 0,96 & 27,78 & 7,56 & 72.179 \\
\hline 2d & 11,51 & 9,90 & 0,96 & 25,41 & 6,24 & 43.691 \\
\hline 3d & 11,57 & 10,52 & 0,96 & 26,99 & 5,69 & 51.810 \\
\hline
\end{tabular}


Tabela 8: Valores dos parâmetros elétricos resultantes dos ajustes do CEE da Figura 38(A) aos diagramas experimentais do alumínio AA1050 com tratamento SAM.

\begin{tabular}{lcccccc}
\hline SAM & $\begin{array}{c}\mathrm{Rs} \\
\left(\Omega \cdot \mathrm{cm}^{2}\right)\end{array}$ & $\begin{array}{c}\mathrm{CPE}_{1} \\
\left(\mu \mathrm{F} . \mathrm{cm}^{-2}\right)\end{array}$ & $\mathrm{a}_{1}$ & $\begin{array}{c}\mathrm{R}_{1} \\
\left(\mathrm{~K} \Omega \cdot \mathrm{cm}^{2}\right)\end{array}$ & $\begin{array}{c}\mathrm{RL} \\
\left(\mathrm{K} \Omega \cdot \mathrm{cm}^{2}\right)\end{array}$ & $\begin{array}{c}\mathrm{L} \\
\left(\mathrm{H} . \mathrm{cm}^{2}\right)\end{array}$ \\
\hline \hline $1 \mathrm{~d}$ & 10,67 & 5,35 & 0,91 & 34,56 & 20,17 & 40.779 \\
\hline 2d & $11,23^{*}$ & 11,01 & 0,95 & 10,28 & 1,49 & 5.579 \\
\hline $3 \mathrm{~d}$ & 11,92 & 13,67 & 0,95 & 16,35 & 3,44 & 20.909 \\
\hline
\end{tabular}

Tabela 9: Valores dos parâmetros elétricos resultantes dos ajustes do CEE da Figura 38(A) aos diagramas experimentais do alumínio AA1050 com tratamento $\mathrm{Cr}(\mathrm{VI})$.

\begin{tabular}{lcccccc}
\hline $\operatorname{Cr}(\mathrm{VI})$ & $\begin{array}{c}\mathrm{Rs} \\
\left(\Omega . \mathrm{cm}^{2}\right)\end{array}$ & $\begin{array}{c}\mathrm{CPE}_{1} \\
\left(\mu \mathrm{F} . \mathrm{cm}^{-2}\right)\end{array}$ & $\mathrm{a}_{1}$ & $\begin{array}{c}\mathrm{R}_{1} \\
\left(\mathrm{~K} \Omega . \mathrm{cm}^{2}\right)\end{array}$ & $\begin{array}{c}\mathrm{RL} \\
\left(\mathrm{K} \Omega . \mathrm{cm}^{2}\right)\end{array}$ & $\begin{array}{c}\mathrm{L} \\
\left(\mathrm{H} . \mathrm{cm}^{2}\right)\end{array}$ \\
\hline $1 \mathrm{~d}$ & 12,14 & 8,45 & 0,95 & 28,75 & 9,32 & 9.324 \\
\hline $2 \mathrm{~d}$ & 12,12 & 9,45 & 0,95 & 27,10 & 8,70 & 40.860 \\
\hline $3 \mathrm{~d}$ & 12,02 & 10,10 & 0,95 & 22,87 & 7,44 & 40.241 \\
\hline
\end{tabular}

Comparando os valores da primeira constante de tempo, $\mathrm{R}_{1} / / \mathrm{CPE}_{1}$, nota-se que o maior valor de resistência e menor capacitância para 1 dia de imersão foram associados ao tratamento SAM, mas após 3 dias de ensaio, a menor resistência e maior capacitância também foram relacionadas com este último tratamento. Estes resultados mostram a rápida degradação da superfície com tratamento SAM.

Comparando os resultados das amostras de alumínio AA1050 com tratamento PB e tratamento com SAM foi observado que este último é um tratamento agressivo ao filme passivo de alumínio presente na superfície das amostras PB, devido à instabilidade deste filme na solução de SAM cujo pH é igual a 3,0. A agressividade desta solução ataca o filme passivo, causando também a formação de pilhas nas regiões de interface entre os precipitados e a matriz de alumínio, resultando, eventualmente, na remoção parcial ou total de alguns destes precipitados. 
Após a preparação de ambos os tratamentos PB e SAM, Figura 39(A) e (B), nota-se que para as amostras submetidas ao tratamento com SAM ocorre formação de produtos de corrosão na interface matriz/precipitado ou a remoção dos intermetálicos, Figura 39(B). Esta remoção de partículas, bem como a adsorção de moléculas de SAM e a formação de produtos hidratados ao redor dos intermetálicos, pode ser responsável pela maior impedância para 1 dia de imersão, pois a menor atividade superficial promovida pela "limpeza" da superfície, juntamente com a maior resistência dos produtos hidratados formados durante o período de $3 \mathrm{~h}$ em solução com SAM a $40 \stackrel{\circ}{\circ}$, produzem aumento da impedância. Após 3 dias de imersão na solução de ensaio, a resistência à corrosão havia diminuído, provavelmente devido à agressividade da solução, observando-se que esta se encontra no limite de estabilidade do óxido de alumínio $(\mathrm{pH}=4,0)$. A Figura 39 mostra pites em maior quantidade e dimensão em uma das amostras tratadas com SAM.

Estudos realizados por Moshier et al. [1987] constataram que o óxido de alumínio formado ao ar é transformado em um filme óxido hidratado, conhecido como pseudo-boehmita $(\mathrm{AlOOH})$, durante a polarização em ambientes onde $\circ \mathrm{pH}$ é neutro. A faixa de $\mathrm{pH}$ em que a boehmita é estável $(4,5$ a 6,3) [Moshier et al., 1987] é menor em comparação à hidrargilita $\left(\mathrm{Al}(\mathrm{OH})_{3}\right)$, cujo intervalo de $\mathrm{pH}$ de estabilidade se dá na faixa entre 4,0 e 9,0. Nota-se, portanto, que para ambas as estruturas de óxido-hidróxido, a solução de SAM com pH igual a 3,0, é altamente agressiva.

Durante o período de ensaio, particularmente nas regiões de cavidades deixadas pela remoção de precipitados intermetálicos, aumentaram a susceptibilidade do alumínio à corrosão por pite. Esta é uma possível explicação para os maiores valores de impedância das amostras com SAM em comparação ao tratamento PB e a diminuição da impedância entre 1 e 3 dias imersão. 
(A)

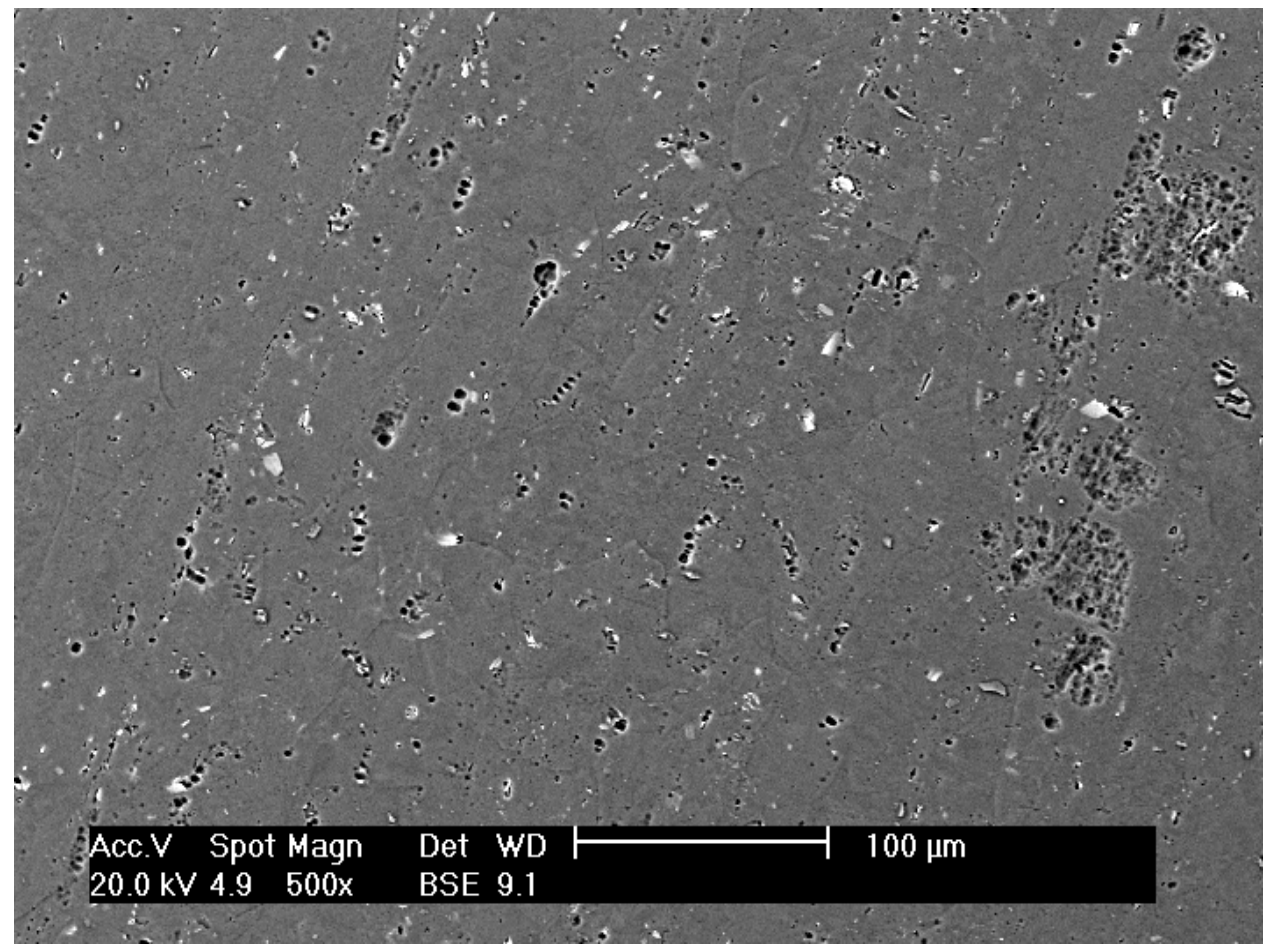

(B)

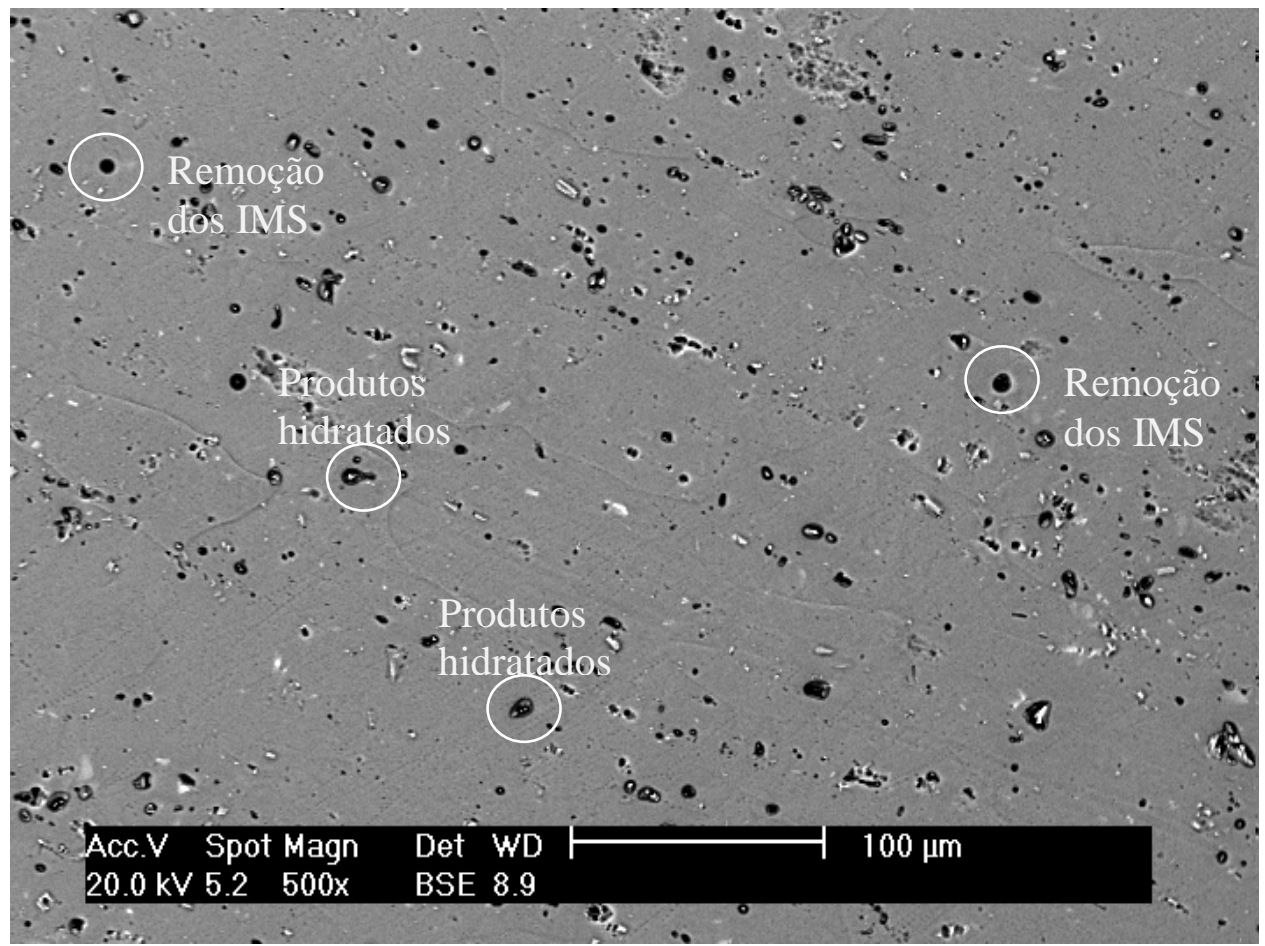

Figura 39: Micrografias obtidas por MEV para alumínio AA1050 após (A) tratamento PB e (B) tratamento SAM (PB seguido por imersão em solução com moléculas auto-organizáveis)

Conforme mencionado anteriormente, o segundo grupo de tratamentos foi composto pelos tratamentos OX e OS. Para as superfícies obtidas por estes tratamentos foi observada a presença de três constantes de tempo, todas 
compostas por pares R//C em paralelo, dispostos em um arranjo em cascata, conforme ilustrado na Figura 38(B). Os modelos representativos da superfície do alumínio AA1050 submetido aos tratamentos OX e OS foram propostos com base na observação da superfície resultante de cada tratamento e dos ajustes propostos para os dados obtidos por EIE e na literatura [Cabral et al., 2005, Cabral et al., 2006, Palomino, 2008, Szurcalo, 2009].

A micrografia da amostra com tratamento OX permite observar a presença de produtos hidratados ao redor dos precipitados, os quais também foram observados na superfície das amostras com tratamento SAM. Tais produtos hidratados se mostraram mais evidentes para o tratamento OX em comparação ao tratamento OS.

As Figuras 40(A) e 40(B) apresentam micrografias obtidas por MEV, com detector para elétrons secundários (SE) e elétrons retroespalhados (BSE), respectivamente. Os produtos hidratados podem ser observados em relevo ao redor do precipitado na parte inferior esquerda das micrografias, enquanto que na parte superior direita, pode ser observada uma cavidade onde restou apenas parte de um precipitado. Estes resultados mostram que diferentes precipitados apresentam comportamentos distintos, com formação de produtos hidratados na parte externa ao pite, isto é, na região catódica, provavelmente em conseqüência do aumento to $\mathrm{pH}$ nestas regiões.

(A) OX- $\boldsymbol{e}^{-}$secundários

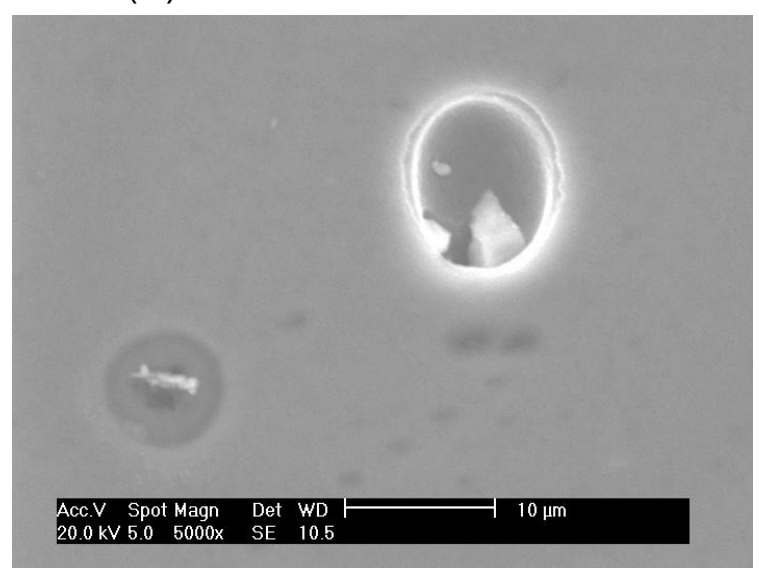

(B) OX- $\boldsymbol{e}^{-}$retroespalhados

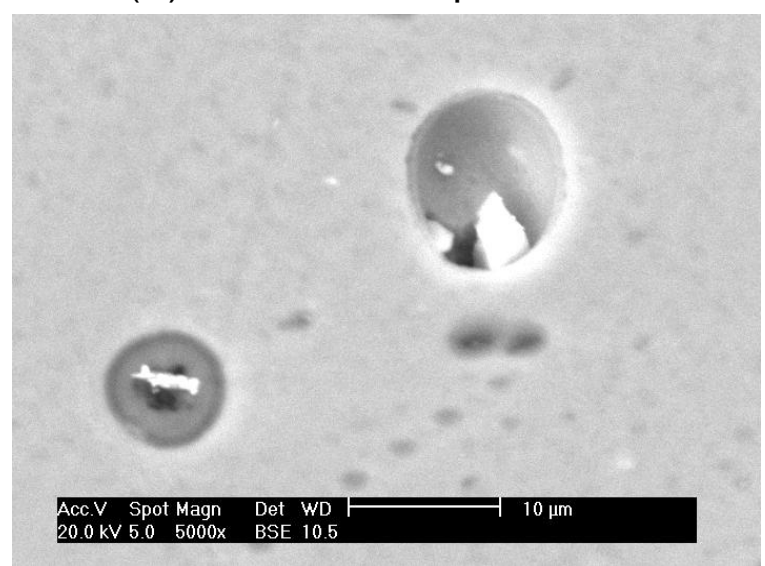

Figura 40: Micrografias obtidas por MEV com detector para elétrons secundários (A) e detector para elétrons retroespalhados (B) para o tratamento OX. 
O circuito elétrico da Figura 38(B) e o software Zview foram utilizados para ajustar os dados experimentais para amostras de alumínio AA1050 com tratamento OX e OS. Apesar da impressão inicial de apenas duas constantes de tempo (Figuras 26B e 28B), em ambos os casos o melhor ajuste foi obtido com um CCE contendo três constantes de tempo, uma descrevendo o comportamento do sistema em altas freqüências ( $A F)$, outra em médias frequências e, a última, em baixas freqüências (BF).

No CCE da Figura 38(B) a resistência, $R_{s}$, está associada à resistência ôhmica entre eletrodo de trabalho e eletrodo de referência. Propõe-se que a primeira constante de tempo em paralelo $\mathrm{R}_{1} / / \mathrm{CPE}_{1}$ está associada ao filme mais externo de óxido-hidróxido, cujo crescimento foi favorecido por imersão em água fervente. A segunda constante, correspondente ao par $\mathrm{R}_{2} / / \mathrm{CPE}_{2}$ em paralelo, aos produtos hidratados formados nas regiões ao redor dos precipitados intermetálicos e, a terceira constante, $\mathrm{R}_{3} / / \mathrm{CPE}_{3}$, relacionada aos processos interfaciais.

Nas Figuras 41 e 42 são apresentados os modelos físicos propostos para exemplificar a superfície após os tratamentos OX e OS respectivamente. Nas Tabelas 10 e 11 são mostrados os valores dos parâmetros elétricos obtidos por meio do ajuste do CCE da Figura 38(B) aos resultados de EIE.

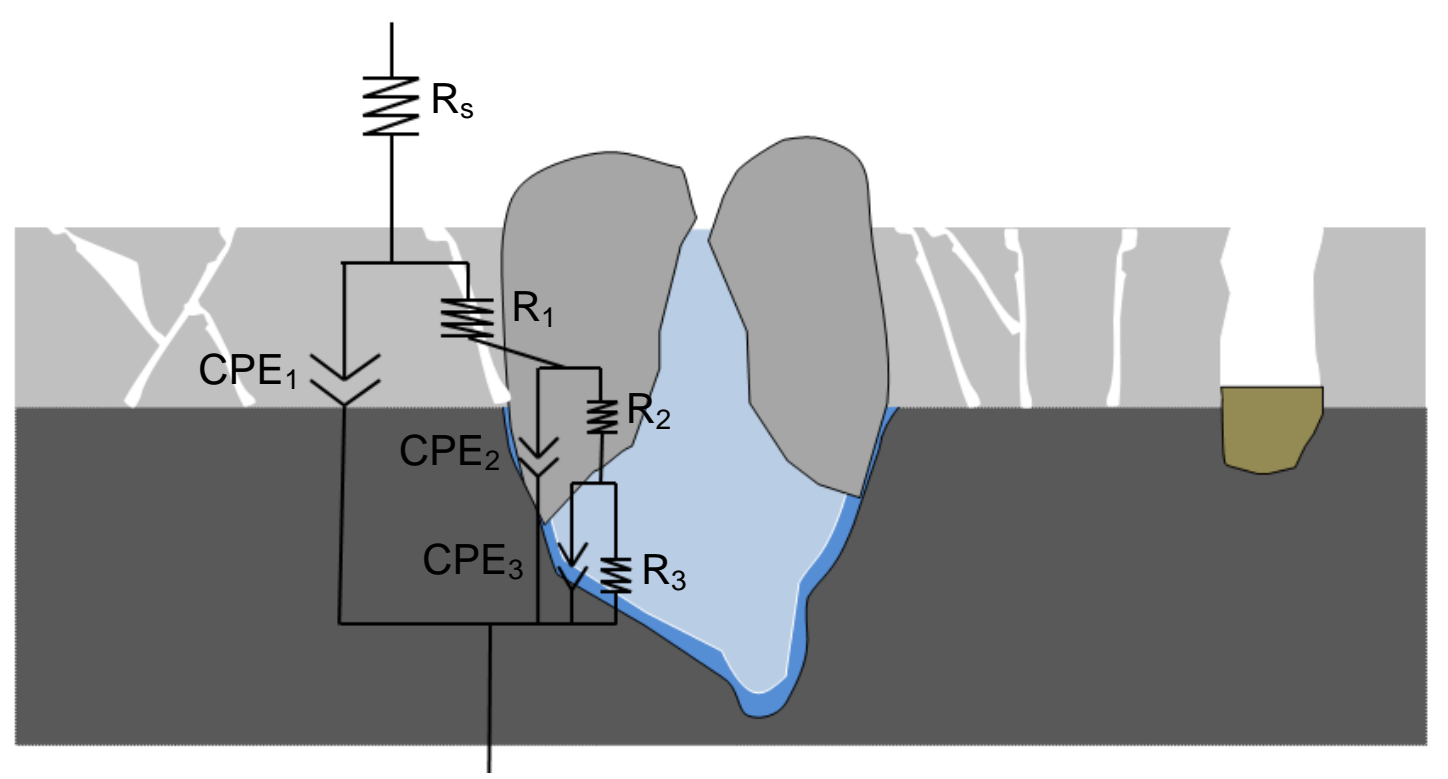

Figura 41: Modelo físico proposto para representação da superfície do AA1050 após tratamento OX e imersão em solução $0,5 \mathrm{~mol} \mathrm{~L}^{-1}$ de $\mathrm{Na}_{2} \mathrm{SO}_{4}(\mathrm{pH}=4,0)$. 


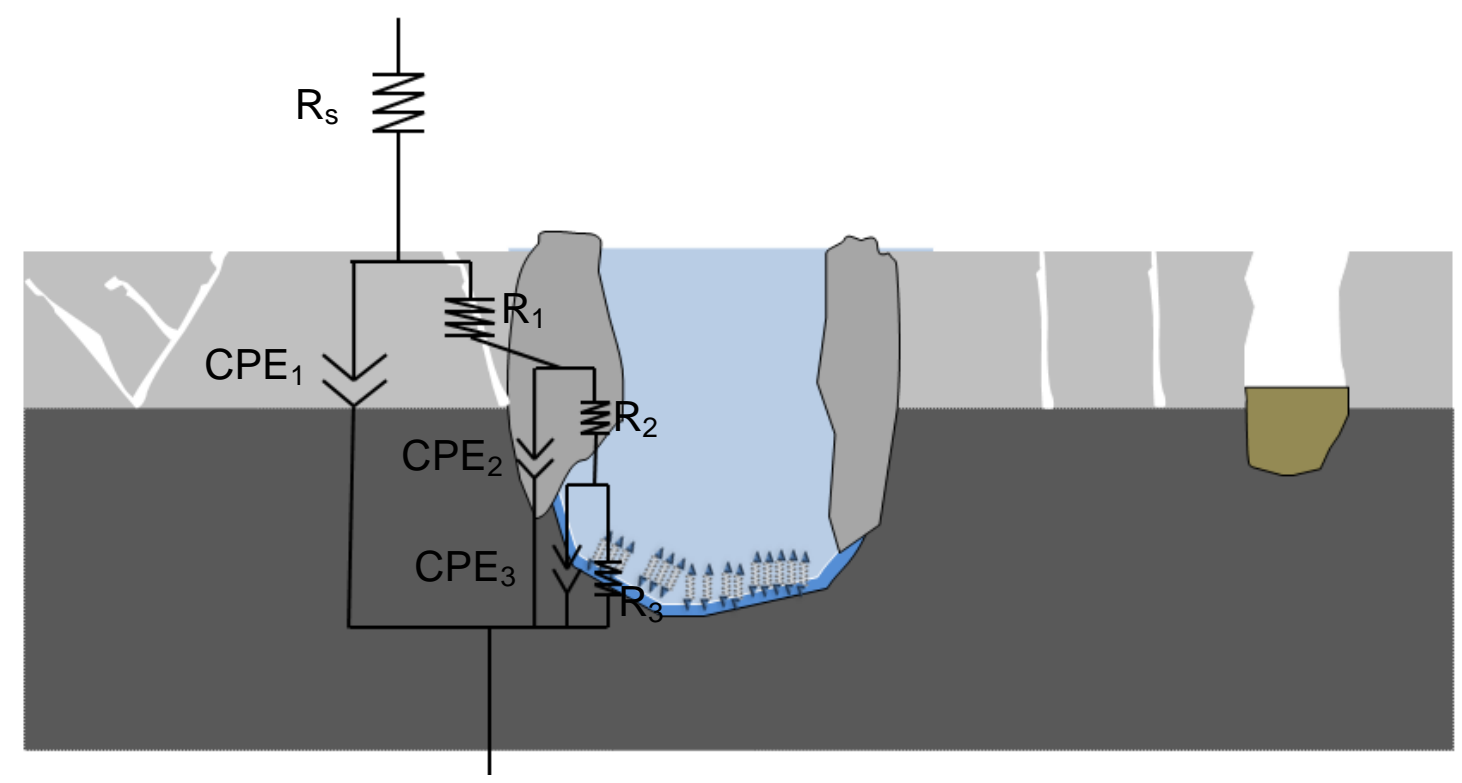

Figura 42: Modelo físico proposto para representar a superfície do AA1050 após tratamento OS e imersão em solução e ensaio $\left(0,5 \mathrm{~mol} \mathrm{~L}^{-1}\right.$ de $\mathrm{Na}_{2} \mathrm{SO}_{4}(\mathrm{pH}=4,0)$.

Tabela 10. Valores dos parâmetros elétricos obtidos com ajuste do circuito elétrico equivalente (CEE) da Figura 38(B) aos resultados experimentais para alumínio AA1050 com tratamento OX após vários períodos de imersão em solução de ensaio, utilizando o software Zview.

\begin{tabular}{cccc}
\hline $\begin{array}{c}\text { Elemento do CEE } \\
\text { ox }\end{array}$ & 1 dia & 2 dias & 3 dias \\
\hline \hline $\mathrm{Rs}\left(\Omega \cdot \mathrm{cm}^{2}\right)$ & 7,50 & 8,67 & 8,77 \\
\hline $\mathrm{CPE}_{1}\left(\mu \mathrm{F} \cdot \mathrm{cm}^{-2}\right)$ & 2,19 & 1,98 & 1,65 \\
\hline$\alpha_{1}$ & 0,81 & 0,83 & 0,85 \\
\hline $\mathrm{R}_{1}\left(\mathrm{~K} \Omega \cdot \mathrm{cm}^{2}\right)$ & 3,40 & 3,14 & 3,96 \\
\hline $\mathrm{CPE} \mathrm{E}_{2}\left(\mu \mathrm{F} \cdot \mathrm{cm}^{-2}\right)$ & 6,13 & 6,17 & 6,65 \\
\hline$\alpha_{2}$ & 0,86 & 0,86 & 0,84 \\
\hline $\mathrm{R}_{2}\left(\mathrm{~K} \Omega \cdot \mathrm{cm}^{2}\right)$ & 172,48 & 189,06 & 332,60 \\
\hline $\mathrm{CPE}_{3}\left(\mu \mathrm{F} \cdot \mathrm{cm}^{-2}\right)$ & 5,62 & 6,89 & 20,43 \\
\hline$\alpha_{3}$ & 0,82 & 0,77 & $1^{*}$ \\
\hline $\mathrm{R}_{3}\left(\mathrm{~K} \Omega \cdot \mathrm{cm}^{2}\right)$ & 8,55 & 2,84 & 1,21 \\
\hline
\end{tabular}

${ }^{*}$ valor fixado. 
Tabela 11. Valores dos parâmetros elétricos obtidos com ajuste do circuito elétrico equivalente (CEE) da Figura 38(B) aos resultados experimentais para alumínio AA1050 com tratamento OS após vários períodos de imersão em solução de ensaio, utilizando o software Zview.

\begin{tabular}{cccc}
\hline \hline $\begin{array}{c}\text { Elemento do CEE } \\
\text { OS }\end{array}$ & 1 dia & 2 dias & 3 dias \\
\hline \hline Rs $\left(\Omega \cdot \mathrm{cm}^{2}\right)$ & 10,02 & 10,09 & 10,13 \\
\hline $\mathrm{CPE}_{1}\left(\mu \mathrm{F} . \mathrm{cm}^{-2}\right)$ & 3,49 & 3,07 & 2,80 \\
\hline$\alpha_{1}$ & 0,79 & 0,81 & 0,81 \\
\hline $\mathrm{R}_{1}\left(\mathrm{~K} \Omega \cdot \mathrm{cm}^{2}\right)$ & 2,94 & 2,82 & 3,32 \\
\hline $\mathrm{CPE}_{2}\left(\mu \mathrm{F} \cdot \mathrm{cm}^{-2}\right)$ & 1,82 & 2,07 & 2,24 \\
\hline$\alpha_{2}$ & $0,96^{\star}$ & $0,93^{*}$ & $0,92^{\star}$ \\
\hline $\mathrm{R}_{2}\left(\mathrm{~K} \Omega \cdot \mathrm{cm}^{2}\right)$ & 5,21 & 5,53 & 7,37 \\
\hline $\mathrm{CPE}{ }_{3}\left(\mu \mathrm{F} . \mathrm{cm}^{-2}\right)$ & 3,26 & 3,14 & 2,93 \\
\hline$\alpha_{3}$ & 0,85 & 0,86 & 0,87 \\
\hline $\mathrm{R} 3\left(\mathrm{~K} \Omega \cdot \mathrm{cm}^{2}\right)$ & 5,41 & 6,21 & 6,72 \\
\hline
\end{tabular}

*valores fixados

A comparação dos valores de $R_{1}$ para os tratamentos OX e OS mostra menores valores de $R_{1}$ para o tratamento OS em todos os tempos de ensaio. Conforme proposto anteriormente, esta menor resistência pode ser resultado do ataque corrosivo da solução de $\operatorname{SAM}(\mathrm{pH}=3,0)$ ao filme de óxido-hidróxido formado durante tratamento OS. A variação de $R_{1}$ observada entre 1 e 3 dias de imersão na solução de ensaio sugere que esta solução é pouco agressiva à camada de óxido-hidróxido superficial resultando, eventualmente, na precipitação de produtos hidratados, o que mostra um comportamento dinâmico (Crescimento e degradação da camada), correspondente à remodelação do filme, conforme já foi reportado na literatura [Brett et al., 1992].

Os valores de $\mathrm{CPE}_{1}$ para os dois tratamentos são próximos, o que seria esperado, uma vez que se trata de um filme similar de óxido-hidróxido. Todavia, para o tratamento $\mathrm{OS}$, os valores de $\mathrm{CPE}_{1}$ foram sempre superiores, o que 
poderia ser explicado pela diminuição da espessura da camada de óxidohidróxido.

A comparação dos valores da resistência associada à segunda constante de tempo $\left(R_{2}\right)$ mostra uma grande diferença entre os dois tratamentos, OX e OS. Foi proposto neste trabalho que esta resistência está relacionada com os produtos hidratados formados ao redor de precipitados nos quais se observou ataque localizado. Este produto, segundo a literatura, consiste em $\mathrm{Al}(\mathrm{OH})_{3}$, hidrargilita [Reboul e Baroux, 2011].

A Tabela 10 mostra que para 1 dia de imersão, a resistência $R_{2}$ associada ao tratamento $\mathrm{OX}\left(\mathrm{R}_{2(\mathrm{OX})} \sim 172 \mathrm{~K} \Omega . \mathrm{cm}^{2}\right)$ é cerca de 35 vezes superior ao tratamento OS $\left(\mathrm{R}_{2(\mathrm{OS})} \sim 5 \mathrm{~K} \Omega . \mathrm{cm}^{2}\right)$, Tabela 11 . O período de 3 horas de imersão em solução com SAM a $40 \stackrel{\circ}{\mathrm{C}}$ e $\mathrm{pH}=3,0$ pode justificar essa diferença, na medida em que a elevada acidez da solução causa o ataque e dissolução parcial dos produtos hidratados. Com a evolução do tempo de ensaio, a diferença nos valores da resistência $R_{2}$, para os dois tratamentos, aumenta ainda mais, o que pode ser explicado pelo crescente acúmulo de produtos hidratados no caso do tratamento $\mathrm{OX}$ em conseqüência de corrosão localizada na solução de ensaio. Para o tratamento OS, o valor de $\mathrm{R}_{2}$ aumenta apenas ligeiramente, o que sugere menor susceptibilidade ao ataque localizado e, conseqüentemente, menor acúmulo de produtos na região em torno dos precipitados ativos.

Segundo a literatura [Reboul e Baroux, 2011], a formação de produtos hidratados é decorrência da propagação dos pites. Conforme descrito por Reboul e Baroux, o aumento do número de pites é limitado e controlado pela reação catódica em uma parte isolada do metal, devido à presença e distribuição de compostos intermetálicos mais nobres na superfície. Durante a propagação, a concentração de $\mathrm{Cl}^{-}$nos pites aumenta. $\mathrm{O}$ acúmulo desses íons dentro dos pites ativos forma uma camada complexa de cloreto $\left(\mathrm{AlCl}_{4}\right)^{-}$, principalmente no fundo dos pites, que substitui o filme de óxido passivo inicialmente presente. Esse complexo é solúvel e enquanto as condições favorecerem sua formação, a propagação continua.

Os íons $\mathrm{Al}^{3+}$ gerados nos sítios ativos anódicos por dissolução do alumínio dentro do pite são hidrolisados, consumindo os íons $\mathrm{OH}^{-}$e resultando em 
acidificação da solução dentro dos pites (por aumento de íons $\mathrm{H}^{+}$disponíveis). A hidrólise dos íons $\mathrm{Al}^{3+}$ na região externa ao pite onde a solução se encontra menos ácida (ou neutra dependendo do $\mathrm{pH}$ da solução de ensaio), por sua vez, forma sobre o pite uma "tampa" volumosa, composta por hidróxido de alumínio $\left(\mathrm{Al}(\mathrm{OH})_{3}\right)$, restringindo a migração de íons na solução, dentro e fora do pite, mantendo assim, a condição mais agressiva da solução dentro dos pites.

Ambos os fenômenos, consumo de $\mathrm{OH}^{-}$e fechamento do pite, contribuem para formação de uma solução mais agressiva (ácida e rica em $\mathrm{Cl}^{-}$) e para a manutenção da atividade no interior dos pites. Por isso, a corrosão por pite no alumínio é chamada de fenômeno auto-catalítico. Por outro lado, a formação de bolhas de hidrogênio $\left(\mathrm{H}_{2}\right.$ gasoso) resultante da auto-corrosão do alumínio contribui, juntamente com a difusão, para limitar o aumento da concentração na solução agressiva dentro do pite. A propagação do pite então cessa, quando a corrente de corrosão diminui, tornando-se insuficiente para permitir a renovação da camada solúvel de $\left(\mathrm{AlCl}_{4}\right)^{-}$de forma suficientemente rápida, no fundo dos pites. A camada de complexo de cloreto é então dissolvida e substituída pelo filme de óxido passivo. A solução agressiva dentro do pite será então diluída pela solução externa, colocando um fim à propagação do pite. [Reboul e Baroux, 2011].

A solução de ensaio usada nos experimentos do presente trabalho contém baixa concentração de íons $\mathrm{Cl}^{-}$, portanto, é necessário considerar que íons sulfato também participam desse processo. Um complexo de sulfato pode também ser formado. Segundo a literatura [Ridley et al., 1999], o alumínio em meio de sulfato pode formar dois complexos $\left[\mathrm{Al}\left(\mathrm{SO}_{4}\right)\right]^{+}$ou $\left[\mathrm{Al}\left(\mathrm{SO}_{4}\right)_{2}\right]^{-}$. Este último complexo poderia substituir o complexo de cloreto na seqüência de propagação do pite. Além disso, Ridley et al. [1997] mostraram que a solução de sulfato aumenta a taxa de dissolução do $\mathrm{Al}(\mathrm{OH})_{3}$ em solução aquosa ácida na temperatura ambiente.

A resistência associada à terceira constante de tempo, $R_{3}$, foi relacionada aos processos interfaciais. Vale ressaltar que os valores de $R_{3}$ para os dois tratamentos, OX e OS, foram da mesma ordem de grandeza. Porém, estes diminuíram entre 1 e 3 dias de ensaio para o tratamento $\mathrm{OX}$, enquanto que para $\mathrm{O}$ tratamento $\mathrm{OS}$, estes aumentaram continuamente com o tempo. Os resultados do 
ajuste também mostram que o elemento de fase constante (CPE) para o tratamento $\mathrm{OX}, \mathrm{CPE}_{3(\mathrm{OX})}$, atinge valores característicos de capacitância de dupla camada elétrica $\left(\mathrm{C}_{(\mathrm{dl})}\right)$ após 3 dias de ensaio, da ordem de $20 \mu \mathrm{F} . \mathrm{cm}^{2}$, enquanto para o tratamento OS, o $\mathrm{CPE}_{3(\mathrm{OS})}$, mostra um pequeno aumento com o tempo de imersão. Neste caso, duas explicações são propostas, primeiramente, as moléculas auto-organizáveis dificultam a propagação dos pites ao limitarem a corrente catódica e anódica pelo cobrimento da superfície interna ao pite, neste caso atuando como inibidor misto e, conseqüentemente, dificultando, por mecanismo barreira, a formação dos complexos solúveis e a dissolução do alumínio em $\mathrm{Al}^{3+}$. Uma segunda explicação pode ser o recobrimento mais rápido de áreas internas ao pite pelas bolhas de hidrogênio, cuja formação é favorecida em meio ácido. Isto desfavoreceria a formação de produtos hidratados, hipótese apoiada pela observação de menor $R_{2(O S)}$ em comparação a $R_{2(O X)}$.

As Figuras 43(A), (B), (C) e (D), apresentam a evolução dos diagramas de EIE para alumínio AA1050 submetido ao tratamento OS e imerso em solução de ensaio por 20 dias. O comportamento indutivo apresentado após os primeiros dias (1, 2 e 3 dias) de imersão em solução de ensaio em amostras submetidas aos tratamentos $\mathrm{PB}, \mathrm{Cr}(\mathrm{VI})$ e SAM, pode ser observado para o alumínio com tratamento OS após 20 dias de imersão, Figura 43(B). Esse comportamento é um indicativo de que os processos de adsorção de espécies presentes na solução de ensaio também estão atuando na superfície com o tratamento OS. Porém, estão "ocultos" em regiões de mais baixas freqüências $(<0,01 \mathrm{~Hz})$ e podem ser identificados nos diagramas de EIE apenas após o período de 12 dias de imersão. Estes resultados podem indicar maior resistência do filme, retardando o processo de chegada das espécies agressivas ao substrato.

Os diagramas de Bode (Figuras 43C e D) sugerem degradação da camada protetora de óxido-hidróxido de alumínio com o tempo de imersão crescente, sendo esta associada à constante de tempo em altas freqüências. Após períodos maiores de exposição ao eletrólito, a constante de tempo associada a esta camada se aproxima cada vez mais daquela relacionada à segunda constante, indicando a sobreposição de ambas na região de médias freqüências. 
OS

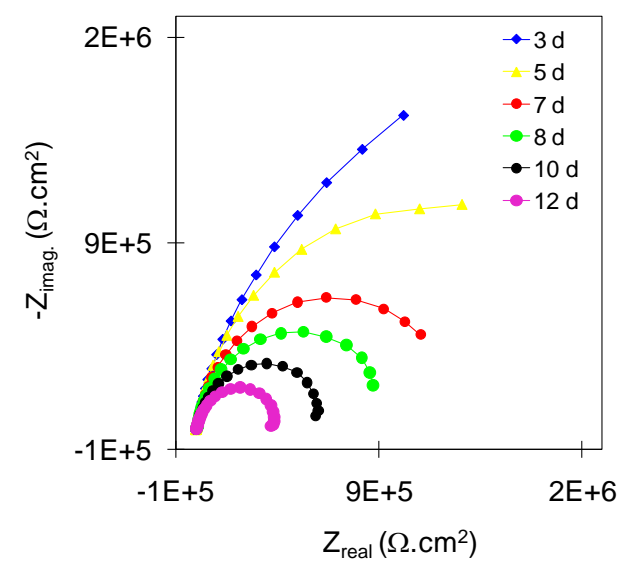

(A)

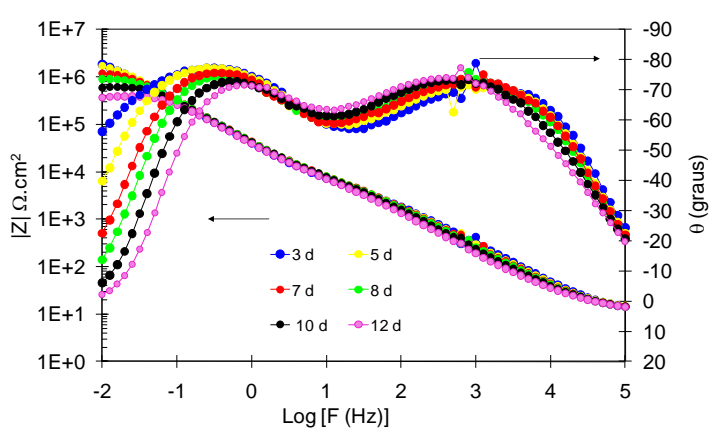

(C)

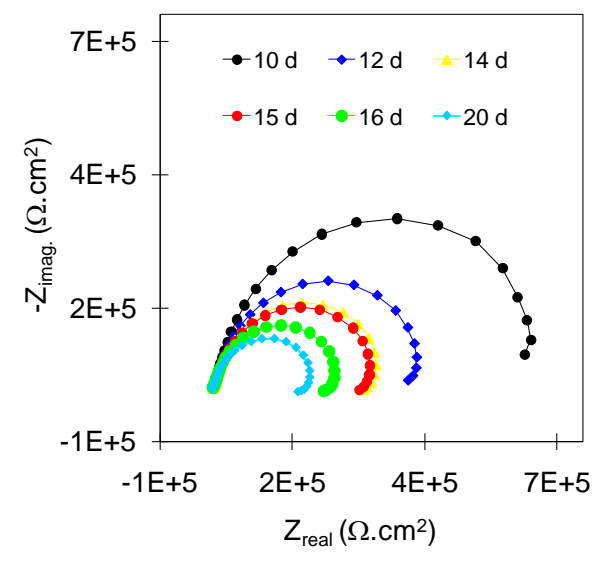

(B)

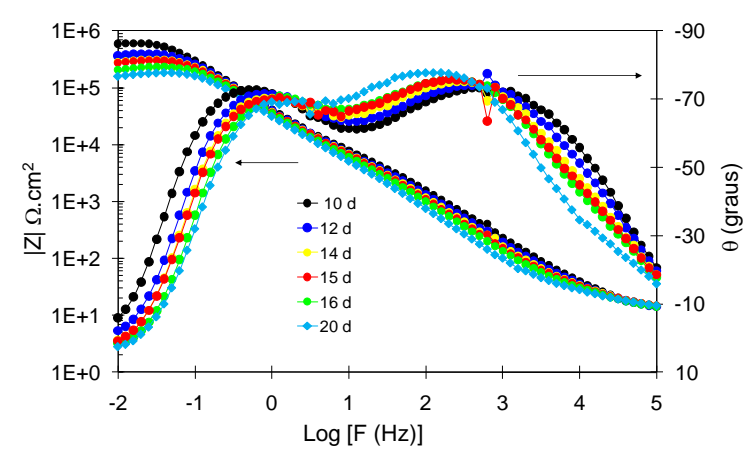

(D)

Figura 43: Evolução dos diagramas de EIE para alumínio AA1050 com tratamento OS até 20 dias de imiersão em solução $0,5 \mathrm{~mol} \mathrm{~L}^{-1}$ de sulfato de sódio, $\mathrm{pH}=4,0$, (A) e (B) Nyquist e (C) e (D) Bode. 


\section{CONCLUSÕES}

A investigação do efeito do eletrodo de referência nos ensaios eletroquímicos confirmou que mesmo em baixas concentrações, íons cloreto, têm influência na resistência à corrosão do alumínio AA1050, particularmente nos tempos iniciais de imersão em solução de ensaio. Os resultados de EIE mostraram resultados de impedância muito distintos para ensaios realizados utilizando o ECS e o ESM, porém, apenas nas primeiras horas de imersão. A diferença, entretanto, diminuiu com a evolução do tempo de imersão. Após $24 \mathrm{~h}$ de exposição os diagramas obtidos com os dois tipos de eletrodo de referência (ECS e ESM) se encontraram praticamente sobrepostos indicando que o sulfato também é responsável por ataque localizado à superfície de alumínio. Isto foi confirmado pela observação da superfície após os ensaios de imersão na solução de sulfato $\left(0,5 \mathrm{~mol} \mathrm{~L}^{-1}, \mathrm{pH}=4,0\right)$ sendo observados pites para os dois tipos de eletrodos de referência utilizados.

Os resultados do presente trabalho permitiram concluir que o tratamento de imersão em soluções de desengraxe e desoxidação promoveu ataque e remoção de precipitados da superfície do alumínio AA1050 mostrando que, além de remover oleosidades e sujeiras, este tratamento causa a "limpeza" da superfície pela redução na quantidade de precipitados.

O tratamento de modificação da superfície do alumínio AA1050 com moléculas auto-organizáveis (SAM) não produziu o efeito esperado, isto é, o aumento da resistência à corrosão da superfície por períodos prolongados. 0 resultado obtido foi atribuído à agressividade da solução com SAM $(\mathrm{pH}=3,0)$ e ao tempo de tratamento $(3 \mathrm{~h})$ adotados neste estudo, gerando ataque à fina camada de óxido-hidróxido e em regiões de interface matriz/precipitados. Se por um lado o ataque provocado pela solução com SAM produziu remoção de precipitados e, consequentemente, a "limpeza" parcial da superfície, por outro, as cavidades deixadas pela remoção dos precipitados, principalmente as mais estreitas podem ter levado a uma maior susceptibilidade ao ataque localizado. Além disso, possíveis falhas no recobrimento podem ter favorecido a criação sítios propícios à corrosão localizada. 
O comportamento frente à corrosão das superfícies com tratamentos de desengraxe e desoxidação $(\mathrm{PB})$ e com $\mathrm{Cr}(\mathrm{VI})$ foram muito similares. $\mathrm{O}$ tratamento com SAM foi mais agressivo à superfície do alumínio AA1050 que o $\mathrm{Cr}(\mathrm{VI})$. No entanto, este último também não apresentou melhora significativa na resistência à corrosão da superfície do alumínio AA1050 por períodos prolongados, embora tenha permitido a observação do fenômeno de auto-regeneração ("Self-healing"). Estes resultados podem ser explicados pelo fato do tratamento com $\mathrm{Cr}(\mathrm{VI})$ adotado neste trabalho não ter formado uma camada de óxido de cromo espessa, como geralmente é observada nas camadas de conversão de cromato.

Os tratamentos que envolveram a etapa de imersão em água fervente produziram uma camada de óxido-hidróxido mais espessa e, consequentemente, uma polarização da reação anódica por aumento da resistência, bem como polarização da reação catódica pela deposição de produtos hidratados (óxidohidróxido) nas regiões catódicas externas ao pite, causando a obstrução de sítios catódicos.

Os resultados deste trabalho indicaram que o tratamento associado à maior resistência da superfície do alumínio AA1050 foi o que consistiu em imersão em água fervente seguida por imersão em solução com SAM (Óxido + SAM), enquanto aquele relacionado com a maior susceptibilidade à corrosão, foi o tratamento com moléculas auto-organizáveis (SAM). 


\section{SUGESTÕES PARA TRABALHOS FUTUROS}

1. Avaliar o efeito do $\mathrm{pH}$ da solução de SAM na resistência à corrosão e morfologia da superfície do alumínio AA1050.

2. Investigação do efeito do tempo de tratamento SAM utilizando períodos mais curtos em comparação ao adotado no presente estudo ( $3 \mathrm{~h}$ ).

3. Caracterização da superfície do alumínio após tratamento SAM utilizando técnicas de análise de superfície, como TEM e XPS, as quais permitem análise de filmes finos. 


\section{REFERÊNCIAS BIBLIOGRÁFICAS}

- $\quad$ ABAL, Associação Brasileira do Alumínio, Guia Técnico do Alumínio. Tratamento de superfície, São Paulo, Abal, 13. 1996.

- ABAL, Relatório de Sustentabilidade do Alumínio - www.abal.org.br, acesso em 10/12/2010.

- Alagta, A., Felhosi, I., Bertoti, I., Kálmán, E. Corrosion protection properties of hydroxamic acid self-assembled monolayer on carbon steel. Corrosion Science, v.50, p.1644-1649, 2008.

- Alwitt, R.S., The Aluminum Water System, in Oxides and oxides films, vol.4, Dekker, M. Editora J.W.Diggel, New York, p.169-254, 1976.

- ANVISA, Agência Nacional de Vigilância Sanitária www.anvisa.gov.br, acesso em 30/12/2010.

- Aoki, I.V., Bernard, M.C., de Torresi, S.I.C., Deslouis, C., de Melo, H.G., Joiret, S., Tribolet, B. Ac-impedance and Raman spectroscopy study of the eletrochemical behavior of pure aluminium in citric acid media. Electrochimica Acta, v.46, p. 1871-1878, 2001.

- Aramaki, K., Shimura, T. Preparation of a one-dimensional polymer film on passivated iron by modification of a carboxylate ion self-assembled monolayer with octyltriethoxysilane for preventing passive film breakdown. Corrosion Science, v.46, n.10, p. 2533-2548, 2004.

- ASM Handbook, Corrosion: Fundamentals, Testing and Protection, Volume 13A, 9ª edição, USA, 2003.

- ASSIS S.L., Investigação da Resistência à corrosão da liga Ti-13Nb13Zr por meio de técnicas eletroquímicas e de analise de superfície.Tese (doutorado), Instituto de Pesquisas Energéticas e Nucleares, 2006.

- Atitudes Sustentaveis, www.atitudessustentaveis.com.br/sustentabilidade/sutentabilidade/, acesso em 13/08/2010. 
- Bain, C.D., Troughton, E.B., Tao, Y-T., Evall, J., Whitesides G.M., Nuzzo R.G., Formation of monolayer films by the spontaneous assembly of organic thiols from solution onto gold. Journal of the American Chemical Society, v.11, n.1, p. 321-335, 1989.

- Baltat-Bazia, A., Celati, N., Keddan, M., Takenouti, H., Wiart, R., Electrochemical impedance spectroscopy and electron microscopies applied to the structure of anodic oxide layers on pure aluminum. Materials Science Forum, v.111-112, p. 359-368, 1992.

- Bechet, B., Epelboin, I., Kedam, M. New data from impedance measuments concerning the anodic dissolution of iron in acidic sulfuric media. Journal of Electroanalytical Chemistry and Interfacial Electrochemistry, v.76, n.1, p.129-134, 1977.

- Bessone, J. B., Mayer, C., Juttner, K., Lorenz, W. J. AC-impedance measurements on aluminium barrier type oxide films. Electrochimica Acta, v.28, n.2, p.171-175, 1983.

- Bessone, J. B., Salinas, D. R., Mayer, C., Ebert, M., Lorenz, W. J. An EIS study of aluminium barrier-type oxide films formed in different media. Electrochimica Acta, v.37, n.12, p. 2283-2290, 1992.

- Bethencourt, M., Botana, F.J., Calvino, J.J., Marcos, M., RodriguezChacón, M.A. Lanthanide compounds as environmentaly-friendly corrosion inhibitors of aluminium alloys: A review. Corrosion Science, v.40, n.11, p.1803-1829, 1998.

- Bierwagen, G.P., Tallman, D.E. Choice and measurement of crucial aircraft coatings system properties. Progress Organic Coating, v.41, n.4, p. 201206, 2001.

- Bonnel, K., Le Pen, C., Pébère, N. E.I.S. characterization of protective coatings on aluminium alloys. Electrochimica Acta, v.44, p. 4259-4267, 1999.

- Bonora, P.L., Deflorian, F., Fedrizzi, L. Electrochemical impedance spectroscopy as a tool for investigating underpaint corrosion.

Electrochimica Acta, v.41, n.7-8, p.1073-1082, 1996. 
- Bressiani, E.F., Seleção de Metais Não Ferrosos, editora da Unicamp, p. 25-43, 1992.

- Brett, C.M.A. On the eletrochemical behavior of aluminium in acidic choride solution. Corrosion Science, v.33, n.2, p. 203-210, 1992

- Brown, G. M., Shimizu, K., Kobayashi, K., Thompson, G. E., Wood G. C. The growth of chromate conversion coatings on high purity aluminium Corrosion Science, v.34, n.7, p.1045-1054, 1993.

- Buchheit, R.G. A compilation of corrosion potencials reported for intermetallic phases in aluminum alloys. Journal of the Electrochimica Society, v. 142, n.11, p. 3994-3396, 1995.

- Buchheit, R.G., Grant, R.P., Hlava, P.F., Mckenzie, B., Zender, G.L. Local dissolution phenomena associated with $\mathrm{S}$ Phase $\left(\mathrm{Al}_{2} \mathrm{CuMg}\right)$ particles in aluminum Alloy 2024-T3. Journal of the Electrochemical Society, v.144, p. 2621-2628, 1997.

- Buchheit, R.G., Mamidupally, S.B., Schmutz, P., Guan, H. Active corrosion protection in Ce-modified hydrocalcite conversi. Corrosion - NACE, 58, 11, 2002.

- Buchheit, R.G., Martinez, M.A., Montes, L.P. Evidence for Cu ion formation by dissolution and dealloying the $\mathrm{Al}_{2} \mathrm{CuMg}$ intermetallic compound in rotating ring-disk collection experiments. Journal of the Electrochemical Society, v.147, n.1, p.119-124, 2000.

- Buchheit, R.G., Montes, L.P., Martinez, M.A., Michael, J., Hlava, P.F. The electrochemical characteristics of bulk-synthesized $\mathrm{Al}_{2} \mathrm{CuMg}$. Journal of the Electrochemical Society, v.146, n.12, p.4424-4428, 1999.

- Burstein, G.T., Cinderey, R.J. The potencial of freshly generated metal surfaces determined from the guillotined electrode - A new technique. Corrosion Science, v.23, n.11, 1991.

- Burstein, G.T., Liu, C. Time-resolved electrochemical impedance of guillotined aluminum electrode. Eletrochimica Acta, v. 39, n.7, p. 873-882, 1994. 
- Cabot, P.L., Garrido, J.A., Pérez, E., Moreira, A.H., Sumodjo, P.T.A, Proud, $\mathrm{W}$. EIS study of heat-treated Al-Zn-Mg alloys in the passive and transpassive potencial regions. Electrochimica Acta, v.40, n.4, p.447-454, 1995.

- Cabral A., Trabelsi W., Serra R., Montemor M.F., Zheludkevich M.L., Ferreira M.G.S. The corrosion resistence of hot dip galvanised stell and AA2024-T3 pre-treated with bis-[Triethoxysily|propyl] tetrasulfide solutions doped with $\mathrm{Ce}\left(\mathrm{NO}_{3}\right)_{3}$. Corrosion Science, v.48, p.3740-3758, 2006.

- Cabral A.M., Duarte R.G., Montemor M.F., Zheludkevich M.L., Ferreira M.G.S. Analytical characterization and corrosion behavior of bis[triethoxisilylpropyl] tetrasulphide pre-treated AA2024-T3, Corrosion Science, v.47, p.869-87, 2005.

- CALLISTER Jr W.D., Ciência e Engenharia de Materiais: Uma Introdução, Editora LTC - Livros Técnicos e Científicos editora S.A, p.705 $.7^{\mathrm{a}}$ edição, 2008.

- Campestrini, P., Terryn, H., Hovestad, A., de Wit, J.H.W. Formation of a cerium-based conversion coating on AA2024: relationship with microestructure. Surface and Coatings Tecnology. v.176, p. 365-381, 2004.

- Campestrini, P., van Westing, E.P.M., de Wit, J.H.W. Influence of surface preparation performance of chromate conversion coatings on Alcald 2024 aluminum alloy Part I: EIS investigation. Electrochimica Acta, v.46, $p$ 2631-2647, 2001a.

- Campestrini, P., van Westing, E.P.M., de Wit, J.H.W. Influence of surface preparation performance of chromate conversion coatings on Alcald 2024 aluminum alloy Part II: EIS investigation. Electrochimica Acta, v.46, p 2631-2647, 2001b.

- Chen, P.J., Wallace, R.M., Henck, S.A. Thermal properties of perfluorinated n-alkanoic acids self-assembled on native aluminum oxide surfaces.

Journal of Vacuum Science and Technology A: Vacuum, Surfaces and Films, v.16, n.2, p. 700-706, 1998. 
- Clark, W.J., Ramsey, J.D., McCreery, R.L., Frankel, G.S. Inhibition of corrosion related reduction processes via chromium monolayer formation. Journal of the Electrochemical Society, v.149, n.5, p. B179-B185, 2002.

- Cohen, S.M. Review: Replacement for chromium pretreatments on aluminum. NACE International, v.51, n.1, p. 71-79, 1995.

- Dai, J., Sullivan, D.M., Bruening, M.L. Ultrathin, layered polyamide and polyimide coatings on aluminium. Industrial and Engeneering Chemistry Research, v.39, n.10, p. 3528-3535, 2000.

- Darken, L., Gurry, R., Physical Chemistry of Metals, ed. McGraw Hill Education, p. 212, 1953.

- Davis, J.R., (Davis \& Associate), Aluminum and Aluminum Alloys, ASM Specialty Handbook, 1993.

- Dawson, J.L., Ferreira, M.G.S. Crevice corrosion on 316 stainless steel in $3 \%$ sodium chloride solution. Corrosion Science, v.26, n.12, p. 1027-1040, 1986.

- de Souza, S., Yoshikawa, D. S., Izaltino, W. A. S., Assis, S. L., I, Costa. Self-assembling molecules as corrosion inhibitors for 1050 aluminum. Surface and Coatings Technology. v.204, n.20, p.3238-3243, 2010.

- de Souza, S., Yoshikawa, D. S., Izaltino, W. A. S., Assis, S. L., I, Costa. Nanostructured surface pre-treatment based on self-assembled molecules for corrosion protection of Alclad 7475-T761 aluminum alloy. Materials and Corrosion, v.62, n.-, p.-, 2011. (DOI: 10.1002/maco.201005631)

- de Wit, J. H., Lenderink, H.J.W. Electrochemical impedance spectroscopy as a tool to obtain mechanistic information on the passive behaviour of aluminium. Electrochimica Acta, v.41, n.7/8, p.1111-1119, 1996.

- de Wit, J.H., Wijenberg, C., Crevecouer, C. Impedance measurements during anodization of aluminum. Journal of the Electrochemical Society, v.126, n.5, p.779-785, 1979.

- Decroly, A., Petitjean, J.-P., Study of the deposition of cerium oxide by conversion on to aluminium alloys. Surface and Coatings Technology, v.194, p. 1-9, 2005. 
- Domingues, L., Fernandes, J.C.S., Da Cunha Belo, M., Guerra-Rosa, L. Anodising of Al 2024-T3 in a modified sulfuric acidqboric acid bath for aeronautical applications. Corrosion Science, v.45, p.149-160, 2003.

- Epelboin, I., Grabrielli, C., Keddam, M. Role de la diffusion dans les phenomeles de passivation et de corrosion localisee du fer en milieu acide. Corrosion Science, 15, p.155-171,1975.

- FERNANDES, J.S., Espectroscopia de Impedância Electroquímica, IST - Instituto Técnico Superior, Portugal, 2000.

- Fischer, H., Modes of inhibiting electrode processes (corrosion included) and their experimental discrimination. I. Defintion, nomenclature and classification of modes of inhibition in electrochemical electrode reactions. Materials and corrosion, v.23, n.6, p.445-452, 1972.

- Franceschetti, D.R., MacDonald, J.R. Electrode kinetics, equivalent circuits, and system characterization: small-signal conditions. Journal of Electroanalytical Chemistry and Interfacial Electrochemistry, v.82, p.271-301, 1977.

- Frankel, G.S., McCreery, R.L. Inhibition of Al alloy by chromates. Electrochemical Society Interface, v.10, n.1-4, p. 34-38, 2001.

- Free, M. L., Understanding the effect of surfactant aggregation on corrosion inhibition of mild steel in acidic medium. Corrosion Science, v.44, p. 28652870, 2002.

- Frenkel, G.S., Sridhar, N. Understanding localized corrosion. Materials Today, v.11, n.10, 2008.

- Frers, S.E., Stefenel, M.M., Mayer, C., Chierchie, E T. AC-Impedance measurements on aluminium in chloride containing solutions and below the pitting potencial. Journal of Applied Electrochemistry, v.20, n.6, p. 996999, 1990.

- GENTIL, V., Corrosão, L.T.C. Editora, 1996.

- Gourgues, A. F. Electron backscatter diffraction and cracking. Materials Science and Technology, v.18, p.119-133, 2002.

- Guillaumin, V., Mankowski, G. Localized corrosion of 2024-T351 aluminium alloy in chloride media. Corrosion Science, v.41, p.421-438, 1998. 
- Hart, R.K. The formation of films on aluminium immersed in water. Transactions of the Faraday Society. v. 53, p.1020-1027, 1957.

- Hoque, E., de Rose, J.A., Hoffmann, P., Mathieu,H.J., Bhushan, B., Cichomski, M. Phosphonate self-assembled monolayers on alumium surfaces. The journal Of Chemical Physics, v.124, p.174710, 2006.

- Infomet, Informações técnicas, www.infomet.com.br/metais-e-ligasassuntos.php, acesso em 2010.

- Izaltino, W.A.S., de Souza, S., Yoshikawa, D.S., Costa, I. Efeito do tempo de tratamento de crescimento de óxido na proteção à corrosão da liga ALCLAD 7475. In: 19ำ congresso brasileiro de engenharia e ciência dos materiais, CBCIMAT, 2010, Campos do Jordão-SP-Brasil.

- Kálman E., Trends in corrosion research. Electrochimica Acta, 46, 24/25. p. 3607-3609, 2001.

- Kendig, M., Jeanjaquet, S. Cr(VI) and Ce(III) Inhibition of Oxygen Reduction on copper. Journal of the Electrochemical Society, v.149, n.2, p.B47B51, 2002.

- Kolics, A., Besing, A. S., Wieckowski, A. Interaction of chromate ions with surface intermetallics on aluminum alloy 2024-T3 in $\mathrm{NaCl}$ solutions. Journal of the Electrochemical Society, v.148, n.8. p. B322-B331, 2001.

- LASIA A., Electrochemical Impedance Spectroscopy and Its Applications, Modern Aspects of Electrochemistry, B. E. Conway, J. Bockris, and R.E. White, Editora Publishers, New York, v.32, p.248, 1999.

- Lenderink, H. J. K., Linden, M. V. D., de Wit, J. H. W. Corrosion of aluminium in acidic and neutral solutions. Electrochimica Acta, v.38, n.14, p.1989-1992, 1993.

- Lewington, T.A., Alexander, M.R., Thompson, G.E., McAlpine, E. Characterisation of alkyl phosphonic acid monolayers self assembled on hydrated surface of aluminium. Surface Engineering, v.18, n.3, p.228-232, 2002.

- Lytle, F.W., Greegor, R.B., Bibbins, G.L., Blohowiak, K.Y., Smith, R.E., Tuss, G.D. An investigation of the structure and chemistry of a Chromiumcoversion surface layer on aluminum. Corrosion Science, v.37, n.3, p.349369, 1995. 
- Maege, I., Jaehne, E., Henke, A., Adler, H-J.P., Bram, C., Jung, C., Stratmamm, M. Self-assembling adhesion promoters for corrosion resistant metal polymer self-assembling adhesion promoters for corrosion resistant metal polymer interfaces. Progress in Organic Coatings, v.34, n.1-4, p.112, 1998.

- Maniasso, N.. Ambientes micelares em química analítica, Química Nova, v.24, n.1, p.87-93, 2001.

- Mansfeld, F., Kendig, M.W. Evaluation of anodized aluminum surface with electrochemical impedance. Journal of the Electrochemical Society, v.135, p.828-833, 1988.

- Mansfeld, F., Pérez, F.J. Surface modification of aluminum alloys in molten salts containing $\mathrm{CeCl}_{3}$. Thin Solid Films, v.270, p 417-421, 1995.

- Mansfeld, F., Shih, H. Detection of pitting with electrochemical impedance spectroscopy. Journal of the Electrochemical Society: Electrochemical Science and Technology, v.138, p.1171-1172, 1988.

- Mansfeld, F., Wang, Y., Shih, H. The Ce-Mo process for the development of a stainless aluminum. Electrochimica Acta, v.37, n.17, p. 2277-2282, 1992.

- Martini, E.A.M., Muller, I.L., Characterization of the film formed on iron in borate solution by electrochemical impedance spectroscopy. Corrosion Science, v.42, n.3, p.433-454, 2000.

- Mattsson E., Basic Corrosion Technology for Scientists and Engineers, New York, ed. John Wiley \& Sons, 1989.

- Mendoza, A.R., Corvo, F. Outdoor and indoor atmospheric corrosion of non-ferrous metals. Corrosion Science, v.42, n.7, p. 1123-1147, 2000.

- Meng, G., Wei, L., Zhang, T., Shao, Y., Wang, F., Dong, C., Li, X. Effect of microcrystallization on pitting corrosion of pure aluminium. Corrosion Science, v.51, p.2151-2157, 2009.

- Moraes, S.L. e Resende, M.O.O. Determinação da concentração micelar critica de ácidos húmicos por medidas de condutividade e espectroscopia, Química Nova, v.27, n.7, p.1123-1133, 2004. 
- Moshier, W.C., Davis, G.D., Ahearn, J.S. The corrosion and passivity of aluminium exposed to dilute sodium sulfate solutions. Corrosion Science, v.27, n.8, p.785-801, 1987.

- Natishan, P.M., McCafferty, E., Hubler, G.K. Surface charge considerations in the pitting of ion-implanted aluminum. Journal of Electrochemical Society, v.135, n.2, p.321-327, 1988.

- OLIVEIRA, J.C.P.T., Evolução da microestrutura e da textura durante a laminação a frio e a recristalização de alumínio com diferentes níveis de pureza. Tese (Doutorado em Engenharia Metalúrgica e de Materiais da Escola Politécnica da Universidade de São Paulo), 2009.

- OTOMAR, H.P., Estudo Comparativo da Estampabilidade da Liga de Alumínio AA 1050 Partindo de Placas Obtidas por Vazamento Direto e Bobinas Obtidas por Vazamento Contínuo. Dissertação (Mestrado em Engenharia Metalúrgica e de Materiais da Escola Politécnica da Universidade de São Paulo), p.151, 2010.

- PADILHA, A.F., AMBROSIO FILHO, F., Técnicas de Análise Microestrutural, São Paulo, ed. Hemus, 1985.

- Palomino, L. M., Suegama, P. H., Aoki, I. V., Montemor, M. F., de Melo, H. G. Electrochemical study of modified non-functional bis-silane layers on $\mathrm{Al}$ alloy 2024-T3. Corrosion Science, v.50, p.1258-1266, 2008.

- PALOMINO, L.M., Caracterização Microestrutural e Eletroquímica e Eletroquímica de Revestimentos Ambientalmente Amigáveis Aplicados sobre a Liga de Al2024-T3, Tese (Doutorado em Engenharia Química da Escola Politécnica da Universidade de São Paulo), 2008.

- Palomino, L.M., Suegama, P.H., Aoki, I.V., Montemor, M.F., de Melo, H.G., Electrochemical study of modified cerium-silane bi-layer on Al alloy 2024T3. Corrosion Science, v.51, n.6, p.1238-1250, 2009.

- Pathak, B.R., Godard, H.P. Equation for predicting the corrosivity of natural fresh waters to Aluminium. Nature, n.218, p.893-894, 1968.

- Pébère, N., Duprat, M., Dabosi, F., Lattes, A., de Savignac, A. Corrosion inhibiton study of a carbon steel in acidic media containing hydrogen sulphide and organic surfactants, Journal of Applied Electrochemistry, v.18, p.225-231, 1988. 
- Pellerite, M.J., Dunbar, T.D., Boardman, L.D., Wood, E.J. Effects of Selfassembled monolayer formation from alkanephosphonic acids on aluminum: Kinetics and Structure. The Journal of Physical Chemistry B. v.107, p.11726-11736, 2003.

- PHILLIPS, V.A., Modern Metallographic Techniques and Their Applications. New York, Wiley-Interscience, p.538, 1971.

- POURBAIX, M., Atlas of Electrochemical Equilibria in Aqueous Solutions, NACE CEBELCOR, Houston, 1974.

- QUEIROZ, F.M., Estudo do Comportamento de Corrosão dos Intermetálicos Presentes na Liga AA 2024-T3, por meios de Técnicas de Microscopia Associada a Técnicas Eletroquímicas, Tese (doutorado), Instituto de Pesquisas Energéticas e Nucleares, 2008.

- Queiroz, F.M., Magnani M., Costa I., de Melo H.G., Investigation of the corrosion behaviour of AA 2024-T3 in low concentrated choride media. Corrosion Science,v.50, p.2646-2657, 2008.

- RAMANATHAN, L. V., Corrosão e seu Controle, São Paulo, Ed. Hemus, 1988.

- Ramsey, J.D., McCreery R.L. In situ Raman microscopy of chromate effects oncorrosion pits in aluminum alloy. Journal of the electrochemical society, v.146, n.11, p.4076-4081, 1999.

- Reboul, M.C., Baroux, B., Metalurgical aspects of corrosion resistence of aluminium alloys. Materials and Corrosion, v.62, n.3, p.215-233, 2011.

- REIS, F. M., Investigação do Tratamento com Moléculas AutoOrganizáveis para Substituição da Cromatização da Liga AA5052H32 no Preparo da Superfície Prévio a Pintura, Dissertação (Mestrado), Instituto de Pesquisas Energéticas e Nucleares, 2005.

- Reis, F.M., de Melo, H.G., Costa, I. EIS Investigation on Al 5052 Alloy Surface Preparation for Self-Assembling Monolayer. Electrochimica Acta, v.51, p.1780-1788, 2006. 
- Ridley, M.K., Wesolowski, D.J., Palmer, D.A., Bénèzeth, P., Kettler, R.M. Effect of sulfate on the release Rate of $\mathrm{Al}^{3+}$ from Gibbsite in low temperatures acidic waters. Environmental Science Tecnology. v.7, n.31, p.1922-1935, 1997.

- Ridley, M.K., Wesolowski, D.J., Palmer, D.A., Kettler, R.M. Association quocientes of aluminum sulphate complexes in $\mathrm{NaCl}$ media from 50 to 125ㄷ: Results of a potentiometric and solubility study. Geochimica et Cosmochimica Acta. v.63, n.3/4, p. 459-472, 1999.

- Roelandts, I. Aluminium and aluminium alloy reference materials. Spectrochimica Acta, v.46B, n.67, p.1101-1119, 1991.

- Sayed, S., Rehim, A., Hassan, H.H., Amin, A. M. Corrosion and corrosion inhibition of $\mathrm{Al}$ and some alloys in sulphate solutions containing halite ions investigated by an impedance technique. Applied Surface Science, v.187, p.279-290, 2002.

- Schreiber, F. Structure and growth of self-assembling monolayers.

Progress in Surface Science, v.65, n.5-8, p.151-256, 2000.

- Scully, J.R., Knight, T.O., Buchheit, R.G., Peebles, D.E. Electrochemical characteristics of the $\mathrm{Al}_{2} \mathrm{Cu}, \mathrm{Al}_{3} \mathrm{Ta}$ and $\mathrm{Al}_{3} \mathrm{Zr}$ intermetallic phases and their relevancy to the localized corrosion of Al alloys. Corrosion Science, v.35, n.1-4, p.185-195, 1993.

- Shimizu, K., Brown, G.M., Kobayashi, K., Skeldon, P., Thompson, G.E., Wood, G.C. Ultramicrotomy a route towards the enhanced understanding of the corrosion and filming behavior of aluminium and its alloys. Corrosion Science, v.40, n.7, p.1049-1072, 1998.

- Shimizu, K., Furneaux, R.C., Thompson, G.E., Wood, G.C., Gotoh, A., Kobayashi, K. On the nature of 'easy paths' for the diffusion of oxygen in thermal oxide films on aluminum, Oxidation of Metals, v.35, n.5/6, p.427439, 1991.

- Shimizu, K., Kobayashi, K, Skeldon, P, Thompson, G.E. Wood, G.C. An atomic force microscopy study of the corrosion and filming behavior of aluminium. Corrosion Science, v.39, n.4, p.701-718, 1997.

- Smialowska, Z.S. Insight into the pitting corrosion behavior of aluminum alloys. Corrosion Science, v.33, n.8, p.1193-1202, 1992 
- Smialowska, Z.S. Pitting corrosion of aluminum. Corrosion Science, v.41, p.1743-1767, 1999.

- Stewart, K.R., Whitesides, G.M., Godfried, H.P., Silvera, I.F. Improved Adhesion of Thin Conformal. Organic Films. to. Metal Surfaces. Review of Scientific Instruments, v.57, n.7, p.1381-1383, 1986.

- Suegama, P. H., Yoshikawa, D. S., de Souza, S., Terada, M., Costa I. Electrochemical, chemical and morphological characterization of selfassembled molecules for corrosion protection of Alclad 7475-T761 aluminum alloys. In: $8^{\text {th }}$ Symposium on Electrochemical Impedance Spectroscopy. Carvoeiro, Portugal, 2010.

- Suegama, P.H., de Melo, H.G., Benedetti, A.V., Aoki, I.V. Influence of cerium (IV) ions on the mechanism of organosilane polymerization and on improvement of its barrier properties. Electrochimica Acta, v.54, n.9, p.2655-2662, 2009.

- Szurkalo, M., Assis, S. L., Banczek, E P., Costa, I. Investigação da resistência à corrosão da liga de alumínio 1050 tratada com moléculas auto-organizáveis. 2008 In: $18^{\text {th }}$, Congresso Brasileiro de Engenharia e Ciência de Materiais- Cbecimat. Porto de Galinhas, Brasil, 2008.

- SZURKALO, M., Investigação do efeito de moléculas auto-organizáveis na resistência à corrosão da liga de alumínio 1050. Dissertação (mestrado), Instituto de Pesquisas Energéticas e Nucleares, 2009.

- The Aluminium Association, Washington, D.C 20006-December, 1998.

- Thompson, G.E., Doherty, P.E., Wood, G.C. Observations of flaws on preconditioned aluminum surfaces. Journal of the Electrochemical Society, n.7, v.129, p.1515-1517, 1982.

- Troughton, E.B., Bain, C.D., Whitesides, G.M., Nuzzo, R.G., Allara, D.L. Porter M.D., Monolayer films prepared by the spontaneous self-assembly of symmetrical and unsymmetrical dialkyl sulfides from solution onto gold substrates: Structure, properties, and reactivity of constituent functional groups. Langmuir, v.4, n.2, p.365-385, 1988.

- Ulman, A. Organic thin films and surfaces: directions for the nineties (Thin Films), Academic Press: New York, 1995. 
- Ulman, A., Journal of Material Education, 11, p.205-207, 1989.

- Van der Walde, K., Brockenbrough, J.R., Craig, B.A., Hillberry, B.M. Multiple fatigue crack growth in pre-corroded 2024-T3 aluminum. International Journal of Fatigue, v.27, p.1509-1518, 2005.

- Van Ooij, W. J., Zhu, D., Stacy, M., Seth, A., Mugada, T., Gandhi, J., Puomi, P. Corrosion protection properties of organofunctional silanes - an overview. Tsinghua Science and Technology, v.10, n.6, p.639-664, 2005.

- Verder, W., Vermilyea, D.A. Aluminum + water reaction. Transactions of the Faraday Society. v. 65, p.561-584, 1969.

- Viomar, A. ; Lopes, A. C. ; Terada, M. ; Rodrigues, P. R. P. ; Banczek, E. P. Filme de SAM como inibidor de corrosão da liga de alumínio 2024. In: 19o CBECiMat Congresso Brasileiro de Engenharia e Ciências dos Materiais, 2010, Campos do Jordão. 2010.

- Wang, D., Ni, Y., Huo, Q., Tallman, D. Self-assembled monolayer and multilayer thin films on aluminum 2024-T3 substrates and their corrosion resistance study. Thin Solid Films, v.471, n.1/2, p.177-185, 2005.

- Wapner, K., Stratmann, M., Grundmeier, G. Structure and stability os adhesion promoting aminopropyl phosphonate layers at polymer/aluminium oxide interfaces. International Journal of Adhesion e Adhesives, v.28, p.59-70, 2007.

- West, J.M., Electrodeposition and Corrosion Processes, $2^{\circ}$ edition. Londres, Ed. Van Nostrand Reinhold, p.1-47, 1971.

- WOLYNEC, S. Técnicas Eletroquímicas em Corrosão, EDUSP, p.13-16, 2003.

- Xingwen, Y., Chunan, C., Zhiming, Y., Derui, Z, Zhongda, Y. Study of Double layer rare earth metal conversion coating on aluminum alloy LY12. Corrosion Science, v.43, p.1283-1294, 2001.

- Yoshikawa D.S., Assis S.L., Izaltino W.A.S., de Souza S., Costa I. Estudo do comportamento de corrosão da liga 5052 tratada com moléculas autoorganizáveis. Tratamento de Superfície, v.1, p.24-29, 2009. 
- Zhao, J., Frankel, G., McCreery, R.L. Corrosion protection of untreated AA2024-T3 in chloride solution by a chromate conversion coating monitored with Raman Spectroscopy. Journal Electrochemical Society, v.145, n.7, p.2258-2264, 1998.

- Zhao, T., Mu, G. The adsorption and corrosion inhibition of anion surfactants on aluminium surface in hydrochloric acid. Corrosion Science, v.41, p.1937-1944 1999. 


\section{Apêndice A}

Os diagramas com os dados ajustados pelos circuitos equivalentes propostos referentes aos ensaios de impedância realizados nos diferentes tratamentos de superfície serão apresentados a seguir.

TRATAMENTO - PB

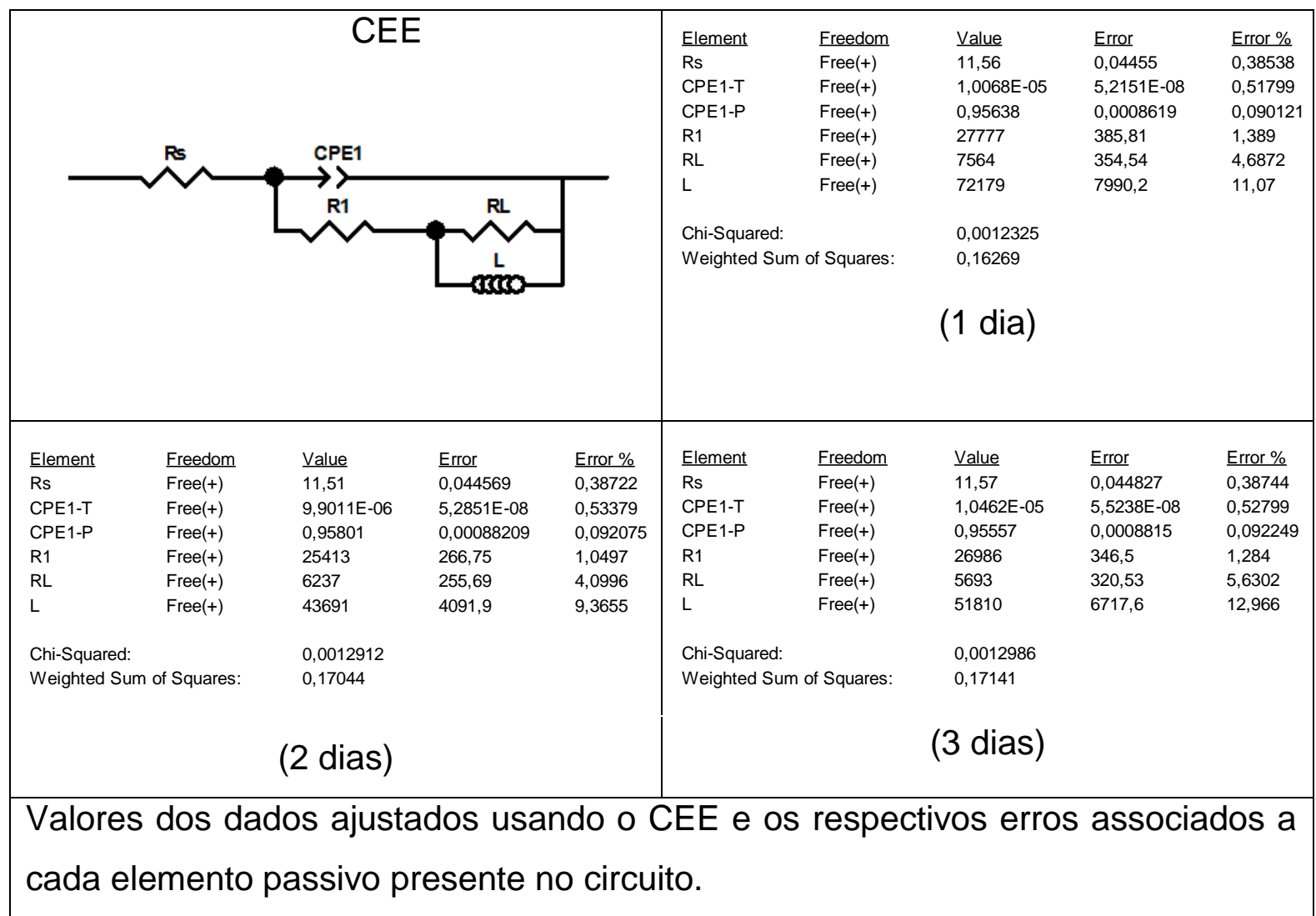

Os valores dos parâmetros elétricos e respectivos erros resultantes do ajuste do CEE aos diagramas experimentais de impedância obtidos para o alumínio AA1050 com tratamento PB em função do tempo de imersão na solução de ensaio.

Diagramas de impedância experimentais e ajustados com o CEE, Figura 38(A), que foram obtidos para o alumínio AA1050 com tratamento PB após A) 1dia, B) 2 dias e C) 3 dias de imersão em solução de ensaio são apresentados a seguir. 


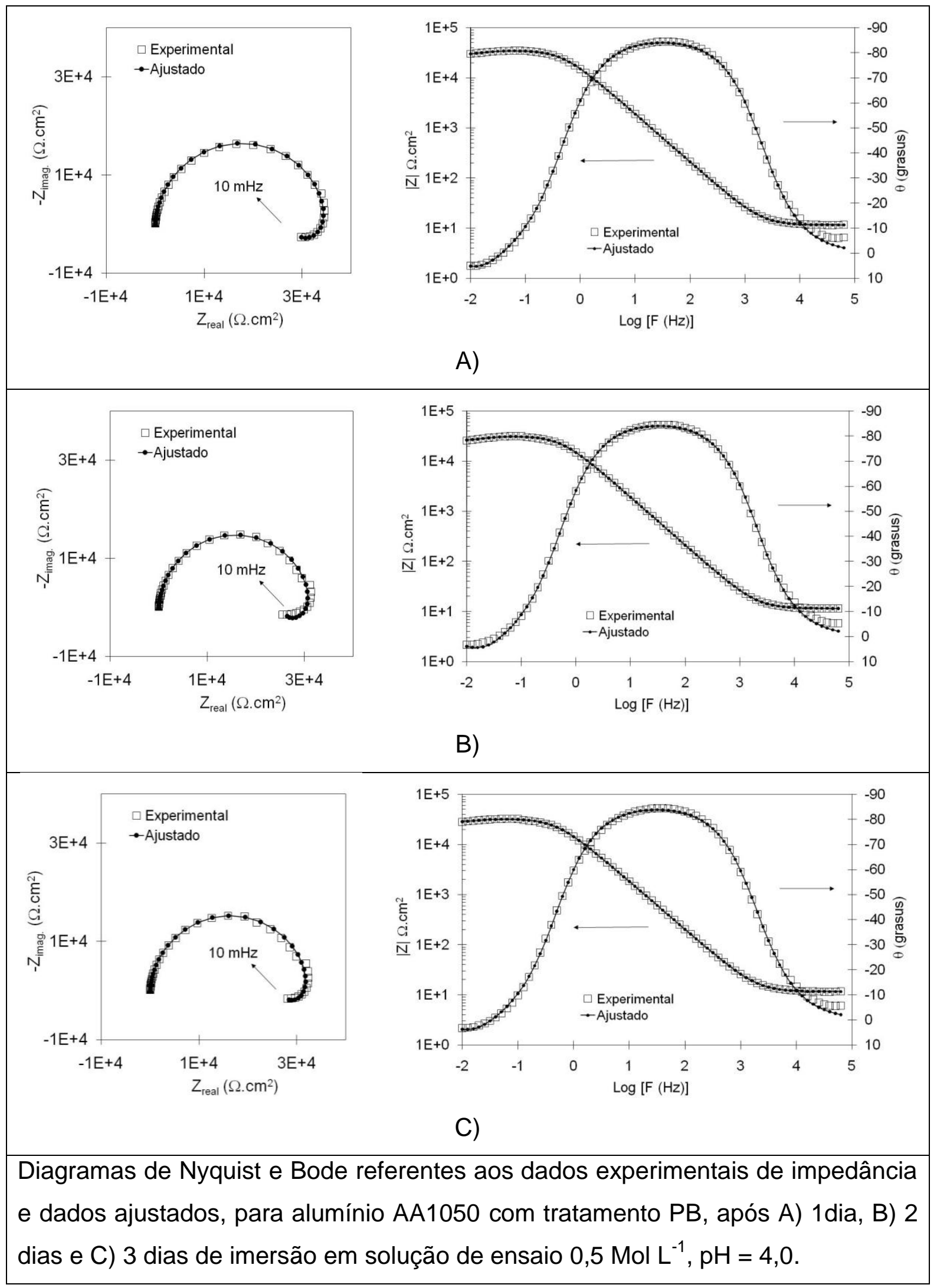


TRATAMENTO - SAM

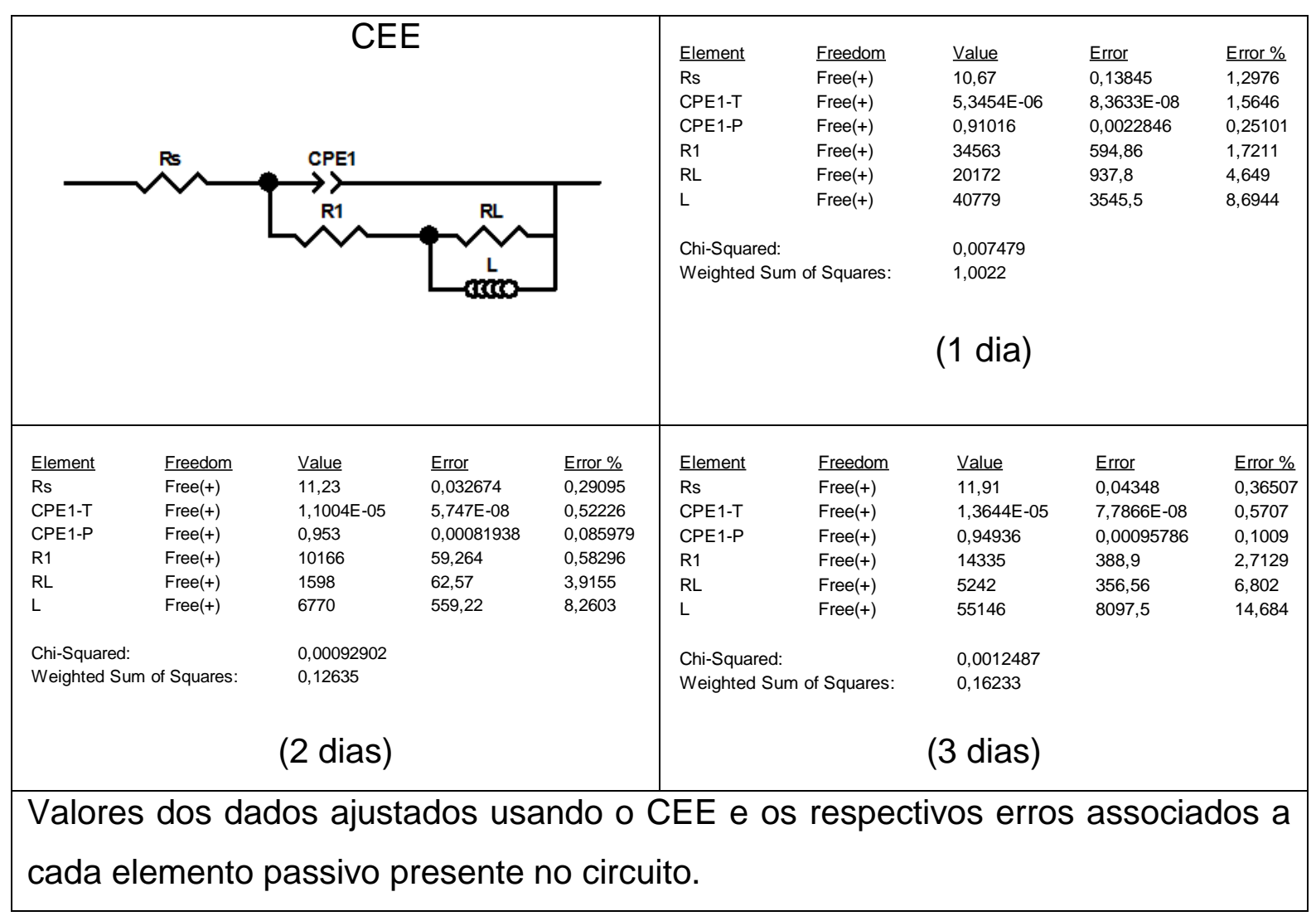

Os valores dos parâmetros elétricos e respectivos erros resultantes do ajuste do CEE aos diagramas experimentais de impedância obtidos para o alumínio AA1050 com tratamento SAM em função do tempo de imersão na solução de ensaio.

Diagramas de impedância experimentais e ajustados com o CEE da Figura 38(A) que foram obtidos para o alumínio AA1050 com tratamento SAM após A) 1dia, B) 2 dias e C) 3 dias de imersão em solução de ensaio são apresentados a seguir. 


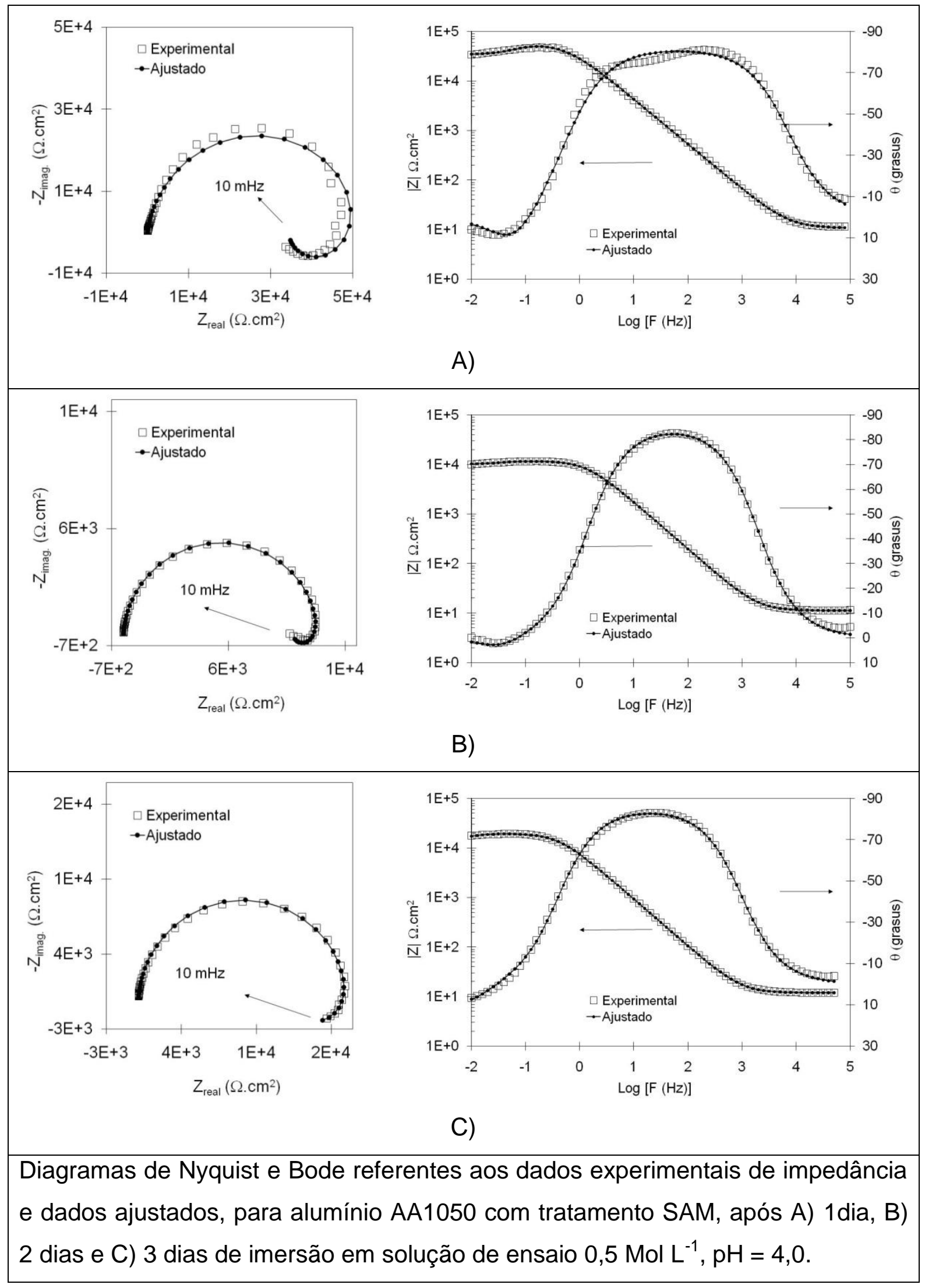


TRATAMENTO - Cr(VI)

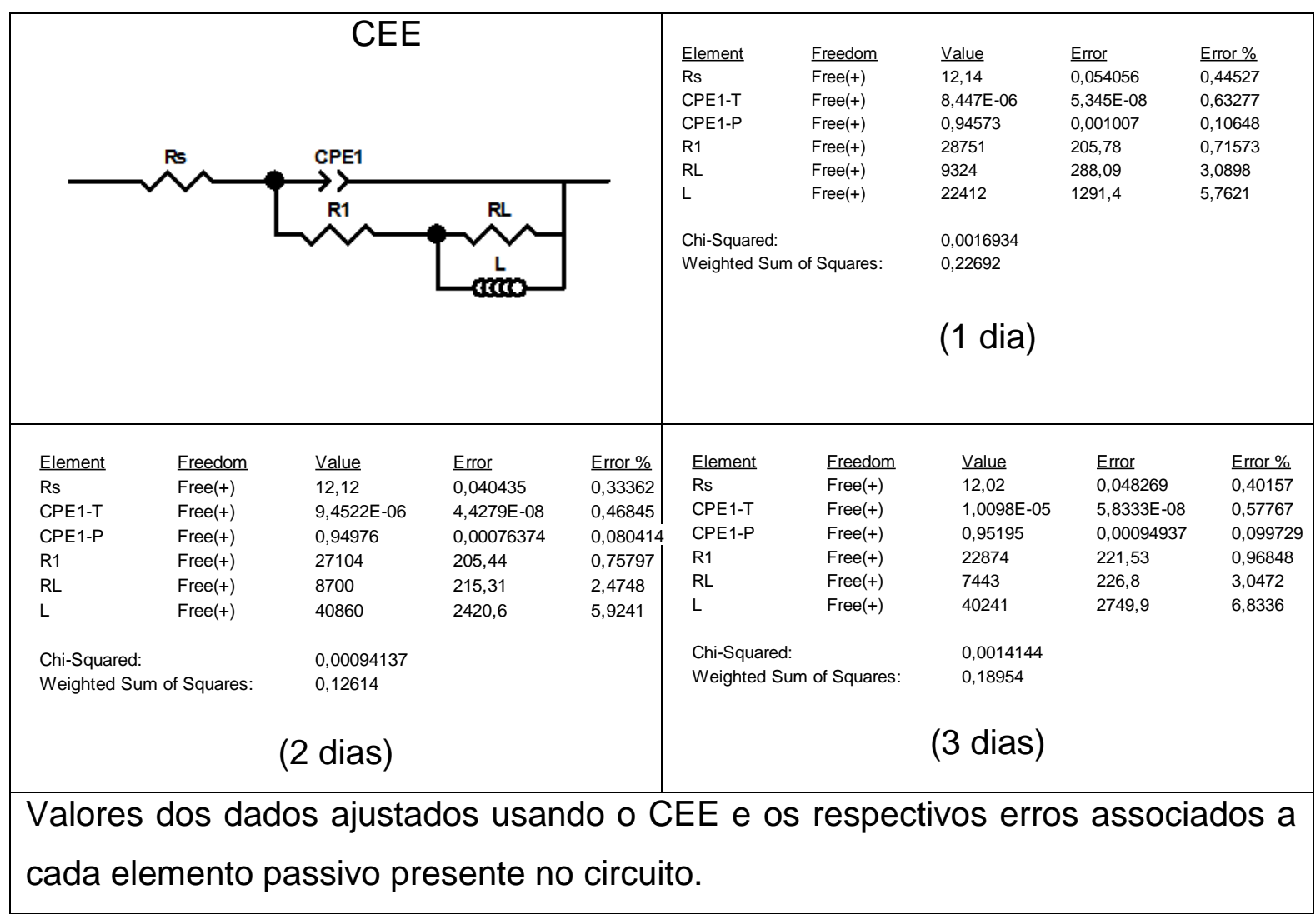

Os valores dos parâmetros elétricos e respectivos erros resultantes do ajuste do CEE aos diagramas experimentais de impedância obtidos para o alumínio AA1050 com tratamento $\mathrm{Cr}(\mathrm{VI})$ em função do tempo de imersão na solução de ensaio.

Diagramas de impedância experimentais e ajustados com o CEE, Figura 38(A), obtidos para o alumínio AA1050 com tratamento $\mathrm{Cr}(\mathrm{VI})$, após A) 1dia, B) 2 dias e C) 3 dias de imersão em solução de ensaio são apresentados a seguir. 


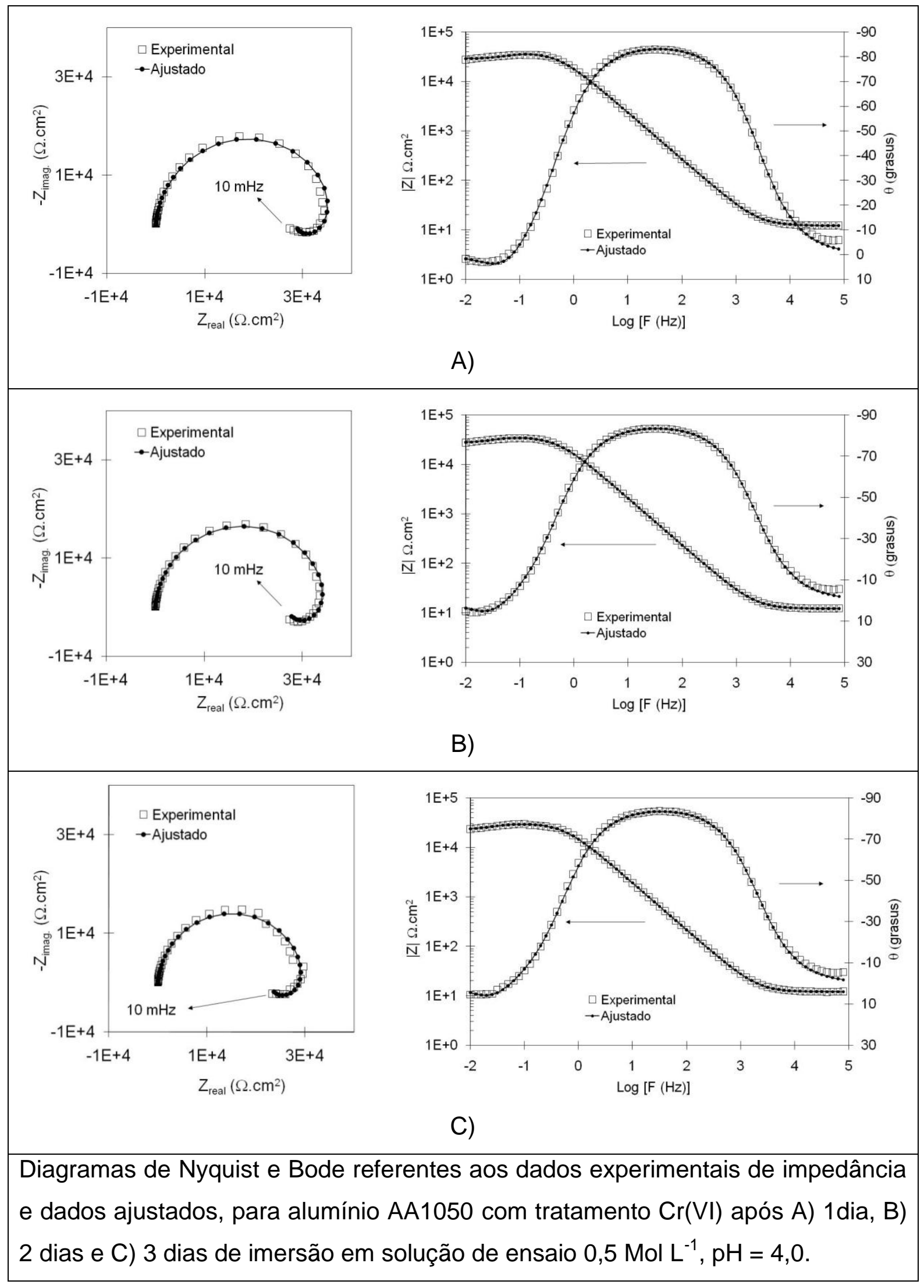


TRATAMENTO - OX

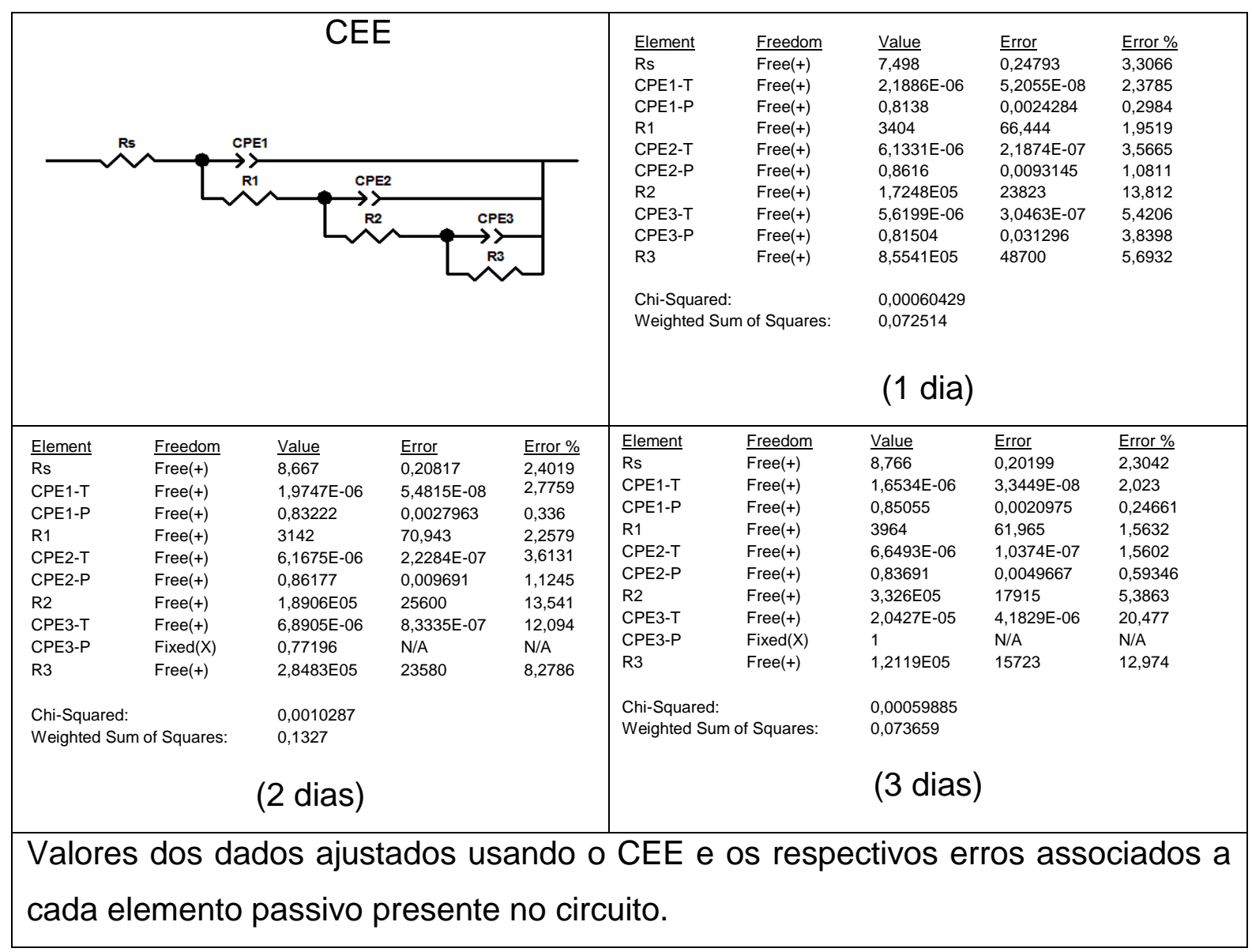

Os valores dos parâmetros elétricos e respectivos erros resultantes do ajuste do CEE aos diagramas experimentais de impedância obtidos para o alumínio AA1050 com tratamento OX em função do tempo de imersão na solução de ensaio.

OS diagramas de impedância experimentais e ajustados com o CEE, Figura 38(B), obtidos para o alumínio AA1050 com tratamento OX, após A) 1dia, B) 2 dias e C) 3 dias de imersão em solução de ensaio são apresentados a seguir. 


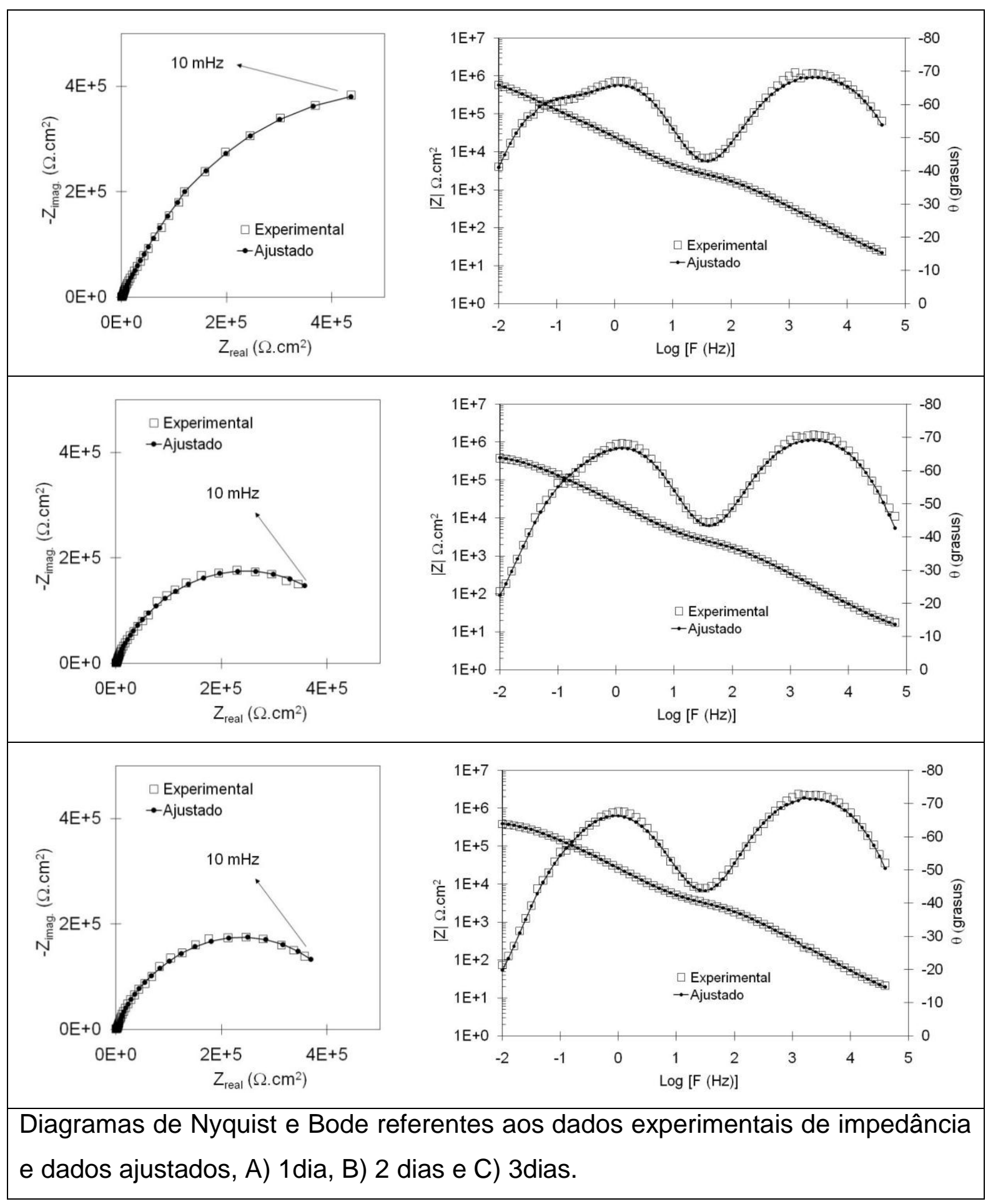


TRATAMENTO - OS

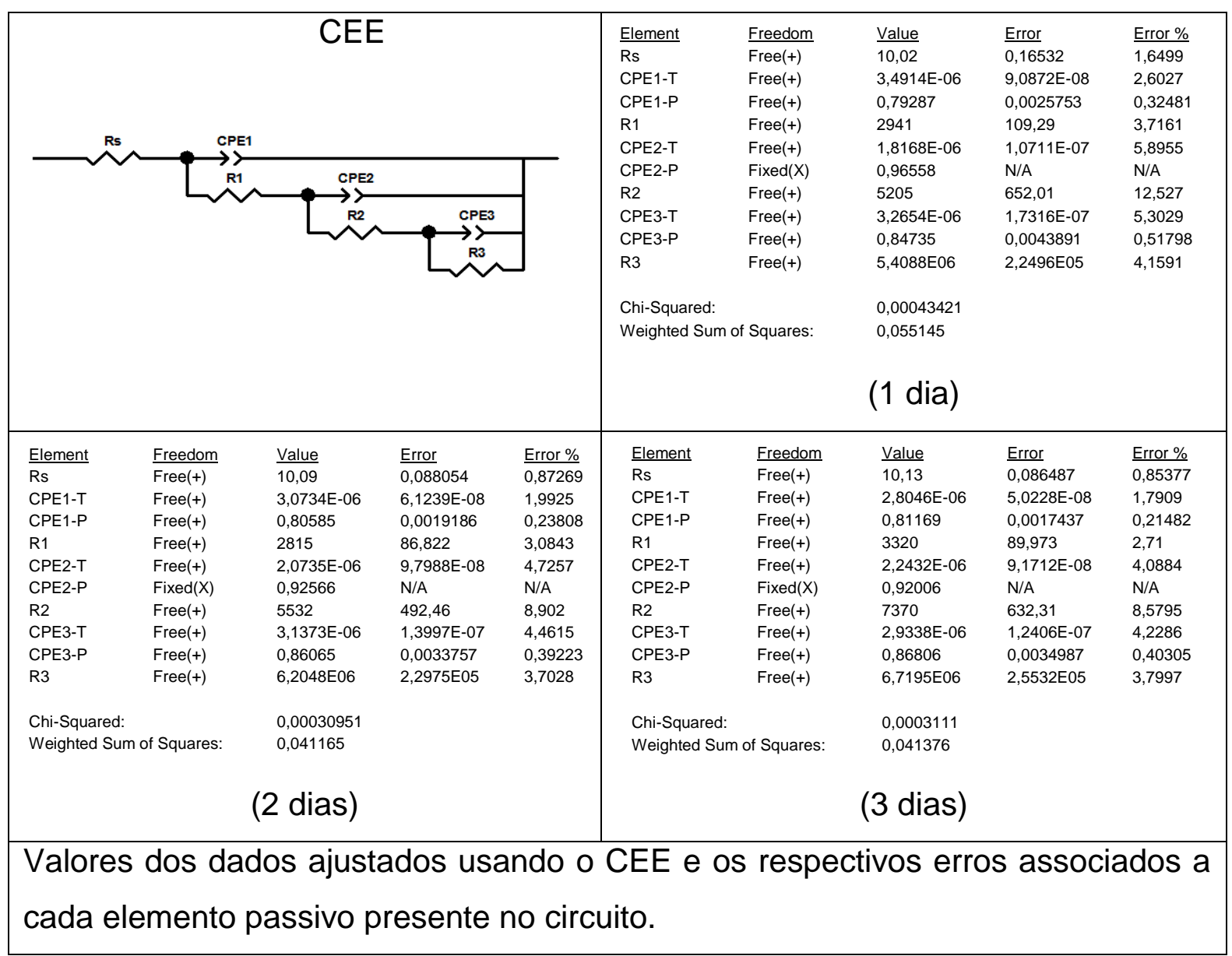

Valores dos parâmetros elétricos e respectivos erros resultantes do ajuste do CEE aos diagramas experimentais de impedância obtidos para o alumínio AA1050 com tratamento OS em função do tempo de imersão na solução de ensaio.

Os diagramas de impedância experimentais e ajustados com o CEE, Figura 38(B), obtidos para o alumínio AA1050 com tratamento OS após A) 1dia, B) 2 dias e C) 3 dias de imersão em solução de ensaio são apresentados a seguir. 


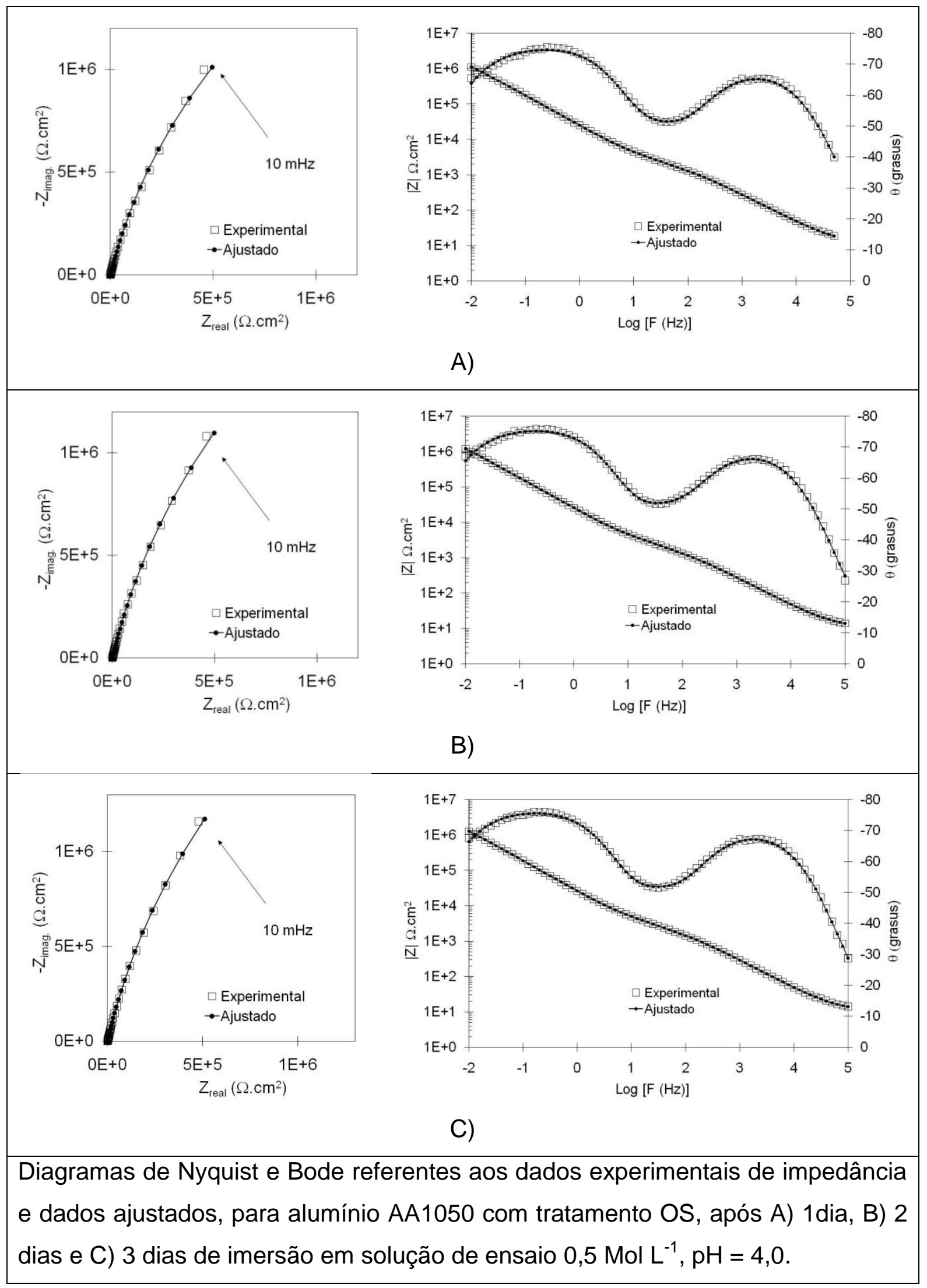

